Caracterização de um aço IF após relaminação no Laminador de Encruamento

Dissertação a ser apresentada à Escola Politécnica da Universidade de São Paulo para obtenção do Título de Mestre em Engenharia.

SÃO PAULO 


\section{Caracterização de um aço IF após a relaminação no Laminador}

\section{de Encruamento}

Dissertação a ser apresentada à Escola Politécnica da Universidade de São Paulo para obtenção do Título de Mestre em Engenharia.

Área de concentração:

Engenharia Metalúrgica e de Materiais

Orientador:

Prof. Dr. André Paulo Tschiptschin

SÃO PAULO 
Este exemplar foi revisado e alterado em relação à versão original, sob responsabilidade única do autor e com a anuência de seu orientador.

São Paulo, de janeiro de 2010.

Assinatura do autor

Assinatura do orientador

FICHA CATALOGRÁFICA

Oliveira, Antônio Fabiano de

Caracterização de uma co IF após a relaminação no laminador de encruamento / A.F. de Oliveira. -- ed.rev. -- São Paulo, 2010.

$142 \mathrm{p}$.

Dissertação (Mestrado) - Escola Politécnica da Universidade de São Paulo. Departamento de Engenharia Metalúrgica e de Materiais.

1.Laminação 2.Difração por raios $X$ 3. Estampagem 4.Textura I.Universidade de São Paulo. Escola Politécnica. Departamento de Engenharia Metalúrgica e de Materiais II.t. 
A Deus, por tudo, à minha esposa, aos meus pais, tia, irmãos, e familiares pelo apoio e incentivo. 


\section{AGRADECIMENTOS}

Ao Senhor meu Deus, em sua infinita Graça e Misericórdia, têm me proporcionado bênçãos inimagináveis e indescritíveis.

À minha esposa Cássia, pela enorme compreensão e motivação para finalização deste trabalho.

Aos meus queridos pais Antônico Cândido e Elizabeth, tia Edith e irmãos Andréa, Anestal, Carla, Rogério, Eduardo, Marcos e sobrinhos, que sempre me incentivaram e apoiaram, mesmo à distância.

Ao meu orientador, Prof. Dr. André Paulo Tschiptschin, pela orientação e apoio.

Ao Grupo USIMINAS, pelas facilidades oferecidas e pela oportunidade.

Ao Prof. Dr. Ronald Lesley Plaut pelo incentivo e atenção.

Aos colegas da Usiminas - Cubatão, pelo apoio e auxílio na revisão do trabalho, em especial Karl Kristian Bagger, Luis Alberto, Sérgio Norifumi Dói e o pessoal do centro de testes.

Aos colegas do laboratório da Usiminas - unidade Cubatão e Ipatinga, pela ajuda na realização dos ensaios de difração de raios-X, levantamento da curva CLC entre outros.

Enfim, a todos que contribuíram para a consolidação deste trabalho, o meu sincero obrigado. 


\section{RESUMO}

A busca contínua da melhoria da competitividade do aço frente aos sucedâneos tem levado ao desenvolvimento de materiais especiais, permitindo atender a três das principais demandas do setor automotivo: redução de peso, economia de combustível e aumento da segurança do usuário. As condições sob as quais é realizado o reprocesso ou relaminação de encruamento dos aços livres de intersticiais, chamado IF - Interstitial Free podem afetar significativamente as características destes, especialmente do ponto de vista de sua estampabilidade, que é fundamentalmente importante para este tipo de produto.

Este trabalho tem por objetivo estudar os efeitos da relaminação de encruamento na estampabilidade de chapas de um aço Intersticial Free - IF microligado ao titânio. A amostra em estudo foi retirada de bobinas laminadas e relaminadas no Laminador de Encruamento No2 da Usiminas - unidade Cubatão, simulando uma condição real de processo, eventualmente necessária, devido a correções a serem efetuadas no acabamento superficial ou ajuste de planicidade. Após o processo de relaminação, foi realizada a caracterização do material através de ensaios para avaliar as propriedades mecânicas, a microestrutura, a textura cristalográfica (ODF) e determinou-se a curva limite de conformação (CLC). Os resultados mostram que os limites de escoamento e de resistência aumentam e o coeficiente de encruamento reduz com a relaminação de encruamento. Por outro lado, a textura na superfície varia conforme o grau de redução, porém pouco afeta no centro da amostra. A anisotropia normal e planar média apresentam correlação inversa com o grau de redução na relaminação. Para as reduções de relaminação estudadas, a dispersão dos pontos em torno da CLC, não evidencia influências significativas nas propriedades de conformação mecânica. 


\begin{abstract}
The continuous search of the improvement of the competitiveness of the steel front to the succedanea has led to the development of special materials, allowing to take care of three of the main demands of the automotive sector: reduction of weight, fuel economy and increase of the safety of the user. The conditions under which the process of strain hardening of Interstitial Free (IF) steel is carried through can significantly affect the characteristics of this steel, especially of the point of view of its conformability.
\end{abstract}

The present work studies the effect of over-rolling performed on a skin-pass mill on the drawability of a Ti-stabilized IF steel. Conventional and larger-than-usual passes (overrolling) have been performed in order to simulate the real-life condition in which there is an eventual necessity for larger reductions, due to problems related to surface finish or due to flatness problems. Tests have been carried out with increasing skin-pass reductions (up to about $1 \%$ ) and the corresponding mechanical properties, microstructures, textures (ODF) and related Forming Limit Curves (FLC) have been assessed. The results have shown that the yield strength increases, the strain-hardening coefficient decreases, with increasing skinpass over-rolling. On the other hand, texture varied slightly at the surface but showed little effect at mid-thickness. Tensile strength, normal and planar anisotropy, however presents an inverse correlation with the over-rolling reduction. The FLC results did not show any marked effect of over-rolling on the forming properties. 


\section{SUMÁRIO}

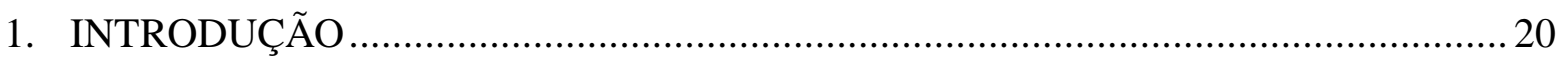

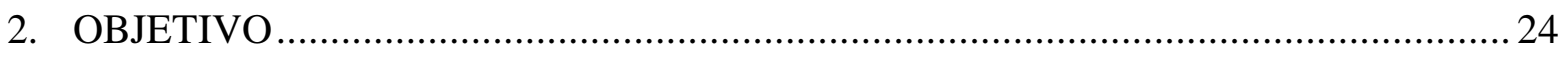

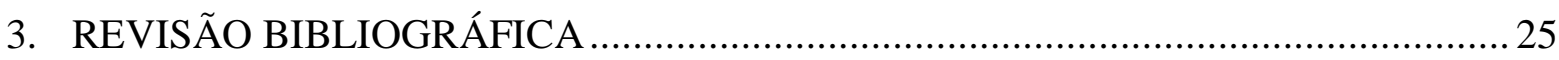

3.1 Tensões e deformações na conformação de chapas .......................................................25

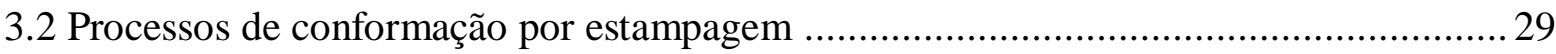

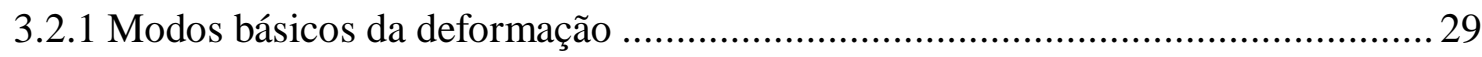

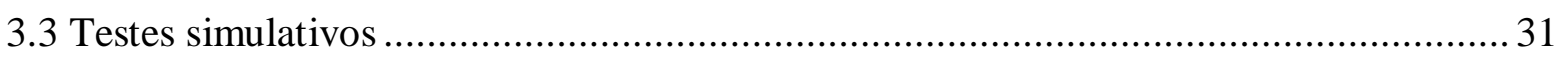

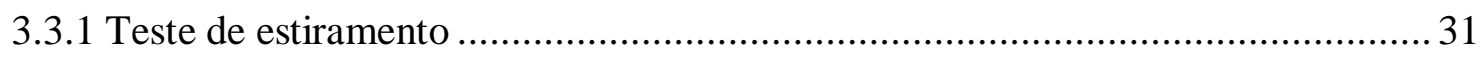

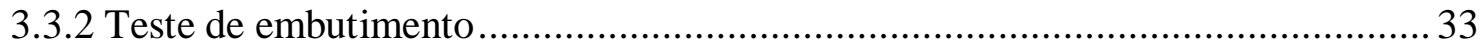

3.3.3 Testes relativos às propriedades fundamentais .................................................... 34

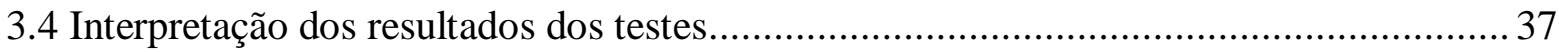

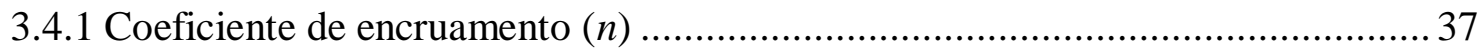

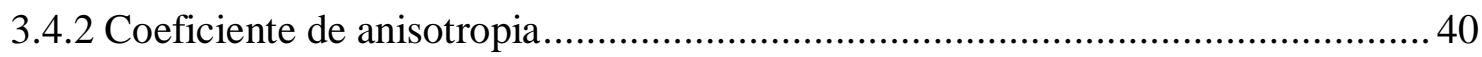

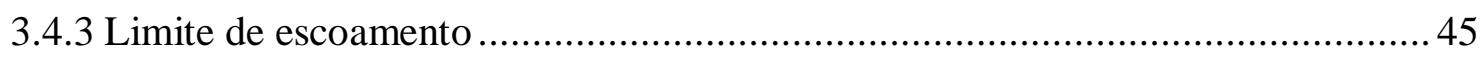

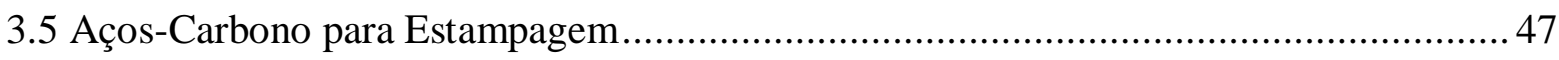

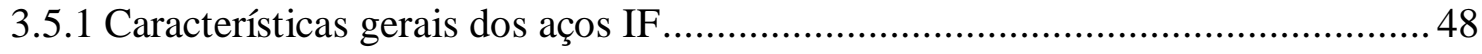

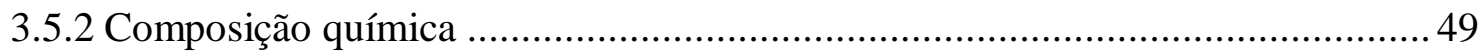

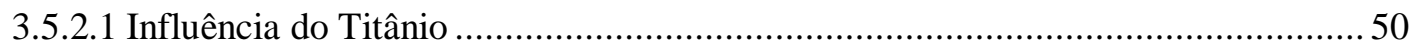

3.5.2.2 Influência do carbono e nitrogênio...................................................................... 50

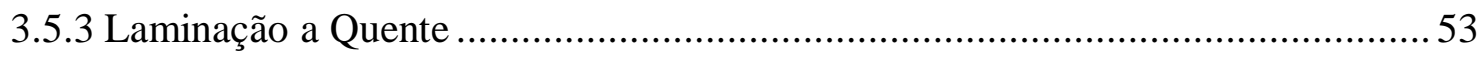

3.5.3.1 Temperatura de Reaquecimento de Placa ............................................................ 53

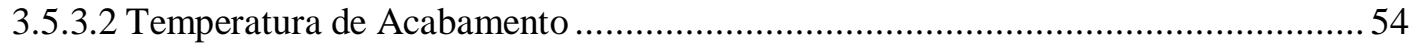

3.5.3.3 Temperatura de Bobinamento ............................................................................ 56

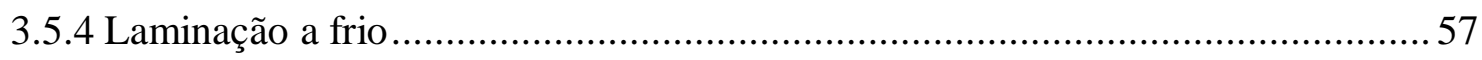

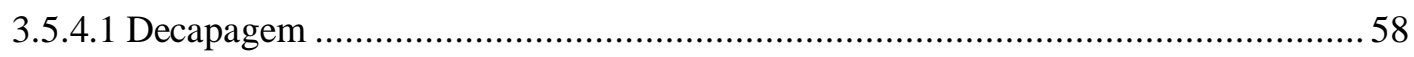

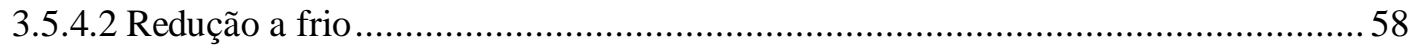

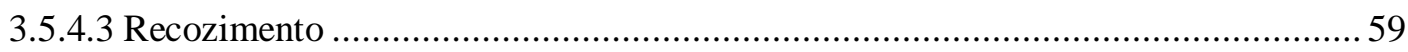

3.5.4.4 Princípio de funcionamento da Laminação de Encruamento...................................... 64

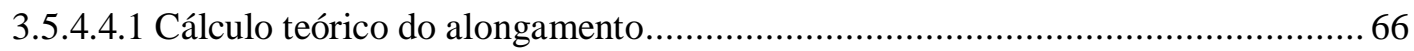


3.5.4.4.2 Fundamentos da Laminação de Encruamento 67

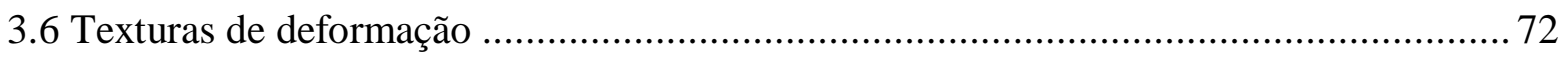

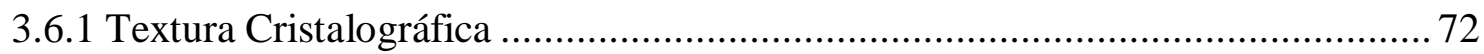

3.6.2 Função de Distribuição de Orientação Cristalina ............................................. 73

3.6.3 Texturas de Laminação a Frio em Materiais CCC .......................................... 73

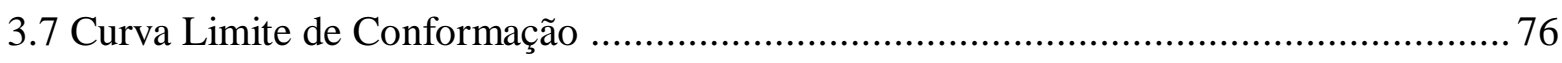

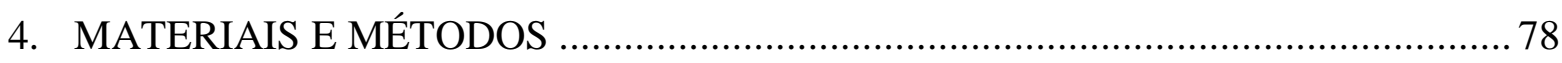

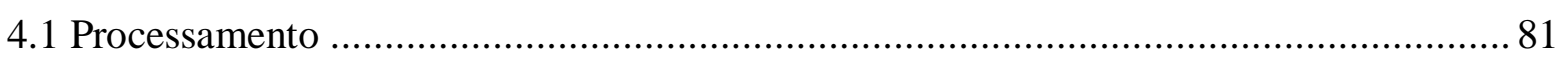

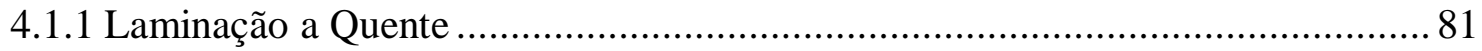

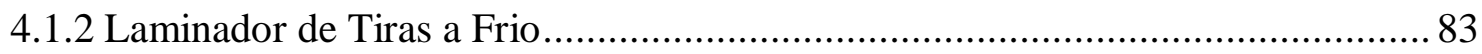

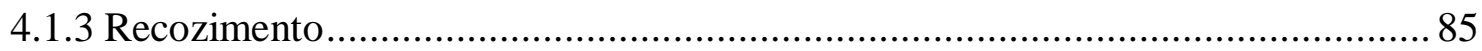

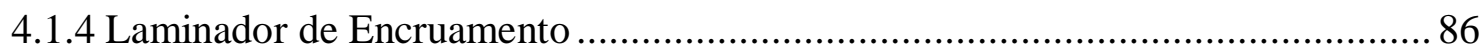

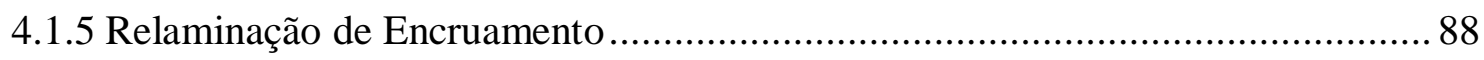

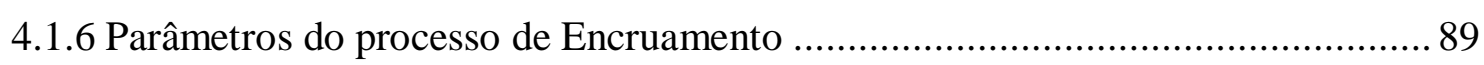

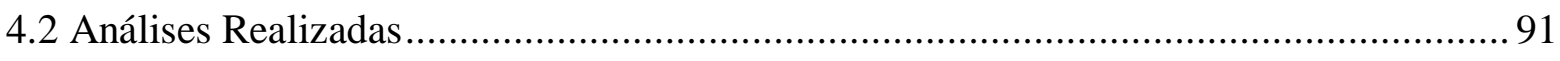

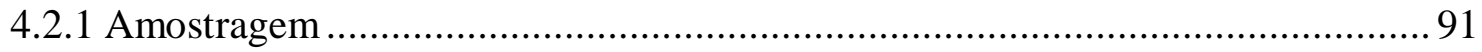

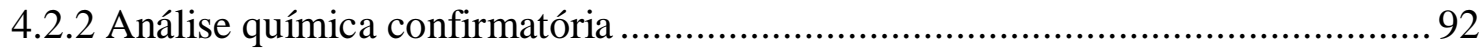

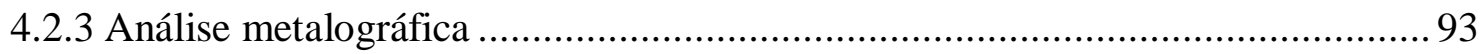

4.2.4 Ensaios mecânicos .................................................................................... 94

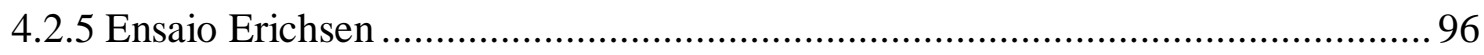

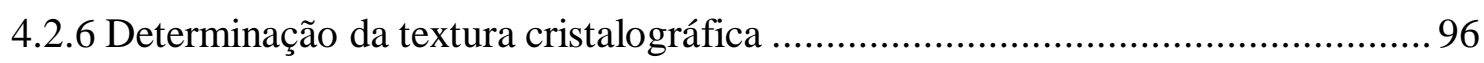

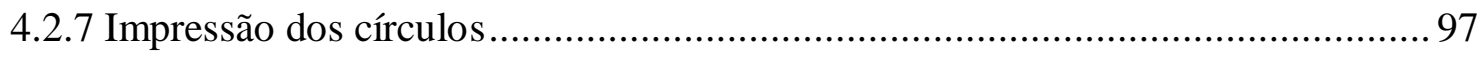

4.2.8 Preparação e ensaio dos corpos de prova para curva CLC ….............................98

4.2.9 Medição das deformações principais ............................................................... 100

4.2.10 Levantamento da CLC ........................................................................... 101

4.2.11 Margem de segurança da CLC ............................................................ 102

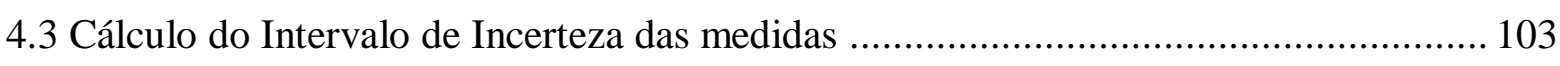

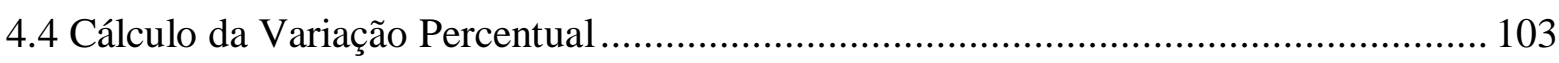

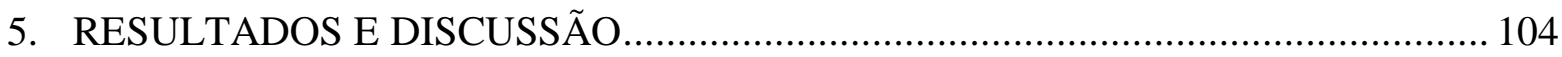

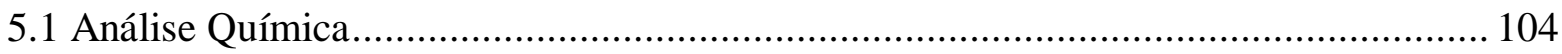

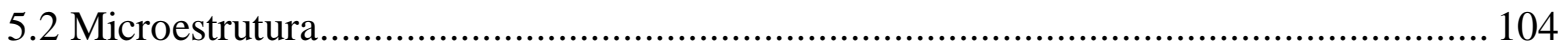

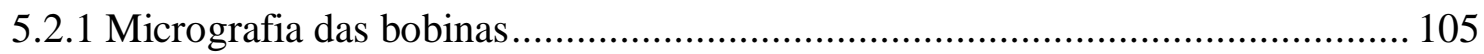

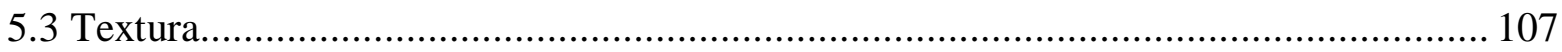




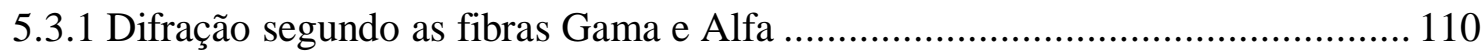

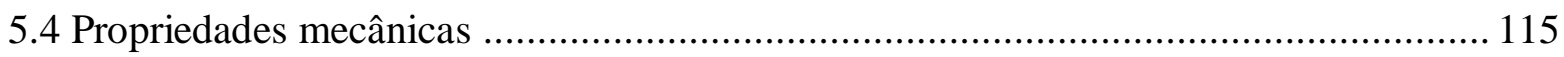

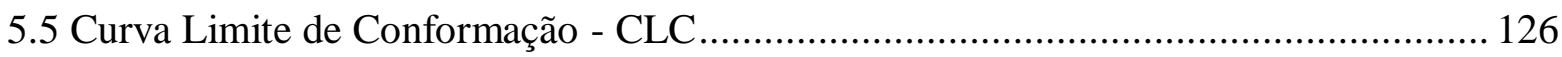

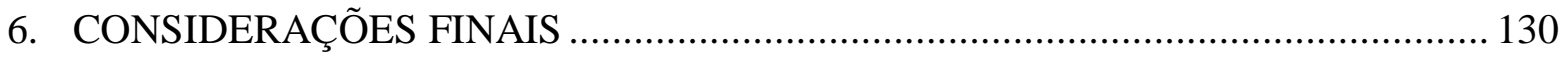

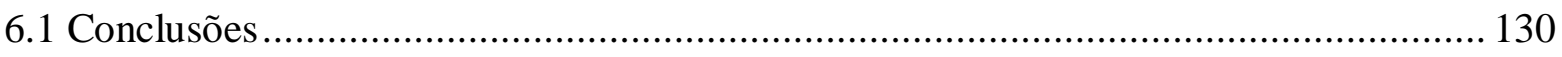

6.2 Relevância do Resultado do Trabalho........................................................................ 133

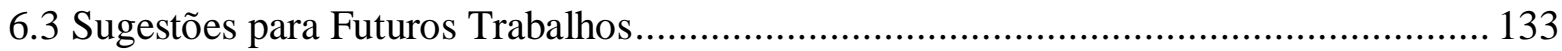

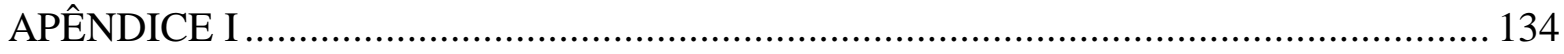

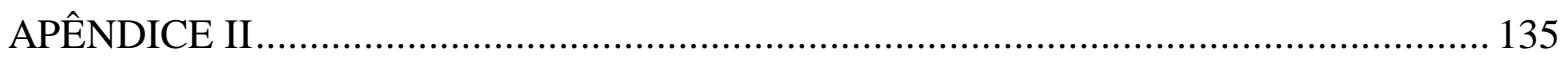

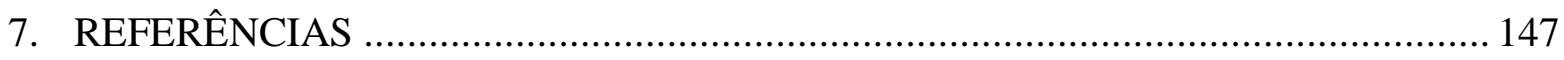




\section{LISTA DE FIGURAS}

FIGURA 1.1 - Aumento da produção mundial de automóveis e de aço [2] ....................... 21

FIGURA 1.2 - Aplicações do aço na composição no segmento automotivo [3] ..................222

FIGURA 3.1 - Sistema de tensões que atua numa chapa nos processos de estiramento e

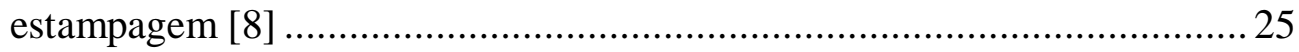

FIGURA 3.2 - Representação gráfica do critério de plasticidade de Von-Mises para um sistema de tensões biaxiais. Chapa isotrópica [9] ....................................26

FIGURA 3.3 - Representação parcial do critério de plasticidade de Von-Mises para um sistema de tensões biaxiais. Chapa anisotrópica [10]............................... 28

FIGURA 3.4 - Fatores de influência durante o processo de estampagem [6] ......................29

FIGURA 3.5 - Regiões do copo com diferentes estados de tensão [5] .............................. 30

FIGURA 3.6 - Esforços atuantes nas diversas regiões do copo [6] ................................... 30

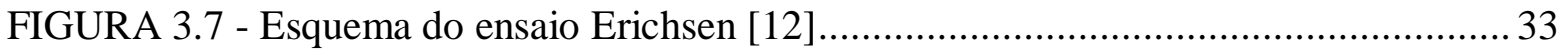

FIGURA 3.8 - Esquema do teste Swift para avaliação da estampabilidade [13] .................. 34

FIGURA 3.9 - Curvas típicas do ensaio de tração de aços baixo carbono [14] .................... 35

FIGURA 3.10 - Direções cristalinas dos materiais durante a laminação [22] ..................... 41

FIGURA 3.11 - Método de amostragem para ensaio de anisotropia [22] .......................... 42

FIGURA 3.12 - Anisotropia planar na formação de orelhas [24] ...................................... 44

FIGURA 3.13 - Cálculo do $\Delta \mathrm{R}$ para verificação formação de orelhas [24] ........................ 45

FIGURA 3.14 - Grau de estampabilidade dos aços [27] ........................................... 48

FIGURA 3.15 - Relação entre o Ti em excesso do aço IF-Ti e as propriedades mecânicas e o parâmetro R [24] .........................................................51

FIGURA 3.16 - Efeito do teor de carbono nas propriedades mecânicas do aço estabilizado com Ti e TiNb [24] .........................................................55

FIGURA 3.17 - Influência da temperatura de reaquecimento de placa na temperatura de recristalização dos aços IF-Ti [32] ................................................... 54

FIGURA 3.18 - Efeito da temperatura de bobinamento na temperatura de recristalização do IF-Nb, IF-NbTi e IF-Ti [30] 
FIGURA 3.19 - Efeito da temperatura de bobinamento em $\mathrm{R}_{\mathrm{m}}$ do IF-Ti [30].

FIGURA 3.20 - Efeito da redução a frio na intensidade relativa de vários componentes da textura de deformação no aço IF-Ti [34]

FIGURA 3.21 - Desenho esquemático de Ciclo térmico e fornos de recozimento [22] .....

FIGURA 3.22 - Influência da temperatura nas propriedades do aço IF-Ti no recozimento contínuo [40]

FIGURA 3.23 - Efeito da taxa de aquecimento durante o recozimento no $\mathrm{R}_{\text {médio }}$ do aço IF e do aço acalmado ao alumínio com temperaturas de bobinamento diferentes [59]

FIGURA 3.24 - Posição dos geradores de pulso no Laminador de Encruamento [11]. 65

FIGURA 3.25 - Efeito da redução da laminação de encruamento no alongamento e no limite de escoamento de aço IF-TiNb $\mathrm{C}=0,0025 \%, \mathrm{Ti}=0,030 \%$, $\mathrm{Nb}=0,006 \%$, temperatura de recozimento igual a $850^{\circ} \mathrm{C}$ [49]

FIGURA 3.26 - Valores de $\mathrm{R}_{\mathrm{m}}$ do aço IF e aço acalmado ao alumínio após o recozimento e após laminação de encruamento de 1,0\% [49]

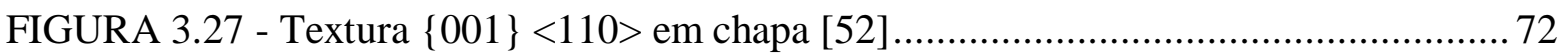

FIGURA 3.28 - Ângulos de Euler $\left(\varphi_{1} \phi \phi_{2}\right)$ conforme notação de Bunge [52] ..................... 73

FIGURA 3.29 - Textura de um aço baixo carbono laminado $60 \%$ a frio; seções de $\varphi_{2}=$ $0^{\circ}$ a $\varphi_{2}=85^{\circ}$, em intervalos de $5^{\circ}[53]$

FIGURA 3.30 - Seções de $\varphi_{2}=0^{\circ}$ e $\varphi_{2}=45^{\circ}$ de um aço IF laminado $60 \%$ a frio [54]

Notação de Bunge [55] .75

FIGURA $3.31-$ Ábacos de $\varphi_{2}=0^{\circ}$ e $\varphi_{2}=45^{\circ}$ para interpretar a FDOC [55] ..................... 75

FIGURA 3.32 - Curva Limite de Conformação (CLC) [57]............................................ 76

FIGURA 3.33 - Método Nakazima de amostragem e o Caminho da Deformação [52] .77

FIGURA 4.1 - Seqüência das etapas de processo. 80

FIGURA 4.2 - Esquema do procedimento experimental e parâmetros operacionais [11]..... 80

FIGURA 4.3 - Seqüência das temperaturas de bobinamento e acabamento 82

FIGURA 4.4 - Tela de parâmetros da carga de enfornamento no Recozimento 83

FIGURA 4.5 - Tela de parâmetros da carga de enfornamento no Recozimento 84 
FIGURA 4.6 - Tela de parâmetros da carga de enfornamento no Recozimento 85

FIGURA 4.7 - Gráfico de temperatura em ciclo do Recozimento ..................................... 85

FIGURA 4.8 - Desenho esquemático do LE2 da Usiminas Cubatão [11] ........................... 86

FIGURA 4.9 - Gráfico de redução no Encruamento da amostra 073351 ........................... 87

FIGURA 4.10 - Gráfico de redução no Encruamento da amostra 073352 .......................... 87

FIGURA 4.11 - Seqüência de grau de relaminação da bobina BRE ................................. 88

FIGURA 4.12 - Evolução da redução adicional durante relaminação e amostragem ........... 88

FIGURA 4.13 - Evolução da redução adicional durante relaminação e amostragem ........... 89

FIGURA 4.14 - Desenho esquemático do Laminador Encruamento com geradores ............ 89

FIGURA 4.15 - Corpo de prova e suas dimensões para o teste de tração, $\mathrm{R}$ e $n$ [13].......... 95

FIGURA 4.16 - Desenho esquemático da amostra dos ensaios Erichsen A, B e C [12] .......96

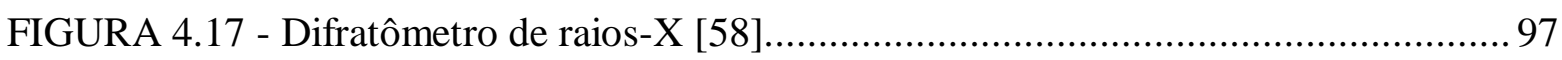

FIGURA 4.18 - Rede de círculos tangenciais e tela semi-impermeável utilizada [58] .........98

FIGURA 4.19 - Desenho esquemático dos corpos de prova [46] .....................................99

FIGURA 4.20 - Diferentes geometrias de Corpos de Prova [46] ...................................... 99

FIGURA 4.21 - Ilustração da máquina de estampagem Erichsen [58] .............................. 99

FIGURA 4.22 - Esquemático de círculos originais e elipses após estampagem [58] ......... 100

FIGURA 4.23 - Corpo de prova com rede de círculos (estricção) [56] ............................ 101

FIGURA 4.24 - Equipamento de medição das deformações - CAMSYS [58] .................... 102

FIGURA 4.25 - Margem de segurança da Curva Limite de Conformação (CLC) [57] ...... 102

FIGURA 5.1 - Microestrutura relaminação BRE10 ..................................................... 105

FIGURA 5.2 - Microestrutura relaminação BRE08 …................................................. 106

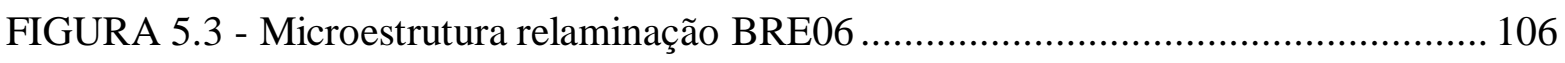

FIGURA 5.4 - Microestrutura relaminação BRE04 ................................................... 106

FIGURA 5.5 - Microestrutura relaminação BRE02 …................................................ 106

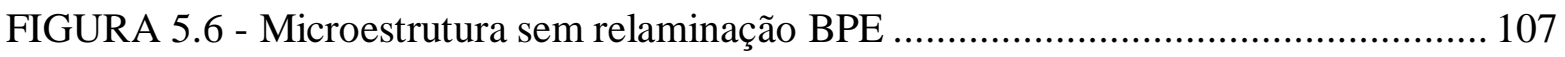

FIGURA 5.7 - ODF nas regiões superficial e central das condições BPE e BRE .............. 108

FIGURA 5.8 - Nível de intensidade nas ODF na região superficial ............................... 109

FIGURA 5.9 - Nível de intensidade nas ODF na região central .................................... 109 
FIGURA 5.10 - ODF ao longo da fibra Gama na superfície da amostra 073351 110

FIGURA 5.11 - ODF ao longo da fibra Gama na superfície da amostra 073352. 111

FIGURA 5.12 - ODF ao longo da fibra Gama no centro da amostra 073351 111

FIGURA 5.13 - ODF ao longo da fibra Gama no centro da amostra 073352. 112

FIGURA 5.14 - ODF ao longo da fibra Alfa na superfície da amostra 073351

FIGURA 5.15 - ODF ao longo da fibra Alfa na superfície da amostra 073352. 113

FIGURA 5.16 - ODF ao longo da fibra Alfa no centro da amostra 073351. 113

FIGURA 5.17 - ODF ao longo da fibra Alfa no centro da amostra 073352. 114

FIGURA 5.18 - Variação do Limite de Escoamento da amostra 073351. 116

FIGURA 5.19 - Variação do Limite de Resistência da amostra 073351. 116

FIGURA 5.20 - Variação do Alongamento Total da amostra 073351 116

FIGURA 5.21 - Variação do Limite de Escoamento da amostra 073352. 117

FIGURA 5.22 - Variação do Limite de Resistência da amostra 073352. 117

FIGURA 5.23 - Variação do Alongamento Total da amostra 073352 118

FIGURA 5.24 - Variação do Índice Erichsen da amostra 073351 119

FIGURA 5.25 - Variação do Índice Erichsen da amostra 073352 119

FIGURA 5.26 - Variação da Anisotropia Normal da amostra 073351. 120

FIGURA 5.27 - Variação da Anisotropia Normal da amostra 073352. 120

FIGURA 5.28 - Variação da Anisotropia Planar da amostra 073351. 120

FIGURA 5.29 - Variação da Anisotropia Planar da amostra 073352.

FIGURA 5.30 - Variação do Coeficiente de Encruamento da amostra 073351 122

FIGURA 5.31 - Variação do Coeficiente de Encruamento da amostra 073352 122

FIGURA 5.32 - CLC do aço IF-Ti nas condições de BRE02 126

FIGURA 5.33 - CLC do aço IF-Ti nas condições de BRE10 127

FIGURA 5.34 - Combinação das CLC nas condições de BRE02 e BRE10. 127

FIGURA 5.35 - Efeito do encruamento na CLC de um aço IF-Ti [21]. 129

FIGURA 5.36 - Comparativo das CLC experimentais e literatura 129

FIGURA 6.1 - Curva Tensão versus deformação no teste de tração [52]. 134

FIGURA 6.4- Microestrutura relaminação BRE10 136 
FIGURA 6.5 - Microestrutura relaminação BRE08 .................................................... 136

FIGURA 6.6 - Microestrutura relaminação BRE06 ...................................................... 136

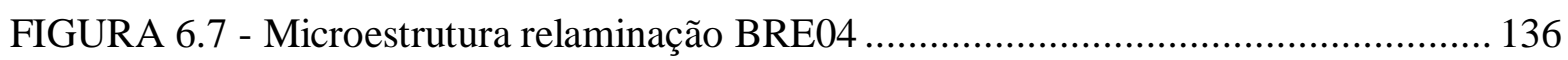

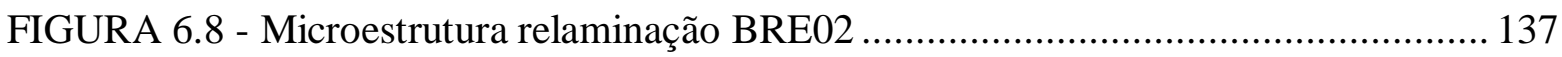

FIGURA 6.9 - Microestrutura sem relaminação BPE .................................................... 137

FIGURA 6.10 - Nível de intensidade nas ODF na Laminação a quente ........................... 137

FIGURA 6.11 - Nível de intensidade nas ODF na Laminação a frio ................................ 138

FIGURA 6.12 - Nível de intensidade nas ODF no recozimento .................................... 138

FIGURA 6.13 - Nível de intensidade nas ODF no Encruamento ...................................... 138

FIGURA 6.14 - Nível de intensidade nas ODF no encruamento com 0,2\% relaminação ... 138

FIGURA 6.15 - Nível de intensidade nas ODF no encruamento com 0,4\% relaminação ... 139

FIGURA 6.16 - Nível de intensidade nas ODF no encruamento com 0,6\% relaminação ... 139

FIGURA 6.17 - Nível de intensidade nas ODF no encruamento com 0,8\% relaminação ... 139

FIGURA 6.18 - Nível de intensidade nas ODF no encruamento com 1,0\% relaminação ... 139

FIGURA 6.19 - ODF ao longo da fibra Gama na superfície da amostra 019318 ............... 140

FIGURA 6.20 - ODF ao longo da fibra Gama no centro da amostra $019318 \ldots \ldots \ldots \ldots \ldots \ldots . . . . . . . . . .140$

FIGURA 6.21 - ODF ao longo da fibra Alfa na superfície da amostra 019381................ 141

FIGURA 6.22 - ODF ao longo da fibra Alfa no centro da amostra 019381 ..................... 141

FIGURA 6.23 - Variação do Limite de Escoamento da amostra 019318........................... 142

FIGURA 6.24 - Variação do Limite de Resistência da amostra 019318 ............................ 143

FIGURA 6.25 - Variação do Alongamento Total da amostra 019318 ............................... 143

FIGURA 6.26 - Variação do Índice Erichsen da amostra 019318 ................................... 144

FIGURA 6.27 - Variação da Anisotropia Normal da amostra 019318 .............................. 145

FIGURA 6.28 - Variação da Anisotropia Planar da amostra 019318................................. 145

FIGURA 6.29 - Variação do Coeficiente de Encruamento da amostra 019318 ................. 146 


\section{LISTA DE TABELAS}

TABELA 3.1 - Características dos principais parâmetros do recozimento em caixa. 61

TABELA 3.2 - Componentes de texturas típicas dos metais CCC laminados. 75

TABELA 4.1 - Etapas de processo da bobina ............................................................. 78

TABELA 4.2 - Parâmetros de processo das Bobinas Experiência .......................................79

TABELA 4.3 - Fluxo de processo de amostragem ....................................................... 91

TABELA 4.4 - Ensaios realizados de acordo com o plano de amostragem .......................91

TABELA 4.5 - Condição da bobina Local de amostragem ............................................. 92

TABELA 4.6 - Procedimento da solução de ataque........................................................93

TABELA 4.7 - Dimensão do corpo de prova do ensaio de tração, $\mathrm{R}$ e $n$............................ 95

TABELA 5.1 - Composição química do aço IF-Ti ........................................................ 104

TABELA 5.2 - Tamanho de grão das amostras BPE e BRE ........................................ 104

TABELA 5.3 - Tamanho de grão das amostras BPE e BRE ......................................... 105

TABELA 5.4 - Resultados dos ensaios de tração.......................................................... 115

TABELA 5.5 - Resultados dos ensaios de tração............................................................ 117

TABELA 5.6 - Resultados dos ensaios de Embutimento de Erichsen .............................. 118

TABELA 5.7 - Resultados do Valor do R de Lankford.................................................... 119

TABELA 5.8 - Resultados do Valor do n médio............................................................. 121

TABELA 5.9 - Propriedades mecânicas do material BPE em relação às normas ABNT 5915:2002 (Grau EEP-IF) e EN 10130:1991+A1: 1998 (Grau DC06)

TABELA 5.10 - Efeito do aumento da redução na laminação de encruamento nas propriedades mecânicas do aço IF-Ti................................................. 124

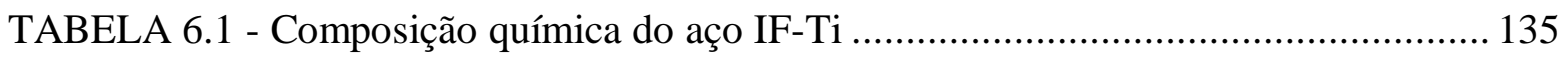

TABELA 6.2 - Tamanho de grão das amostras BPE e BRE ........................................ 135

TABELA 6.3 - Resultados dos ensaios de tração........................................................ 142

TABELA 6.4 - Resultados dos ensaios de Embutimento de Erichsen .............................. 143

TABELA 6.5 - Resultados do Valor do R de Lankford................................................. 144

TABELA 6.6 - Resultados do Valor do n médio.............................................................. 145 


\section{LISTA DE NOTAÇÕES}

$\sigma \quad$ Tensão real

$\varepsilon \quad$ Deformação real

S Tensão de engenharia

e Deformação de engenharia

$\varepsilon_{\mathrm{t}} \quad$ Deformação real no sentido da espessura

$\varepsilon_{\mathrm{w}} \quad$ Deformação real no sentido da largura

$\sigma_{\mathrm{o}} \quad$ Tensão inicial real

$\sigma_{\mathrm{x}}, \varepsilon_{\mathrm{x}}, \mathrm{e}_{\mathrm{x}} \quad \mathrm{x}$ é o índice que indica as direções principais de tensão real, deformação real e convencional respectivamente. Esse índice varia de 1 a 3.

AL Alongamento total

BQ Bobina a Quente - Laminador de Tiras a Quente

BF Bobina a Frio - Laminador de Tiras a Frio

BR Bobina Recozida - Recozimento em Caixa

BPE Bobina Produto Encruada

BRE Bobina Relaminada Encruada

CLC Curva Limite de Conformação

CQ Commercial Quality

DDQ Deep Drawing Quality

$\mathrm{Df}_{1}$ Comprimento do maior eixo da elipse ou do círculo deformado

$\mathrm{Df}_{2}$ Comprimento do menor eixo da elipse ou do círculo deformado

$\mathrm{D}_{\mathrm{i}} \quad$ Diâmetro inicial da malha ou rede

DL Direção de Laminação

Dpa Desvio-padrão 
DQ Drawing Quality

EDDQ Extra Deep Drawing Quality

H-EDDQ Hiper Extra Deep Drawing Quality

IE Índice de Embutimento Erichsen

IF Aços ultrabaixo carbono livre de intersticiais (Interstitial Free)

LE Limite de Escoamento

e $\quad$ Alongamento da tira $(\%)$

$\mathrm{L}_{\mathrm{E}} \quad$ Comprimento da tira antes do encruamento (mm)

$\mathrm{L}_{\mathrm{S}} \quad$ Comprimento da tira depois do encruamento ( $\left.\mathrm{mm}\right)$

$\mathrm{V}_{\mathrm{E}} \quad$ Velocidade de entrada $(\mathrm{m} / \mathrm{s})$

$\mathrm{V}_{\mathrm{S}} \quad$ Velocidade de saída $(\mathrm{m} / \mathrm{s})$

$\mathrm{G}_{\mathrm{E}} \quad$ Rolo gerador de entrada

G $\quad$ Rolo gerador de saída

LR Limite de Resistência

$n \quad$ Coeficiente de encruamento

$\mathrm{n}_{0}, \mathrm{n}_{45}, \mathrm{n}_{90} \quad$ Coeficiente de encruamento no ângulo indicado em relação à DL

DL Direção de Laminação

DN Direção Normal ao plano de laminação

ODF ou FDOC Função de Distribuição de Orientação

$\mathrm{R}_{\mathrm{m}} \quad$ Coeficiente de Anisotropia Normal médio

$\Delta \mathrm{R} \quad$ Coeficiente de Anisotropia Planar

$\mathrm{R}_{0}, \mathrm{R}_{45}, \mathrm{R}_{90}$ Coeficientes de Anisotropia Normal no ângulo indicado em relação à DL

SEDDQ Super Extra Deep Drawing Quality

DT Direção Transversal ao plano da chapa 
VP Variação Percentual

$\mathrm{W}_{\mathrm{f}} \quad$ Largura final da chapa após o ensaio de tração

$\mathrm{W}_{\mathrm{o}} \quad$ Largura inicial da chapa antes do ensaio de tração

F $\quad$ Freqüência de pulsos $(\mathrm{Hz})$

N Quantidade de pulsos por rotação

V Velocidade angular do rolo $(\mathrm{m} / \mathrm{s})$

D Diâmetro do rolo (m)

L Comprimento instantâneo

$\mathrm{L}_{\mathrm{o}} \quad$ Comprimento original 


\section{INTRODUÇÃO}

A estampagem profunda, ou simplesmente estampagem, é o processo utilizado para modelar chapas planas em artigos com forma de copo, tais como pias, cápsulas, pára-lamas de automóveis e vários outros objetos, de uso comum na vida diária.

O seu surgimento deu-se em virtude de que os metais apresentam um limite à deformação uniforme, o que torna a operação de estiramento simples limitada a não mais de $30 \%$ de deformação, na maioria das ligas [1]. Este é o ponto a partir do qual começa haver uma instabilidade na deformação plástica dos metais, com uma região deformando-se preferencialmente a outras e tendo como conseqüência, uma falha no material que provocará a sua ruptura.

Surgem então, os aços para estampagem, pressionados principalmente pela indústria automobilística. Com isto, as siderúrgicas intensificaram os estudos de materiais que tivessem melhor desempenho em relação à estampabilidade de suas peças. Houve então, uma grande evolução desde os AISI 1010 efervescentes da década de 50, até os aços livres de intersticiais dos dias atuais.

Esta evolução ocorreu com um melhor conhecimento dos fundamentos e das origens das propriedades ligadas à estampagem e um enorme trabalho de investigação tecnológica envolvendo a composição e o processamento de chapas finas de aço. Com a instalação de novos equipamentos nas unidades das siderúrgicas, tais como, o sistema de Desgaseificação a vácuo $(\mathrm{RH})$, permitiram a obtenção de aços livres de intersticiais, de elevada 
estampabilidade, contribuindo para o aumento da produção dos aços laminados a frio, como mostra a FIG. 1.1.
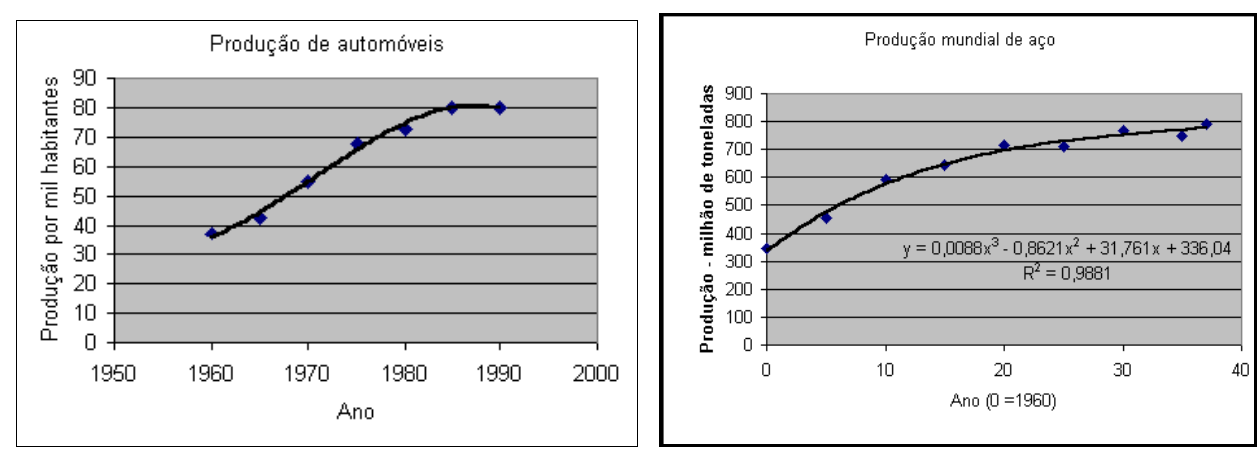

FIGURA 1.1 - Aumento da produção mundial de automóveis e de aço [2]

Com relação ao comportamento destes aços durante a estampagem, isto é, sua estampabilidade, depende de três fatores principais: grau de anisotropia, coeficiente de encruamento e qualidade superficial. Estes fatores são verificados nos aços IF, sendo sua excelente conformabilidade o principal diferencial em relação aos aços acalmados ao alumínio. Com isto, as principais características dos aços IF são:

- Alto Alongamento

- Baixo Limite de Escoamento

- Alto valor do coeficiente de Anisotropia Normal

- Baixo valor do coeficiente de Anisotropia Planar

- Baixa susceptibilidade ao envelhecimento

Estas características conferem a esta classe de aços uma ampla aplicação principalmente na indústria automobilística, nas peças que necessitam da alta estampabilidade tais como, cavidades no piso traseiro, alojamento do pneu sobressalente e a parte interior das portas frontal, traseira e outras, caixa de roda, lateral interna e externa, conforme FIG. 1.2. 


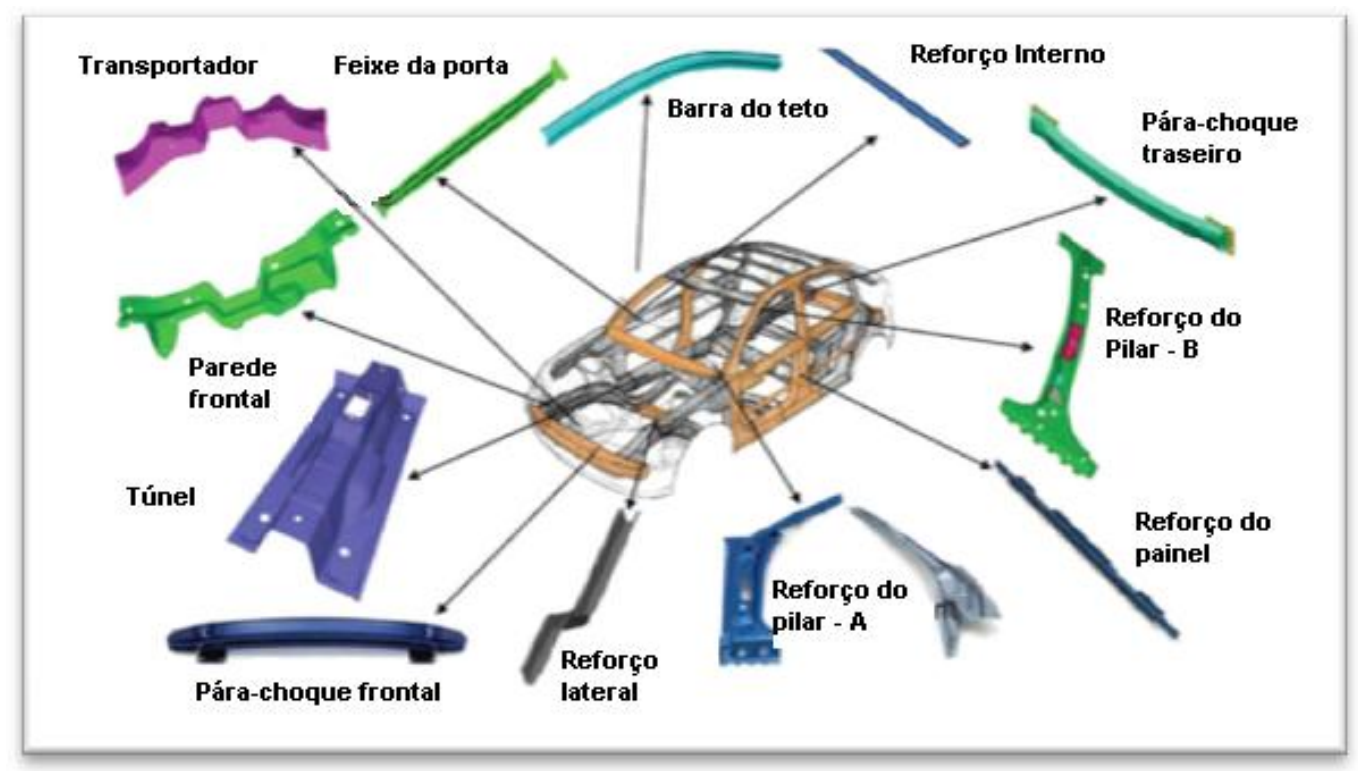

FIGURA 1.2 - Aplicações do aço na composição no segmento automotivo [3]

Tais características e propriedades somente podem ser alcançadas na ausência de elementos intersticiais como o carbono e nitrogênio. Isto é conseguido através da adição de elementos formadores de carbonetos e/ou nitretos (elementos estabilizantes) em uma matriz com teores muito reduzidos de carbono. A conjugação destes dois fatores é essencial, pois enquanto a simples redução dos teores de carbono leva a aços envelhecíveis e com propriedades mecânicas inadequadas a operações de estampagem severa, onde somente a simples adição de elementos estabilizantes em aços comuns, irá elevar a alta resistê'’ncia do material, no entanto com baixa dutilidade [3].

Além disso, a redução dos teores de carbono favorece a formação de uma textura de recristalização favorável à conformação. Esta textura depende de maneira significativa da composição química e das condições de processo da laminação a quente, do tamanho de grão, da temperatura de bobinamento, da redução a frio e do recozimento [17]. A textura pode ser associada com a quantidade de carbonetos de titânio ou nióbio [4]. A precipitação 
destes, por sua vez, ocorre antes da laminação a frio, o que confere um papel de destaque às variáveis da laminação a quente destes aços.

O controle sistemático das variáveis de processamento durante a fabricação deste aço é imprescindível para garantia de suas principais propriedades, por exemplo, o valor do coeficiente de anisotropia e a textura cristalográfica (orientação dos grãos dos planos cristalográficos do material) que por sua vez, estão relacionados com a estampabilidade da chapa, que é um dos indicadores utilizados para avaliar a textura.

$\mathrm{Na}$ realização deste trabalho utilizaram-se três bobinas do aço IF, com semelhança na composição química, dimensão, etapas do processo e equipamentos, com o propósito de constatar a repetibilidade, validação dos dados e confiabilidade do processo de fabricação. Foram realizados ensaios mecânicos, analisadas as microestruturas, textura cristalográfica e o levantamento de CLC, das amostras obtidas nas etapas de laminação e relaminação.

Esta dissertação compõe-se de seis seções. Na primeira seção, INTRODUÇÃO apresenta-se a síntese do conteúdo; na segunda seção OBJETIVO, os objetivos dos experimentos. Na terceira seção, REVISÃO BIBLIOGRÁFICA aborda-se a estampagem de maneira geral e a influência dos parâmetros de fabricação industrial nas características ligadas à estampagem do aço IF-Ti. Na quarta, MATERIAIS E MÉTODOS descreve-se o procedimento de fabricação do aço IF-Ti utilizado no experimento, bem como os ensaios realizados para caracterizá-lo. Na quinta seção, RESULTADOS e DISCUSSÃO são apresentados e analisados os resultados dos ensaios. Na sexta seção, CONSIDERAÇÕES FINAIS apresentam-se as conclusões, a relevância dos resultados e as recomendações para futuros trabalhos. 


\section{OBJETIVO}

O presente trabalho tem como objetivo principal estudar a influência do reprocesso ou relaminação no laminador de encruamento em relação às propriedades do aço IF em diversos graus de redução. Este processo é chamado de relaminação, é praticado com frequência, e visa à melhoria da qualidade superficial e forma do material. No entanto, por diversas vezes tem-se constatado o desvio de aplicação do pedido original da bobina, por não atendimento de algumas propriedades mecânicas após o procedimento de relaminação, comprometendo a aplicação do produto e gerando perdas no processo.

Para verificação e quantificação deste procedimento, também serão analisados neste trabalho os seguintes itens:

- Verificar a influência dos graus de redução no laminador de encruamento em relação ao tamanho de grão do aço IF.

- Verificar a influência do grau de redução no laminador de encruamento nas propriedades mecânicas do aço IF.

- Verificar a influência do grau de redução no laminador de encruamento em relação à anisotropia normal e planar e o coeficiente de encruamento.

- Procurar reconfirmar os valores de literatura que estabelece a relação de n e IEE;

- Estudar a evolução das fibras $\alpha$ e $\gamma$ em chapas (superfície e região central) suscetíveis aos graus de redução.

- Verificar o efeito do grau de redução no laminador de encruamento na textura do aço IF, através das Figuras de Função de Distribuição de Orientação - ODF.

- Verificar a estampabilidade do aço IF utilizando as Curvas CLC. 


\section{REVISÃO BIBLIOGRÁFICA}

\subsection{Tensões e deformações na conformação de chapas}

A deformação plástica por estampagem ou conformação de chapas pode ser definida como a possibilidade de uma chapa ser processada por deformação plástica sem apresentar defeitos ou fraturas [5]. Em muitos processos de estampagem de aço, demanda-se uma ou mais operações denominadas de conformação de chapas. As principais são dobramento, corte, estiramento e embutimento ou estampagem profunda, sendo que as duas últimas operações são os tipos básicos de mecanismos de deformação.

Ao submeter uma chapa metálica de pequena espessura a uma operação de estiramento ou estampagem profunda, pode-se considerar que no plano da chapa atua um sistema biaxial de tensões, conforme FIG. 3.1. Desse modo, pode-se caracterizar, conforme Nakazima [7], o plano de tensões $\left(\sigma_{1}, \sigma_{2} \neq 0\right.$ e $\left.\sigma_{3}=0\right)$ como aquele que representa os processos mais comumente encontrados na conformação de chapas metálicas.

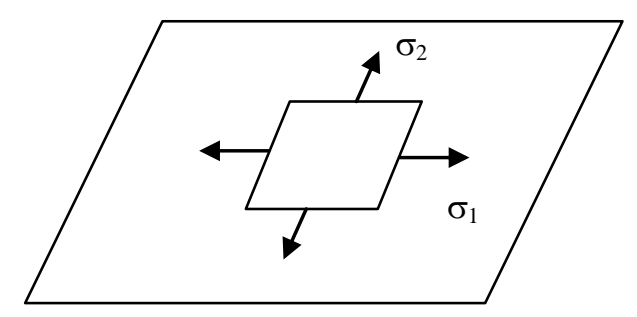

FIGURA 3.1 - Sistema de tensões que atua numa chapa nos processos de estiramento e estampagem [8]

A intensidade e sentido destas tensões variam em pontos diferentes da chapa, e podem variar também num mesmo ponto à medida que ocorre a deformação. O sistema de tensões originará inicialmente deformações elásticas segundo três eixos principais $\varepsilon_{1}, \varepsilon_{2}$ e $\varepsilon_{3}$. Num 
determinado ponto de uma chapa isotrópica, o metal iniciará a deformação plástica quando as tensões aplicadas neste ponto excedem o critério de Von-Mises, o qual, no caso de um sistema de tensões biaxiais, vem dado pela relação:

$\sigma_{1}^{2}+\sigma_{2}^{2}-\sigma_{1} \sigma_{2}=X_{0}^{2}$

sendo, $\mathrm{X}_{0} \mathrm{o}$ valor do limite de elasticidade num ensaio de tração e $\sigma_{1}$ e $\sigma_{2}$ as tensões aplicadas. A cada valor do par $\sigma_{1}, \sigma_{2}$ que satisfaça a equação [3.1] associam-se deformações segundo os três eixos principais $\varepsilon_{1}, \varepsilon_{2}, \varepsilon_{3}$. A expressão é a equação de uma elipse, a qual representada graficamente na FIG. 3.2, define os domínios de deformações elásticas e plásticas.

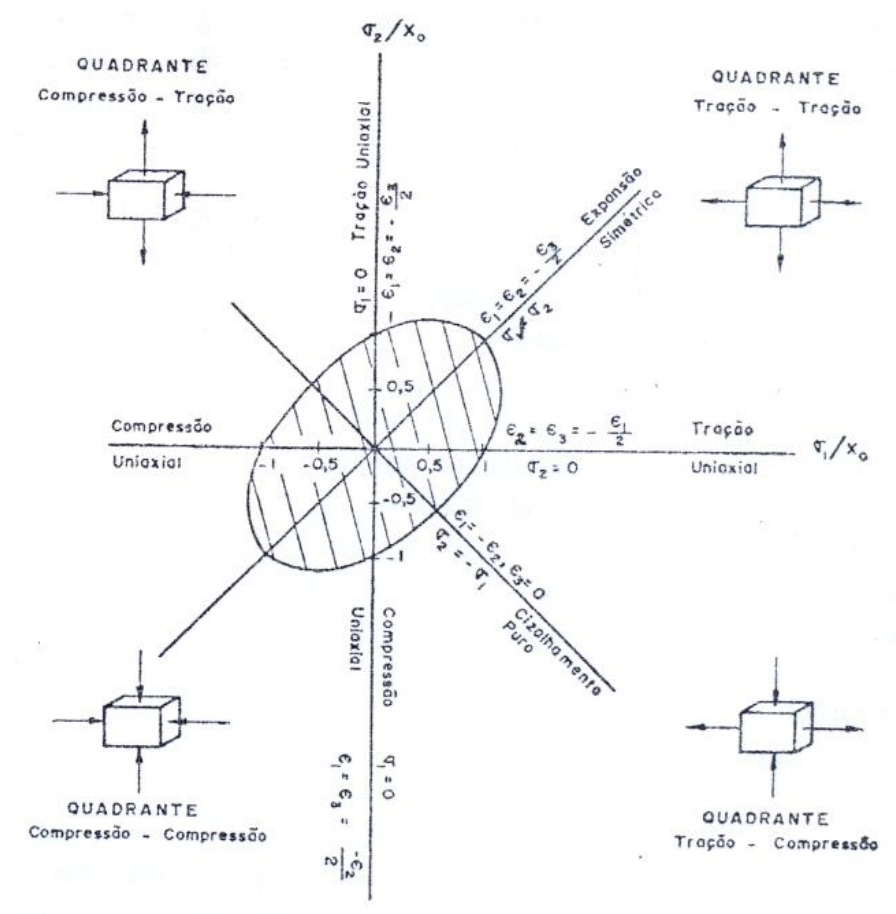

FIGURA 3.2 - Representação gráfica do critério de plasticidade de Von-Mises para um sistema de tensões biaxiais. Chapa isotrópica [9] 
As relações entre $\sigma_{1}, \sigma_{2}$ e os valores correspondentes de $\varepsilon_{1}, \varepsilon_{2}$, $\varepsilon_{3}$ estão indicadas na FIG. 3.2. Assim, pode observar-se que para $\sigma_{1}=1, \sigma_{2}=0$ e $\sigma_{2}=1, \sigma_{1}=0$ as deformações principais são: $\varepsilon_{2}=\varepsilon_{3}=-\varepsilon_{1} / 2$ e $\varepsilon_{1}=\varepsilon_{3}=-\varepsilon_{2} / 2$.

Existe um coeficiente, denominado de anisotropia normal [10] que é definido a partir de um ensaio de tração uniaxial pela relação:

$$
R=\frac{\ln \frac{w}{w_{0}}}{\ln \frac{\mathrm{e}}{\mathrm{e}_{0}}}
$$

sendo, $\mathrm{e}_{0}$ e $\mathrm{w}_{0}$ os valores da espessura e largura iniciais do corpo-de-prova, $e$ e $w$ os valores da espessura e largura após uma determinada deformação.

Ao contrário, quando $\sigma_{2}=0, \sigma_{1}=-1$ e $\sigma_{2}=-1, \sigma_{1}=0$, resulta nos casos de compressão uniaxial. Pode-se observar ainda, que quando $\sigma_{1}=\sigma_{2}$ obtém-se expansão simétrica, com $\varepsilon_{1}=$ $\varepsilon_{2}=-\varepsilon_{3} / 2$. E quando $\sigma_{2}=-\sigma_{1}$ resulta em cisalhamento puro com $\varepsilon_{1}=-\varepsilon_{2}, \varepsilon_{3}=0$. Se o material é anisotrópico, o critério de plasticidade de Von-Mises deduzido por Hill [9] no caso de uma chapa possuindo simetria rotacional na direção da espessura, é dado pela expressão:

$\sigma_{1}^{2}+\sigma_{2}^{2}-\sigma_{1} \sigma_{2} \frac{2 R}{R+1}=X_{0}^{2}$

Esta equação representa também uma elipse cuja excentricidade depende do valor de $\mathrm{R}$, conforme FIG. 3.3. 


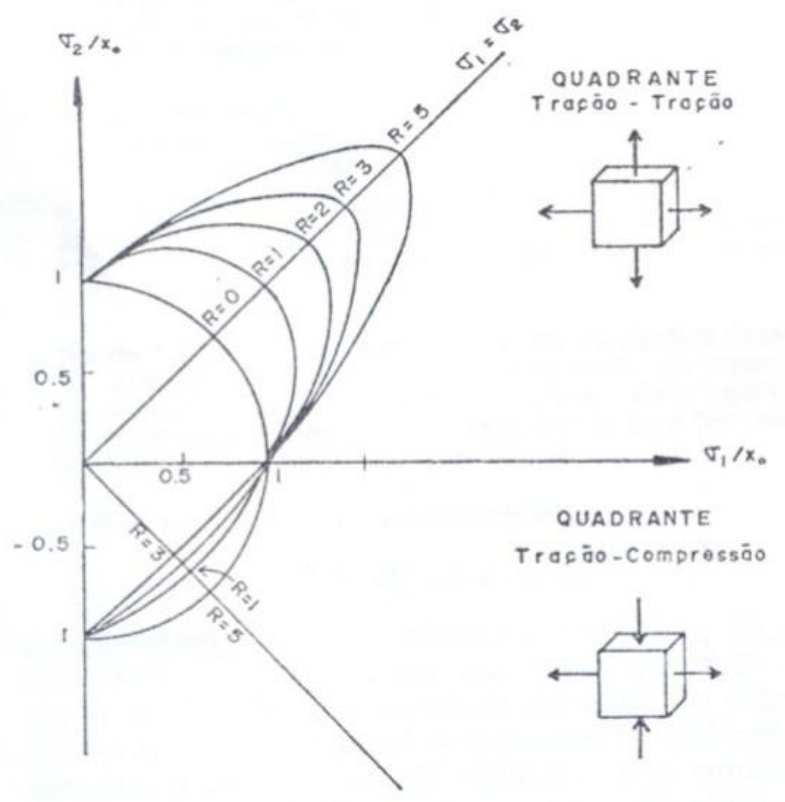

FIGURA 3.3 - Representação parcial do critério de plasticidade de Von-Mises para um sistema de tensões biaxiais. Chapa anisotrópica [10]

O critério de Von-Mises é um critério de plasticidade e indica tão somente, os valores de $\sigma_{1}$ e $\sigma_{2}$ que irão iniciar a deformação plástica. No caso de deformações plásticas são necessárias teorias mais complexas, pois não conseguem conciliar a natureza anisotrópica da deformação individual dos grãos cristalinos com o comportamento macroscópico do metal.

Nos processos de estiramento e estampagem observa-se que as deformações dependem do sistema de tensões que atua localmente. A medição destas deformações em diversas zonas de peças conformadas permitiu observar que as deformações principais podem estender-se na região compreendida entre $\varepsilon_{1}=\varepsilon_{2}$ e $\varepsilon_{1}=-\varepsilon_{2}$ passando por $\varepsilon_{1}=0$. Esta variedade possível de deformações indica que será extremamente difícil avaliar a qualidade de uma chapa para conformar uma peça determinada a partir de ensaios de laboratórios simples, como por exemplo, o ensaio de tração uniaxial. Mesmo nos ensaios que simulam conformação, por exemplo, ensaio de Erichsen ou Swift, não é fácil medir tal aptidão, já que na maioria dos 
casos a chapa não é submetida à complexa gama de tensões que atuam ao ser conformada a peça real.

\subsection{Processos de conformação por estampagem}

O processo de estampagem é controlado por diversos fatores de natureza mecânica e metalúrgica. Entre os fatores principais de natureza mecânica podem-se mencionar: forma e dimensões da peça, máquina de conformação, o tipo de prensa empregado, a forma e dimensões das ferramentas (punção e matrizes) e as condições de lubrificação, conforme mostra a FIG. 3.4. Esses fatores têm influência direta na definição dos estados de tensão e deformação existentes em cada instante do processo nas diversas regiões da peça. Os estados de tensão alteram as condições de escoamento e, portanto, de comportamento plástico do material.

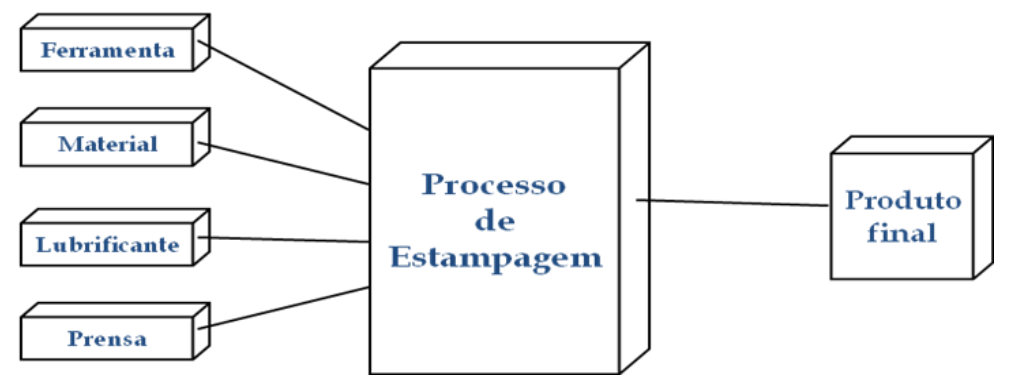

FIGURA 3.4 - Fatores de influência durante o processo de estampagem [6]

\subsubsection{Modos básicos da deformação}

A FIG. 3.5 mostra um esquema básico para a operação de conformação por estampagem de um copo de fundo plano. Nessa operação são necessários três componentes principais: a matriz, o punção cilíndrico e o sujeitador ou prensa-chapas. Essa operação consiste em deformar uma chapa em direção à cavidade circular da matriz, através da ação do punção na 
região central da chapa e, ao mesmo tempo, a aba ou flange, sob ação do prensa-chapas, movimenta-se em direção à cavidade.

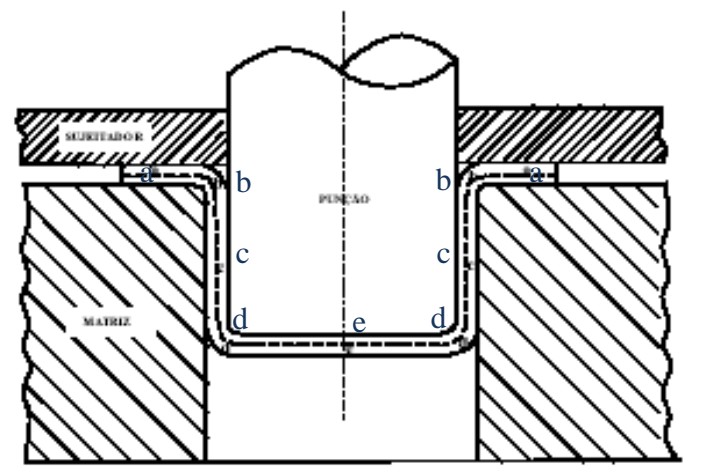
(a) : Região da aba ou flange do copo
(b) : Região do dobramento da matriz
(c) : Região lateral ou parede do copo
(d) : Região do dobramento no punção
(e) : Região do fundo do copo

FIGURA 3.5 - Regiões do copo com diferentes estados de tensão [5]

Depois de iniciada a operação, no flange ocorre uma redução gradativa da circunferência do disco à medida que seu material penetra na cavidade da matriz. Nessa região atuam tensões de compressão circunferenciais, que tendem a enrugar a chapa conforme FIG. 3.6. Para evitar o enrugamento, aplica-se uma tensão de compressão através do prensa-chapas, que promove esforços de tração no flange, denominados de tensões de estiramento radial. Também ocorrem os esforços de atrito que dependem do nível da tensão do prensa-chapas, das condições superficiais da chapa, da matriz e do prensa-chapas quanto à aspereza superficial e do tipo de lubrificante.

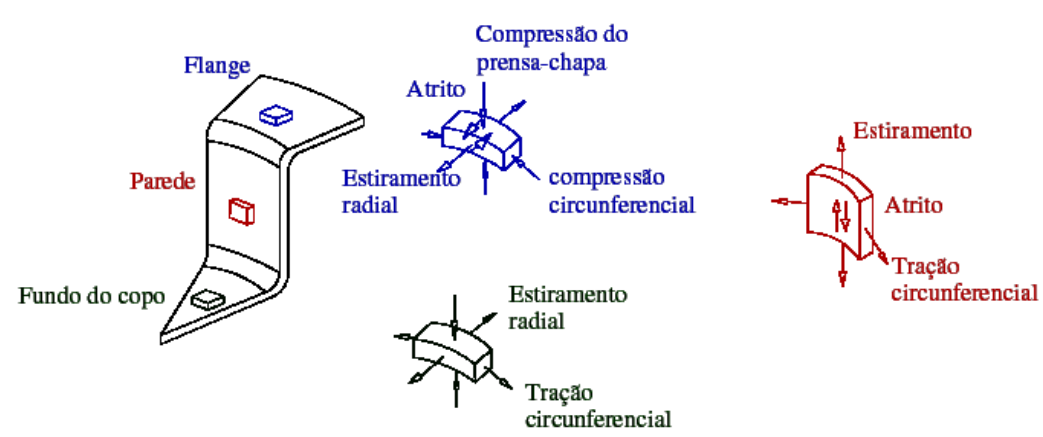

FIGURA 3.6 - Esforços atuantes nas diversas regiões do copo [6] 
Nas laterais ou parede do copo, na FIG. 3.6 atuam as tensões de tração que provocam o estiramento das paredes do copo e tensões de compressão perpendiculares à superfície da parede, que provocam afinamento da espessura da parede. No fundo do copo da FIG. 3.6, o esforço predominante é a tensão de compressão exercida pela extremidade do punção, que é transmitida às demais partes do copo através de tensões de tração radiais.

\subsection{Testes simulativos}

Os testes simulativos buscam basicamente reproduzir em laboratórios o tipo de conformação a que o esboço ou blank seriam submetidos se processados numa prensa industrial, variando-se as formas de punções, matrizes, dimensões dos esboços e as condições de atrito.

A simulação em laboratório dos processos industriais de estampagem apresenta limitações dentre as quais podemos citar: as condições de lubrificação, a velocidade de deformação, o acabamento superficial da chapa e do ferramental, o efeito de escala, a temperatura das matrizes e outros. Estes fatores são variáveis de difícil controle, por isso inúmeros testes foram desenvolvidos, cada um deles, com o objetivo de tentar reproduzir condições específicas: estado de tensões e deformações, modos de conformação predominante e interação material/ferramenta. Através de uma análise criteriosa destes testes laboratoriais, podem-se obter grandes reduções no número de peças com falhas em prensas industriais.

\subsubsection{Teste de estiramento}

O objetivo geral dos testes de estiramento em prensa é simular a operação de conformação por estiramento, valendo-se de um punção sólido hemisférico ou da substituição deste por pressão hidráulica. O material nestes tipos de testes é submetido a um sistema biaxial de 
trações, geralmente simétrico. Neles procura-se avaliar a capacidade do material de distribuir as deformações o mais homogeneamente possível, evitando-se assim o aparecimento precoce de estricções. Pode-se também estimar indiretamente a presença de inclusões, pois estas propiciam a formação de estricção localizada e de fratura prematura, por serem concentradoras de deformações nos materiais ensaiados.

Eles medem em sua maioria a profundidade atingida pelo estampo no momento da aparição da estricção localizada ou do estabelecimento da trinca, para diversas condições de atrito e formas de punção. No teste Erichsen [12] um esboço quadrado de $90 \mathrm{~mm}$ de aresta, lubrificado com graxa grafitada, é fixado pelo prensa-chapa com carga da ordem de uma tonelada e submetido a um sistema biaxial de tensões de tração, através de um punção sólido hemisférico 20 mm de diâmetro, como mostra a FIG. 3.7.

A grandeza medida é a profundidade de penetração do punção em (milímetros), no início da ruptura do corpo de prova. Um valor elevado no teste Erichsen indica que o material apresenta boa conformabilidade no estiramento. Como principais vantagens do teste Erichsen apontam-se a rapidez e a simplicidade na execução, além de haver pouca influência do operador nos valores medidos. No entanto, o ensaio tem como resultado um valor não adimensional e é dependente da espessura.

O ensaio Nakazima e o Bulge Test são ensaios semelhantes, sendo que no segundo, o punção rígido hemisférico é substituído por pressão hidráulica. Em ambos os ensaios, a chapa é fixada através de pressão elevada no prensa-chapa, de modo a impedir que o material, durante a conformação, corra para dentro da matriz. Eles simulam o estiramento puro sendo o valor da altura da calota hemisférica em milímetros o parâmetro a se medir. A principal 
vantagem do Bulge Test é a eliminação da componente de atrito entre a cabeça do punção e o esboço. Os testes Erichsen e Bulge, apresentam um bom índice de correlação quanto ao desempenho do material quando conformado na prensa, havendo predominância de estiramento.

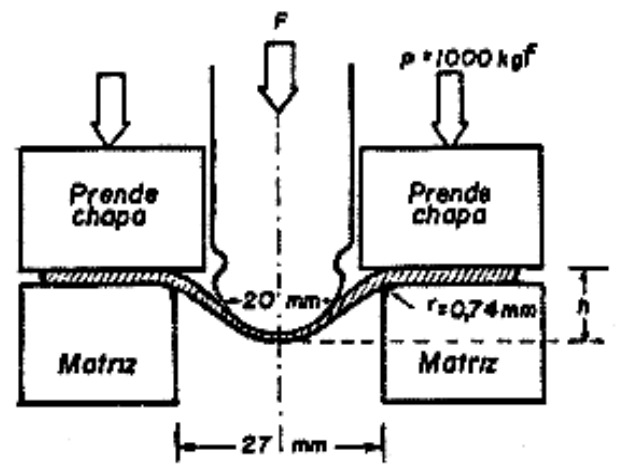

FIGURA 3.7 - Esquema do ensaio Erichsen [12]

\subsubsection{Teste de embutimento}

Nos testes simulativos onde predomina a estampagem ou embutimento, a pressão no prensachapas é pequena, atuando somente no sentido de evitar a formação de rugas e possibilitando, desta forma, o escoamento do material para dentro da matriz. No modo de deformação por estampagem pura não se objetiva atingir a fratura. O que ocorre é que o material deforma-se até determinado ponto por estampagem. Daí a necessidade de se frisar que nos testes de estampagem profunda, o que na realidade se observa é a predominância do modo de deformação por estampagem profunda, conforme norma NBR 5915:2002 [13].

O teste Swift é o que possui maior similaridade com o modo de conformação por embutimento. Ele consiste em formar uma peça cilíndrica a partir de um esboço circular utilizando um punção de fundo plano. As dimensões das ferramentas dependem da espessura da chapa conforme se pode observar na FIG. 3.8. O teste Swift consiste em realizar-se uma 
série de ensaios nos quais se vai aumentando o diâmetro do esboço até que não se consiga embutir mais completamente o esboço sem a ocorrência de trincas e dobras. Estabelece-se então a razão crítica dos diâmetros, que é a razão entre o maior diâmetro do esboço embutido com sucesso pelo diâmetro do punção.

Internacionalmente, a razão crítica dos diâmetros é conhecida por LDR - Limit Draw Ratio. Este teste demanda um grande número de ensaios para os diferentes tamanhos de esboço além de ser sensível às variações das condições de lubrificação. Sua principal vantagem é produzir uma grandeza adimensional e praticamente independente da espessura do esboço. O teste Swift correlaciona-se de maneira razoável com o índice de anisotropia $\mathrm{R}$ de Lankford, sendo de grande utilidade na avaliação da estampabilidade de aços carbono e aços inoxidáveis ferríticos.

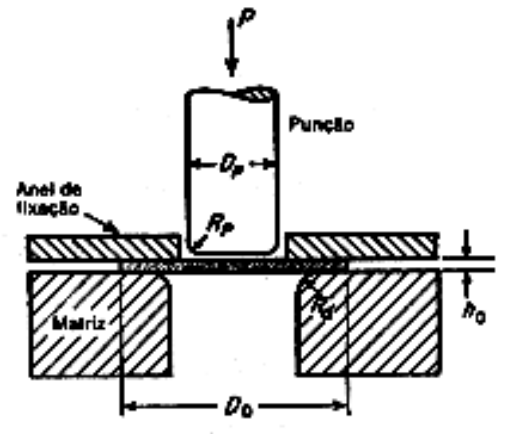

(a)

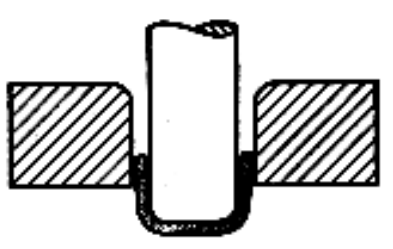

(b)

FIGURA 3.8 - Esquema do teste Swift para avaliação da estampabilidade [13]

\subsubsection{Testes relativos às propriedades fundamentais}

As propriedades fundamentais são obtidas através do ensaio de tração [14], onde um corpo de prova é submetido a um esforço de tração uniaxial. A máquina registra a força $\mathrm{P}$ versus a variação de comprimento do corpo de prova $\Delta \mathrm{L}$. Em lugar da força e do alongamento 
freqüentemente utilizam-se as tensões e deformações convencionais ( $S$, e) ou tensões e deformações reais $(\sigma, \varepsilon)$. Por definição:

\begin{tabular}{|l|l|l|}
\hline \multicolumn{1}{|c|}{ Propriedades } & \multicolumn{1}{|c|}{ Engenharia } & \multicolumn{1}{c|}{ Real } \\
\hline Tensão & $\mathrm{S}=\mathrm{P} / \mathrm{A}_{0}$ & $\sigma=\mathrm{S}(1+\mathrm{e})$ \\
\hline Deformação & $\mathrm{e}=\left(\Delta \mathrm{L} / \mathrm{L}_{0}\right)=\left(\mathrm{L}_{\mathrm{i}}-\mathrm{L}_{0}\right) / \mathrm{L}_{0}$ & $\varepsilon=\ln \left(\mathrm{L}_{\mathrm{i}} / \mathrm{L}_{0}\right)=\ln (1+\mathrm{e})$ \\
\hline
\end{tabular}

$\mathrm{L}_{0}=$ comprimento inicial do corpo de prova

$\mathrm{L}_{\mathrm{i}}=$ comprimento do corpo de prova em um instante $\mathrm{i}$

$\mathrm{A}_{0}=$ área da seção transversal inicial do corpo de prova

A FIG. 3.9 apresenta as curvas típicas do ensaio de tração de aços baixo carbono, laminados a frio e destinados a operações de estampagem.

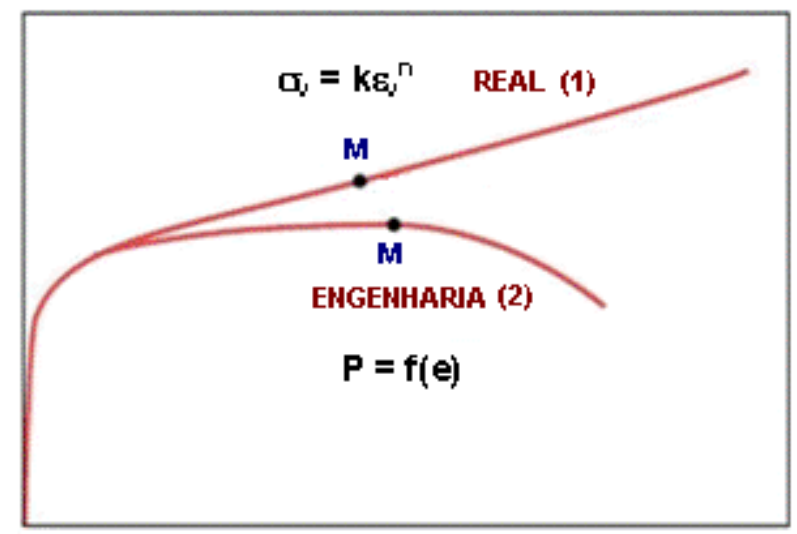

FIGURA 3.9 - Curvas típicas do ensaio de tração de aços baixo carbono [14]

A curva representada por uma linha (1) na FIG. 3.9 é denominada curva tensão vs. deformação real, e a curva representada pela linha (2) é denominada tensão vs. deformação de engenharia. As equações dadas para a tensão e deformação real são válidas enquanto a deformação da seção de referência permanece essencialmente uniforme. Nesse sentido, 
admite-se, em geral, que a seção de referência se deforma uniformemente até as proximidades do ponto de tensão máxima do diagrama convencional tensão-deformação. Após esse ponto, o corpo de prova começa a sofrer estricção, e a deformação se concentra na região de estricção. A deformação por sua vez, deve ser medida em termos do diâmetro na região de estricção, ao invés de em função da referência do corpo de prova. Se esses fatores forem considerados, obtém-se uma curva tensão-deformação como a curva (2) da FIG. 3.9.

Os parâmetros que caracterizam a resistência mecânica do material são:

- Limite de Escoamento: $\mathrm{LE}=\mathrm{P}_{\mathrm{a}} / \mathrm{A}_{0}$ sendo $\mathrm{P}_{\mathrm{a}}$ a carga para $0,2 \%$ de deformação, e $\mathrm{A}_{0}$ a área inicial do corpo de prova.

○ Limite de Resistência: $\mathrm{LR}=\mathrm{P}_{\mathrm{b}} / \mathrm{A}_{0}$ sendo, $\mathrm{P}_{\mathrm{b}}$ a carga máxima do ensaio.

○ $\mathrm{AL} \%=\left(\Delta \mathrm{L} / \mathrm{L}_{\mathrm{o}}\right) \times 100=\left[\left(\mathrm{L}_{\mathrm{f}}-\mathrm{L}_{0}\right) / \mathrm{L}_{0}\right] \times 100$, ou Alongamento Total Percentual.

A equação de Hollomon, abaixo apresentada, é considerada satisfatória para aços com baixo carbono, sendo largamente adotada:

$\sigma=K \varepsilon^{n}$

onde,

$\mathrm{K}=$ coeficiente de resistência

$n=$ coeficiente de encruamento 


\subsection{Interpretação dos resultados dos testes}

\subsubsection{Coeficiente de encruamento $(n)$}

O resultado do ensaio de tração convencional é geralmente expresso pela curva tensão versus deformação. Pode-se ainda representá-lo utilizando a curva tensão real $(\sigma)$ versus deformação real $(\varepsilon)$, cuja interpretação pode levar a importantes conclusões sobre o comportamento intrínseco do material.

Equações que se ajustam à curva tensão real versus deformação real têm sido propostas por vários autores. No entanto, são empíricas e se atêm, em geral, ao modelo que se ajusta melhor ao formato da curva. Como exemplo, tem-se a equação de Hollomon, EQUAÇÃO 3.4, que é a mais utilizada devida sua simplicidade e facilidade de determinação de $n$, coeficiente de encruamento por deformação e $K$, constante plástica de resistência [15].

Através dos cálculos mostrados no APÊNDICE I, pode-se calcular o valor $n$ da equação de Hollomon através do cálculo de deformação no ponto de carga máxima, denominado alongamento uniforme, a partir do qual se inicia a deformação localizada ou estricção. No entanto, a grande dificuldade, como se pode ver na FIG. 6.1 desse apêndice (que é típico de aços baixo e ultrabaixo carbono), é que a curva tensão deformação é extremamente suave nas proximidades da carga máxima. Por isso, fica bastante difícil a localização exata do ponto correspondente ao alongamento uniforme.

Outro método para calcular $n$ consiste em tomar a forma logarítmica da equação de Hollomon e plotar em um gráfico os valores de $\ln (\sigma)$ versus $\ln (\varepsilon)$. Assim obtém-se o $n$ através da inclinação da curva e o $K$ através da interseção com o eixo das ordenadas. Esse 
método é útil para se encontrar o $n$, apesar de ser mais preciso que o anterior. Também se pode utilizar o método de Nelson e Winlock [16] para determinar o $n$. Esse método utiliza dois pontos da curva tensão-deformação convencional e calcula o índice $n$ conforme EQUAÇÃO 3.5. O primeiro ponto corresponde à carga máxima $\left(\mathrm{P}_{\mathrm{u}}\right)$ e ao alongamento uniforme $\left(\mathrm{e}_{\mathrm{u}}\right)$. O segundo ponto pode ser qualquer um que esteja no trecho da curva tensão versus deformação que corresponde a uma deformação inferior a $\left(\mathrm{e}_{u}\right)$.

$$
\frac{P_{u}}{P_{2}}=\frac{\left(1+e_{2}\right)}{\left(1+e_{u}\right)}\left(\frac{n}{\ln \left(1+e_{2}\right)}\right)^{n}
$$

Tendo em vista a EQUAÇÃO 3.5, fixando-se um valor para $\mathrm{e}_{2}$, pode-se determinar $n$ em função do quociente $\mathrm{P}_{\mathrm{u}} / \mathrm{P}_{2}$. Os valores de $\mathrm{P}_{\mathrm{u}}$ e $\mathrm{P}_{2}$ podem facilmente serem determinados no gráfico tensão-deformação convencional, assim como e 2 . Para a escolha do valor pré-fixado de $\mathrm{e}_{2}$, é preciso considerar que $\mathrm{e}_{2}$ deve estar distante do ponto de carga máxima. Além disso, ele deve estar distante do limite de escoamento por dois motivos: primeiro, para evitar a correção decorrente da deformação elástica; segundo, para baixas deformações, as curvas logarítmicas tensão-deformação desviam-se em muitos casos de linhas retas, em geral isso acontece para deformações menores que 5\% [17]. Portanto, o valor de $\mathrm{e}_{2}$ entre 5 e $12 \%$.

Em analogia com o valor $\mathrm{R}$, onde a anisotropia planar altera as curvas tensão-deformação dependendo da direção em que se realiza o ensaio, o teste é feito em três direções diferentes e toma-se o valor médio. De forma semelhante para determinar $n$, tomam-se corpos de prova a $0^{\circ}, 45^{\circ}$ e $90^{\circ}$ em relação à direção de laminação e tem-se: 
$n_{\text {médio }}=\frac{1}{4}\left(n_{0}+2 n_{45}+n_{90}\right)$

que determina o valor médio do coeficiente $n$ de encruamento ou de endurecimento por deformação.

A equação de Hollomon é considerada satisfatória para os aços carbono, sendo adotada por quase todos os autores e entidades de vários países, inclusive o International Deep Drawing Research Group (IDDRG). No entanto, ela não descreve satisfatoriamente o comportamento de alguns materiais em tração como, por exemplo, materiais que sofrem mudança de fase por deformação, aços tipo Dual-Phase e alguns inoxidáveis austeníticos, conforme Klein [15] e Melo [18].

O $n$ é uma medida da capacidade de encruamento do material e, portanto, de distribuir mais uniformemente as deformações por toda a peça [5]. Logo, desejam-se altos valores de $n$ para a conformação de chapas. Além disso, o $n$ está associado à deformação sofrida para o ponto de carga máxima, ou seja, o ponto de estricção e, quanto mais o valor $n$ cresce, maior é a deformação uniforme, e o material pode deformar mais, sem alcançar a estricção. Assim, um material que tenha um baixo $n$, quando submetido a uma operação de estiramento, atinge o alongamento uniforme rapidamente.

As deformações localizadas ou instabilidades plásticas iniciam-se mais cedo. Já o material que tenha o índice $n$ elevado endurece rapidamente por deformação, transmitindo, para as partes vizinha a mais deformada, os esforços a que está sujeito. Dessa forma, pode deformar-se uniformemente por um período mais longo que o primeiro, retardando o aparecimento dessas deformações localizadas. 
O coeficiente de encruamento $n$ decresce com o aumento da concentração de solutos substitucionais, com a diminuição do tamanho de grão e com aumento da fração volumétrica de alguns tipos de segunda fase [19].

Sabe-se que o sistema de esforços e deformações numa operação de estiramento é biaxial. Assim, sob a condição biaxial, a instabilidade plástica aparece, dependendo de inúmeros fatores, sob a condição de estricção "difusa” ao invés de estricção localizada (como no ensaio de tração), aumentando, então, a possibilidade de o material se deformar sob condições não-uniformes.

Até a deformação uniforme, pode-se considerar que há certa semelhança entre o comportamento uniaxial e biaxial [20]. Entretanto, vários trabalhos assumem que a capacidade de estiramento é perfeitamente relatada pelo $n$. Porém, como a deformação uniforme vai até o início da estricção, o valor $n$ não pode ser interpretado como a capacidade de estiramento sem considerar a contribuição do estiramento após essa deformação uniforme.

\subsubsection{Coeficiente de anisotropia}

Durante os processos de conformação de chapas, grãos cristalinos individuais são alongados na direção da maior deformação de tração. O alongamento é conseqüência do processo de escorregamento cristalino durante a deformação. Nos materiais policristalinos, os grãos tendem a girar para alguma orientação preferencial, devido a um confinamento mútuo entre grãos. Este mecanismo faz com que os planos atômicos e direções cristalinas dos materiais com orientação aleatória (materiais isotrópicos) adquiram uma textura (orientação 
preferencial ou anisotropia), conforme a FIG. 3.10, com desenho esquemático do alongamento dos grãos durante a laminação.

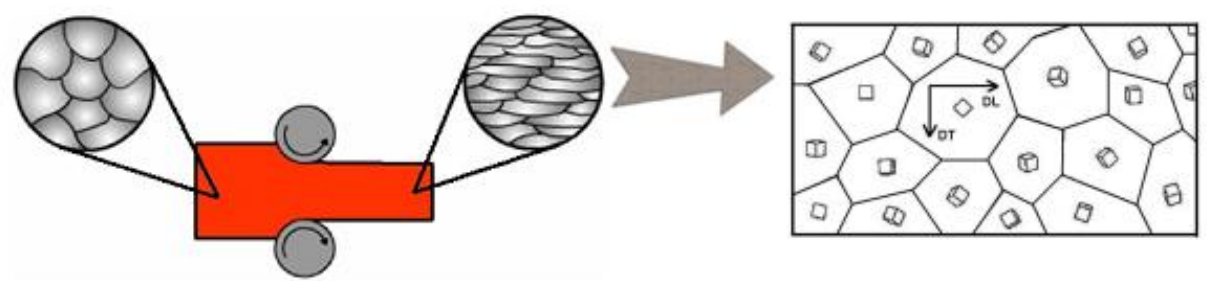

FIGURA 3.10 - Direções cristalinas dos materiais durante a laminação [22]

A anisotropia em materiais sob a forma de chapas provém de três fatores: tensões internas, linhas de segregação (fibragem mecânica) e textura cristalográfica [17] e pode ser do tipo planar ou normal. A primeira acontece quando a anisotropia ocorre no plano da chapa, e a segunda, quando ela ocorre na direção da espessura da chapa.

A anisotropia é medida através do valor $\mathrm{R}$ de Lankford, que é a razão entre a deformação no sentido da largura $\left(\varepsilon_{\mathrm{w}}\right)$ e a deformação no sentido da espessura $\left(\varepsilon_{\mathrm{t}}\right)$ de um corpo de prova, num teste de tração convencional a uma deformação da ordem de 15 a $20 \%$ na direção do comprimento, conforme a expressão:

$$
R=\frac{s_{\text {w }}}{s_{t}}
$$

onde, $\varepsilon_{\mathrm{w}}$ e $\varepsilon_{\mathrm{t}}$ são deformações verdadeiras na largura e espessura, respectivamente. 
Como a deformação na direção da espessura é de difícil medição, além de apresentar erros relativamente maiores, utiliza-se a deformação longitudinal. Sabendo-se que o volume se conserva durante a deformação plástica, deduz-se que:

$R=\frac{\ln \left[\frac{w_{0}}{w_{f}}\right]}{\ln \left[\frac{I_{0} w_{0}}{l_{f} w_{f}}\right]}$

$\mathrm{W}_{0}$ e $\mathrm{w}_{\mathrm{f}}$ são, respectivamente, as larguras iniciais e finais; $1_{0}$ e $1_{\mathrm{f}}$ são, respectivamente, os comprimentos iniciais e finais.

Os corpos de prova para o teste de tração são retirados da chapa orientados a $0^{\circ}, 45^{\circ}$ e $90^{\circ}$ com a direção de laminação indicada na FIG. 3.11, segundo Almeida [22] as seguintes condições definem o tipo da isotropia ou anisotropia em função dos valores de R, sendo:

(1) $\mathrm{R}_{0}=\mathrm{R}_{45}=\mathrm{R}_{90}=1$ : isotropia total

(2) $\mathrm{R}_{0}=\mathrm{R}_{45}=\mathrm{R}_{90} \neq 1$ : isotropia planar e anisotropia normal pura

(3) $\mathrm{R}_{0} \neq \mathrm{R}_{45} \neq \mathrm{R}_{90} \neq 1$ : anisotropia planar e normal

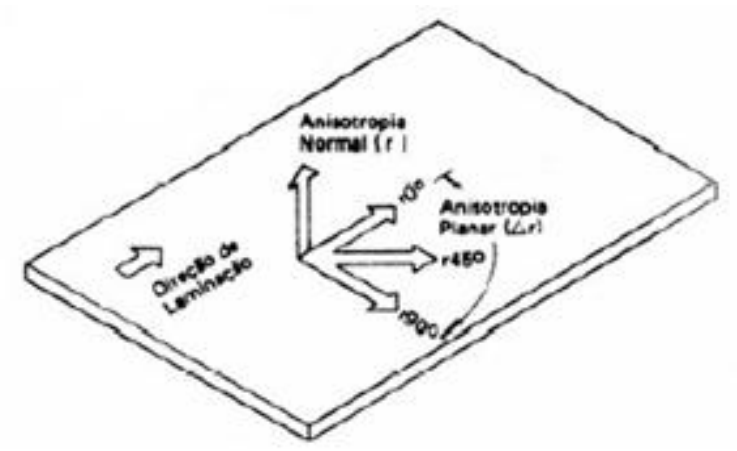

FIGURA 3.11 - Método de amostragem para ensaio de anisotropia [22] 
Em geral, o caso (3) é o mais comum, e praticamente não é possível obter um material apenas com anisotropia normal. Anisotropia normal $\left(\mathrm{R}_{\mathrm{m}}\right)$ é a média nas três direções, isto é:

$R_{m}=\frac{1}{4}\left(R_{0}+2 R_{45}+R_{90}\right)$

O coeficiente de anisotropia normal indica uma resistência à deformação diferente na direção da espessura se comparada com a resistência à deformação no plano da chapa. Isto é, anteriormente foram comparadas as curvas de tensão-deformação em diferentes direções no plano da chapa e agora serão comparadas as mesmas em relação às deformações na direção da espessura da chapa.

Um alto valor de $R_{m}$ é indicativo de que, depois de estirado, o material aumenta consideravelmente na largura, enquanto sua espessura não diminui tanto. Isso indica que ele tem grande resistência ao afinamento; conseqüentemente, é adequado para suportar esforços biaxiais de tração e, evidentemente, exige menor esforço na estampagem profunda [22].

Outro indicativo é a anisotropia planar, constatada experimentalmente, é descrita por:

$\Delta R=\frac{1}{2}\left(R_{0}-2 R_{45}+R_{90}\right)$

O coeficiente de anisotropia planar $(\Delta \mathrm{R})$ indica a diferença de comportamento mecânico que o material pode apresentar no plano da chapa, isto é, as propriedades mecânicas variam conforme a direção em que se faz o ensaio. Além disso, indica a tendência à formação de orelhamento, conforme apresenta a FIG. 3.12. 


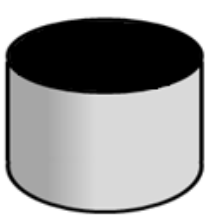

$\Delta R=-0,06$

Sem orelhamento

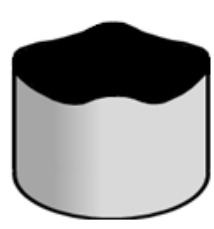

$\Delta \mathrm{R}=+0,42$

$0-90^{\circ}$

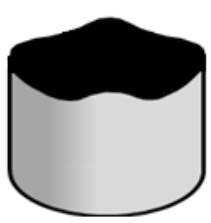

$\Delta \mathrm{R}=+0,75$

$0-90^{\circ}$

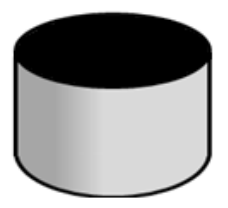

$\Delta R=0$

Sem orelhamento

FIGURA 3.12 - Anisotropia planar na formação de orelhas [24]

Um valor de $\Delta \mathrm{R}$ positivo indica à formação de orelhas a $0^{\circ}$ e $90^{\circ} \mathrm{com}$ a direção de laminação, enquanto um $\Delta \mathrm{R}$ negativo leva à formação de orelhas a $45^{\circ}$ em relação à direção de laminação [23], conforme indica FIG 3.12. Infelizmente, um material com uma anisotropia normal alta geralmente tem também uma alta anisotropia planar. Muitos fabricantes de aço estão trabalhando no problema de obter-se uma chapa de metal com alto valor de $R_{m}$ e $\Delta R$ com valor zero.

O grau de anisotropia é estreitamente relacionado à estrutura cristalina do metal ou liga. Em geral, a anisotropia desenvolve-se mais fortemente em metais com estrutura hexagonal (berílio, titânio, zircônio) do que em metais com estrutura cúbica de corpo centrado ou face centrada (aço, cobre, alumínio, bronze). O tipo e quantidade de elementos de liga também influenciam a natureza da anisotropia. Para um dado metal e composição, a anisotropia plástica é uma conseqüência de toda sua história de processamento. Especialmente importante para o aço são, a temperatura de reaquecimento de placa, temperatura de bobinamento, temperatura de acabamento, percentual de redução a frio e ciclo de recozimento e redução no encruamento. 


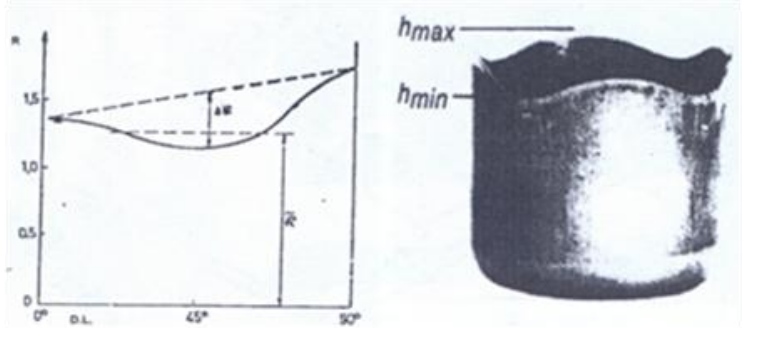

FIGURA 3.13 - Cálculo do $\Delta \mathrm{R}$ para verificação formação de orelhas [24]

Conforme Evangelista [25], o valor $\mathrm{R}_{\mathrm{m}}$ influencia a profundidade média possível de ser obtida em uma operação de estampagem profunda (embutimento). $\mathrm{O}$ valor de $\Delta \mathrm{R}$ mede a variação de R no plano da chapa, determinando a extensão do fenômeno de earing (orelhas). A diferença de altura medida através do $\mathrm{H}_{\operatorname{máx}}$ e $\mathrm{H}_{\text {min }}$ no copo estampado, conforme FIG.3.13 determina a intensidade do orelhamento apresentado no material estampado. Utilizando a relação de alturas e aplicando na EQUAÇÃO 3.11, é possível determinar o valor de $\Delta \mathrm{R}$ do determinado material.

$\Delta \mathrm{R}=\left(\mathrm{H}_{\text {máx }}-\mathrm{H}_{\text {mín }} / \mathrm{H}_{\text {min }}\right) * 100$

Um nível de estampagem ótimo, é obtido pela combinação de um elevado valor de $\mathrm{R}_{\mathrm{m}}$ e um valor de $\Delta \mathrm{R}$ igual a zero.

\subsubsection{Limite de escoamento}

O limite de escoamento é um valor facilmente levantado através do ensaio de tração convencional, e está correlacionado com o sucesso ou não de uma operação de estampagem. A existência, ou não, do patamar de escoamento, é definida no ensaio de tração. A combinação da existência do patamar de escoamento definido e de uma deformação na peça 
que esteja situada na região de deformação em que ocorre o patamar definido $\pm 2 \%$ resultará em um efeito chamado linhas de distenção ou Linhas de Lüders.

Em função deste defeito, todo um esforço é desenvolvido durante a fabricação do material para que não ocorra o escoamento descontínuo e que o mesmo não retorne, por um fenômeno chamado de envelhecimento, por um prazo de seis meses, estando o material submetido à temperatura ambiente sendo, portanto definido como resistente ao envelhecimento, conforme norma Brasileira NBR-5915.

O limite de escoamento também se relaciona com o problema de rigidez de forma, que pode ser subdividido em problemas relativos a retorno elástico e falta de rigidez. No tocante ao retorno elástico é consenso que o decréscimo do limite de escoamento diminui o retorno elástico da peça conformada. Assim sendo, fatores que aumentam o LE agravam o retorno elástico, por exemplo: tamanho de grão menor, maior redução no passe de encruamento, ocorrência de envelhecimento, etc. No sentido contrário, LE baixo, ocorre falta de rigidez. Peças como portas e capôs, em suas regiões centrais, sofrem baixas deformações $<2 \%$, o que implica em estarem mais susceptíveis a deflexões, as quais são nocivas ao produto.

Deve-se, portanto buscar uma solução de compromisso entre ambas as situações. Em função da facilidade de sua obtenção, o limite de escoamento é muito utilizado para caracterização de materiais destinados à conformação nas prensas, estando relacionado nas normas técnicas específicas para este tipo de operação. Somente mais recentemente os parâmetros $\mathrm{R}_{\mathrm{m}}$ e $n$ vêm sendo introduzidos nas normas, principalmente pela disponibilização de equipamentos automatizados que permitem a rápida realização de ensaios e emissão dos resultados. 


\subsection{Aços-Carbono para Estampagem}

Os aços-carbono para estampagem, cujo maior consumidor é a indústria automobilística, têm experimentado uma constante evolução motivada por dois fatores:

- Desenvolvimento das técnicas ou processos metalúrgicos de fabricação;

- Aumento da exigência dos consumidores.

A chave para o desenvolvimento metalúrgico dos principais aços-carbono atualmente utilizados para aplicações em operações de estampagem na prensa foi o desenvolvimento da Desgaseificação a vácuo. Essa técnica de processamento data de meados do século $\mathrm{XX}$ foram efetivamente usados em escala comercial em 1950, para a remoção de hidrogênio em grandes peças placas, perfis forjados, etc. Na década de 1960, foi usada para a fabricação de aços mais limpos e obtenção de composição química mais uniforme e precisa, com novas técnicas de adição de ligas e agitação de banho [26].

Assim, as indústrias siderúrgicas têm procurado desenvolver materiais com melhores performances e níveis de qualidade. Nesse sentido, ao longo dos anos, foram sendo progressivamente desenvolvidos aços que podem ser classificados conforme seu grau de estampabilidade. Na FIG. 3.14, o grau commercial quality (CQ) é obtido através de um aço de concepção baixo carbono acalmado ao alumínio, recozido no recozimento contínuo RCo e, quando o envelhecimento é crítico, produzido no recozimento em caixa - RCa. Caso se deseje um aço com melhor conformabilidade, os graus DQ e DDQ são fornecidos como aço acalmado ao alumínio produzido no $\mathrm{RCa}$ ou através da concepção ultrabaixo carbono produzido tanto no RCa quanto no RCo. 
Já os graus EDDQ e SEDDQ são obtidos através da concepção IF com menores elementos em solução sólida que os tipos anteriores. O tipo H-EDDQ é produzido através da concepção IF, porém com uma composição química especial $\mathrm{C}, \mathrm{N}$, S, e P em níveis mais baixos que os graus anteriores e parâmetros específicos de processo com alta taxa de redução a frio e alta temperatura de recozimento. Pode-se ainda, obter $\mathrm{R}$ maiores que 2,7 através da produção de aços IF laminados a quente na fase ferrítica com lubrificação [27].

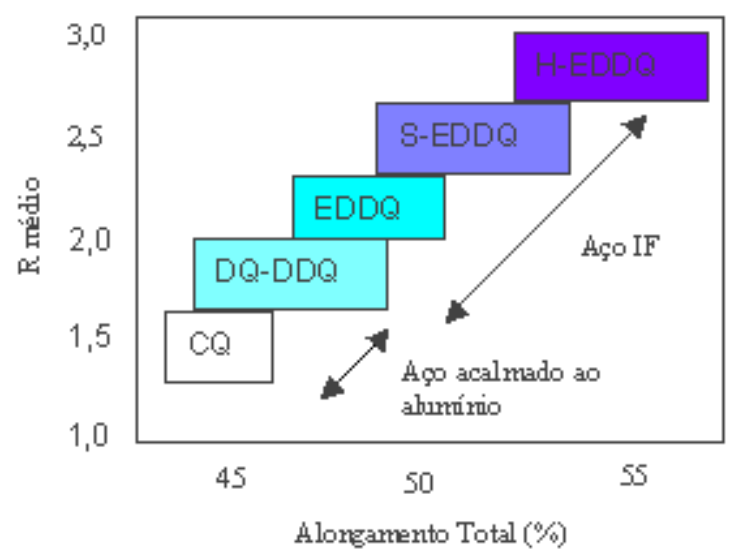

FIGURA 3.14 - Grau de estampabilidade dos aços [27]

Os próximos itens irão abordar os aços ultrabaixo carbono microligado e resistentes ao envelhecimento, comumente conhecidos como aços IF. Essa denominação IF - livre de intersticial ou Interstitial Free, decorre da completa precipitação dos elementos intersticiais presentes no aço $\mathrm{C}$ e $\mathrm{N}$ pela combinação desses com elementos microligantes.

\subsubsection{Características gerais dos aços IF}

Os aços IF possuem excelentes propriedades mecânicas no que diz respeito à estampabilidade. Por isso, sua importância tecnológica e industrial tem aumentado, e a produção crescente continuamente desde a época do seu surgimento, isto é, no final dos anos 
1960. Nessa época, os aços IF eram produzidos com $\mathrm{C}=50$ a 100 ppm e $\mathrm{N}=40$ a 80 ppm. Atualmente, fabricam-se aços com $\mathrm{C}<30$ ppm e $\mathrm{N}<40$ ppm [28].

Baixo limite de escoamento, alto alongamento uniforme associado a um coeficiente de encruamento elevado e uma adequada textura cristalográfica, são características que proporcionam uma conformabilidade superior com alto valor de $\mathrm{R}$, comparativamente aos aços baixo carbono convencional [24]. Os aços IF são obtidos a partir da redução de teores de C e $\mathrm{N}$ em solução sólida e da adição de elementos microligantes, como titânio e nióbio, capazes de fixar todos os átomos de carbono e nitrogênio sob a forma de carbonetos e nitretos [29].

A produção dos aços IF pode ser feita segundo três concepções diferentes: usando somente o Ti (IF-Ti), somente o $\mathrm{Nb}$ (IF-Nb) ou uma combinação desses dois (IF-NbTi ou IF-TiNb) como estabilizantes. Os mecanismos de estabilização desses três tipos de aço diferem ligeiramente entre si. Nos aços IF-Ti, o Ti combina com o $\mathrm{N}$ e $\mathrm{S}$ antes do $\mathrm{C}$, para formar compostos como TiN, TiS, TiC e $\mathrm{Ti}_{4} \mathrm{C}_{2} \mathrm{~S}_{2}$. Nos aços IF-Nb, o $\mathrm{Nb}$ combina com o $\mathrm{C}$ formando $\mathrm{NbC}$, o $\mathrm{N}$ combina com $\mathrm{Al}$ formando $\mathrm{AlN}_{3}$, e o $\mathrm{S}$ combina com o $\mathrm{Mn}$ formando MnS. Nos aços IF-NbTi com Nb>Ti, o Ti combina com o $\mathrm{N}$ e o $\mathrm{S}$ formando TiN e o TiS, respectivamente, e o $\mathrm{Nb}$ combina com o $\mathrm{C}$ para formar o NbC. Já nos aços, IF-TiNb com $\mathrm{Ti}>\mathrm{Nb}$, o Ti é responsável por combinar com $\mathrm{N}, \mathrm{S}$ e $\mathrm{C}$ assim como nos aços contendo somente titânio, e o nióbio adicionado permaneceria em solução sólida.

\subsubsection{Composição química}

Nos aços IF o controle da composição química é de fundamental importância para obter excelente estampagem, isto é, alto valor R e ductilidade. Muitos estudos relatam o efeito da 
composição nas propriedades mecânicas dos aços IF-Ti. O efeito de alguns elementos será descrito abaixo.

\subsubsection{Influência do Titânio}

O Ti é muito efetivo em combinar-se com o N, S e C formando facilmente o TiN e TiS, antes do TiC. O mínimo de quantidade necessária para que o titânio combine com todos esses elementos e estabilize o aço IF-Ti é baseada na abordagem estequiométrica:

$T i_{\text {estequiomético }}=4(\% C)+3,42(\% N)+1,5(\% S)$

Tem sido proposto que a adição de Ti acima da quantidade requerida para combinar com todo o $\mathrm{C}, \mathrm{N}$ e $\mathrm{S}$ é benéfica no aumento de $\mathrm{R}_{\mathrm{m}}$ [24] [30]. O titânio em excesso (Ti*) para estabilizar o N, S e C é dado pela equação:

$T i^{*}=\% T i_{\text {total }}-4(\% C)+3,42(\% N)+1,5(\% S)$

O efeito do Ti* nas propriedades mecânicas do aço IF-Ti pode ser visto na FIG. 3.15. O efeito positivo Ti* até um valor de $0,04 \%$ está de acordo com vários estudos e, é atribuído ao crescimento do tamanho de grão ferrítico [30]. Entretanto, um valor excessivo de Ti* $>0,04 \%$ para as condições do trabalho da FIG. 3.15 proporciona um pequeno efeito deletério nas propriedades mecânicas e pode ser explicado pelo retardamento do processo de recristalização.

3.5.2.2 Influência do carbono e nitrogênio 
$\mathrm{O}$ efeito do $\mathrm{C}$ e $\mathrm{N}$ na estampabilidade dos aços IF depende principalmente da quantidade de microligantes em excesso e do modo de processamento do aço. Assim como em todos os tipos de aços IF, o IF-Ti, como citado anteriormente, deve possuir microligantes em quantidade suficiente para combinar com todo o $\mathrm{C}$ e $\mathrm{N}$ em solução sólida. O processamento desse aço deve ser realizado de modo que não ocorra dissolução de precipitados nem formação de precipitados finos na laminação a quente e, assim, afete as etapas subseqüentes do processo de fabricação do aço, o que influi negativamente sua estampabilidade. Como exemplo disso, tem-se o fato do $\mathrm{C}$ e $\mathrm{N}$ em solução sólida diminuírem o valor $\mathrm{R}$ devido à diminuição da formação da componente de textura recristalizada benéfica $\{111\}$ e aumento da textura desfavorável $\{110\}$ e $\{100\}$ [1] e ao fato de precipitados finos de Ti impedirem o crescimento de grão durante o recozimento.

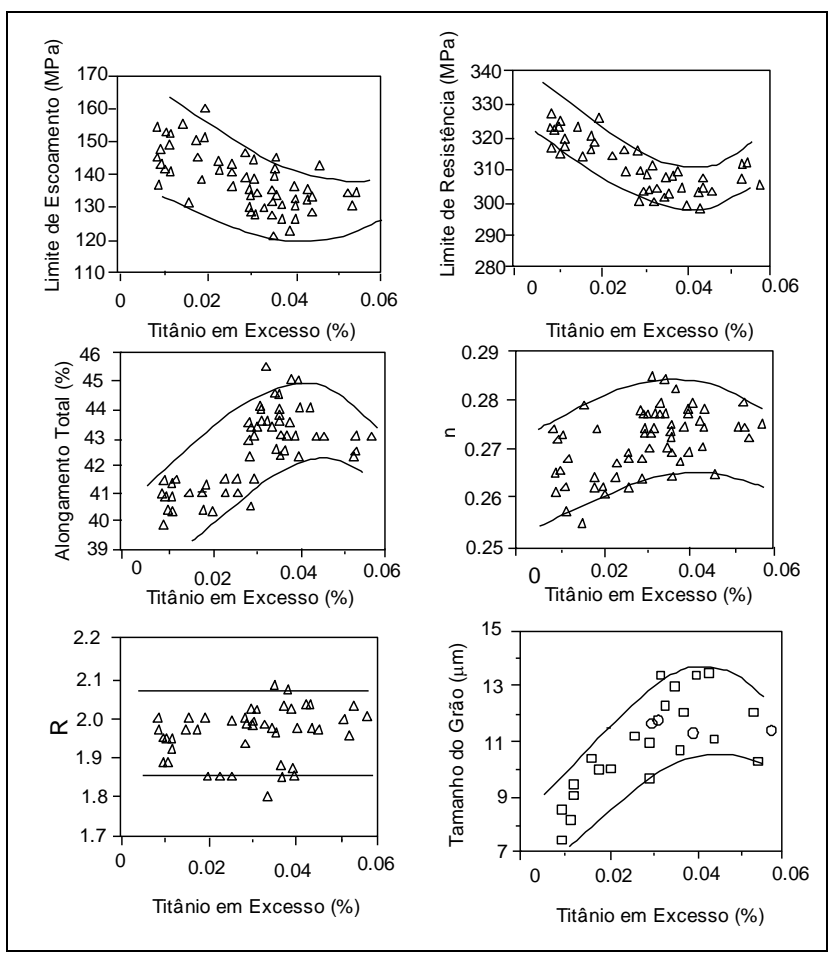

FIGURA 3.15 - Relação entre o Ti em excesso do aço IF-Ti e as propriedades mecânicas e o parâmetro R [24] 
No caso do N, seu teor total não exerce efeitos significativos nas propriedades mecânicas do aço IF-Ti, pois a formação de precipitados TiN ocorre a altas temperaturas, antes da laminação a quente, e esses precipitados possuem alta estabilidade. Dessa forma, todo o N em solução sólida é "retirado" logo no início do processo e não participa das alterações microestruturais subseqüentes [3] [30].

Já o C também possui pouco efeito nas propriedades mecânicas do aço IF-Ti. Entretanto, a diminuição do $\mathrm{C}$ aumenta o alongamento, $n$ e $\mathrm{R}_{\mathrm{m}}$ e diminui o limite de resistência e o limite de escoamento para os aços IF-TiNb conforme FIG. 3.16. Além disso, para um mesmo teor de carbono, o aço IF-Ti possui melhores propriedades de estampabilidade que o IF-Nb. Esta é explicada pelo tamanho de grão ferrítico que, no caso dos IF-Ti, é maior devido à formação de precipitados de carbono grosseiros TiC comparados com os precipitados finos de $\mathrm{NbC}$ do IF-TiNb [24].

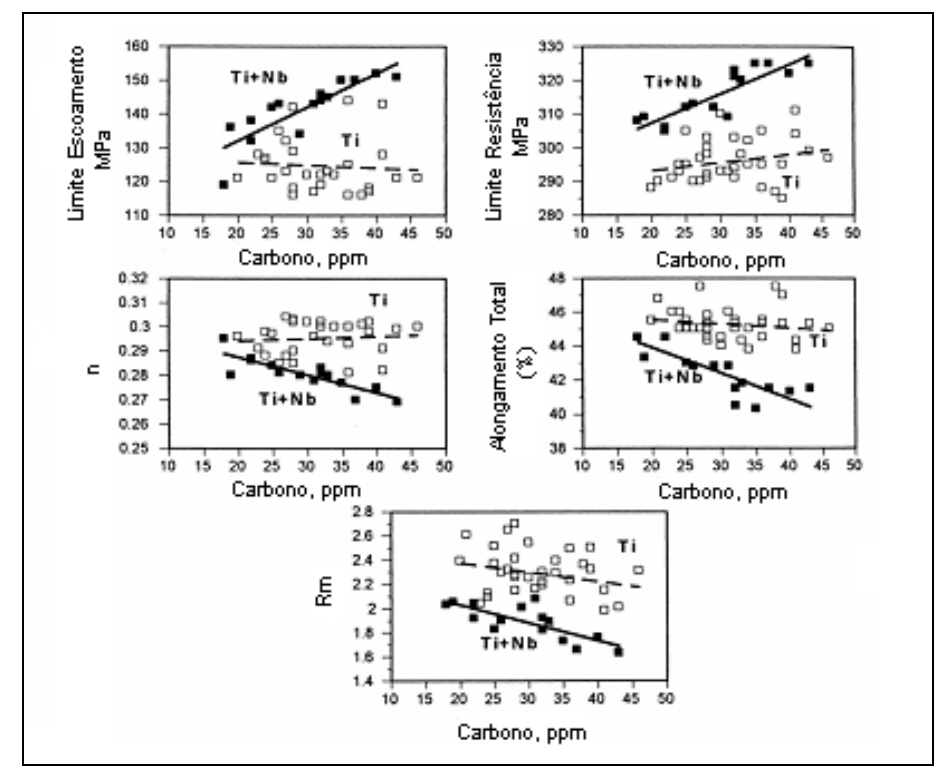

FIGURA 3.16 - Efeito do teor de carbono nas propriedades mecânicas do aço estabilizado com Ti e $\mathrm{TiNb}[24]$ 


\subsubsection{Laminação a Quente}

Na laminação a quente, três parâmetros exercem influência decisiva nas propriedades mecânicas dos vários tipos de aços IF. São eles:

- TRP - Temperatura de Reaquecimento de Placa

- $\mathrm{T}_{\mathrm{a}}$ - Temperatura de Acabamento

- $\mathrm{T}_{\mathrm{b}}$ - Temperatura de Bobinamento

\subsubsection{Temperatura de Reaquecimento de Placa}

Durante o reaquecimento da placa, a dissolução de precipitados poderá ocorrer. Assim, a temperatura de reaquecimento de placa (TRP) poderá determinar as características dos precipitados, tais como: morfologia, tipo, tamanho e dispersão, bem como o tamanho de grão laminado a quente e seus efeitos na recristalização e nas propriedades mecânicas. De maneira geral, um baixo tamanho de grão e precipitados grosseiros e dispersos de laminado a quente favorecem a estampabilidade.

Conforme Sanagi et al. [31] e Hoile [2], em temperaturas de reaquecimento de placa em torno de $1250^{\circ} \mathrm{C}$, carbonetos e carbonitretos podem se dissolver quase completamente, enquanto outros precipitados, tais como TiN e TiS, são relativamente estáveis. Na temperatura de $1000^{\circ} \mathrm{C}$, todos permanecem como precipitados finos, independentemente das concentrações de Ti e C no aço. Assim, a baixa TRP impede a completa dissolução dos precipitados de Ti e favorece a formação dos precipitados grosseiros. Esses precipitados agem como sítios preferenciais para a recristalização e, conseqüentemente, diminuem a temperatura de recristalização conforme FIG. 3.17. 
Outro aspecto que pode ser observado na FIG. 3.17 é a influência do C e do Ti dentro da composição química estudada: à medida que a concentração do carbono diminui ou a do Ti aumenta, há uma melhoria nas características do material, aumento do valor $\mathrm{R}$ e do alongamento total, e diminuição na temperatura de recristalização.

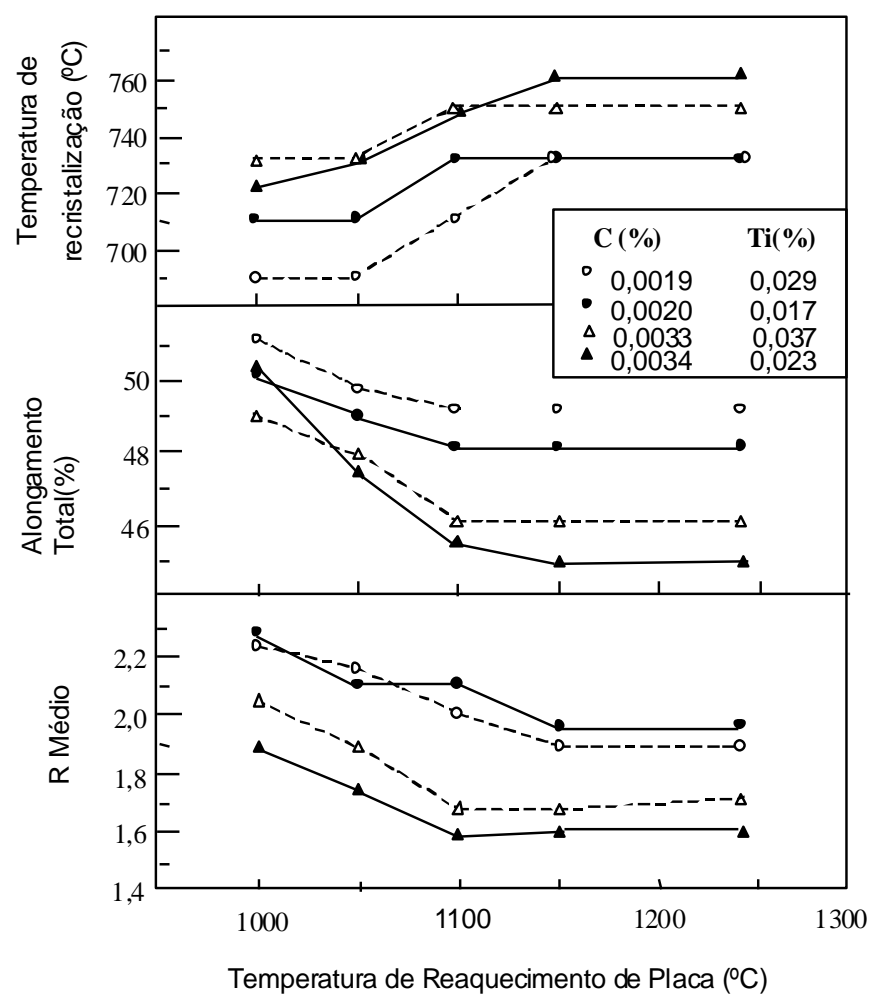

FIGURA 3.17 - Influência da temperatura de reaquecimento de placa na temperatura de recristalização dos aços IF-Ti [32]

\subsubsection{Temperatura de Acabamento}

Conforme Hoile [2] constatou que a laminação a quente com alta redução e velocidade, aumenta o valor $\mathrm{R}$ e o alongamento em alguns aços IF. Relataram que o precipitado torna-se grande e espaçado a altas reduções, favorecendo, assim, a recristalização. A temperatura de acabamento de um aço IF qualquer pode ser realizada em três níveis: 
- $\mathrm{T}_{\mathrm{a}}$ fica acima de $\mathrm{AR}_{3}$ - temperatura abaixo da qual ocorre a transformação de Austenita para Ferrita durante o resfriamento;

- Quando o material é laminado a temperaturas um pouco mais baixas que $\mathrm{AR}_{3}$, ou seja, é laminado na região bifásica;

- Quando o aço é laminado na fase ferrítica, corresponde a uma $\mathrm{T}_{\mathrm{a}}$ mais baixa ainda.

No primeiro caso, o valor $\mathrm{R}$ apresenta um máximo quando a $\mathrm{T}_{\mathrm{a}}$ está uma pouco acima de $\mathrm{AR}_{3}$. Se a $\mathrm{T}_{\mathrm{a}}$ está muito acima de $\mathrm{AR}_{3}$, ocorre um aumento do tamanho de grão laminado a quente e, conseqüentemente, uma queda no valor $\mathrm{R}$. Se a temperatura estiver abaixo de $\mathrm{AR}_{3}$, que é o segundo nível, o valor $\mathrm{R}$ diminui [2], e forma-se uma estrutura mista de grãos pequenos e grandes, à qual se atribui a queda no valor R. Com uma diminuição ainda maior na temperatura de acabamento, terceiro nível aparece grãos não-recristalizados na microestrutura devido à laminação na região ferrítica. Nesse caso, o valor $\mathrm{R}$ é maior que no segundo e no primeiro caso. Não há, ainda, consenso na literatura sobre a causa desse fenômeno.

Bhattacharya et al. [30] confirmam o que foi descrito acima para as duas primeiras situações, nas quais a $T_{a}$ influi muito pouco no valor $R$ para o aço IF-Ti, e é mais expressiva no IF-Nb. Além disso, mostram que a $\mathrm{T}_{\mathrm{a}}$ tem maior efeito quando o material é processado com menor temperatura de reaquecimento de placa, com temperatura de $1100^{\circ} \mathrm{C}$ em relação à $1200^{\circ} \mathrm{C}$.

Caso haja um rápido resfriamento da tira logo após o final do trem acabador, o grão laminado a quente diminui, e o valor $\mathrm{R}$ aumenta. Assim, se o resfriamento for atrasado ou não for suficientemente severo, o tamanho de grão excessivo poderá ocorrer após a laminação a frio e recozimento, piorando o $\mathrm{R}_{\mathrm{m}}$ [2]. Contudo, como citado por Gorni et al 
[33], foi constatado que esse efeito não é muito grande, pois um aumento na taxa de resfriamento de 40 para $120^{\circ} \mathrm{C} / \mathrm{s}$ refinou o tamanho de grão do aço IF em 0,5 unidades ASTM.

\subsubsection{Temperatura de Bobinamento}

Quando se empregam altas temperaturas de bobinamento, são produzidos precipitados grosseiros e amplamente dispersos, ao contrário, com baixas temperaturas de bobinamento, há uma distribuição mais uniforme de finos precipitados. Assim, a temperatura de bobinamento é um importante parâmetro que controla a temperatura de recristalização e as propriedades mecânicas. A FIG. 3.18 mostra que, aumentando a $T_{b}$ para alguns tipos de aço IF, a temperatura de recristalização se reduz e é mais efetiva para os aços IF-Nb.

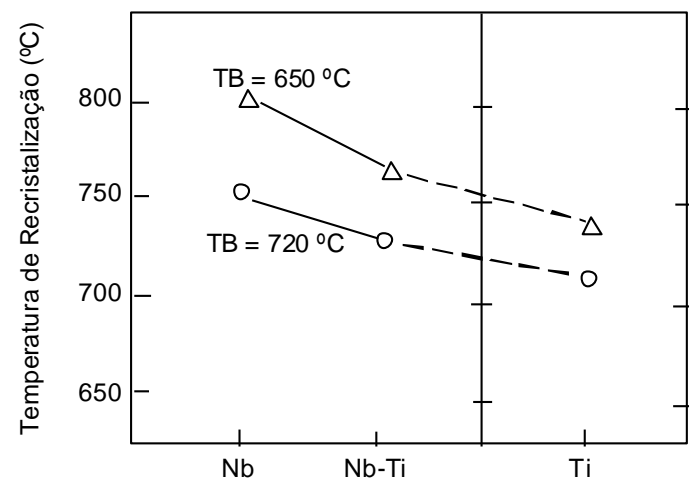

FIGURA 3.18 - Efeito da temperatura de bobinamento na temperatura de recristalização do IF-Nb, IF-NbTi e IF-Ti [30]

Vários estudos mostram que o valor $\mathrm{R}, \mathrm{n}$ e a ductilidade aumentam, e a resistência diminui com o aumento da $\mathrm{T}_{\mathrm{b}}$. 
A FIG. 3.19 mostra que, efetivamente, um aumento da $T_{b}$ provoca um aumento no valor $R_{m}$ e que esse aumento está relacionado com o Ti em excesso, com valores ligeiramente maiores que o estequiométrico é melhor para a obtenção do $\mathrm{R}_{\mathrm{m}}$ para altas $\mathrm{T}_{\mathrm{b}}$.

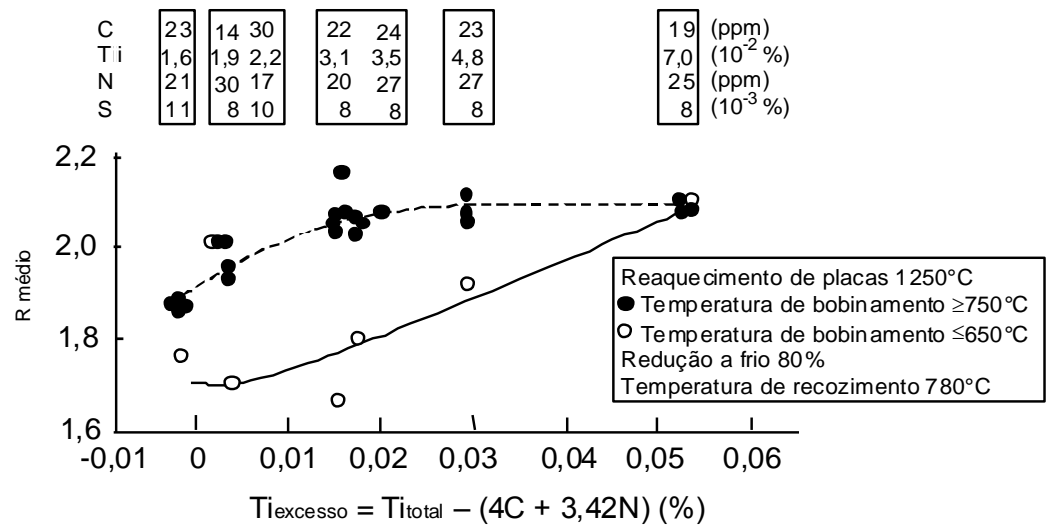

FIGURA 3.19 - Efeito da temperatura de bobinamento em $\mathrm{R}_{\mathrm{m}}$ do IF-Ti [30]

Com a diminuição da $T_{b}$, diminui-se o tamanho de grão laminado a quente, o que favorece a formação de textura adequada nas etapas subseqüentes da laminação a frio. Entretanto, a diminuição da $T_{b}$ proporciona duas condições: a formação de precipitados finos e a diminuição da remoção de $\mathrm{C}$ em solução sólida através do crescimento dos precipitados, principalmente nos casos em que o material e o processo não estão dentro dos limites aceitáveis para obter um alto valor $\mathrm{R}_{\mathrm{m}}$, por exemplo, baixa quantidade de Ti [2]. Tanto a primeira quanto a segunda, conforme citado anteriormente, afetam negativamente a textura e as propriedades mecânicas.

\subsubsection{Laminação a frio}

Vários parâmetros operacionais influenciam a estampabilidade da chapa durante a laminação a frio. As principais etapas do processo de laminação a frio são:

- Retirada de camada de óxido na Decapagem 
- Redução a frio no Laminador de Tiras a Frio

- Velocidade de aquecimento e resfriamento no recozimento

- Tempo e temperatura de encharque no recozimento

- Redução na laminação de encruamento

\subsubsection{Decapagem}

A bobina a quente (BQ) é processada na linha de Decapagem imersa num tanque com uma solução de ácido clorídrico, visando melhor remoção da camada de óxidos formados na superfície da bobina após a laminação a quente. É realizada também durante este processo, a inspeção de qualidade superficial e o aparamento lateral da bobina. Para melhor eficiência de remoção da camada de óxido, a combinação de variáveis, tais como concentração, velocidade da tira, grau de resistência devem estar ajustadas e compatíveis com a capabilidade do equipamento.

\subsubsection{Redução a frio}

São duas as principais funções da redução a frio. Uma é produzir a dimensão requerida pelo cliente, ou melhor, obter a espessura adequada à fabricação do produto a que se destina a chapa. A outra é a otimização do valor R como se pode ver na FIG. 3.20 Held et al. [34], em que o aumento da redução a frio aumenta a textura $\{111\}$, e a redução de $90 \%$ é a melhor para se obter um alto valor $\mathrm{R}$.

Entretanto, na prática industrial, reduções acima de $90 \%$ são impraticáveis devido à limitação de redução que o laminador a frio possui; assim, as reduções são limitadas em torno de $80 \%$. Além disso, com o aumento da redução a frio, o valor $\mathrm{R}_{90}$ tende a ser maior 
do que para outras direções, exceto em altas reduções, com valores $>90 \%$, em que $R_{45}$ se torna dominante.

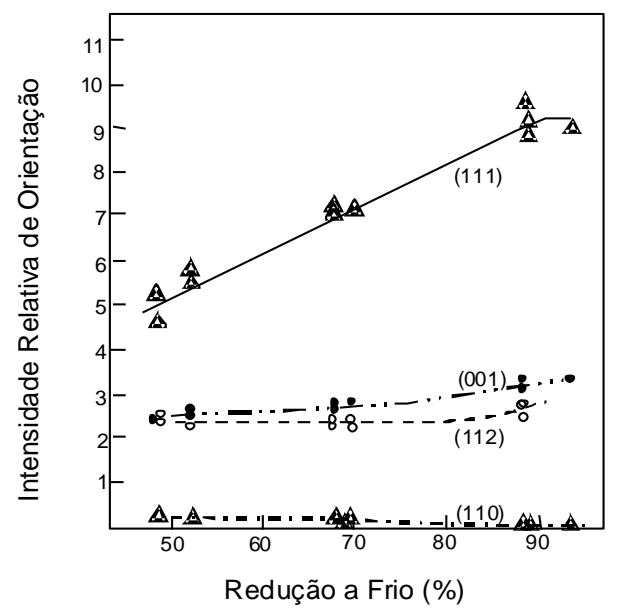

FIGURA 3.20 - Efeito da redução a frio na intensidade relativa de vários componentes da textura de deformação no aço IF-Ti [34]

\subsubsection{Recozimento}

Após a laminação a frio, as chapas de aço se apresentam com elevada dureza, com elevado estado de encruamento, e o nível de resistência mecânica será tanto maior quanto mais alto for o percentual de redução durante a laminação a frio. As chapas apresentam uma baixa ductilidade, o que as torna impróprias para os casos que exigem operação de conformação como, por exemplo, embutimento e estiramento. Para que essas operações possam se tornar viáveis, é necessário que esses materiais sejam "amolecidos", o que é possível através do tratamento térmico de recozimento.

A ductilidade da chapa é restaurada por fenômenos que ocorrem no recozimento, ou seja, a recuperação e a recristalização. A recuperação, que em geral ocorre em temperaturas baixas, com temperaturas bem menores que a temperatura de fusão, onde engloba vários processos 
termicamente ativados que reduzem a energia armazenada no metal durante a deformação a frio devido à redução do número e ao rearranjo de defeitos cristalinos. Como a recuperação não envolve a migração de contornos de alto ângulo, o material deformado retém sua identidade cristalográfica, ou seja, sua textura, embora a densidade e a distribuição de defeitos cristalinos sejam alteradas [35].

A recristalização é um processo de eliminação de defeitos cristalinos através da migração de contornos de alto ângulo "varrendo a microestrutura" e "absorvendo defeitos cristalinos" mudando a orientação da rede cristalina através das etapas de nucleação e crescimento [36] [37]. Dessa forma, o encruamento é totalmente removido, e a resistência mecânica retorna a valores similares aos que existiam antes do encruamento. Em síntese, o processamento de aços para estampagem profunda requer não apenas altas reduções a frio antes do recozimento, mas também granulação fina após o recozimento. Felizmente, segundo a quarta lei da recristalização [37], o tamanho de grão final depende fortemente do grau de deformação e fracamente da temperatura de recozimento. Quanto maior o grau de deformação e/ou menor a temperatura de recozimento, tanto menor será o tamanho de grão final após a recristalização [36].

As operações de recozimento de chapas de aço em produção industrial podem ser realizadas através de dois tipos básicos:

- Rca: Recozimento em caixa

- Rco: Recozimento contínuo

O primeiro é caracterizado por baixa taxa de aquecimento, uma temperatura de encharque relativamente baixa e longos períodos de recozimento. Já o recozimento contínuo 
caracteriza-se por rápido aquecimento, alta temperatura de encharque e baixo tempo de aquecimento. Além disso, o recozimento contínuo possui características próprias como maior limpeza superficial e uniformidade de propriedades mecânicas. A FIG. 3.21 ilustra esquematicamente o ciclo de recozimento térmico para o recozimento em caixa, e suas características típicas são mostradas na TAB. 3.1. Essas características, principalmente o tempo e a temperatura, são determinados em função da composição química de aço, do nível de redução durante a laminação a frio, do nível de resistência mecânica e da ductilidade requerida no produto final.
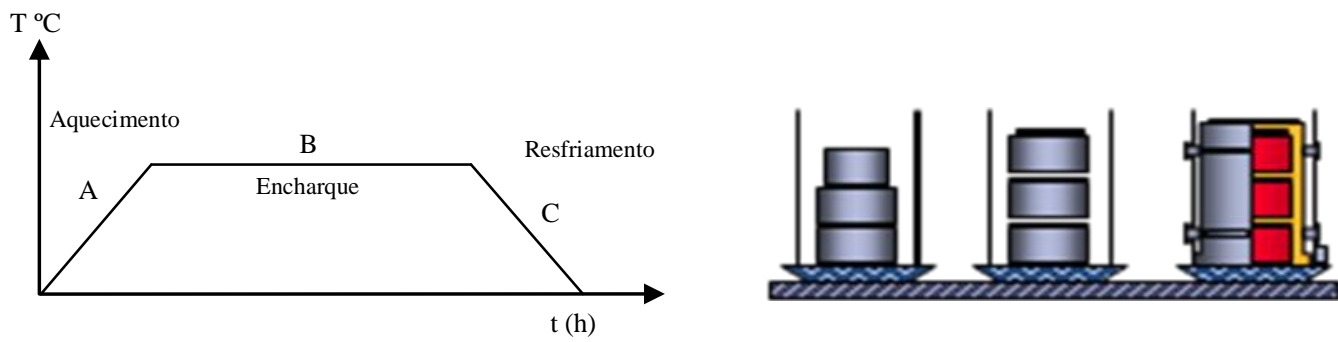

FIGURA 3.21 - Desenho esquemático de Ciclo térmico e fornos de recozimento [22]

A TAB. 3.1 relaciona os principais parâmetros praticados para material processo de material IF e seus respectivos resultados.

TABELA 3.1 - Características dos principais parâmetros do recozimento em caixa

\begin{tabular}{|l|c|}
\hline \multicolumn{1}{|c|}{ Parâmetros } & Recozimento em caixa \\
\hline Velocidade de Aquecimento & 10 a $50^{\circ} \mathrm{C} / \mathrm{h}$ \\
\hline Tempo de encharque & 4 a $15 \mathrm{~h}$ \\
\hline Velocidade de resfriamento & 20 a $50^{\circ} \mathrm{C} / \mathrm{h}$ \\
\hline Temperatura de encharque & 680 a $720^{\circ} \mathrm{C}$ \\
\hline Tempo total de processo & 60 às $90 \mathrm{~h}$ \\
\hline
\end{tabular}


Nos estágios de aquecimento e encharque no recozimento em caixa ocorre o fenômeno de recuperação, recristalização e algum crescimento de grão. Já nos estágios subseqüentes, ocorre resfriamento, para o recozimento em caixa. Como nos aços IF há pouco ou nenhum C dissolvido após o aquecimento e encharque os estágios subseqüentes não afetam significativamente as suas propriedades mecânicas [38]. Isso é válido para os valores de parâmetros de processo típicos, como os descritos na TAB. 3.1. O efeito da temperatura no recozimento de aços IF tem sido relatado por diversos autores [3] [30] [39] [40].

Todos mostram que o aumento desse parâmetro melhora a estampabilidade através do aumento da ductilidade devido, queda no limite de escoamento e aumento no alongamento total, da diminuição do limite de resistência e do aumento do valor $\mathrm{n}$ e do $\mathrm{R}$ até cerca de $800^{\circ} \mathrm{C}$, conforme FIG. 3.22. O aumento do valor R com o aumento da temperatura no recozimento está associado com o rápido crescimento de grãos com orientação $\{111\}$ [30].
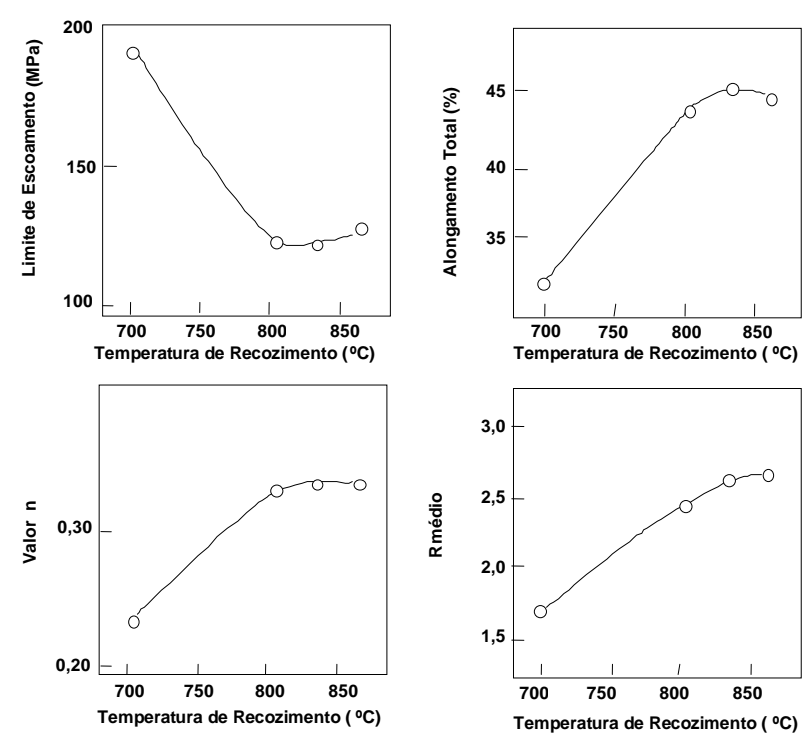

FIGURA 3.22 - Influência da temperatura nas propriedades do aço IF-Ti no recozimento contínuo [40] 
Outra variável que afeta a estampabilidade é a velocidade de aquecimento no recozimento. A FIG. 3.23 mostra como o valor $\mathrm{R}$ varia com a taxa de aquecimento para aço IF e aço acalmado ao alumínio. Ao contrário do aço acalmado ao alumínio, o valor $\mathrm{R}$ do aço IF é pouco afetado pelas taxas de aquecimento do recozimento em caixa. O valor $\mathrm{R}$ também é maior para materiais com altas temperaturas de bobinamento maiores, conforme já citado anteriormente.

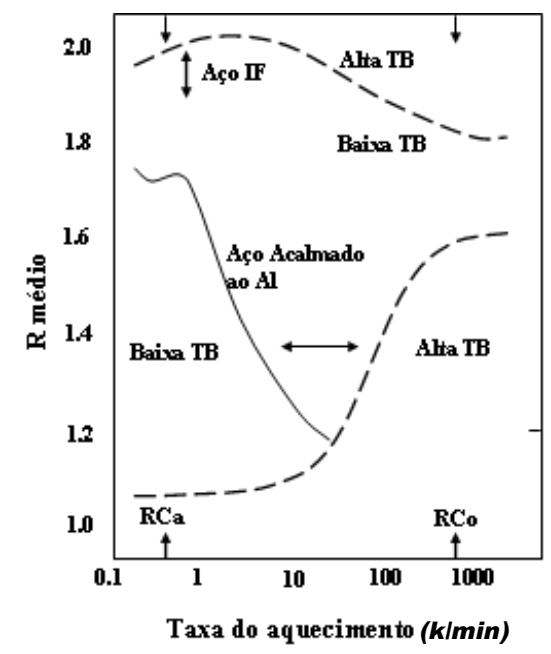

FIGURA 3.23 - Efeito da taxa de aquecimento durante o recozimento no $\mathrm{R}_{\text {médio }}$ do aço IF e do aço acalmado ao alumínio com temperaturas de bobinamento diferentes [59]

A recristalização e o crescimento de grão durante o recozimento são vinculados ao efeito "âncora" dos precipitados. Os precipitados finos possuem maior efeito e limitam o $\mathrm{R}_{\mathrm{m}}$ do produto. No caso de materiais IF, sabe-se que uma densa dispersão de finos precipitados não prejudica a recuperação e a nucleação de grãos recristalizados com orientação $\{111\}$. Entretanto, a força de arraste exercida pelo ancoramento do contorno de grão pelas partículas finas atrasa o crescimento dos grãos com orientação $\{111\}$, permitindo, assim, o crescimento de outras orientações, notavelmente $\{100\}$, resultando em um decréscimo no valor R [2]. 
A textura cristalina promovida pela recristalização difere consideravelmente da textura de laminação. Sabe-se, por exemplo, que, durante o recozimento de aços IF ocorre uma intensificação da fibra <111>//ND e das demais componentes de texturas próximas, enquanto ocorre uma redução na intensidade das componentes do tipo $\{100\}<u v w>$ [41].

Examinando a distribuição de precipitados em dois aços com composição química e com tamanho de grão similar, Subramanian et al. [42] observaram que o aço IF-Ti com menor dispersão de precipitados grosseiros exibe maior intensidade $\{111\}$ em relação à dispersão de finos precipitados. $\mathrm{O}$ fator predominante foi o efeito dos precipitados no tamanho de grão durante a recristalização. Portanto, um fino balanço deve ser acertado entre a otimização do tamanho de grão laminado a quente e a otimização da precipitação através de um cuidadoso controle dos parâmetros de laminação a quente.

\subsubsection{Princípio de funcionamento da Laminação de Encruamento}

Considerando que a largura da tira permanece inalterada no passe de laminação de encruamento, fato verificado na prática em medições realizadas no material, tem-se que a diminuição da espessura da tira traduz-se por um aumento do seu comprimento, isto é, um alongamento. Com a tira tensionada, este alongamento é percentualmente igual ao aumento da sua velocidade de saída em relação à de entrada, conforme EQUAÇÃO 3.15.

$$
e=\frac{L_{s}-L_{E}}{L_{E}} \times 100=\frac{V_{s}-V_{E}}{V_{E}} \times 100=\left(\frac{V_{s}}{V_{E}}-1\right) \times 100
$$


Para medir a velocidade $\mathrm{V}_{\mathrm{E}}$ e $\mathrm{V}_{\mathrm{S}}$, o sistema utiliza dois geradores de pulsos solidários a dois rolos defletores, conforme ilustrado na FIG 3.24, onde o deslizamento da tira deverá ser considerado.

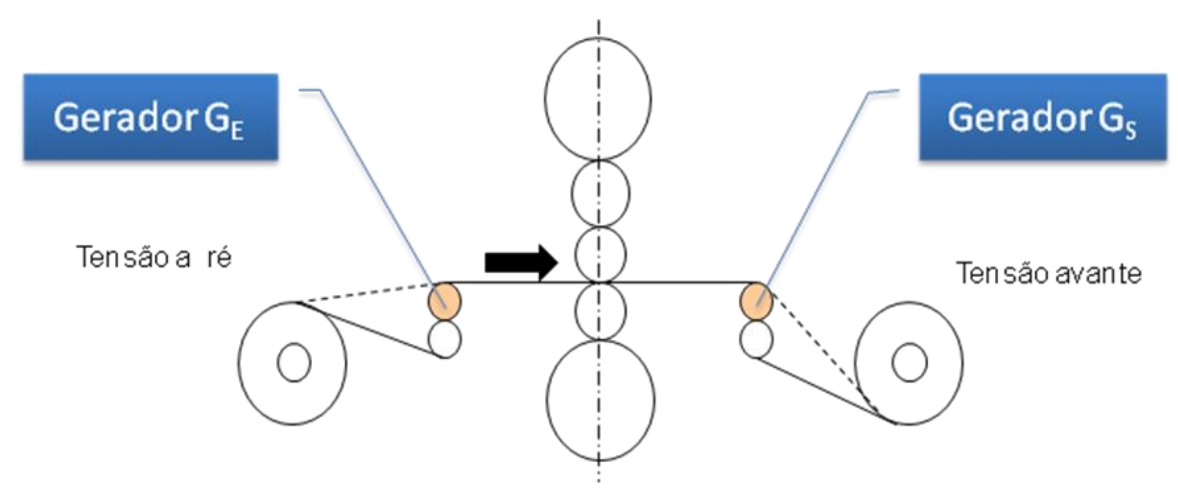

FIGURA 3.24 - Posição dos geradores de pulso no Laminador de Encruamento [11]

O primeiro gerador de pulsos está colocado na entrada do laminador, logo depois da bobinadeira, e o segundo na saída, imediatamente antes da bobinadeira. De acordo com a EQUAÇÃO 3.15, o alongamento é então calculado pela relação entre os dois sinais fornecidos pelos geradores. Uma redução nas tensões avante e de ré proporcionam uma maior força de laminação para se manter o alongamento, desta forma a impressão de rugosidade aumenta quando se reduz estas tensões. Na prática este fator é pouco utilizado, pois a variação nestas tensões pode provocar problemas de bobinamento e deslizamento de material [11].

Uma das características fundamentais das tiras laminadas a frio é sua planicidade que vem a cada dia sendo mais exigida pelo mercado. Para tal, os recursos disponíveis são: 
a) Coroamento mecânico, por usinagem de cilindros de trabalho de acordo com a largura do material a ser laminado.

b) Sistema bending e o sistema de contraflexão do cilindro de trabalho e do cilindro de encosto para permitir o efetivo ajuste do comprimento da mesa dos cilindros de acordo com seu posicionamento, substituindo em parte o coroamento de cilindros de trabalho obtido por usinagem.

c) Cilindro intermediário superior foi colocado entre o cilindro de trabalho e de encosto superior permitindo, com sua flexão, uma distribuição variável de forças sobre a tira de aço e, também, permitindo uma atuação mais efetiva do sistema bending.

O sistema bending é um sistema que permite, através do acionamento de pistões, fletir os cilindros para atuar na correção de alguns defeitos de forma, como por exemplo, a ondulação nas bordas e a ondulação central. O laminador possui dois modos de atuação do sistema bending: o bending increase (ou positivo) e o bending decrease (negativo). O bending positivo é utilizado quando há necessidade de corrigir ondulações de borda no material. A sua atuação faz com que o comprimento do centro do material se iguale com o comprimento das bordas. Quando o material apresenta ondulação central, é necessária a utilização do bending negativo, que atua no sentido de alongar as bordas da tira de aço para igualar o seu comprimento com o comprimento do centro. O sistema atua fazendo uma pressão (força do bending) nas extremidades dos cilindros, no sentido de aproximá-las.

\subsection{Cálculo teórico do alongamento}

Cada gerador fornece uma quantidade de pulsos cuja freqüência $\mathrm{f}$ é proporcional à velocidade de rotação do rolo ao qual está acoplado: 
$f=\frac{N x V}{\pi x D}$

onde,

$V=\frac{\pi x D}{N} x f$

Como visto na EQUAÇÃO 3.15, o alongamento é calculado através da relação entre velocidades. Substituindo $\mathrm{V}_{\mathrm{E}}$ e $\mathrm{V}_{\mathrm{S}}$ na EQUAÇÃO 3.18, temos então:

$e=\frac{\frac{\pi x D_{S}}{N_{S}}}{\frac{\pi x D_{E}}{N_{E}}} x \frac{f_{S}}{f_{E}}-1=\frac{D_{S}}{D_{E}} \times \frac{N_{E}}{N_{S}} \times \frac{f_{S}}{f_{E}}-1$

3.5.4.4.2 Fundamentos da Laminação de Encruamento

A laminação de encruamento ou passe de encruamento, também conhecida como Skin Pass Mill ou Temper Rolling, é uma das etapas mais importantes na fabricação de aços laminados a frio, uma vez que as propriedades mecânicas e geométricas das chapas laminadas a frio são por ela influenciadas [1].

A deformação causada pela laminação de Encruamento é influenciada, principalmente pelos seguintes fatores, conforme [44] [47] [48]:

- Grau e velocidade de redução. 
- Tamanho de grão e qualidade do material.

- Condições de atrito influenciadas pela textura superficial do cilindro, do material e da utilização de lubrificantes.

Segundo Duggan et al [60], pode ocorrer deformação no centro do material durante o processo de redução a frio no Laminador de Encruamento. O gradiente de deformação se dá através da presença de uma superfície ou tensão de cisalhamento. Uma conseqüência natural desta teoria, é a inclusao das componentes de cisalhamento na geometria de laminação,que leva a uma taxa reduzida da textura. Ou seja, durante a etapa de crescimento de grão existe uma tensão de cisalhamento correspondente ao esforço aplicado para redução do material, que tem sua intensidade diminuída da região superficial para o centro do material. Assim, os efeitos do cisalhamento são maximizados na superfície de laminação quando aumentam ambos, a deformação e o atrito gerado.

A laminação de Encruamento possui quatro finalidades básicas:

- Melhoria da qualidade do produto no que se refere às propriedades mecânicas do material recozido, tendo como principal efeito a eliminação do patamar de escoamento, exceto para alguns aços, como o IF.

- Melhoria da rugosidade e brilho superficial. Para realizar este propósito, deve-se controlar a rugosidade dos cilindros de trabalho e força de laminação.

- Melhoria das características de forma do material (planicidade).

- Melhoria da aparência superficial através da redução de defeitos (depressões, marcas de rolo, incrustações, etc.). 
A eliminação do patamar de escoamento está vinculada ao fato de que, caso ela não seja eliminada, o material apresenta o defeito conhecido como linha de distenção ou Lüders bands ou Stretcher strains, quando for estampado após o recozimento. No ensaio de tração, esse fenômeno ocorre precisamente ao atingir o patamar de escoamento definido. Para eliminação desse defeito em aços baixo carbono após o recozimento, normalmente, é utilizado um passe de encruamento com deformação de 0,8 a 1,5\% [1]. Nesse caso, o passe de encruamento introduz discordâncias móveis, as quais irão movimentar livremente quando da aplicação de um esforço, diferentemente daquelas que se encontram ancoradas. Assim, fica eliminado o aparecimento das linhas de Lüders e favorecido o processamento do aço nas linhas e aplicações subseqüentes [1] [48].

A transferência de rugosidade na superfície da chapa pela laminação de encruamento tem como objetivo produzir uma rugosidade superficial específica para se obter um acabamento adequado durante o processo de pintura das chapas. Além disso, como influi no atrito, a rugosidade é requerida nos casos em que o cliente necessita de uma rugosidade específica para adequar às suas necessidades de processo e produto. Normalmente, para se obter um material com rugosidade superficial com faixas de rugosidade maiores, costuma-se aumentar o grau de deformação no encruamento em relação ao mesmo material que não necessita de rugosidade [48].

Já no ajuste e adequação das propriedades mecânicas do material após o recozimento, o passe de encruamento possui importantes funções, por exemplo: aços destinados à fabricação de embalagem de produtos alimentícios, especialmente latas, caso em que a rigidez da embalagem é conferida pela deformação adequada no passe de encruamento e, os aços destinados a aplicações elétricas e magnéticas como lâminas de motores elétricos, em 
que as perdas magnéticas são minimizadas com o aumento do Tamanho de grão no Reoczimento após passe de encruamento. Nesse último caso, o passe de encruamento deve fornecer energia crítica para o crescimento de grão após o material ser recozido pelo cliente. Isso é conseguido com deformações de 5 a $10 \%$ [1].

Na correção de forma e defeitos na chapa, o passe de encruamento melhora a planicidade do material e diminui ou elimina as imperfeições presentes na superfície da chapa. No caso de materiais que não envelhecem como os aços IF, não se verificam a necessidade imediata de processamento na laminação de encruamento. Entretanto, a laminação de encruamento é vital no processo final de produção desses aços não apenas para correção de forma e de defeitos, mas também para proporcionar acabamento superficial superior e rugosidade superficial [49]. Além disso, o IF pode ser produzido para atender graus de estampagem inferiores, e uma das formas é a produção com laminação de encruamento. Em relação aos efeitos, a laminação de encruamento nos aços IF diminui o alongamento total e aumenta o limite de escoamento [49], como se pode ver na FIG 3.25.

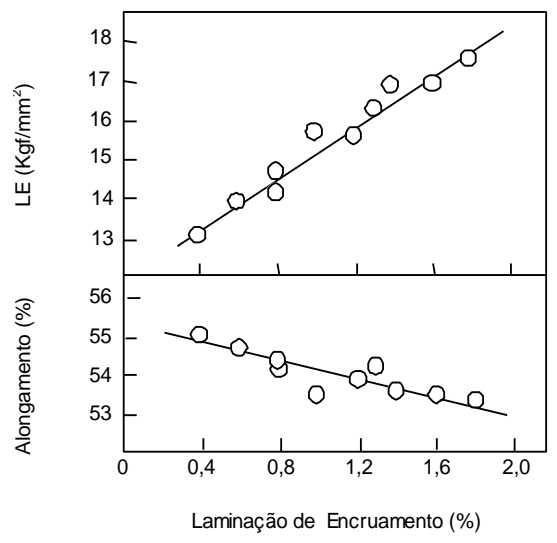

FIGURA 3.25 - Efeito da redução da laminação de encruamento no alongamento e no limite de escoamento de aço IF-TiNb C $=0,0025 \%, \mathrm{Ti}=0,030 \%, \mathrm{Nb}=0,006 \%$, temperatura de recozimento igual a $850^{\circ} \mathrm{C}$ [49] 
Em trabalho de Muschenborn et al [21], em que um aço IF-Ti sofreu vários passes de encruamento variando de 2 a 10\%, em laminador de laboratório, constatou-se, também, um expressivo aumento do limite de escoamento e uma pequena diminuição do alongamento e do valor $n$. Entretanto, o limite de resistência e o valor R não se alteraram significativamente com essa variação no grau de encruamento. No caso do valor R, esse trabalho está de acordo com [51] para aços IF. Porém, para aço acalmado ao alumínio, o valor $\mathrm{R}$ diminui com o encruamento, conforme FIG. 3.26.

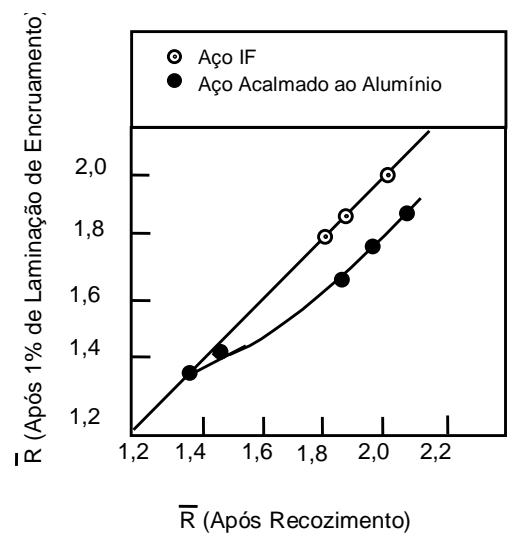

FIGURA 3.26 - Valores de $\mathrm{R}_{\mathrm{m}}$ do aço IF e aço acalmado ao alumínio após o recozimento e após laminação de encruamento de 1,0\% [49]

Após a laminação de encruamento, o material vai para linha de acabamento. Entretanto, pode apresentar defeitos superficiais como ondulações, marcas de rolo e/ou de cilindro, amassamentos provocados durante o manuseio, rugosidade inadequada e alguns outros defeitos que são identificados antes, durante ou após a linha de inspeção. A fim de corrigir esses defeitos, caso sejam passíveis de correção, o material pode ser reprocessado no laminador de encruamento, operação que será denominada nesta dissertação "relaminação de encruamento". 


\subsection{Texturas de deformação}

Os materiais policristalinos são constituídos de pequenos cristais, denominados grãos ou cristalitos, os quais são separados uns dos outros por fronteiras denominadas contornos de grão. De modo geral, as orientações de todos os grãos podem estar concentradas em maior ou menor escala, ao redor de alguma ou de algumas orientações particulares. Nesta última condição, o agregado policristalino apresenta orientação preferencial ou textura cristalográfica. Assim, a textura pode ser genericamente definida como uma condição na qual a distribuição de orientações dos grãos de um policristal não aleatória. Além disso, é importante destacar que a textura não se refere à forma dos grãos, mas sim à forma como a rede cristalina desses grãos é arranjada espacialmente.

\subsubsection{Textura Cristalográfica}

Há vários métodos de representar a textura de um material policristalino. Para todos eles, é preciso que as orientações cristalinas presentes no material, conforme FIG. 3.27, sejam determinadas de algum modo. Tem-se usado a difração de raios-X, técnica através da qual se mede as frações volumétricas de regiões associadas a uma dada orientação cristalina, a partir da intensidade difratada.

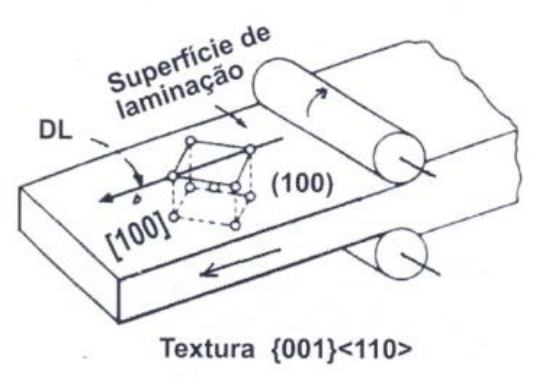

FIGURA 3.27 - Textura $\{001\}<110>$ em chapa [52] 


\subsubsection{Função de Distribuição de Orientação Cristalina}

A Função de Distribuição de Orientação Cristalina (FDOC ou ODF) especifica a freqüência de ocorrência de determinadas orientações $\{h \mathrm{hl}\}\langle\mathrm{uvw}\rangle$ em uma amostra do material. Esta probabilidade, numa amostra sem textura, é igual à unidade. Na ODF, a orientação de um cristal é definida por três ângulos de Euler, os quais constituem três rotações consecutivas que, aplicadas aos eixos [100], [010] e [001] da célula cristalina do cristal, tornam os mesmos coincidentes com os eixos DL, DT e DN, conforme FIG. 3.28.
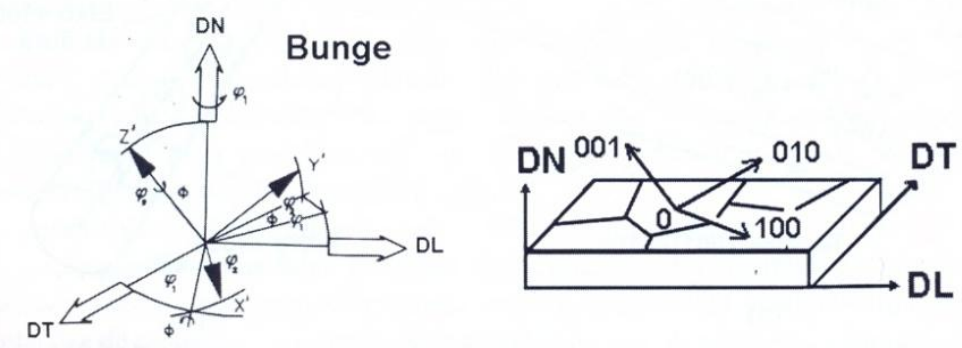

FIGURA 3.28 - Ângulos de Euler $\left(\varphi_{1} \phi \phi_{2}\right)$ conforme notação de Bunge [52]

\subsubsection{Texturas de Laminação a Frio em Materiais CCC}

As texturas de laminação a frio dos materiais cúbicos de corpo centrado se caracterizam por apresentarem suas orientações principais localizadas em duas fibras parciais: $\{h k 1\}<110>$ e $\{111\}<u v w>$. A primeira é chamada de fibra DL por ter várias orientações com as direções <110> paralelas à DL. A segunda é chamada de fibra DN por ter várias componentes com as normais dos planos $\{111\}$ paralelas à DL. A FIG. 3.29 mostra a textura de um aço baixo carbono laminado a frio, típica de materiais CCC. 


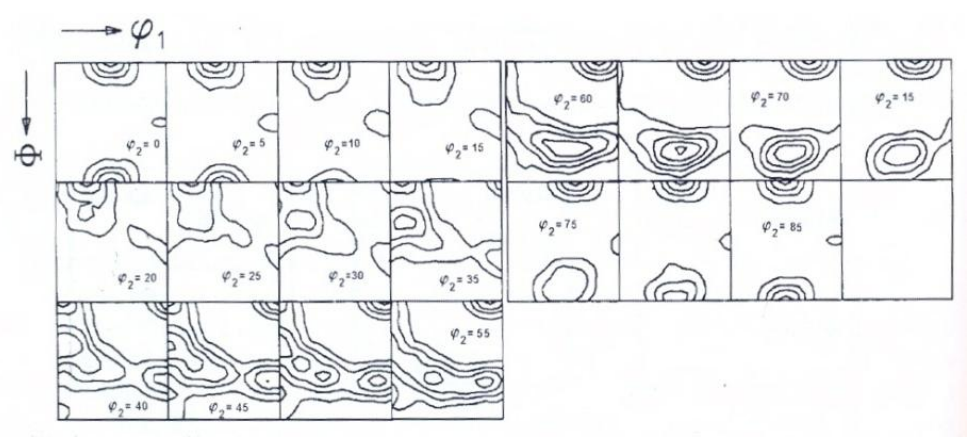

FIGURA 3.29 - Textura de um aço baixo carbono laminado $60 \%$ a frio; seções de $\varphi_{2}=0^{\circ}$ a $\varphi_{2}=85^{\circ}$, em intervalos de $5^{\circ}[53]$

As fibras DL e DN são mais bem observadas na seção de $\varphi_{2}=45^{\circ}$. A FIG 3.29 mostra as seções de $\varphi_{2}=0^{\circ}$ a $\varphi_{2}=45^{\circ}$ da textura de um aço Intersticial Free laminado $60 \%$ a frio, que podem ser analisadas com os ábacos da FIG 3.31. Na seção $\varphi_{2}=0^{\circ}$, os picos da função correspondem à orientação $\{001\}\langle 110\rangle$, que também pode ser vista em $\left(\varphi_{1}=0^{\circ}\right.$ e $\left.\phi=0^{\circ}\right)$ e $\left(\varphi_{1}=90^{\circ}\right.$ e $\left.\phi=0^{\circ}\right)$, e na seção $\left(\varphi_{2}=45^{\circ}\right)$.

Observa-se que a fibra DL vai de $\{001\}<110>$ até próximo de $\{110\}<110>$ e que a fibra DN envolve orientações que vão de $\{111\}<112>$ a $\{111\}<110>$, passando por $\{111\}<123>$. A orientação $\{001\}\langle 110\rangle$, também observada na seção de $\varphi_{2}=0^{\circ}\left(\mathrm{em} \phi=0^{\circ}, \varphi_{2}=45^{\circ}\right)$, é característica da laminação a frio de aços ferríticos e tende a ser consumida durante a recristalização. Este tipo de comportamento é o esperado para outros materiais cúbicos de corpo centrado e demais aços ferríticos. 

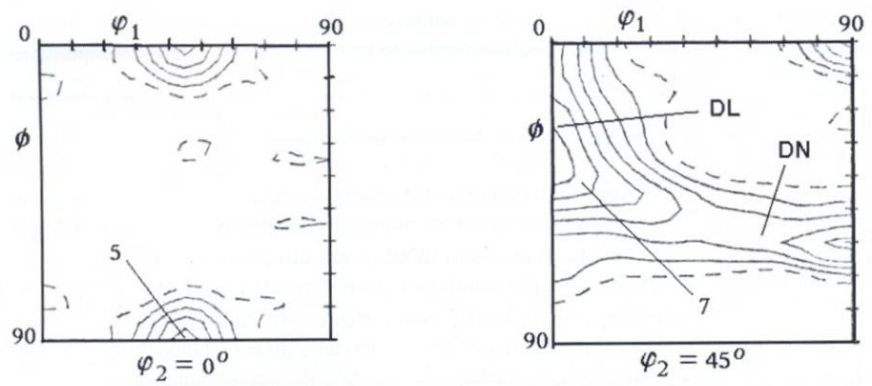

FIGURA 3.30 - Seções de $\varphi_{2}=0^{\circ}$ e $\varphi_{2}=45^{\circ}$ de um aço IF laminado $60 \%$ a frio [54]

Notação de Bunge [55]
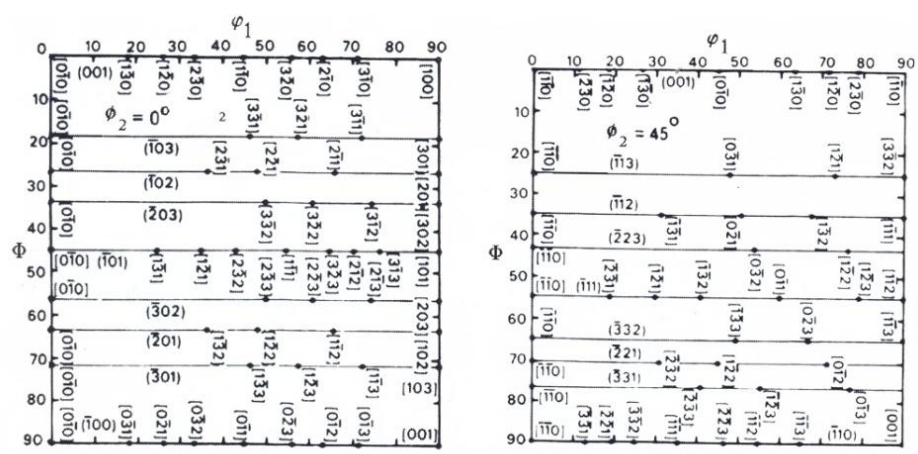

FIGURA $3.31-$ Ábacos de $\varphi_{2}=0^{\circ}$ e $\varphi_{2}=45^{\circ}$ para interpretar a FDOC [55]

A TAB. 3.2 mostra os valores dos ângulos de Euler para as principais componentes observadas nesses materiais.

TABELA 3.2 - Componentes de texturas típicas dos metais CCC laminados

\begin{tabular}{|c|c|c|c|c|}
\hline$\{\mathbf{h k l}\}$ & $\langle\mathbf{u v w}\rangle$ & $\boldsymbol{\varphi}_{\mathbf{1}}$ & $\boldsymbol{\phi}$ & $\boldsymbol{\varphi}_{\mathbf{2}}$ \\
\hline 001 & 110 & $0(90)$ & 0 & 45 \\
\hline 211 & 011 & 0 & 35 & 45 \\
\hline 111 & 011 & $0(60)$ & 55 & 45 \\
\hline 111 & 112 & $30(90)$ & 55 & 45 \\
\hline 11118 & 4411 & 90 & 63 & 45 \\
\hline 332 & 110 & 0 & 64 & 45 \\
\hline 113 & 110 & 0 & 64 & 45 \\
\hline 110 & 110 & 0 & 90 & 45 \\
\hline
\end{tabular}




\subsection{Curva Limite de Conformação}

A curva limite de conformação (CLC) permite representar de uma maneira abrangente a estampabilidade de uma chapa. O limite de conformação de uma chapa é definido como sendo o estado em que se inicia o afinamento localizado, o qual culmina na fratura [51].

A CLC tem sido empregada largamente como critério na otimização do processo de estampagem e no projeto de matrizes. Conforme na FIG. 3.32, estes diagramas indicam as deformações principais $\varepsilon_{1}$ e $\varepsilon_{2}$ na instabilidade difusa ou localizada no estado plano de tensão, para diferentes caminhos de deformação. Para as possíveis combinações de deformações, observa-se que com ambas as deformações principais ativas têm-se maior distribuição das deformações e a estricção se torna mais difusa, sendo importante se ter altos valores de $n$, enquanto que no caso de ter uma deformação principal fortemente positiva e outra fortemente negativa, há a tendência de se ter uma compensação, e a deformação ao longo da espessura é pequena. Esta situação é a mais próxima da estampagem profunda.

Por sua vez, quando uma das deformações principais no plano da chapa se aproxima de zero, a estricção é menos difusa e há o afinamento da chapa.

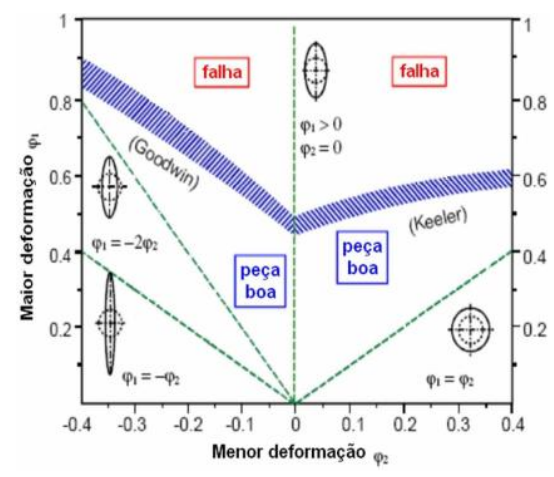

FIGURA 3.32 - Curva Limite de Conformação (CLC) [57] 
Na FIG 3.32 podemos observar a CLC separando as regiões de sucesso (peça boa) e falha no corpo de prova ou peça estampada. As micrografias desta figura ilustram as diferentes microestruturas do material, respectivamente, na condição tração-compressão (lado esquerdo) e tração-tração (lado direito).

A FIG. 3.33 ilustra o "caminho da deformação" - strain-path, percorrido pelos corpos de prova para as condições de estampagem profunda, plano de deformação e estiramento biaxial balanceado. Para o levantamento dos dados da curva CLC, empregam-se diferentes geometrias de corpos de prova, conforme a FIG. 3.33 com demonstração dos corpos de prova na determinação do caminho da deformação.
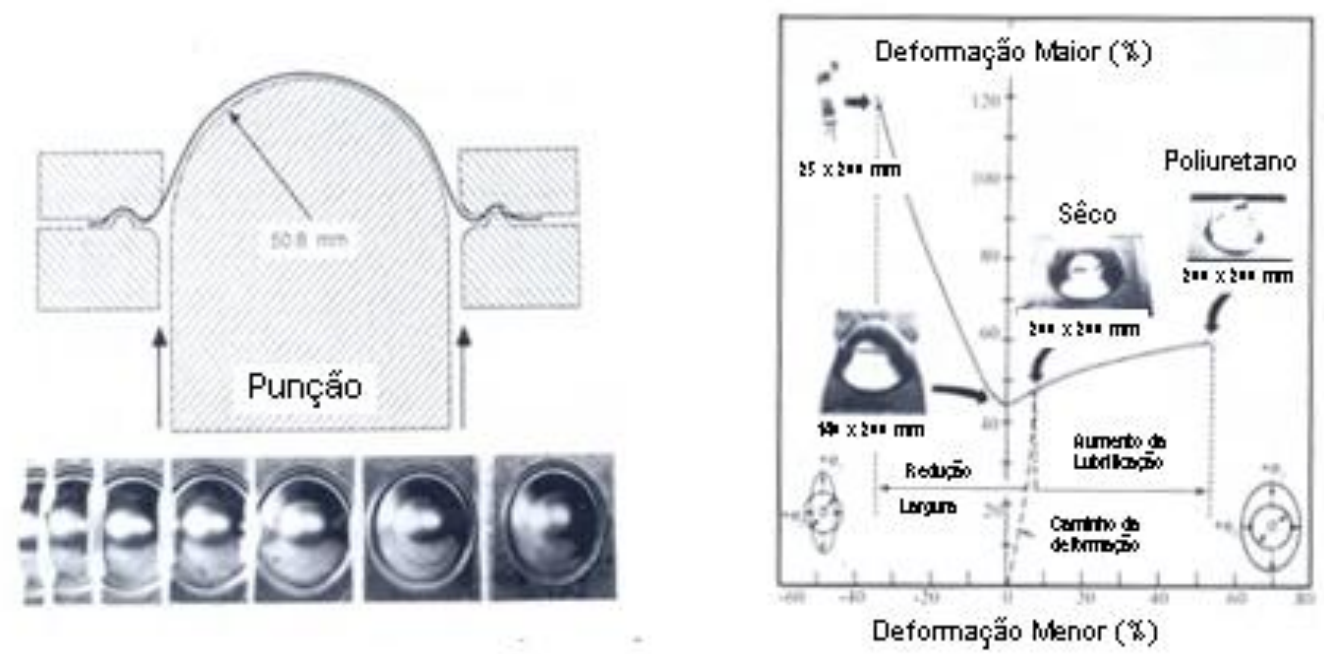

FIGURA 3.33 - Método Nakazima de amostragem e o Caminho da Deformação [52] [53]

Na próxima etapa, serão apresentados os materiais e métodos utilizados para a realização deste estudo. 


\section{MATERIAIS E MÉTODOS}

Neste capítulo serão discutidos os aspectos relativos à fabricação do aço IF-Ti, utilizado neste estudo e produzido conforme o plano de trabalho:

a) Relaminação de encruamento com diferentes taxas de redução.

b) Ensaios laboratoriais para verificação das propriedades do material amostrado.

Além disso, será descrito como foram realizados os ensaios para caracterização das propriedades mecânicas nas principais etapas do plano de amostragem, conforme FIG 4.1. Neste fluxo temos a sequiência do processo de fabricação do aço IF-Ti desde a fabricação da placa até os ensaios para verificação das propriedades do material. Após a placa laminada a quente, essa se transforma em bobina laminada a quente, denominada BQ. Na seqüência temos a formação da BF na Laminação a frio através da junção de duas ou mais BQs, e ainda, outras formas que a bobina se apresenta à medida que a mesma é processada nos equipamentos tais como: BR, BPE e BRE com as nomenclaturas, conforme TAB. 4.1.

TABELA 4.1 - Etapas de processo da bobina

\begin{tabular}{|c|l|}
\hline Etapas & \multicolumn{1}{|c|}{ Condição da bobina } \\
\hline 1 & Placa Teste \\
\hline 2 & BQ - Bobina a Quente \\
\hline 3 & BF - Bobina a Frio \\
\hline 4 & BR - Bobina Recozida \\
\hline 5 & BPE - Bobina Produto Encruada \\
\hline 6 & BRE - Bobina Relaminada Encruada \\
\hline
\end{tabular}

A TAB. 4.1 representa o fluxo da bobina com as respectivas etapas de processo da bobina que foi adotado para o estudo, sendo que até a etapa 5 representa o fluxo convencional do aço IF-Ti e na etapa 6, uma etapa adicional com a relaminação do material, devido à 
necessidade de adequação ou ajuste das características superficiais e da forma do material produzido.

Para a realização deste trabalho, foi utilizado o material IF-Ti da dimensão 0,75 x 1200 mm, produzido e processado em escala industrial nas instalações da USIMINAS - Cubatão, através dos processos mostrados na FIG. 4.1. Na TAB. 4.2 estão relacionados os parâmetros de processo das bobinas utilizadas neste trabalho, que estão coincidentes com os parâmetros do material IF em produção convencional.

TABELA 4.2 - Parâmetros de processo das Bobinas Experiência

\begin{tabular}{|c|c|c|c|}
\hline Equipamento & Item & Parâmetros & Unidade \\
\hline \multirow{4}{*}{ LTQ } & Grau de redução & $85-90$ & $\%$ \\
\hline & Temperatura Acabamento & $900-950$ & ${ }^{\circ} \mathrm{C}$ \\
\hline & Temperatura Bobinamento & $600-650$ & ${ }^{\circ} \mathrm{C}$ \\
\hline & Temperatura Reaquecimento & $1150-1250$ & ${ }^{\circ} \mathrm{C}$ \\
\hline Laminação a Frio & Grau de redução & $75-80$ & $\%$ \\
\hline \multirow{4}{*}{ Recozimento } & Taxa de aquecimento & $30-40$ & ${ }^{\circ} \mathrm{C} / \mathrm{h}$ \\
\hline & Temperatura de encharque & $650-750$ & ${ }^{\circ} \mathrm{C}$ \\
\hline & Tempo de encharque & $15-25$ & $\mathrm{~h}$ \\
\hline & Taxa de resfriamento & $20-30$ & ${ }^{\circ} \mathrm{C} / \mathrm{h}$ \\
\hline Encruamento & Grau de redução & 0,50 & $\%$ \\
\hline
\end{tabular}

Para melhor compreensão do fluxo do processo e metodologia de amostragem utilizada no estudo, a FIG. 4.1 apresenta correlação do fluxo do processo com os respectivos equipamentos e produtos gerados durante cada etapa de fabricação do material IF. 


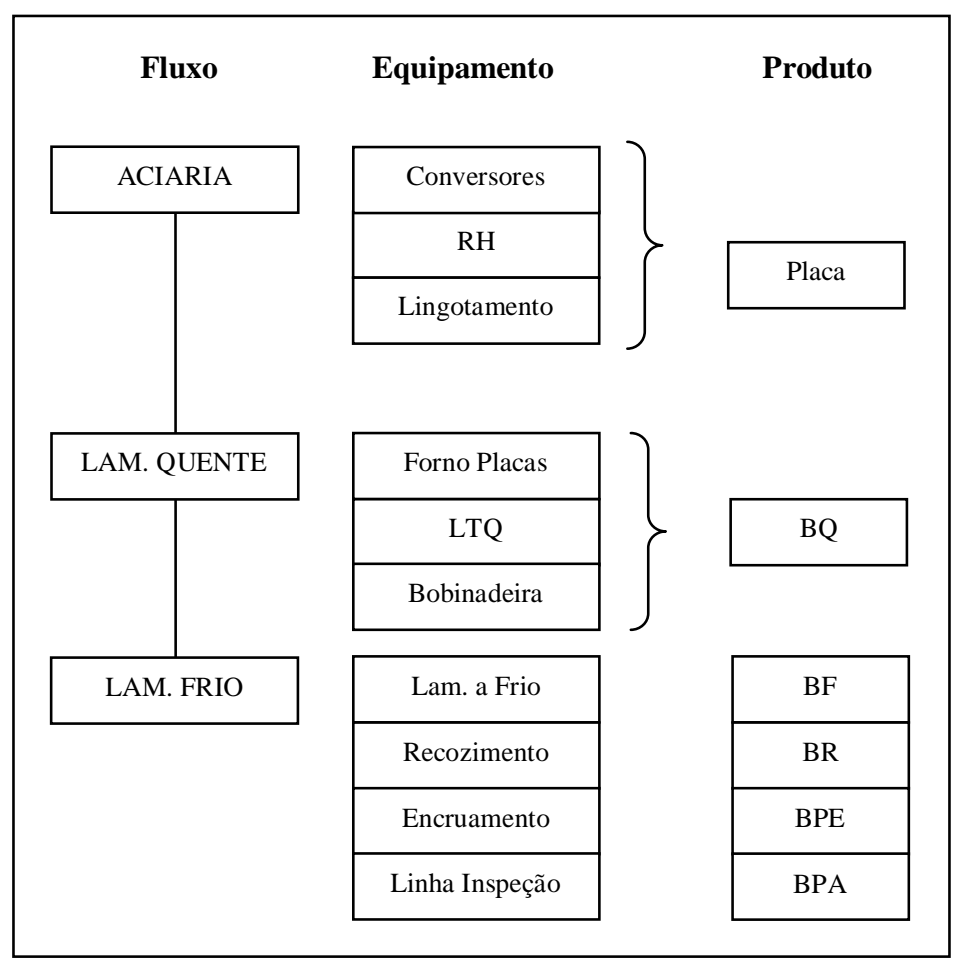

FIGURA 4.1 - Seqüência das etapas de processo

Na FIG. 4.2 é apresentado um esquema do procedimento experimental e parâmetros operacionais praticados durante o processamento do material IF para a bobina 073351, com prática semelhante para bobina 073352. Neste fluxo de relaminação convencional e experiência, são determinados diferentes valores de redução.

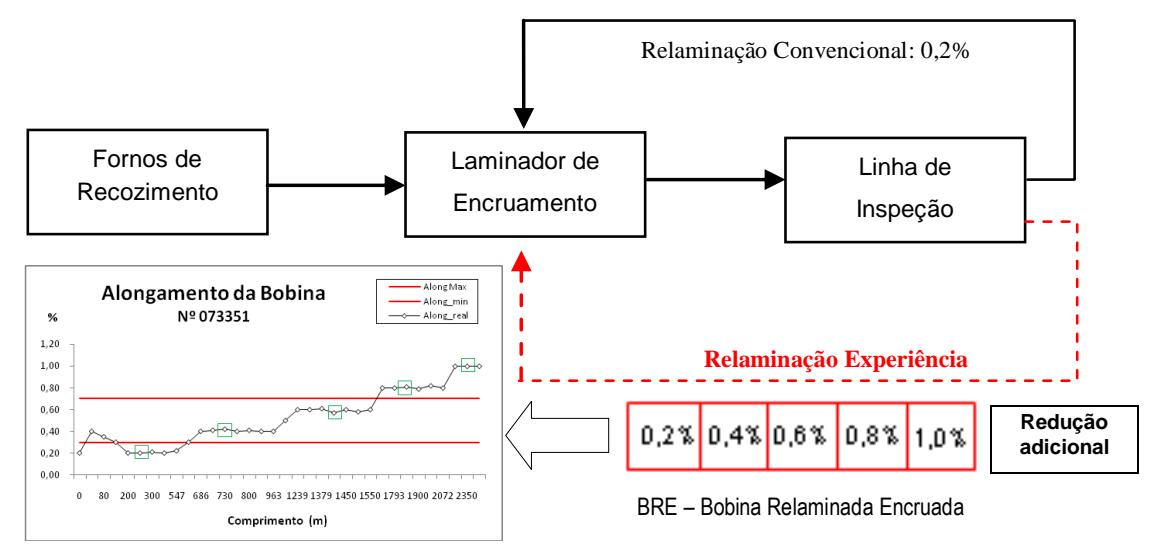

FIGURA 4.2 - Esquema do procedimento experimental e parâmetros operacionais [11] 


\subsection{Processamento}

\subsubsection{Laminação a Quente}

No início da etapa de laminação a quente, a placa obtida do lingotamento contínuo com espessura de aproximadamente $210 \mathrm{~mm}$ foi reaquecida no forno do tipo Pusher com temperatura em torno de $1200^{\circ} \mathrm{C}$. Em seguida, foi desenfornada e desbastada no laminador reversível R1, em cinco passes, e depois em três passes, no laminador reversível R2, a fim de reduzir sua espessura.

Nesta etapa, a placa agora é chamada de esboço com espessura de $33 \mathrm{~mm}$, redução em torno de $85 \%$. Logo em seguida, o esboço foi laminado no trem acabador, laminador contínuo de seis cadeiras de forma a produzir um laminado a quente com espessura de aproximadamente 3,50 mm, o que corresponde a uma redução em torno de 90\%. Assim, a placa inicial originou a uma Bobina laminada a Quente (BQ). Os parâmetros de processo da BQ conforme apresentado na TAB. 4.2.

Os gráficos da FIG. 4.3 a seguir, apresentam as curvas reais de temperatura de acabamento e bobinamento durante o processo de laminação a quente das placas utilizadas para o estudo.

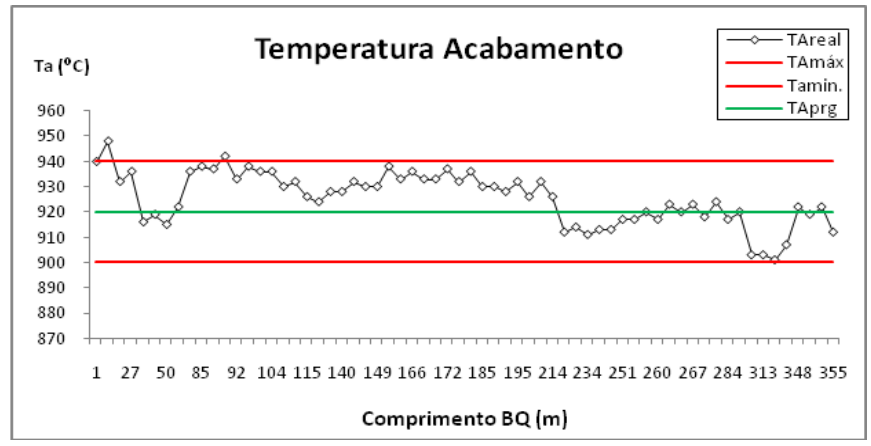

(a) Temperatura de acabamento da bobina 073351 


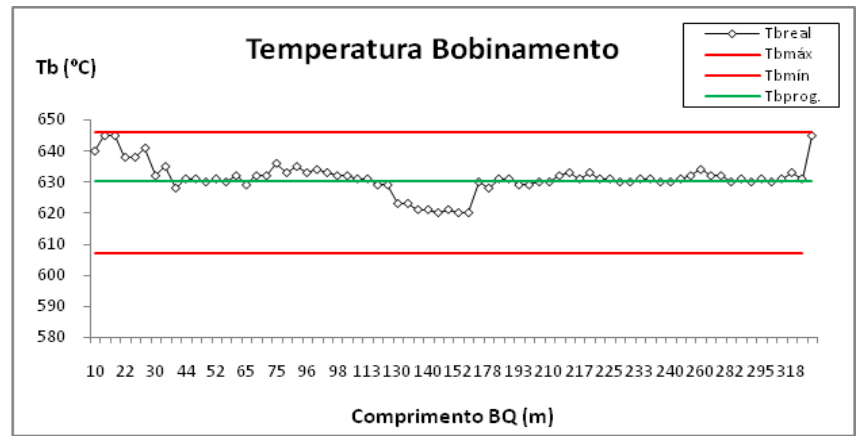

(b) Temperatura de bobinamento da bobina 073351

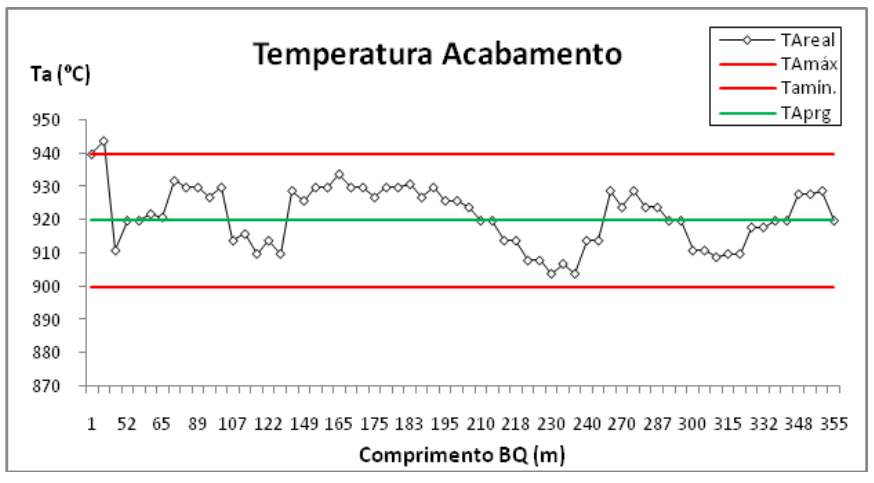

(c) Temperatura de acabamento da bobina 073352

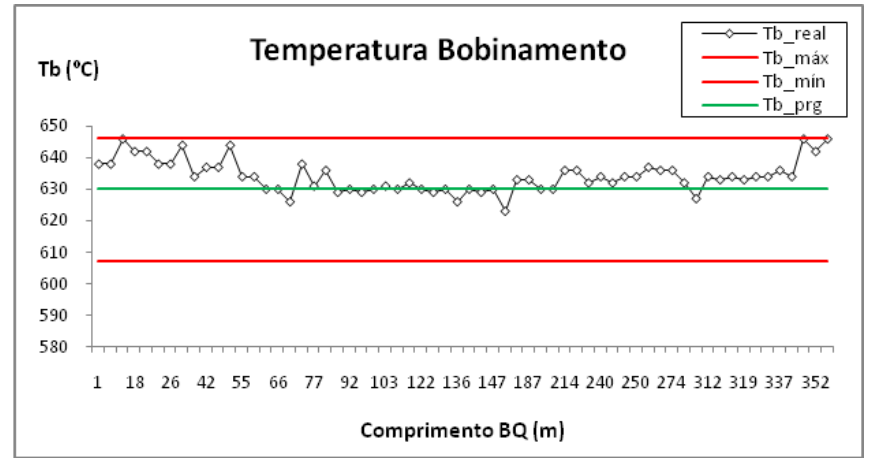

(d) Temperatura de bobinamento da bobina 073352

FIGURA 4.3 - Seqüência das temperaturas de bobinamento e acabamento

Após a Laminação a Quente a BQ é decapada e laminada no Laminador a Frio, e na seqüência enfornada nos fornos de Recozimento. 


\subsubsection{Laminador de Tiras a Frio}

Após o processo de redução no Laminador de Tiras a quente, a Bobina a Quente (BQ) foi direcionada para os processos denominados de Laminação a Frio. Inicialmente processada na Decapagem e na sequência no Laminador de Tiras a Frio. Tendo como um dos principais objetivos a adequação da espessura conforme especificação do pedido, a variação de espessura nesta etapa deve ser mais homogênea possível, evitando variações superiores ao limite superior e inferior.

Na FIG. 4.4 é apresentado resultado de desempenho de espessura ao longo da bobina em função da velocidade, com respectivos limites e a variação nas pontas inicial e final.

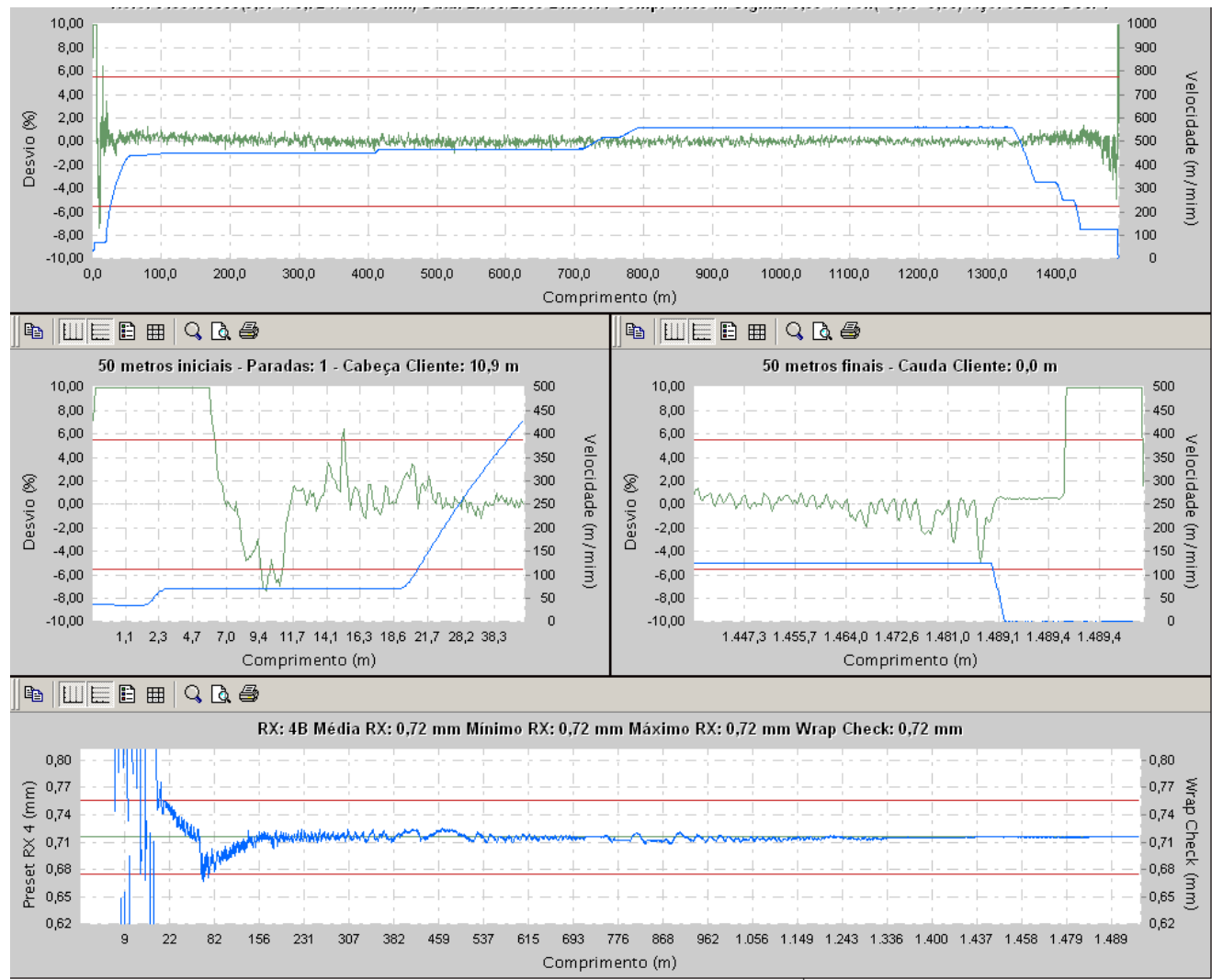

FIGURA 4.4 - Tela de parâmetros da carga de enfornamento no Recozimento 
Outra variável significativa do processo de redução a frio, é a variação da planicidade da bobina, que é resultado das condições de distribuição de tensão ao longo da bobina através de um rolo denominado stressometer. Este equipamento determina e este parâmetros para melhorar o nível de planicidade da bobina (longitudinal e transversal) através de atuação de células de carga, solidárias ao rolo e em combinação com sistema de refrigeração da cadeira acabadora do laminador. Os resultados de planicidade da bobina são plotados e avaliados em gráficos conforme FIG. 4.5.

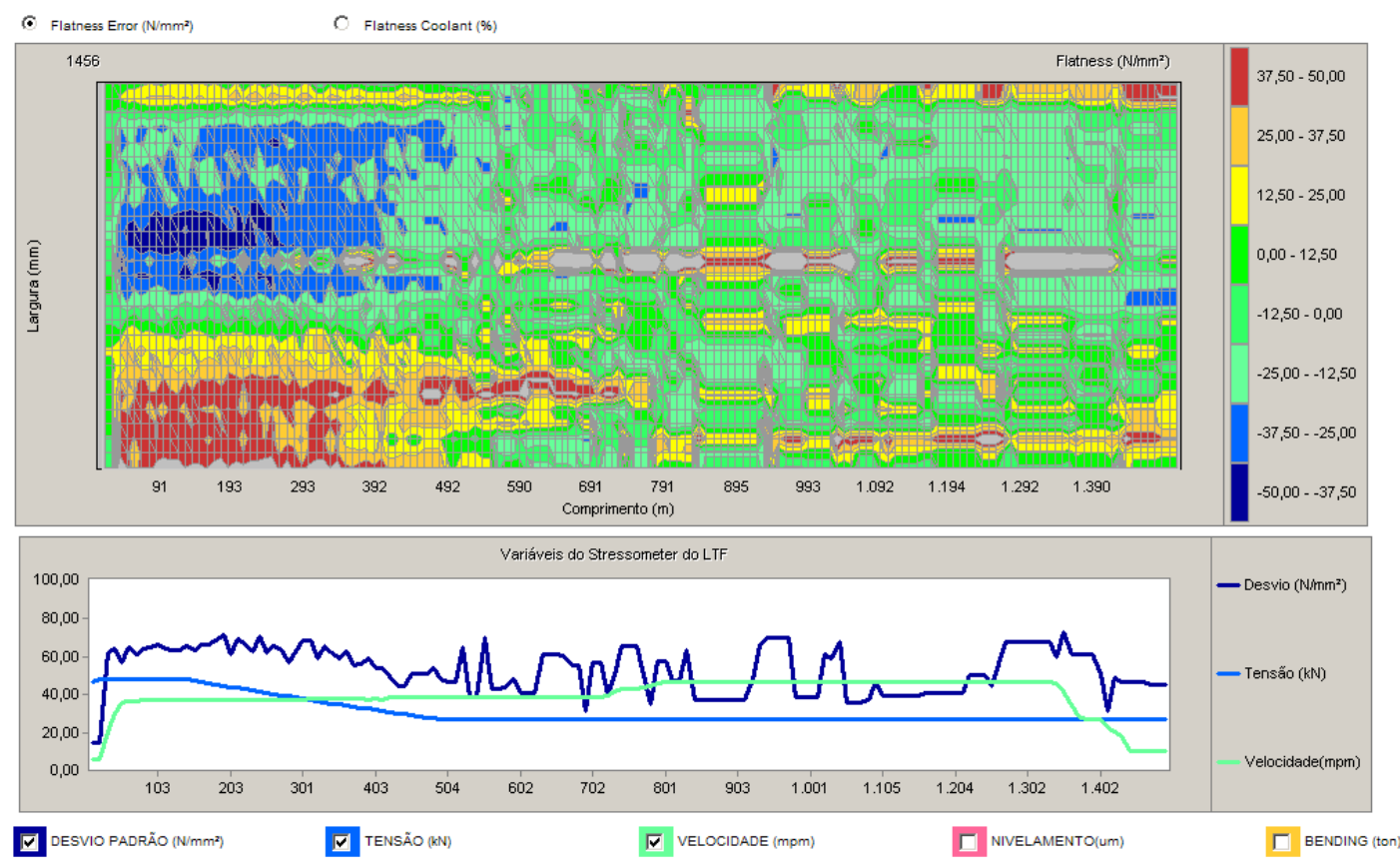

FIGURA 4.5 - Tela de parâmetros da carga de enfornamento no Recozimento

Na FIG. 4.5 é apresentado também, o resultado da distribuição de planicidade da bobina, sendo que a variação de cor indica o nível de intensidade da tensão nas diversas regiões da bobina, onde o nível de tensionamento decresce da cor vermelha até o azul. A cor verde representa a condição ideal de tensionamento e consequentemente excelente nível de planicidade. 


\subsubsection{Recozimento}

Após o processo de redução no Laminador de Tiras a Frio, a Bobina a Frio (BF) foi encaminhada para o processo de Fornos de Recozimento para ajuste de propriedades mecânicas. A bobina BF foi então processada pelo Recozimento 5, cujo processo utiliza o gás $\mathrm{H}_{2}$ e, seus respectivos dados de processo de enfornamento e formação da carga, conforme FIG. 4.6.

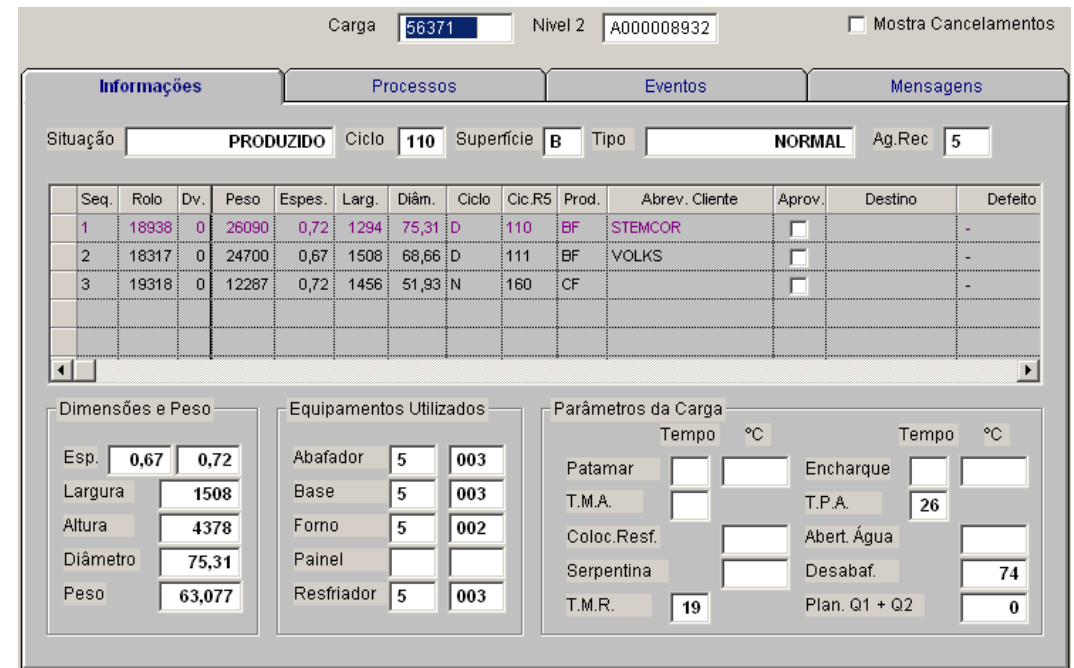

FIGURA 4.6 - Tela de parâmetros da carga de enfornamento no Recozimento

Nesta tela da FIG. 4.6, são estabelecidos todos os parâmetros e eventos para a carga de bobinas a serem produzidas com o seguinte ciclo de temperatura, conforme FIG. 4.7.

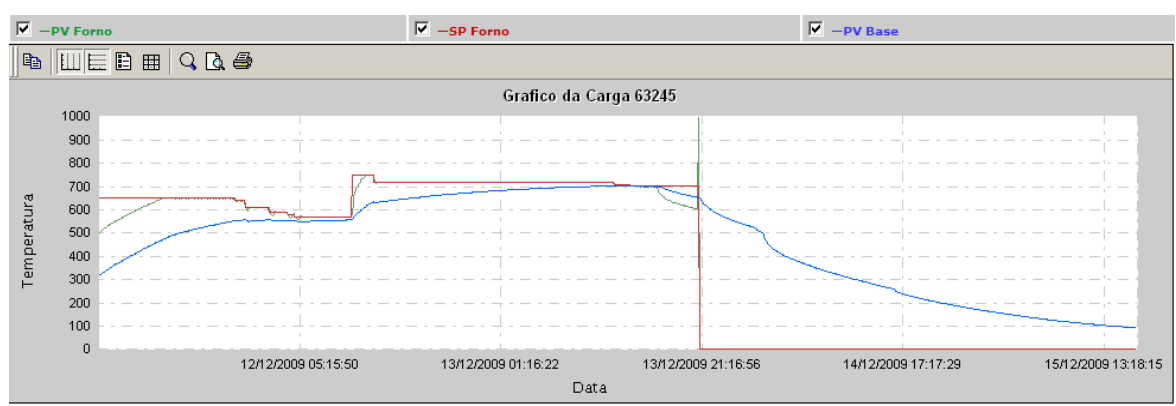

FIGURA 4.7 - Gráfico de temperatura em ciclo do Recozimento 
A FIG. 4.7 apresenta um gráfico com curvas de processo relativo aos parâmetros de temperatura vs. tempo do forno e de base. Sendo que os valores de temperatura estão conforme a posição dos respectivos termopares do forno e de base. Estas curvas de temperatura correspondem às etapas de aquecimento, encharque e resfriamento.

\subsubsection{Laminador de Encruamento}

Após o processo de recozimento a Bobina Recozida (BR) foi para o Laminador de Encruamento 2 para o passe de encruamento. A bobina BR foi então processada pelo laminador de encruamento, conforme a FIG. 4.8 com grau de deformação entre 0,30 a 0,70\%, objetivando 0,50\% com a nomenclatura de BPE - Bobina Produto Encruada.

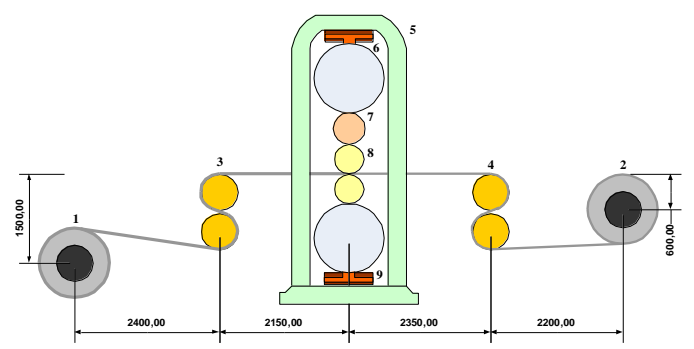

FIGURA 4.8 - Desenho esquemático do LE2 da Usiminas Cubatão [11]

A FIG. 4.8 apresenta um desenho esquemático do Laminador de Encruamento é feita com baixas taxas de redução ou redução superficial, tem por finalidade uniformizar as condições de superfície do aço, provocando maior rigidez à chapa, acabamento superficial (rugosidade ou aspereza) e melhorar o aplainamento. Embora a redução de espessura seja pequena, a laminação de encruamento evita os distúrbios superficiais, quebras de superfície e linhas de distensão ou banda de Lüders que aparecem normalmente na superfície do aço recémrecozido. Os cilindros de trabalho exercem esforços perpendiculares à superfície, ao mesmo tempo imprimem o acabamento superficial pela transferência de certa taxa de sua rugosidade. 
A BPE é enviada para a Linha de Inspeção onde são inspecionadas suas características dimensionais e superficiais, conforme especificação do pedido original. Em alguns casos, ocorrem defeitos relacionados à planicidade, como ondulação central ou lateral. Dependendo da planicidade ou defeitos de rugosidade, torna-se necessário então a relaminação da bobina no Laminador de Encruamento.

Esta relaminação pode comprometer as propriedades da bobina, caso seja o valor aplicado durante a relaminação seja excessivo.

Nesta etapa, a BPE apresenta conforme FIG. 4.9 e 4.10, grau de redução objetivado de 0,5\%.

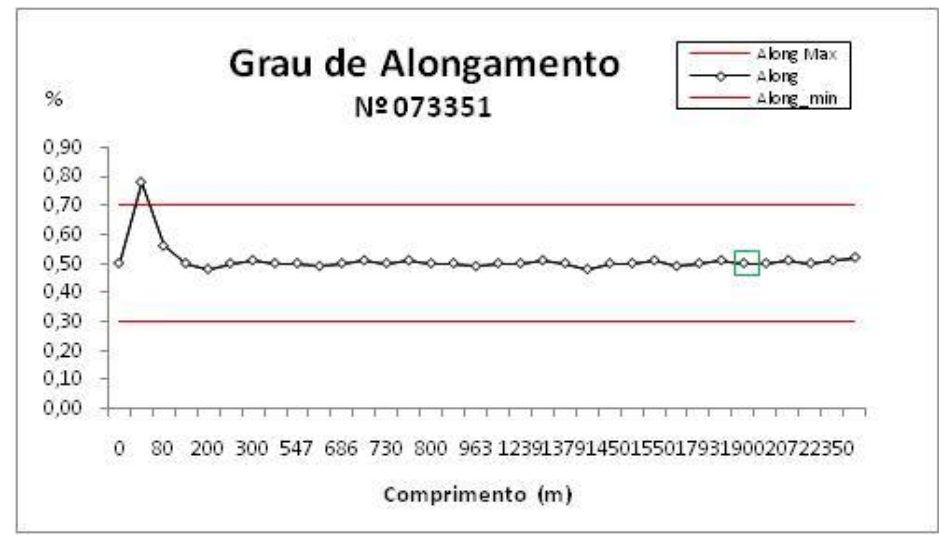

FIGURA 4.9 - Gráfico de redução no Encruamento da amostra 073351

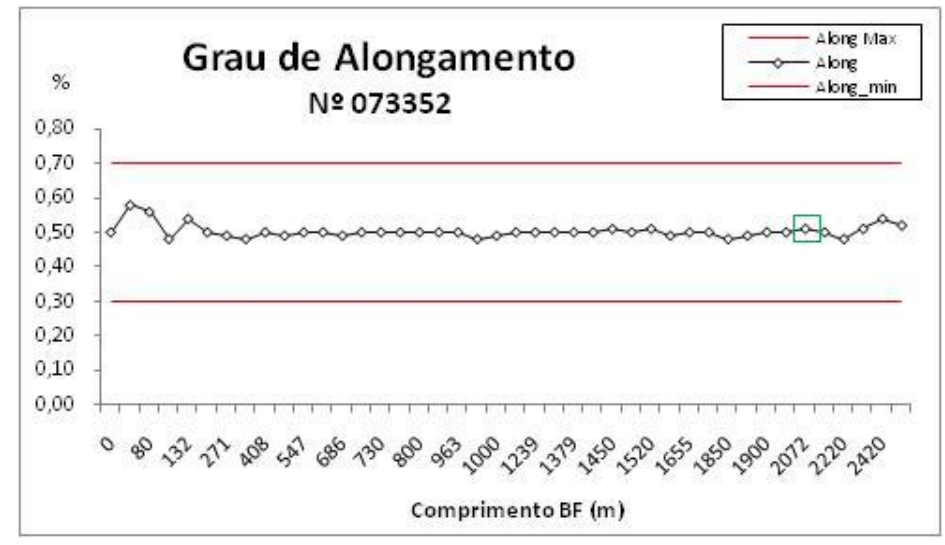

FIGURA 4.10 - Gráfico de redução no Encruamento da amostra 073352 


\subsubsection{Relaminação de Encruamento}

Após o recozimento e a laminação de encruamento, a BPE retornou para o laminador de encruamento para ser relaminada e então denominada de BRE, com graus de deformação de 0,$2 ; 0,4 ; 0,6 ; 0,8$ e $1,0 \%$. As alterações no grau de deformação foram realizadas interrompendo-se a relaminação de encruamento cada 1/5 do comprimento total da bobina, de forma que, após o bobinamento, a mesma deveria conter cinco partes com diferentes graus de deformação, conforme desenho esquemático, da FIG. 4.11.

\begin{tabular}{|c|c|c|c|c|c|c|}
\hline BRE & $\begin{array}{c}\text { \% redução } \\
\text { Parte 1 }\end{array}$ & $\begin{array}{c}\text { \% redução } \\
\text { Parte 2 }\end{array}$ & $\begin{array}{c}\text { \% redução } \\
\text { Parte 3 }\end{array}$ & $\begin{array}{c}\text { \% redução } \\
\text { Parte 4 }\end{array}$ & $\begin{array}{c}\text { \% reduçāo } \\
\text { Parte 5 }\end{array}$ \\
\hline \hline 0,2 & 0,4 & 0,6 & 0,8 & 1,0 \\
\hline
\end{tabular}

FIGURA 4.11 - Seqüência de grau de relaminação da bobina BRE

Durante o processo de encruamento foram estabelecidos 5 graus de redução, aumentando gradativamente o grau de redução em cada região da bobina. $\mathrm{O}$ aumento gradativo da redução adicional em função do comprimento e os locais onde foram retiradas as amostras para ensaio, em cada etapa da redução, conforme apresentado nas FIG. 4.12 e 4.13

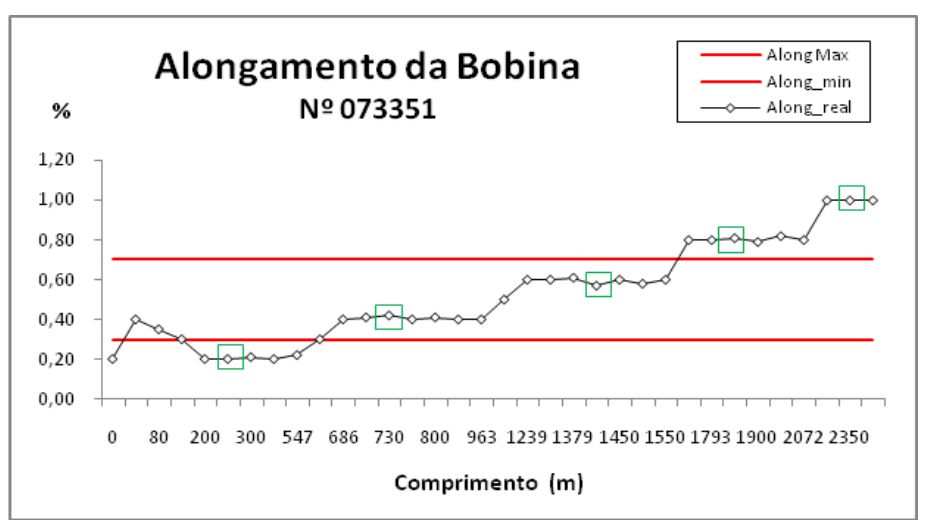

FIGURA 4.12 - Evolução da redução adicional durante relaminação e amostragem 


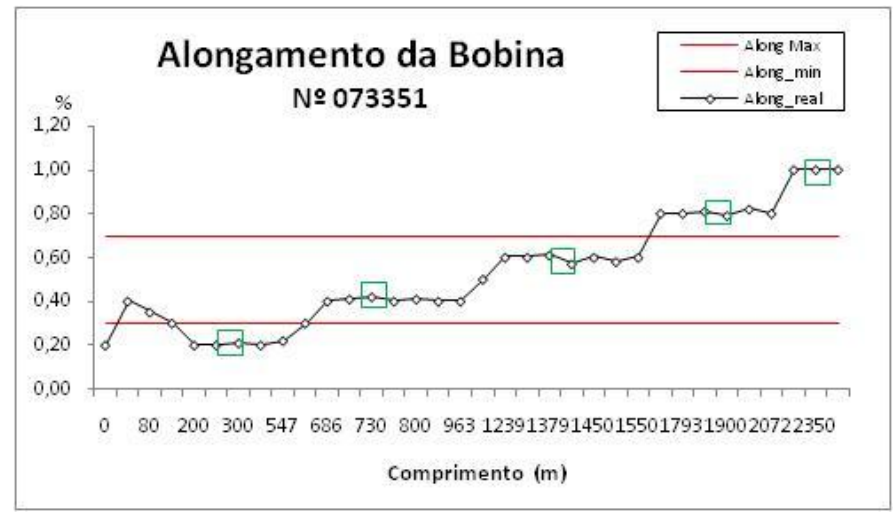

FIGURA 4.13 - Evolução da redução adicional durante relaminação e amostragem

\subsubsection{Parâmetros do processo de Encruamento}

Na FIG. 4.14 apresenta desenho esquemático do Laminador de Encruamento e em seguida dados de processo no Encruamento aplicados durante o processamento do material.

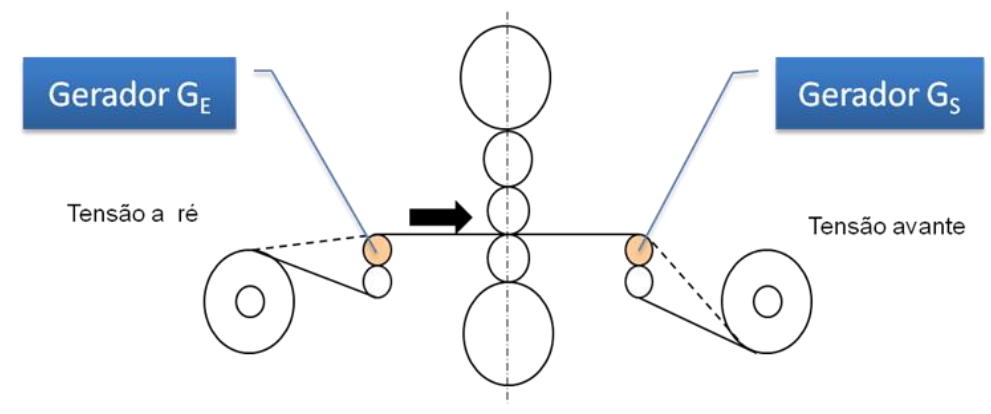

FIGURA 4.14 - Desenho esquemático do Laminador Encruamento com geradores

A seguir dados do laminador aplicados durante o processamento do material em experiência.

\begin{tabular}{|l|c|l|c|}
\hline \multicolumn{4}{|c|}{ Variáveis de processo do Laminador } \\
\hline Redução inicial no encruamento $(\%)$ & $0,50 \%$ & Temperatura laminação $\left({ }^{\circ} \mathrm{C}\right)$ & $37-39$ \\
\hline Dimensão da bobina $(\mathrm{mm})$ & $0,72 \times 1250$ & Força Laminação $(\mathrm{t})$ & $40-45$ \\
\hline Rugosidade da chapa $(\mu \mathrm{Ra})$ & $0,70-1,00$ & Velocidade máxima $(\mathrm{mpm})$ & $800-1100$ \\
\hline Tração avante $(\mathrm{MPa})$ & $25-30$ & Bending do Trabalho $(\mathrm{MPa})$ & $30-35$ \\
\hline Tração a ré $(\mathrm{MPa})$ & $20-25$ & Bending do Intermediário $(\mathrm{MPa})$ & $6-10$ \\
\hline
\end{tabular}




\begin{tabular}{|l|c|l|c|}
\hline \multicolumn{4}{|c|}{ Características físico-químicas da solução de encruamento } \\
\hline Densidade $\left(20^{\circ} \mathrm{C}\right)$ & $1,07-1,09$ & Solubilidade em água & Solúvel \\
\hline Materiais voláteis & Não há & Concentração (processo): & $5 \%$ \\
\hline Viscosidade & Devido alta diluição na água, considerar semelhante viscosidade da água. \\
\hline
\end{tabular}

\begin{tabular}{|c|c|c|}
\hline \multicolumn{3}{|c|}{ Dados do Cilindro de trabalho } \\
\hline Parâmetros & Superior & Inferior \\
\hline Diâmetro $[\mathrm{mm}]$ & 418,87 & 418,90 \\
\hline Rugosidade $[\mu \mathrm{Ra}]$ & $2,40-2,50$ & $2,40-2,70$ \\
\hline Dureza $[\mathrm{ShC}]$ & $90-92$ & $88-90$ \\
\hline
\end{tabular}

\begin{tabular}{|l|c|}
\hline \multicolumn{2}{|c|}{ Módulo de Elasticidade do Laminador } \\
\hline Tensão de deformação [MPa] & $1050-1150$ \\
\hline Resistência [MPa] & $950-1050$ \\
\hline Tipo do material aplicado & Aço Forjado \\
\hline
\end{tabular}

\begin{tabular}{|c|c|c|}
\hline \multicolumn{3}{|c|}{ Composição química do cilindro de trabalho (\% em peso) } \\
\hline Elementos & Superior & Inferior \\
\hline Carbono & $0,85-0,89$ & $0,86-0,88$ \\
\hline Cromo & $3,0-3,1$ & $3,0-3,1$ \\
\hline Fósforo & $0,01-0,03$ & $0,01-0,03$ \\
\hline Manganês & $0,50-0,60$ & $0,50-0,60$ \\
\hline Molibdênio & $0,25-0,28$ & $0,25-0,28$ \\
\hline Silício & $0,55-0,60$ & $0,55-0,60$ \\
\hline
\end{tabular}




\subsection{Análises Realizadas}

\subsubsection{Amostragem}

A amostragem é executada em várias etapas conforme seqüência das etapas do processo apresentados na FIG. 4.1. Em cada uma dessas etapas retiraram-se amostras conforme TAB. 4.3 e realizaram-se ensaios conforme TAB. 4.4. Nessas tabelas, as amostras foram identificadas com o seguinte critério:

- as letras indicam a condição da bobina e local a ser processada;

- os algarismos indicam o grau de deformação na relaminação de encruamento.

TABELA 4.3 - Fluxo de processo de amostragem

\begin{tabular}{|c|c|c|c|}
\hline \multicolumn{5}{|c|}{ Fluxo de processo } \\
\hline Etapa & 1 & 2 & 3 \\
\hline \multirow{2}{*}{ Equipamento } & Aciaria & $\begin{array}{c}\text { Laminador de } \\
\text { Encruamento }\end{array}$ & $\begin{array}{c}\text { Laminador de } \\
\text { Encruamento }\end{array}$ \\
\hline \multirow{2}{*}{ Amostra } & Placa & BPE & BRE02 \\
\cline { 3 - 4 } & & & BRE04 \\
\cline { 3 - 4 } & & & BRE06 \\
\cline { 3 - 4 } & & & BRE08 \\
\hline
\end{tabular}

TABELA 4.4 - Ensaios realizados de acordo com o plano de amostragem

\begin{tabular}{|c|c|c|}
\hline Etapa & Amostra & Ensaios \\
\hline 1 & Corrida & Análise química \\
\hline 2 & BPE & Erichsen, metalografia \\
\hline 3 & $\begin{array}{c}\text { BRE02, BRE04, BE06, BE08, } \\
\text { BE10 }\end{array}$ & $\begin{array}{c}\text { Tração, R,n, Erichsen, } \\
\text { metalografia. }\end{array}$ \\
\hline
\end{tabular}


TABELA 4.5 - Condição da bobina Local de amostragem

\begin{tabular}{|c|l|l|}
\hline & Condição da bobina & \multicolumn{1}{c|}{ Local de amostragem } \\
\hline BPE & Bobina Encruada & $\begin{array}{l}\text { Amostra após encruamento final do material, retirada na saída } \\
\text { do Laminador de Encruamento. }\end{array}$ \\
\hline BRE & Bobina Relaminada & Amostra após relaminada o material, retirada na linha de \\
& & Tesoura a Frio. \\
\hline
\end{tabular}

Como o processo de encruamento durante a relaminação ocorreu com vários graus de alongamento na mesma bobina, foi necessário calcular a posição das chapas a serem amostradas, dividindo o comprimento total por cinco partes da bobina, sendo $1 / 5$ da bobina representando cada grau de redução. Sendo assim, todas as amostras do material relaminado foram retiradas na linha de Tesoura a Frio 2, conforme TABELA 4.5.

A caracterização das amostras foi realizada nos laboratórios da Usiminas - Cubatão, com avaliação da análise química confirmatória, da análise metalográfica, do ensaio de tração, da determinação dos valores $\mathrm{R}$ e $n$, do ensaio Erichsen e levantamento de curvas CLC usando método do Nakazima, da difração de raios-X para análise de textura. Esses ensaios e análises são detalhados nos itens a seguir.

\subsubsection{Análise química confirmatória}

Realizar análises químicas confirmatórias ou check analysis em amostra retirada do material processado após a laminação a quente com o objetivo de verificar se o material havia incorporado algum elemento químico em relação à análise química na etapa 1 conforme apresentado na FIG. 4.1. 
Para os elementos carbono e enxofre, o método utilizado para análise química é o de absorção infravermelho (fusão), efetivado através de um aparelho CS444, da LECO. Para o nitrogênio, o método utilizado é o de análise por condutividade térmica utilizando o sistema Wheatstone Bridge e o aparelho TC436, da LECO. Todos os demais elementos foram determinados através de espectrometria de absorção óptica, utilizando-se um ARL3460.

\subsubsection{Análise metalográfica}

As análises metalográficas realizadas de acordo com procedimento especial de ataque adotado no laboratório do Centro de Teste da Usiminas - Cubatão envolveu a utilização das seguintes soluções de ataque em seqüência, conforme TAB. 4.6.

TABELA 4.6 - Procedimento da solução de ataque

\begin{tabular}{|c|c|}
\hline $1^{\underline{a}}$ solução & $\begin{array}{l}\text { Ácido pícrico } 4 \% \text { em álcool } \\
\text { Tempo de ataque: } 60 \mathrm{~s}\end{array}$ \\
\hline $2^{\mathrm{a}}$ solução & $\begin{array}{l}\text { A - } 100 \mathrm{ml} \text { de água destilada e } 5 \mathrm{ml} \text { de ácido sulfúrico } \\
\text { B - peróxido de hidrogênio } 30 \% \\
\text { Tempo de ataque: } 10 \text { a } 15 \mathrm{~s}\end{array}$ \\
\hline $3^{\underline{a}}$ solução & $\begin{array}{l}100 \mathrm{ml} \text { de álcool etílico } \\
2 \mathrm{~g} \text { de ácido pícrico } \\
2 \mathrm{ml} \text { de ácido nítrico } \\
\text { Tempo de ataque: } 30 \text { a 40s }\end{array}$ \\
\hline
\end{tabular}

A segunda solução de ataque é uma mistura feita no momento de atacar a amostra, na razão de 1/1 entre as soluções A e B. As micrografias foram obtidas através de microscópio óptico Axioplan, com ampliação de 140 vezes. 
Além disso, determinou-se o tamanho de grão pela norma ASTME112: 1998 através da contagem dos interceptos dos contornos de grão sobre uma linha de teste de comprimento conhecido, cujo valor é dividido pelo número de interceptos, obtendo assim o diâmetro médio do grão. Neste trabalho, contou-se a mesma amostra dez vezes, em posições diferentes e, determinou-se, após isso, o valor médio do diâmetro do tamanho de grão.

\subsubsection{Ensaios mecânicos}

Estes ensaios possibilitam a obtenção de várias propriedades mecânicas do material, tais como: LE, LR, Anisotropia, Alongamento total, entre outros.

Os testes de tração e a determinação dos valores $\mathrm{R}, \Delta \mathrm{R}$ e $n$ foram realizados em amostras retiradas a $1 \frac{1}{4}$ da largura da chapa retirada da bobina, conforme TAB. 4.4. Nessas chapas, retiraram-se amostras no sentido transversal de laminação para o teste de tração. Para a determinação de $\mathrm{R}, \Delta \mathrm{R}$ e $n$, as amostras foram retiradas no sentido transversal, longitudinal e a 45 graus em relação ao sentido de laminação. Todos esses testes realizados na máquina universal de ensaios Instron 4482, a uma velocidade de deformação de $3 \mathrm{~mm} / \mathrm{min}$., em corpos de prova (CP) com dimensões definidas (FIG. 4.15 e TAB. 4.7), submetidos ao acabamento de fresa, visando eliminar o efeito do encruamento da operação de corte nas bordas do CP.

O teste de tração foi realizado conforme a norma NBR 6673:1981. Em cada amostra, realizaram-se seis ensaios de tração para a caracterização mecânica em termos de limite de escoamento a $0,2 \%$ de deformação, já que o IF não apresenta patamar de escoamento nítido, limite de resistência e alongamento total. 
Os valores de R e $n$ foram medidos conforme norma EN 10.130:1991+A1:1998 utilizandose um software contido na máquina Instron. Esse software calcula o $\mathrm{R}$ através da EQUAÇÃO 3.2, com os dados obtidos das dimensões originais do CP e das dimensões após $16 \%$ de deformação pelo ensaio de tração. Já o valor $n$ foi calculado pela forma logarítmica da equação de Hollomon, EQUAÇÃO 3.4, utilizando os dados de tensão e deformação logarítmicas do intervalo de deformação de 10 a $18 \%$. Em cada amostra descrita na TAB. 4.7, realizaram-se seis ensaios de $\mathrm{R}$ e $n$.

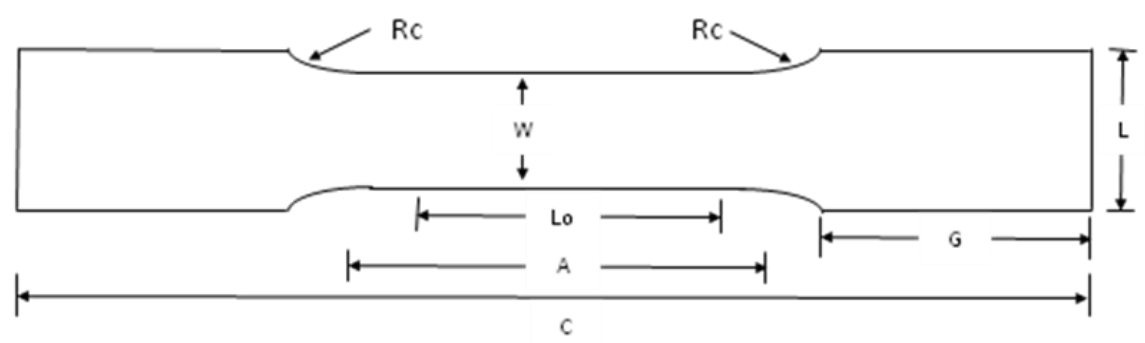

FIGURA 4.15 - Corpo de prova e suas dimensões para o teste de tração, R e $n$ [13]

TABELA 4.7 - Dimensão do corpo de prova do ensaio de tração, R e $n$

\begin{tabular}{c|c|c|c|c|c|c}
\hline \multicolumn{7}{c}{ Dimensões (mm) } \\
\hline $\mathrm{L}_{\mathrm{o}}$ & $\mathrm{A}$ & $\mathrm{C}$ & $\mathrm{W}$ & $\mathrm{R}_{\mathrm{c}}$ & $\mathrm{L}$ & $\mathrm{G}$ \\
\hline $80 \pm 0,35$ & 115 a 130 & $\geq 250$ & $20 \pm 1,0$ & $\geq 20$ & 30 & $\geq 50$ \\
\hline
\end{tabular}

A espessura dos corpos de prova para os testes realizados é a que se obteve na chapa após cada processo. Na média, todos os CPs apresentaram uma espessura de 0,75 mm com um intervalo de incerteza de $0,03 \mathrm{~mm}$. 


\subsubsection{Ensaio Erichsen}

No desenho esquemático da FIG. 4.16 dos ensaios Erichsen, foi realizado de acordo com método Erichsen Modificado, descrito na norma NBR 5902:1980, consistiu em deformar - à temperatura ambiente, com um penetrador provido de uma ponta esférica - um corpo de prova, preso entre uma matriz e um anel de fixação, até ocorrer à queda na carga impressa pelo punção no $\mathrm{CP}$, quando este começa a romper. Nesse momento, determinou-se a profundidade da calota produzida via medidor automático acoplado à máquina Erichsen modelo 142/20. Os corpos de prova foram obtidos de uma amostra de 300x100 $\mathrm{mm}^{2}$ retirada no sentido transversal da laminação, a 1/4 da largura chapa.

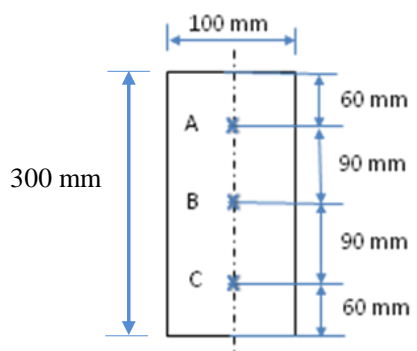

FIGURA 4.16 - Desenho esquemático da amostra dos ensaios Erichsen A, B e C [12]

\subsubsection{Determinação da textura cristalográfica}

As análises de textura realizadas em amostras de $50 \times 50 \mathrm{~mm}^{2}$ foram retiradas no centro da largura da chapa e na direção de Laminação. Foi realizada inicialmente a análise superficial das amostras, garantindo a avaliação da camada encruada. Nesta etapa, não foi realizada qualquer tipo de lixamento. Em seguida, foi analisado o centro das amostras, para tal foi realizado o lixamento até a metade da espessura, ou seja $0,38 \mathrm{~mm}$ de desbaste com lixas de granulometria a partir de 100 até 1200 mesh, sucessivamente, para garantir a planicidade. Em seguida, as amostras foram submetidas a ataque químico em solução de 5\% HF e 95\% de $\mathrm{H}_{2} \mathrm{O}$, para a remoção de deformações induzidas pelo lixamento. A determinação das 
texturas foi amostrada das etapas após o encruamento e na relaminação com os graus de redução de $0,2 \%, 0,4 \%, 0,6 \%, 0,8 \%$ e $1,0 \%$. Estes ensaios foram realizados para os pontos $\mathrm{A}$ e B da FIG. 4.16.

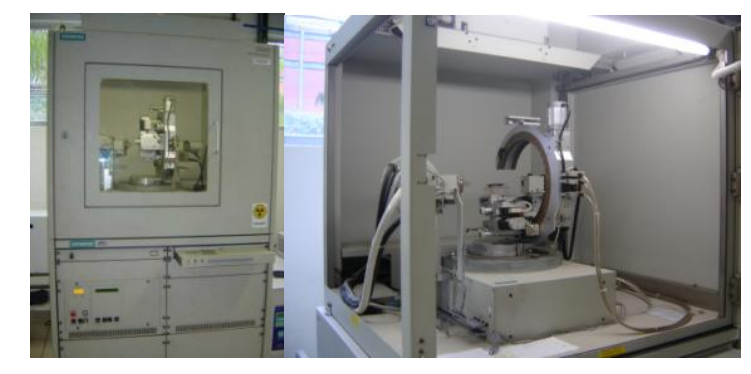

FIGURA 4.17 - Difratômetro de raios-X [58]

A textura cristalográfica medida por difração de raios-X, utilizando o Difratômetro D5000, fabricado pela Siemens, conforme FIG. 4.17. Foram levantadas as Figuras de pólo dos planos (110), (200) e (222), pelo método de reflexão de Schulz. Com base nas Figuras de pólo medidas, foram calculadas as Figuras de ODF. A configuração instrumental utilizada durante os ensaios:

- Configuração: $\theta-2 \theta, \varphi: 0$ a $70^{\circ}, \varphi: 0^{\circ}$ a $360^{\circ}$

- Fenda de Schulz, filtro de Zr

- Potência: $40 \mathrm{KV}$ e $40 \mathrm{~mA}$

\subsubsection{Impressão dos círculos}

A impressão de círculos é a primeira etapa da preparação dos CPs a serem estampados para levantamento da CLC. Para a leitura das deformações, foi utilizado o leitor Camsys do laboratório de materiais. O processo de gravação dos círculos se iniciou com o desengraxe da área do corpo de prova por uma solução de limpeza, seguido de uma solução inibidora de corrosão $\left(\mathrm{H}_{3} \mathrm{PO}_{4}\right.$ a $\left.10 \%\right)$ para evitar a sua oxidação após o processo de marcação. Após isto, 
foram gravados eletroquimicamente círculos tangenciais com um diâmetro de 2,0 mm, por meio de processo eletroquímico, conforme FIG. 4.18.

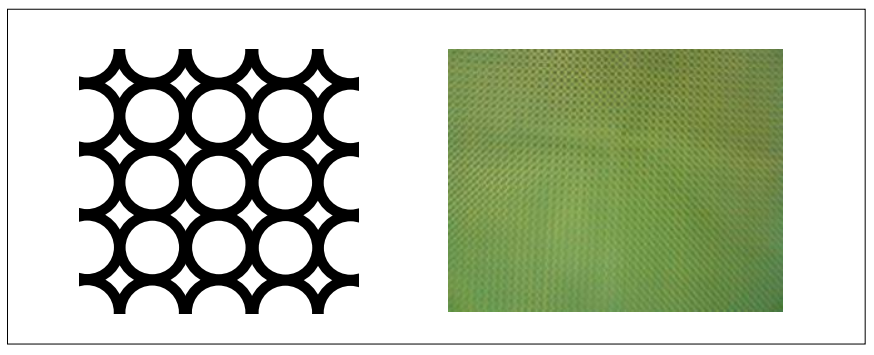

FIGURA 4.18 - Rede de círculos tangenciais e tela semi-impermeável utilizada [58]

A fim de se obter um ataque seletivo, utilizou-se uma tela semi-impermeável (stencil), que foi colocada sobre a chapa. Em seguida através de um retificador e um eletrólito apropriado promoveu-se a eletrólise, limpou-se o eletrólito do corpo de prova, neutralizando-o com solução de bicarbonato de sódio a $20 \%$. Finalmente fez-se a secagem e a proteção da superfície gravada com óleo de proteção contra corrosão. A escolha dos círculos tangenciais de diâmetro de 2,0 mm representou um compromisso entre a boa precisão na medida da deformação e presença de um número razoável de círculos impressos que permitiu uma avaliação confiável.

\subsubsection{Preparação e ensaio dos corpos de prova para curva CLC}

Os corpos de prova foram preparados nas dependências do Centro de Testes Mecânicos da Usiminas-Cubatão, obedecendo aos modelos similares aos ensaios de Nakazima, ou seja, os corpos de prova são retangulares, com comprimento constante e igual a $220 \mathrm{~mm}$ e larguras variando: 220,175, 140, 130, 120, 110, 100, 80 e 50 mm na FIG. 4.19, sendo que a aresta da menor dimensão coincide com a direção de laminação. Variando-se a largura do corpo de prova, pode-se variar a restrição lateral, isto é, a quantidade de material que é permitido fluir para o interior da matriz, na direção da largura, conforme FIG. 4.20. 


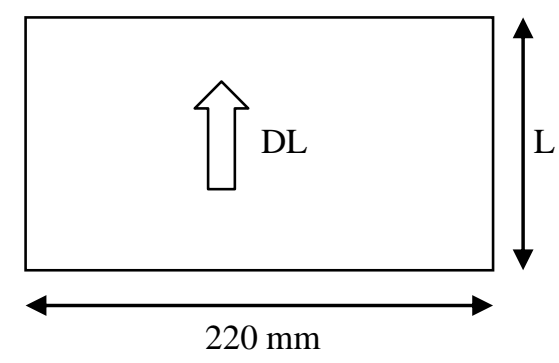

FIGURA 4.19 - Desenho esquemático dos corpos de prova [46]

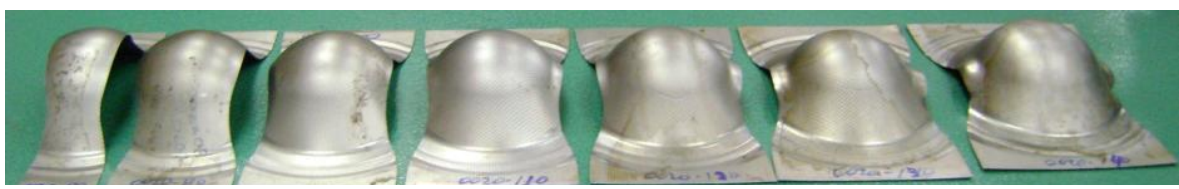

FIGURA 4.20 - Diferentes geometrias de Corpos de Prova [46]

Foi utilizada a máquina de estampagem Erichsen do Centro de Teste Mecânicos da USIMINAS-Cubatão conforme FIG. 4.21, onde as forças foram testadas segundo algumas variáveis, tais como: altura do domo, velocidade do punção, temperatura do óleo, etc. Inicialmente, os corpos de prova sofreram lubrificação com graxa grafitada, para que houvesse a formação de um filme entre o material e o punção, com raio de $100 \mathrm{~mm}$, e desta forma, o arraste de material por atrito ser o mínimo possível. Após o início da estricção, o ensaio é paralisado e a máquina é descarregada.

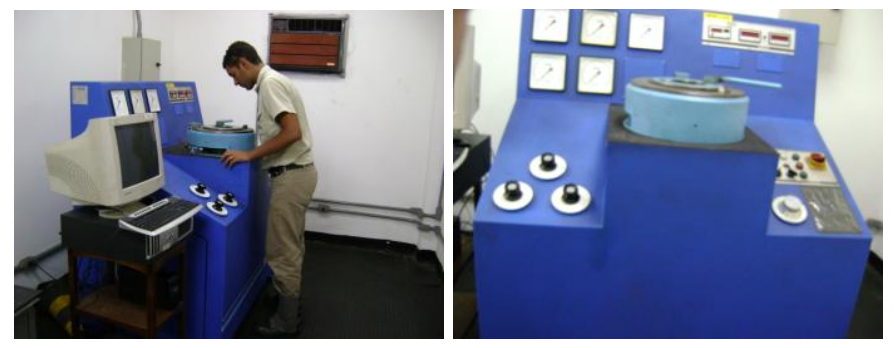

FIGURA 4.21 - Ilustração da máquina de estampagem Erichsen [58] 


\subsubsection{Medição das deformações principais}

A rede de círculos após deformações principais coincidirão sempre com os eixos maior e menor da elipse que se forma no estágio de conformação em questão. Durante a conformação a rede de círculos deforma-se, convertendo-se em uma rede de elipse, função do estado de deformação dado. Isto pode ser visto esquematicamente na FIG. 4.22, para uma rede de círculos onde se mostra o caso em que duas deformações principais são positivas situações mais próximas do estiramento, e o caso onde uma deformação é positiva FIG. 4.22(a), e outra é negativa FIG. 4.22(b) situação próxima da estampagem profunda.

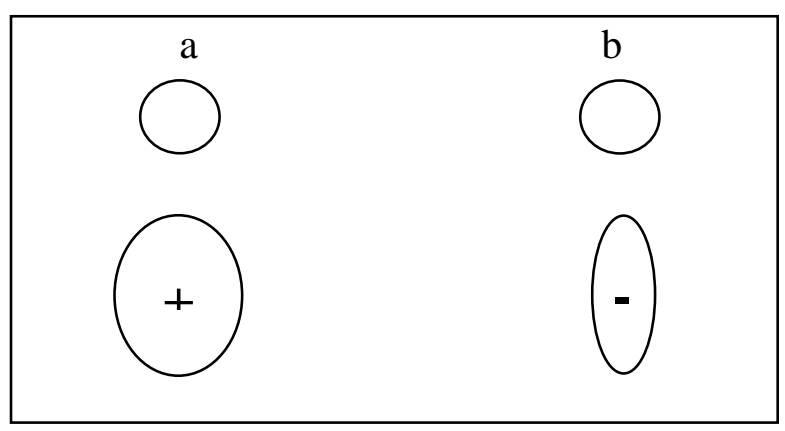

(a) Situação de carregamento tração-tração - Estiramento

(b) Situação de carregamento tração-compressão - Estampagem profunda

FIGURA 4.22 - Esquemático de círculos originais e elipses após estampagem [58]

Após o registro das leituras, foram determinadas as deformações críticas nas amostras. Para cada peça-exemplo, foram feitas medidas dos eixos maior e menor, em aproximadamente dez elipses, obtendo-se a seguir as deformações principais correspondentes. Considerando $\mathrm{D}_{\mathrm{o}}$ como o diâmetro original da rede de círculos, que no caso foi de $2,0 \mathrm{~mm}$, as duas deformações principais: maior e menor, para cada elipse medida, são obtidas a partir da equação de deformação real $(\varepsilon)$ : 
$\varepsilon=\ln \frac{L}{L_{0}}$

Portanto, as equações das deformações principais (maior e menor), são dadas por:

$$
\begin{aligned}
& \varepsilon=\ln \frac{D_{1}}{D_{0}} \quad \text { (Deformação maior) } \\
& \varepsilon=\ln \frac{D_{2}}{D_{0}} \quad \text { (Deformação menor) }
\end{aligned}
$$

\subsubsection{Levantamento da CLC}

É comum ter-se uma razoável dispersão dos resultados, necessitando assim de um tratamento estatístico dos mesmos, com a necessidade de se determinar um valor razoável de réplicas de um mesmo ensaio. A técnica de medição da deformação localizada descrita por Ghosh e Hecker [56] se resume em efetuar as medições das deformações (maior e menor) sobre a chapa previamente gravada com círculos (gravação eletroquímica) e levada até a fratura. A medição é efetuada na região adjacente a região de deformação localizada conforme FIG. 4.23.
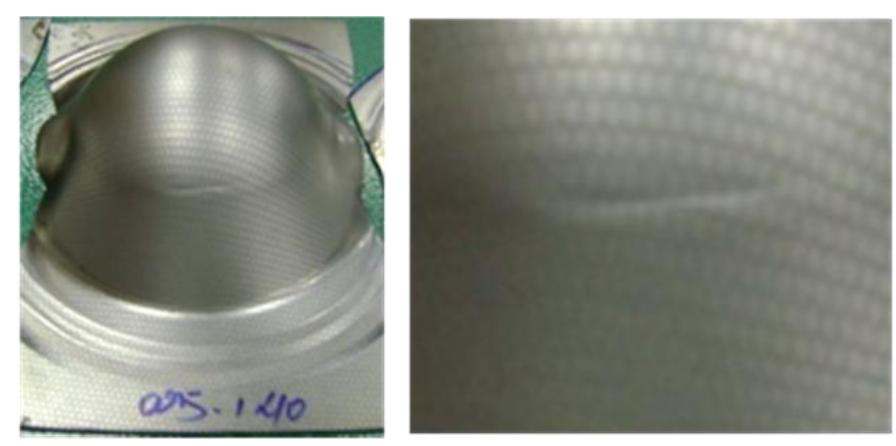

FIGURA 4.23 - Corpo de prova com rede de círculos (estricção) [56] 
Na FIG. 4.24 é apresentado o analisador de imagens CAMSYS foi calibrado apresentando alguma deformação nos círculos teoricamente perfeitos (por volta de 2,5 de diferença no cálculo do $\varepsilon$ ).

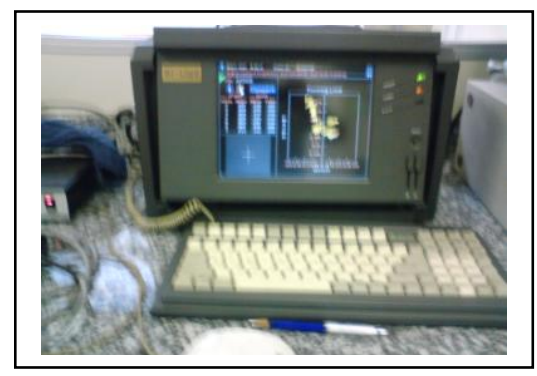

FIGURA 4.24 - Equipamento de medição das deformações - CAMSYS [58]

\subsubsection{Margem de segurança da CLC}

A FIG. 4.25 apresenta o caminho da deformação, a região da zona de falha (parte superior da CLC) e zona de seguranca (parte inferior da CLC). Dentro da zona de segurança é possive verificar a margem de segurança da CLC (linha vermelha pontilhada).

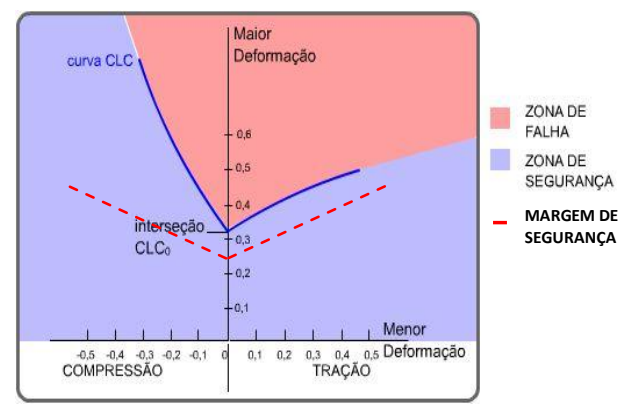

FIGURA 4.25 - Margem de segurança da Curva Limite de Conformação (CLC) [57]

A definição da margem de segurança da CLC é importante e necessário quando se está construindo a curva de deformação. Esta margem permite avaliar a regiões criticas e seus respectivos limites dentro da zona de segurança, a partir da qual poderá haver alta probabilidade de falha no material durante o processo de estampagem ou estiramento. 


\subsection{Cálculo do Intervalo de Incerteza das medidas}

Devido ao fato de ocorrerem valores medidos bem diferentes da média de um total de seis valores para a mesma condição de LE e do valor de R, optou-se em determinar o intervalo de incerteza para essas medidas através da seguinte metodologia:

- excluiu-se o maior e o menor valor medido;

- calculou-se o Desvio Padrão (DPa) conforme EQUAÇÃO 4.4, que é a variação de incerteza das medidas.

Também foram excluídos os resultados de LR e AL, correspondente ao ensaio em que se obteve o maior e o menor valor de LE. Da mesma forma, excluem-se os valores $R_{90}, R_{45}$ e $\mathrm{R}_{0}$ e, conseqüentemente, o $\Delta \mathrm{R}$, quando se excluiu o maior e o menor valor de $\mathrm{R}$. Além disso, como os valores $\mathrm{n}_{90}, \mathrm{n}_{45}$ e $\mathrm{n}_{0}$ são obtidos do mesmo $\mathrm{CP}$ em que se mediram o $\mathrm{R}_{90}, \mathrm{R}_{45}$ e $\mathrm{R}_{0}$, optou-se por excluir esses valores quando eles correspondiam aos valores de $R_{90}, R_{45}$ e $R_{0}$ excluídos.

$\mathrm{Dpa}=\sqrt{\frac{\mathrm{n \sum x^{2 } - ( \sum x ) ^ { 2 }}}{\mathrm{n}(\mathrm{n}-1)}}$

\subsection{Cálculo da Variação Percentual}

Com o intuito de comparar a variação de uma medida com a mesma medida obtida na etapa anterior, calculou-se a variação percentual (VP), utilizando a EQUAÇÃO 4.5.

$$
V P=\left(\frac{y-x}{x}\right) * 100
$$

onde y é a medida obtida da etapa posterior e x é medida da etapa anterior. 


\section{RESULTADOS E DISCUSSÃO}

\subsection{Análise Química}

Com o intuito de confirmar a composição química do aço utilizado, realizaram-se análises químicas de corrida, conforme TAB. 5.1.

TABELA 5.1 - Composição química do aço IF-Ti

\begin{tabular}{|c|c|c|c|c|c|c|c|c|c|}
\hline \multicolumn{10}{|c|}{ Composição Química (\% em peso) } \\
\hline $\begin{array}{c}\text { Amostra do } \\
\text { distribuidor }\end{array}$ & $\mathbf{C}$ & $\mathbf{M n}$ & $\mathbf{P}$ & $\mathbf{S}$ & $\mathbf{A l}$ & $\mathbf{T i}$ & $\mathbf{N b}$ & $\mathbf{N}$ & $\mathbf{T i}^{*}$ \\
\hline $\mathbf{0 7 3 3 5 1}$ & 0,0039 & 0,1242 & 0,0106 & 0,0063 & 0,0349 & 0,0602 & 0,0004 & 0,0023 & 0,020 \\
\hline $\mathbf{0 7 3 3 5 2}$ & 0,0038 & 0,1240 & 0,0106 & 0,060 & 0,0345 & 0,599 & 0,0003 & 0,0021 & 0,018 \\
\hline
\end{tabular}

\subsection{Microestrutura}

As TAB. 5.2 a 5.3 mostram os valores médios do tamanho de grão, o intervalo de incerteza dessa medida e a variação percentual do tamanho de grão do material BRE em relação ao material BPE.

TABELA 5.2 - Tamanho de grão das amostras BPE e BRE

\begin{tabular}{|c|c|c|c|}
\hline \multicolumn{2}{|c|}{ Amostra } & \multicolumn{2}{c|}{ Tamanho de grão } \\
\hline \multicolumn{1}{|c|}{ Bobina 073351 } & ASTM & VP (\%) \\
\hline \multirow{2}{*}{ BPE } & $8,0 \pm 1,0$ & - \\
\hline \multirow{4}{*}{ BRE } & BRE02 & $8,3 \pm 1,0$ & $3,8 \%$ \\
\cline { 2 - 4 } & BRE04 & $8,2 \pm 1,9$ & $-1,2 \%$ \\
\cline { 2 - 4 } & BRE06 & $8,4 \pm 0,7$ & $2,4 \%$ \\
\cline { 2 - 4 } & BRE08 & $8,5 \pm 0,9$ & $1,2 \%$ \\
\cline { 2 - 4 } & BRE10 & $8,2 \pm 0,8$ & $-3,5 \%$ \\
\hline
\end{tabular}


TABELA 5.3 - Tamanho de grão das amostras BPE e BRE

\begin{tabular}{|c|c|c|c|}
\hline \multicolumn{2}{|c|}{ Amostra } & \multicolumn{2}{c|}{ Tamanho de grão } \\
\hline \multirow{2}{*}{ Bobina 073352 } & ASTM & VP(\%) \\
\hline \multirow{2}{*}{ BPE } & $8,0 \pm 0,8$ & - \\
\hline \multirow{4}{*}{ BRE } & BRE02 & $8,3 \pm 0,9$ & $3,8 \%$ \\
\cline { 2 - 4 } & BRE04 & $8,0 \pm 1,0$ & $-3,6 \%$ \\
\cline { 2 - 4 } & BRE06 & $8,2 \pm 0,8$ & $2,5 \%$ \\
\cline { 2 - 4 } & BRE08 & $8,4 \pm 1,0$ & $2,4 \%$ \\
\cline { 2 - 4 } & BRE10 & $8,2 \pm 0,7$ & $-2,4 \%$ \\
\hline
\end{tabular}

Verificou-se nas tabelas que, os valores médios do tamanho de grão variaram em torno de 8 ASTM $(22,5 \mu \mathrm{m})$ e não houve variação significativa na condição após a relaminação em relação à BPE. Além disso, a incerteza de medição sugere que a variação obtida nos materiais não é significativa. Assim, acredita-se que não houve variação do tamanho de grão causada pelos graus de redução durante o encruamento nas respectivas bobinas.

\subsubsection{Micrografia das bobinas}

As FIG. 5.1 a 5.6 mostram as micrografias das bobinas 073351 e 073352 na condição de Bobina Produto Encruada (BPE) e da Bobina Relaminada Encruada (BRE). Sendo que a faixa inferior escura corresponde a uma das superfícies da amostra.

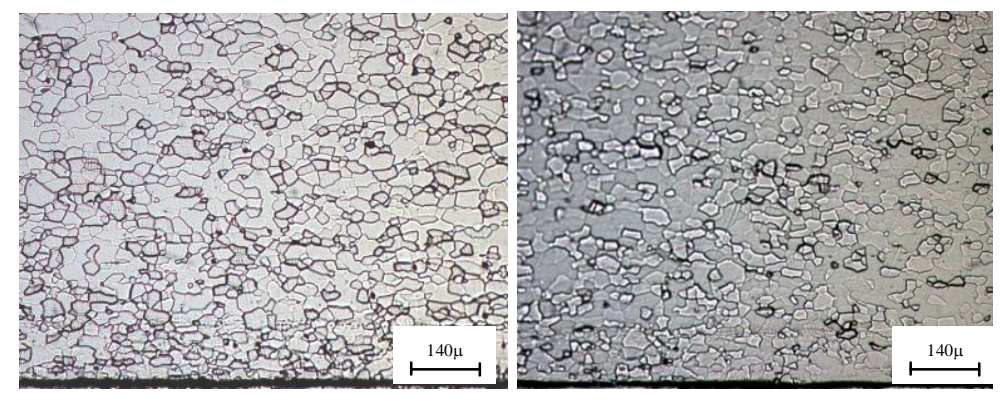

FIGURA 5.1- Microestrutura relaminação BRE10 


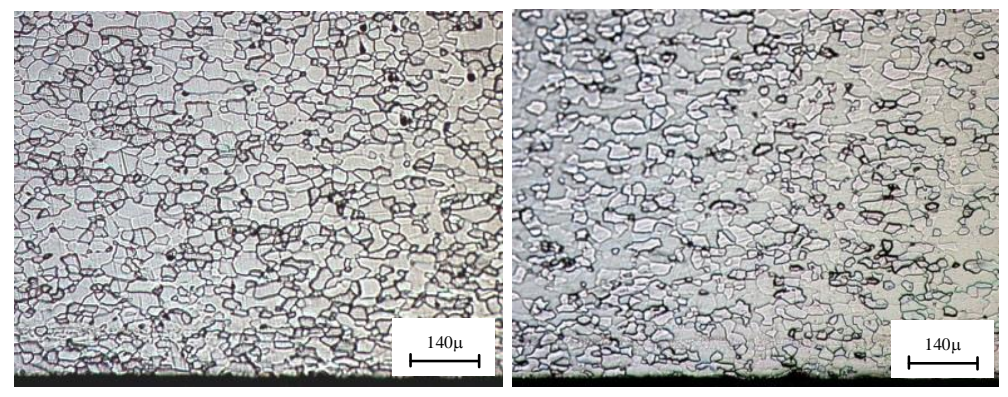

FIGURA 5.2 - Microestrutura relaminação BRE08
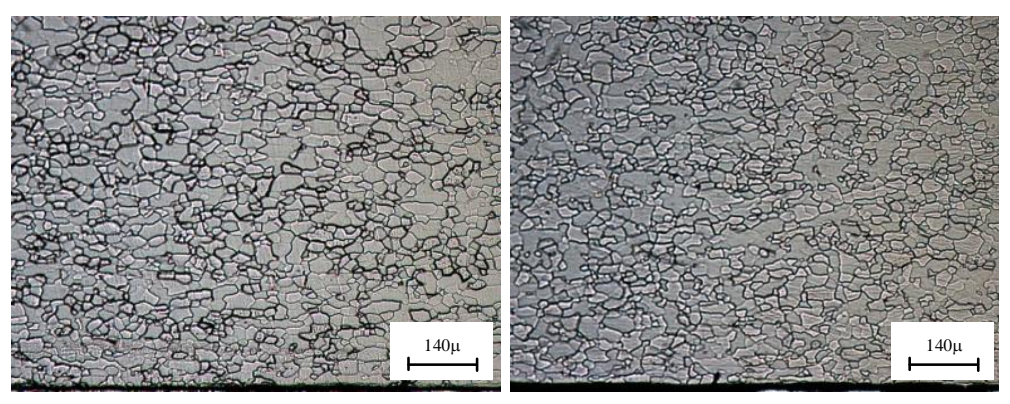

FIGURA 5.3 - Microestrutura relaminação BRE06
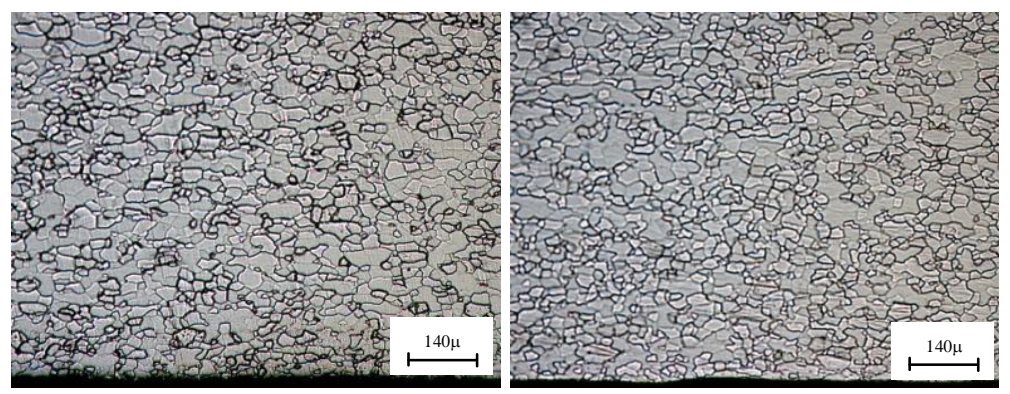

FIGURA 5.4 - Microestrutura relaminação BRE04
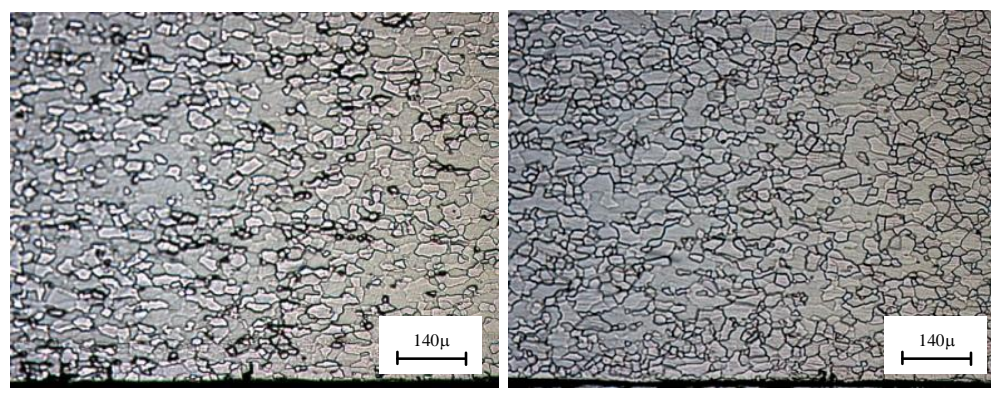

FIGURA 5.5 - Microestrutura relaminação BRE02 

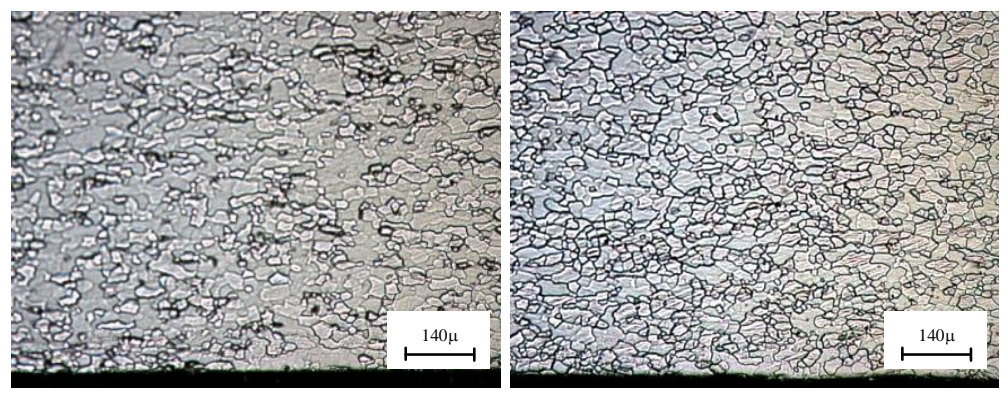

FIGURA 5.6 - Microestrutura sem relaminação BPE

Nas micrografias das amostras, pode-se verificar que se trata de uma estrutura típica de aços

IF totalmente recristalizada, isto é, com grãos ferríticos fracamento panquecados. Além disso, as micrografias mostram grãos com tamanhos semelhantes ao longo das etapas da bobina.

\subsection{Textura}

A textura do aço IF em estudo medidos na condição BPE e BRE medidos na superfície e no centro das amostras (metade da espessura) por difração de raios-X das respectivas bobinas 073351 e 073352, conforme FIG. 5.7.
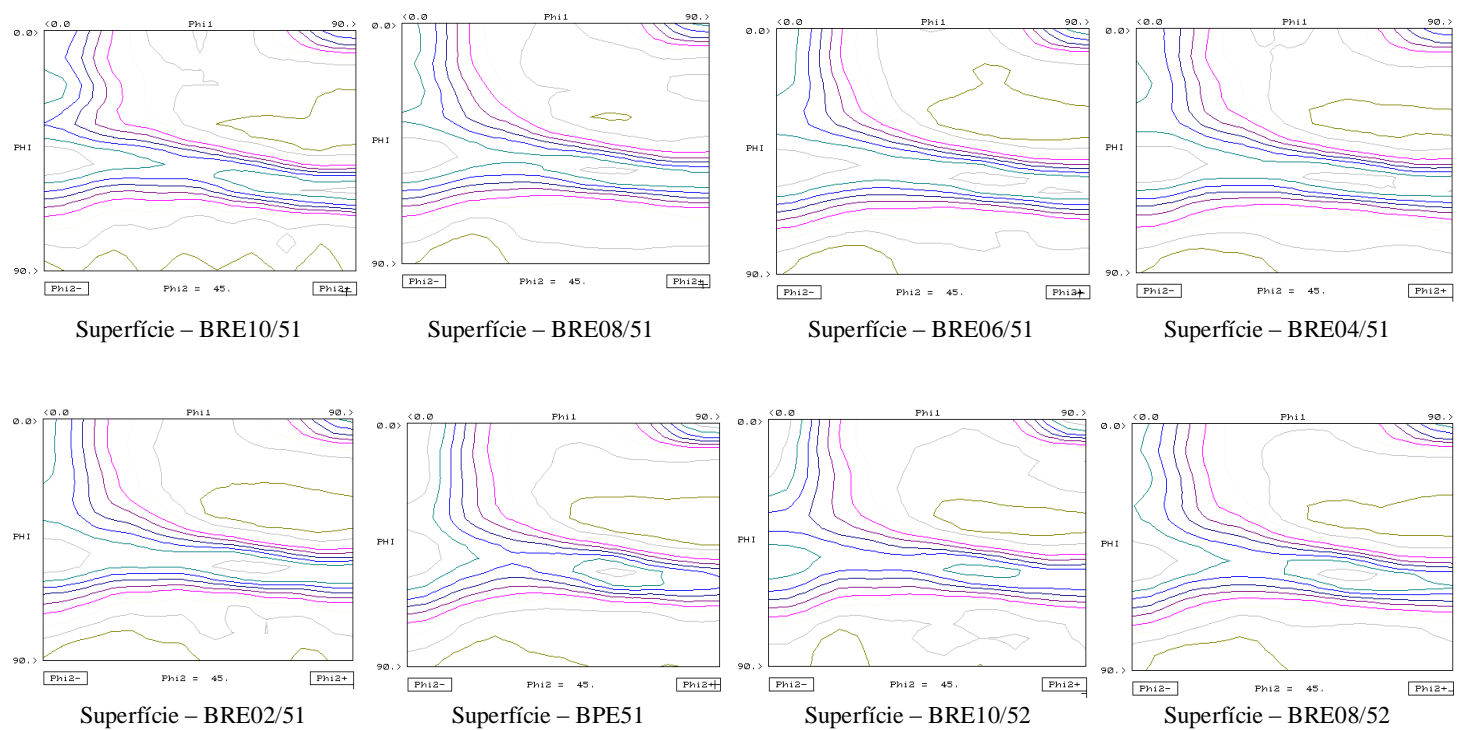

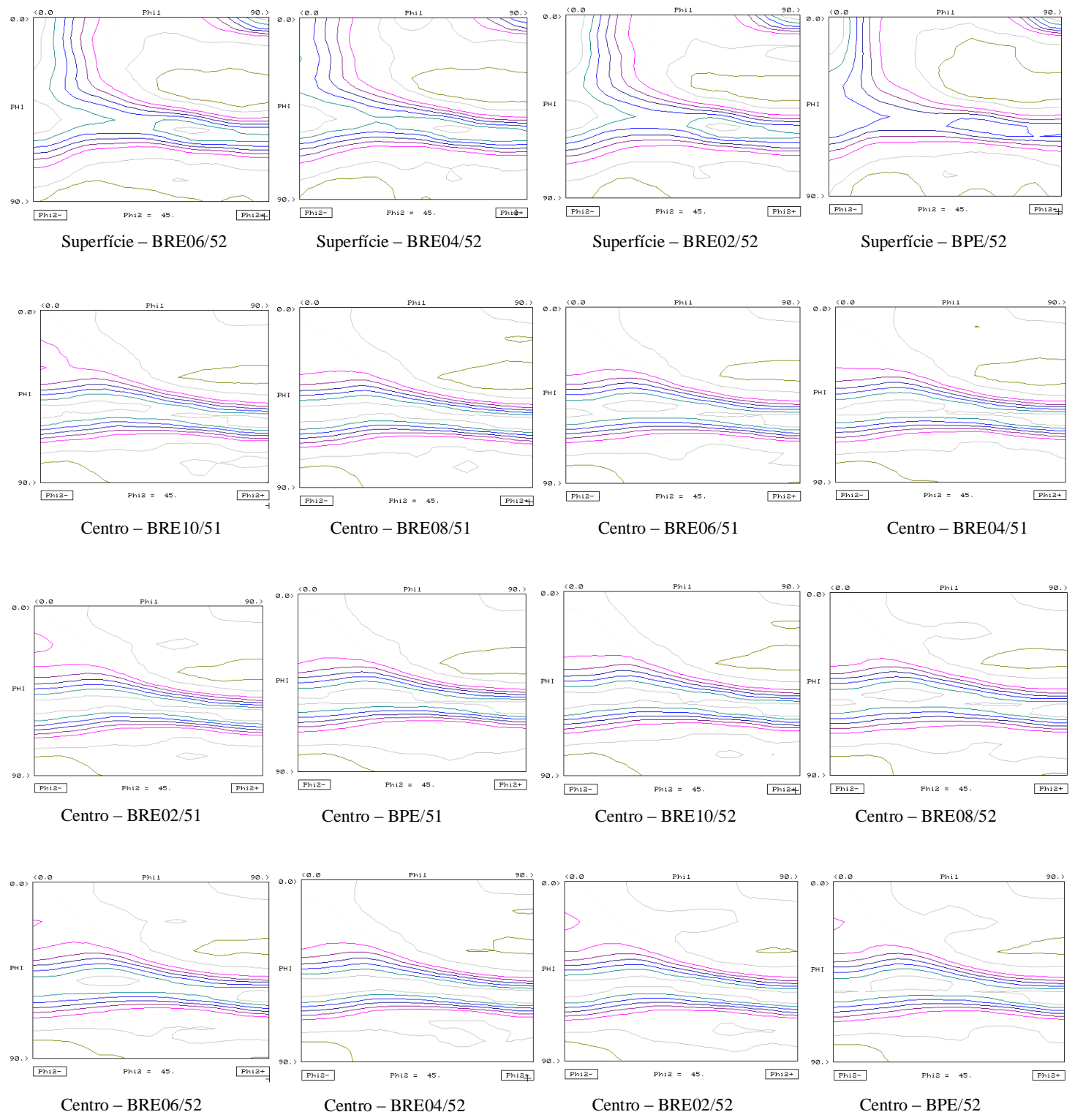

FIGURA 5.7 - ODF nas regiões superficial e central das condições BPE e BRE

Os resultados da textura do aço IF em estudo medidos na condição BPE e BRE, medidos na superfície das amostras com destaque a intensidade de orientação, estão conforme FIG. 5.8. 

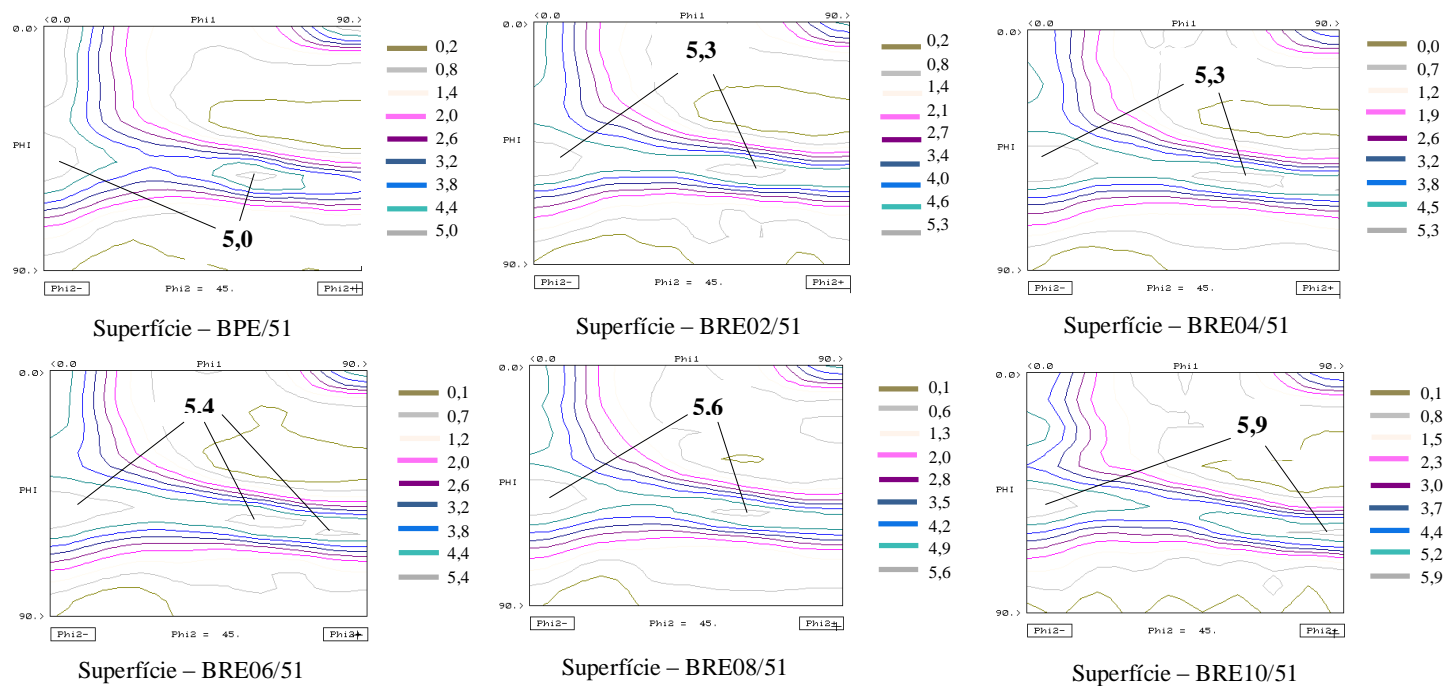

FIGURA 5.8 - Nível de intensidade nas ODF na região superficial

Os resultados da textura do aço IF em estudo medidos na condição BPE e BRE, medidos no centro das amostras com destaque a intensidade de orientação, estão conforme FIG. 5.9.
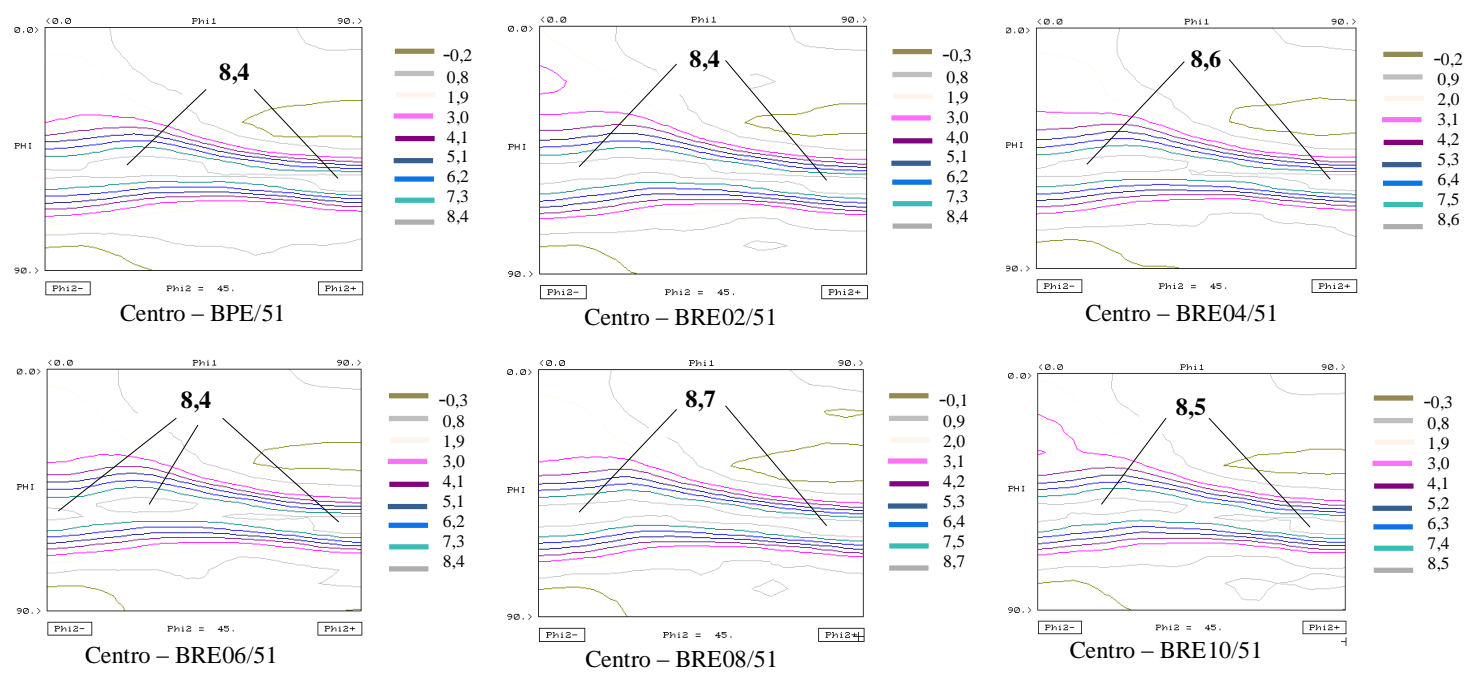

FIGURA 5.9 - Nível de intensidade nas ODF na região central

A aplicação de quantidades distintas de taxa de redução até um limite máximo de $1 \%$ em um material IF processado no recozimento em caixa, não produziu alterações significativas nas texturas cristalográficas da região central das figuras apresentadas. Entretanto, a intensidade 
da textura obtida na região superficial é bastante diferente daquela observada no material na região central.

Enquanto que na região sem encruamento a textura é típica de aços IF recristalizados destinados a estampagem, ou seja, com forte predominância da componente $(111)<110>$, na outra a textura se assemelha a de materiais na condição como laminado a frio, onde, além da componente $(111)<110\rangle$, são observadas as componentes $(100)<110\rangle$ e $(112)<110\rangle$. A presença desse segundo grupo de componentes de textura interfere com a estampabilidade e permite explicar eventuais quedas no valor $\mathrm{R}$ de Lankford em materiais encruados, em comparação com aqueles somente recozidos.

\subsubsection{Difração segundo as fibras Gama e Alfa}

As FIG. 5.10 a 5.11 apresentam a intensidade de textura da fibra Gama na Superfície com encruamento adicional.

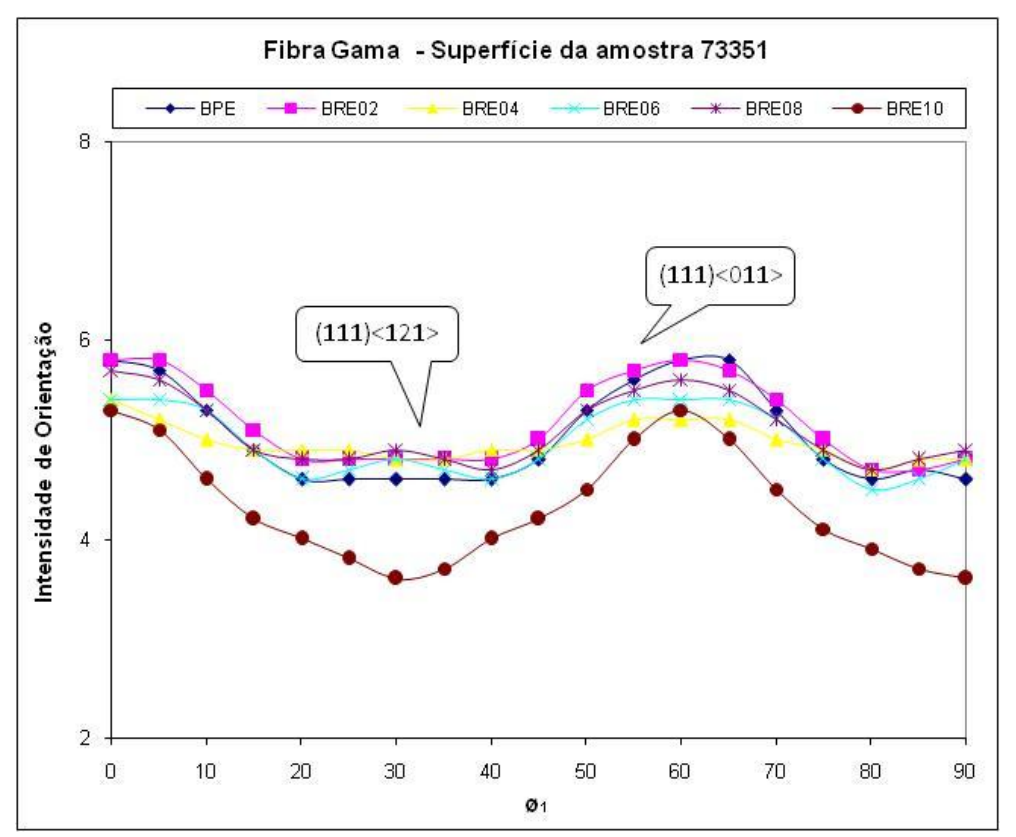

FIGURA 5.10 - ODF ao longo da fibra Gama na superfície da amostra 073351 


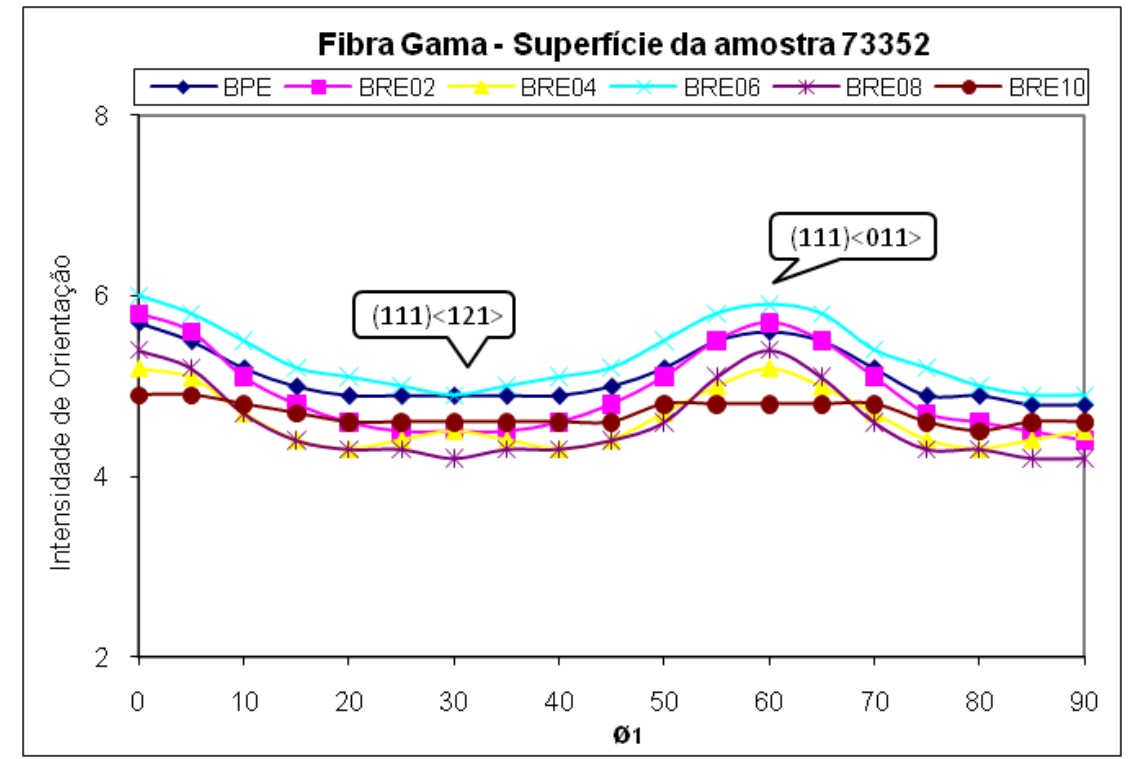

FIGURA 5.11 - ODF ao longo da fibra Gama na superfície da amostra 073352

As FIG. 5.12 a 5.13 apresentam a intensidade de textura da fibra Gama no centro (meio da espessura) com encruamento adicional.

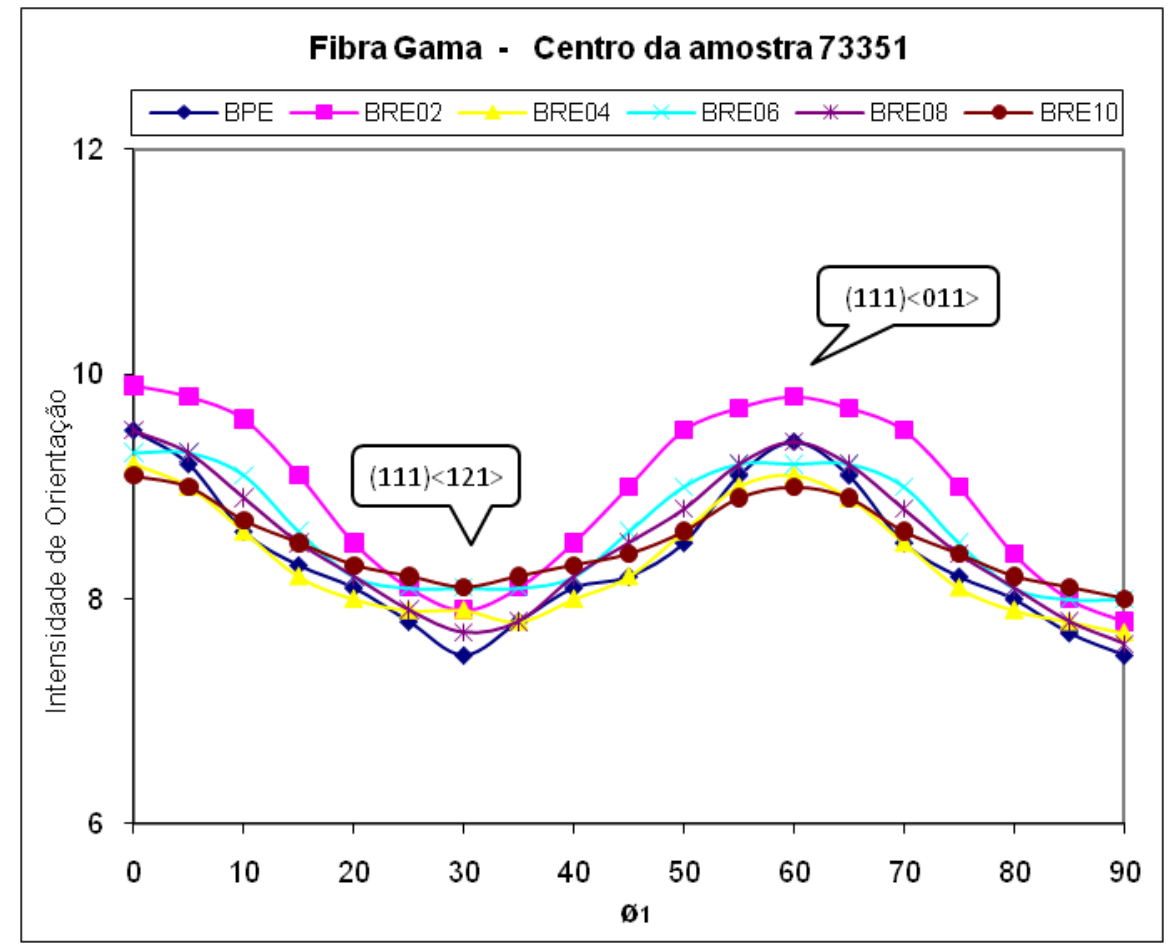

FIGURA 5.12 - ODF ao longo da fibra Gama no centro da amostra 073351 


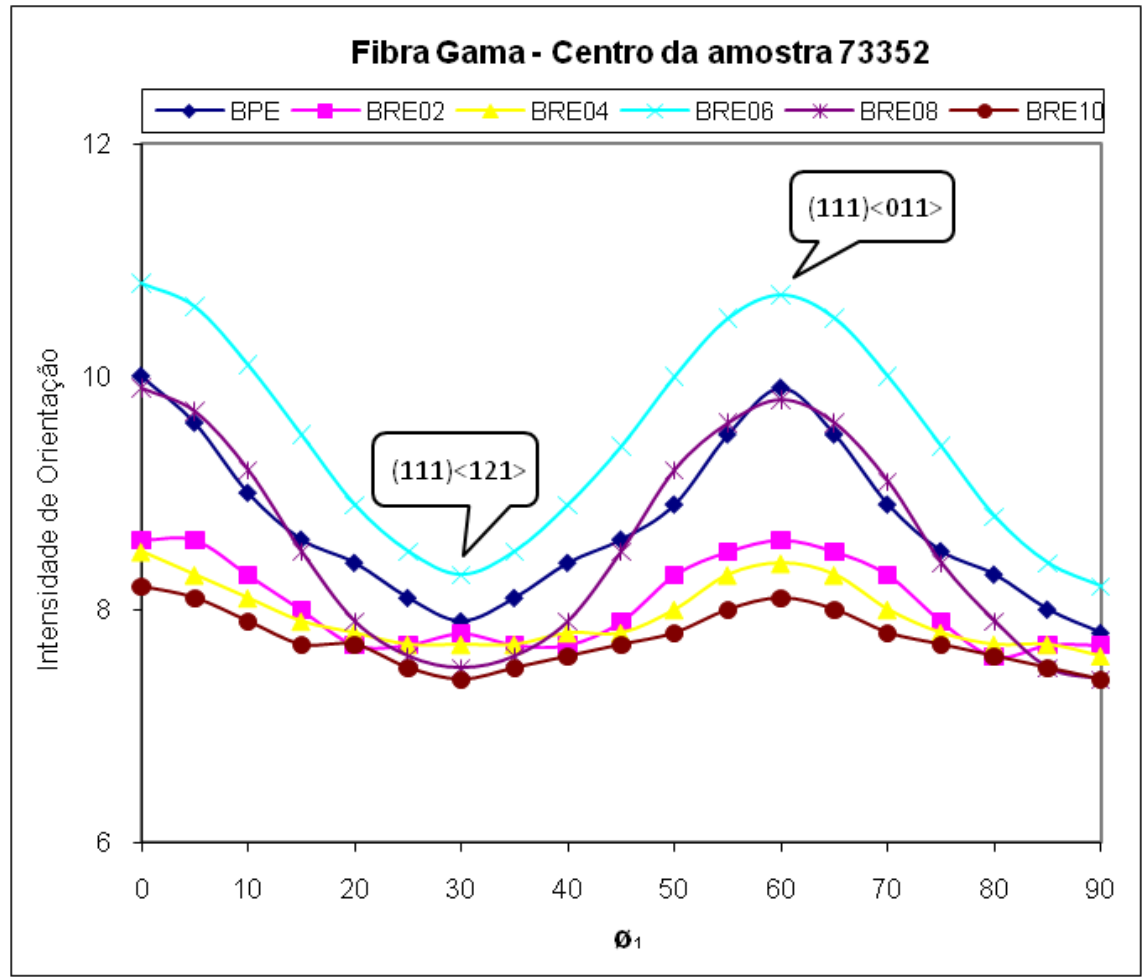

FIGURA 5.13 - ODF ao longo da fibra Gama no centro da amostra 073352

As FIG. 5.14 e 5.15 apresentam a intensidade de textura das fibras Alfa das amostras.

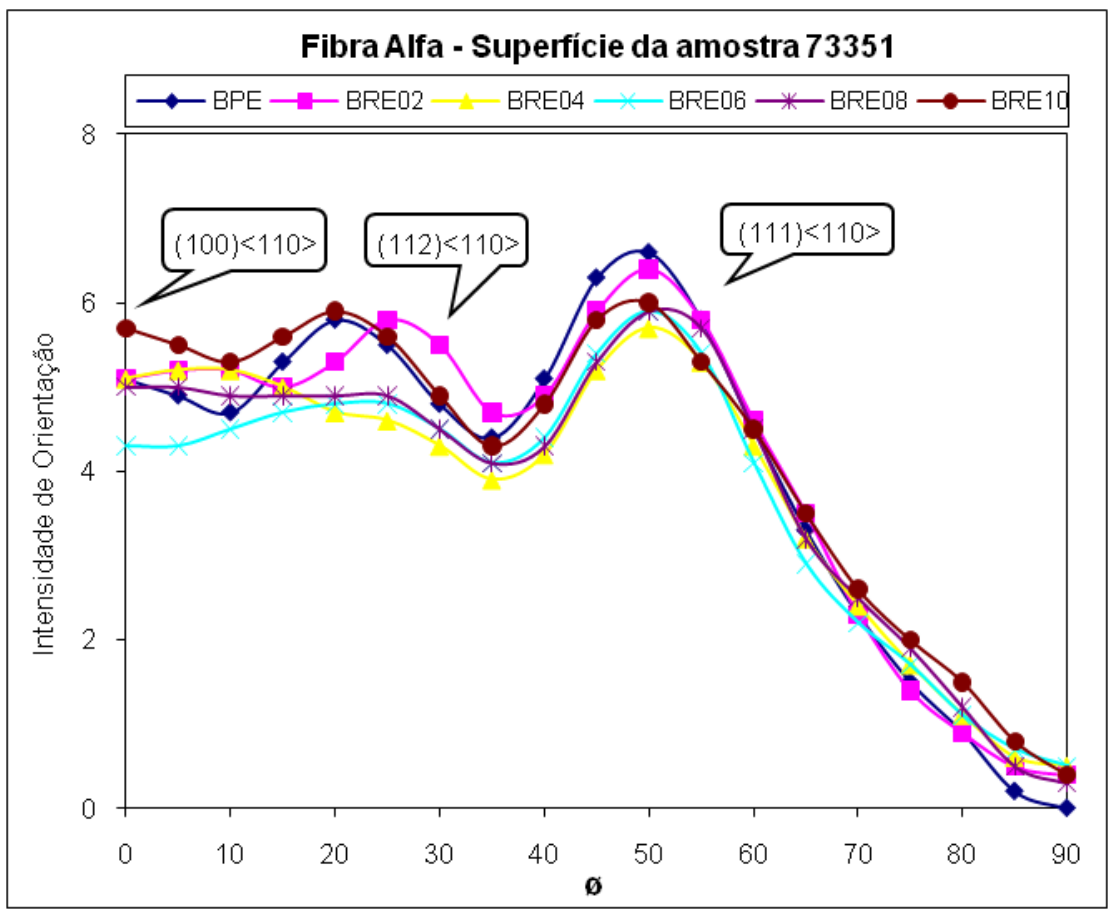

FIGURA 5.14 - ODF ao longo da fibra Alfa na superfície da amostra 073351 


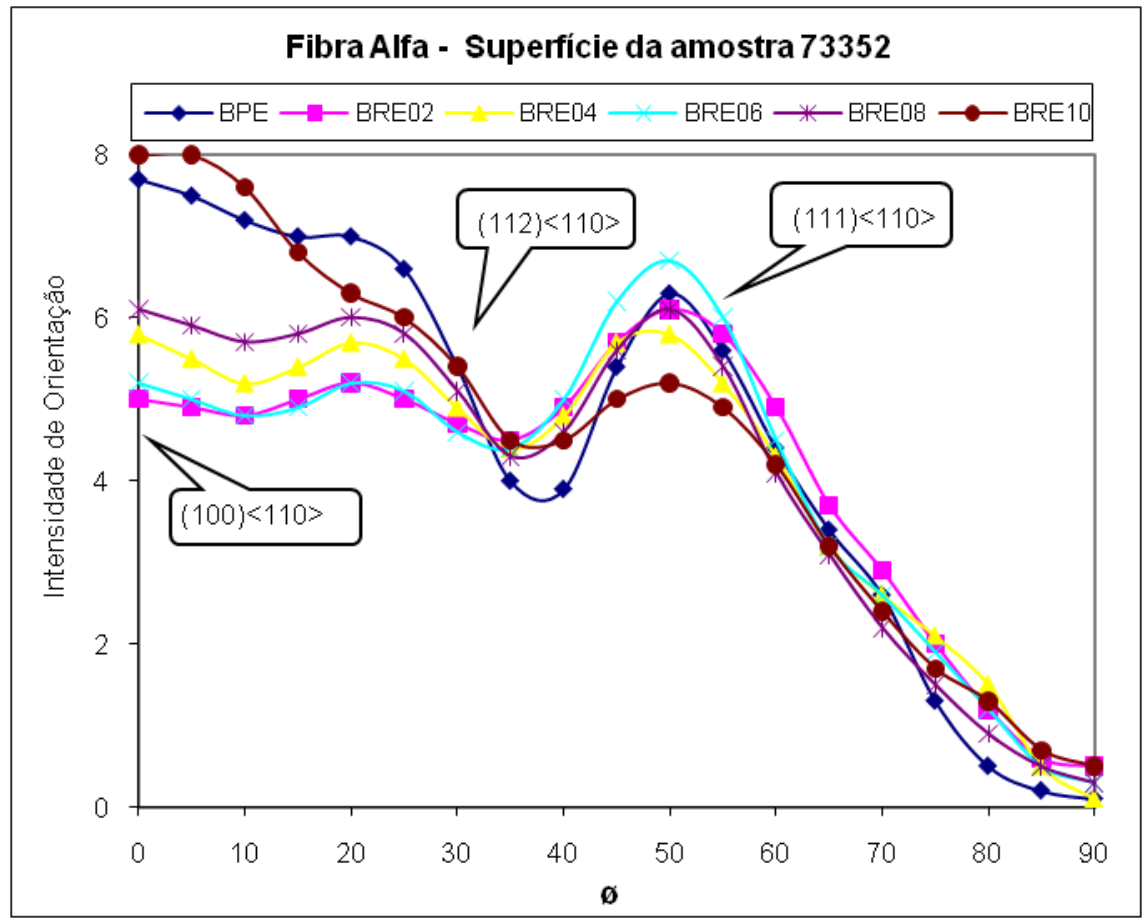

FIGURA 5.15 - ODF ao longo da fibra Alfa na superfície da amostra 073352

As FIG. 5.16 e 5.17 apresentam a intensidade de textura das fibras Alfa das amostras

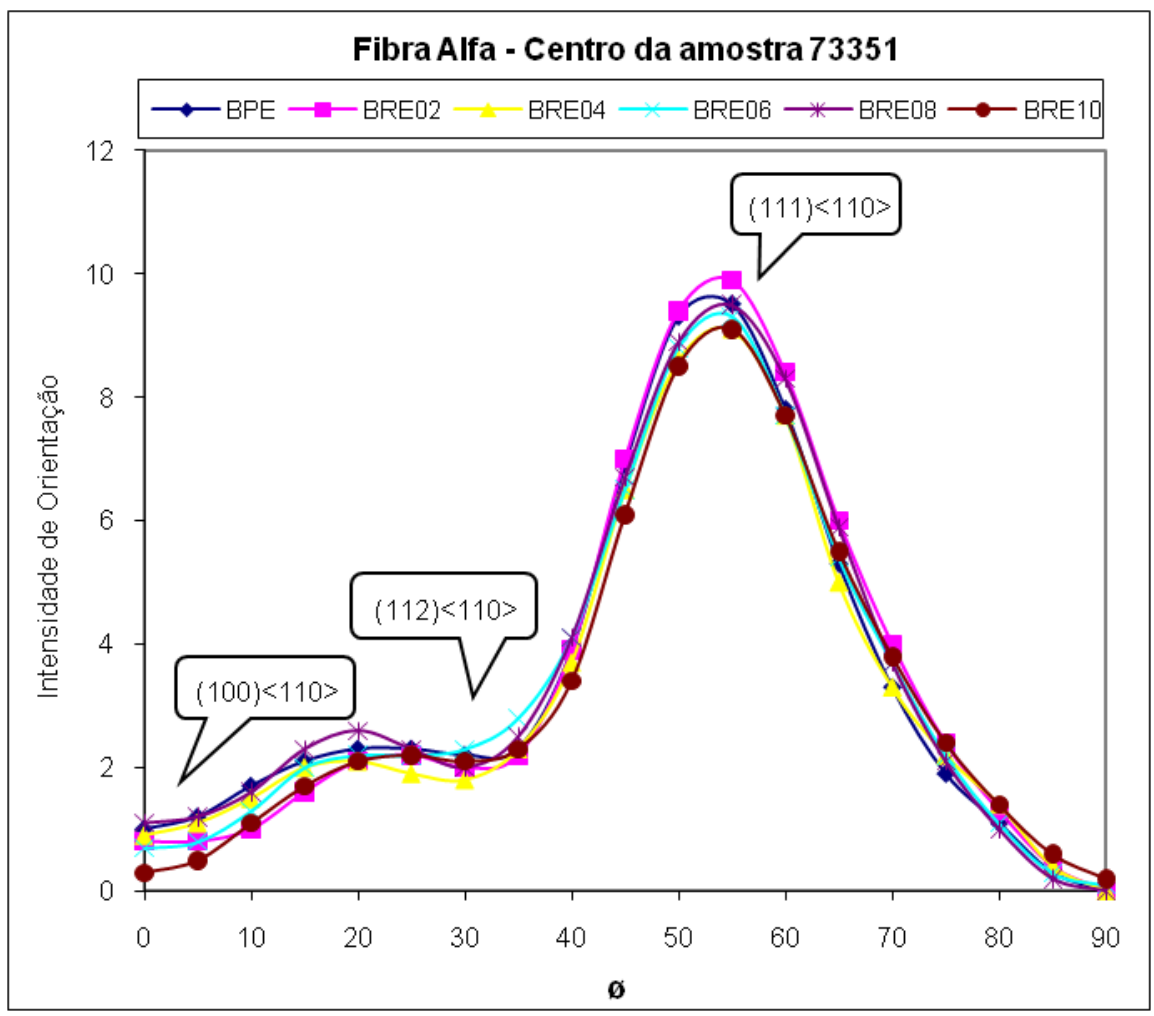

FIGURA 5.16 - ODF ao longo da fibra Alfa no centro da amostra 073351 


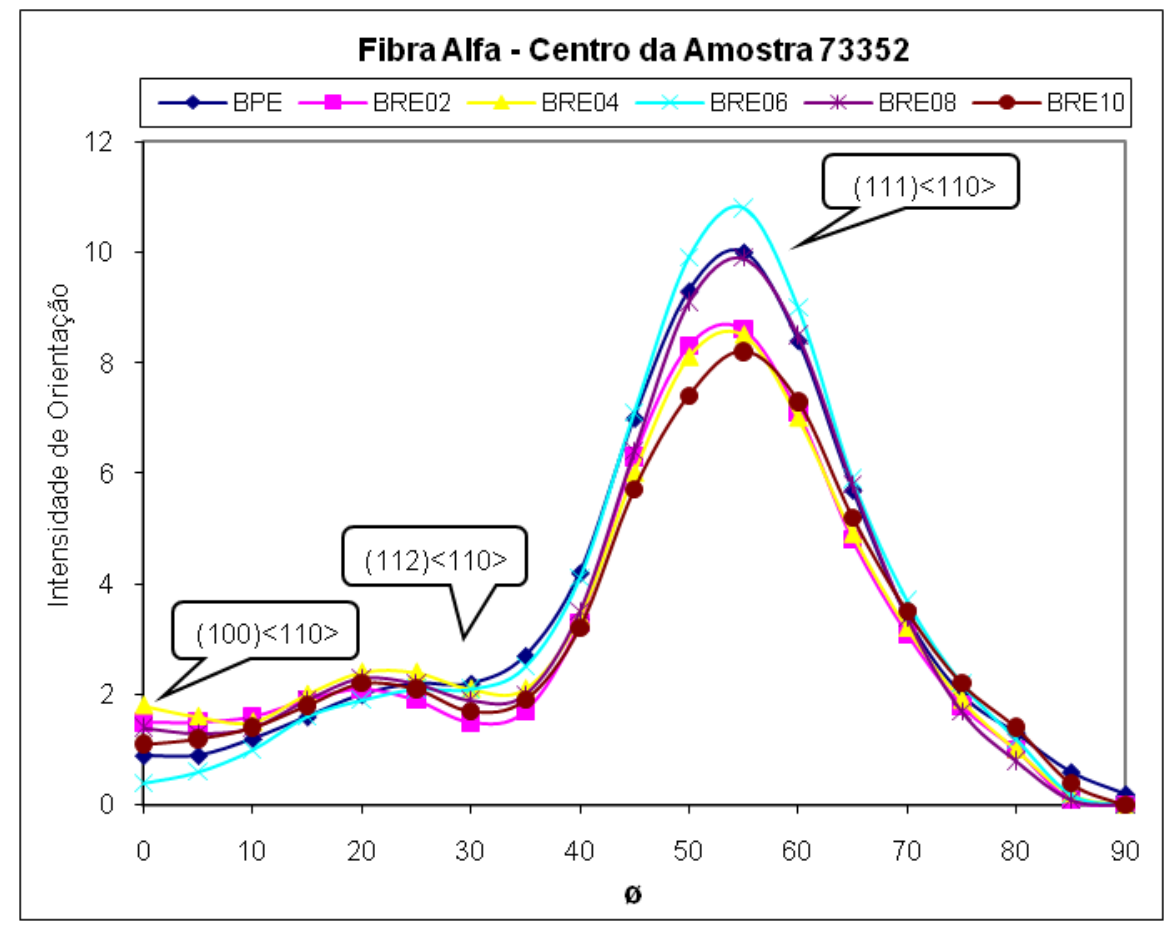

FIGURA 5.17 - ODF ao longo da fibra Alfa no centro da amostra 073352

A análise das Figuras acima, mostra que a intensidade de textura na fibra alfa na superfície, possui uma textura caracterizada pelo forte presença da componente $(111)<110>$. Essa componente é característica de materiais com grande aptidão a estampagem, como é o caso dos aços IF. Quando o encruamento é introduzido, provoca a rotação dos cristais segundo a direção $\langle 110\rangle$ de forma que uma textura $(100)<110\rangle$ e $(112)<110\rangle$ começam a se intensificar, como se vê nas FIG. 5.14 e 5.15 referentes à fibra Alfa na superfície. Essas texturas, principalmente a $(100)<110>$ são extremamente prejudiciais para estampagem. Costuma-se dizer que materiais com grande aptidão a estampagem possuem forte presença de textura $\{111\}<u v w>$ e ausência de textura $\{100\}<u v w>$.

Os resultados sugerem que a laminação de encruamento tende a produzir na superfície da chapa recozida uma textura similar aquela do material na condição como laminado a frio. Isso explica de certa forma, a ligeira queda no valor $\mathrm{R}$ de Lankford, que muitas vezes se observa quando se comparam materiais iguais nessas duas condições. 
Já no centro da amostra esta mudança não ocorre, pois não se observa influência do encruamento, nos níveis aplicados, na intensidade de textura dos materiais. Isso é bastante nítido nas FIG. 5.16 e 5.17, onde as curvas referentes a todos os níveis do encruamento que se agrupam em praticamente uma só curva. As figuras indicam que para o encruamento de 1\% (BRE10) existe uma tendência para diminuição da intensidade das componentes de textura $(111)<121>$ e $(111)<011>$. O pequeno espalhamento que se observa na amostra da FIG. 5.17, aparentemente não caracteriza a influência do encruamento e talvez possa ser atribuído a oscilações de processamento ao longo de uma bobina.

Para a fibra gama, como a difração toma como referência o plano (111), o que se observa é simplesmente uma atenuação de todas as componentes de textura em função da aplicação do encruamento.

\subsection{Propriedades mecânicas}

As propriedades mecânicas obtidas a partir do ensaio de tração no aço IF-Ti nas condições de BPE e BRE das amostras 073351 e 073352 estão apresentadas respectivamente nas TAB. 5.4 e 5.5 .

TABELA 5.4 - Resultados dos ensaios de tração

\begin{tabular}{|c|c|c|c|c|c|c|c|}
\hline \multirow{2}{*}{\multicolumn{2}{|c|}{$\begin{array}{c}\text { Amostra } \\
\text { Bobina } 073351\end{array}$}} & \multicolumn{2}{|c|}{ Limite de Escoamento } & \multicolumn{2}{|c|}{ Limite de Resistência } & \multicolumn{2}{|c|}{ Alongamento Total } \\
\hline & & $\mathrm{LE}(\mathrm{MPa})$ & $\mathrm{VP}(\%)$ & $\mathrm{LR}(\mathrm{MPa})$ & $\mathrm{VP}(\%)$ & $\mathrm{AL}(\%)$ & VP $(\%)$ \\
\hline \multicolumn{2}{|c|}{ BPE } & $171 \pm 3$ & - & $305 \pm 4$ & - & $45,0 \pm 0,8$ & - \\
\hline \multirow{5}{*}{ 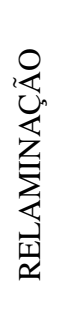 } & BRE 02 & $175 \pm 2$ & 2,3 & $308 \pm 2$ & 1,0 & $43,7 \pm 1,2$ & $-2,9$ \\
\hline & BRE 04 & $178 \pm 5$ & 1,7 & $314 \pm 2$ & 1,9 & $43,2 \pm 1,8$ & $-1,1$ \\
\hline & BRE 06 & $184 \pm 1$ & 3,4 & $325 \pm 5$ & 3,5 & $42,0 \pm 2,1$ & $-2,8$ \\
\hline & BRE 08 & $192 \pm 3$ & 4,3 & $328 \pm 3$ & 0,9 & $41,0 \pm 1,1$ & $-2,4$ \\
\hline & BRE 10 & $194 \pm 2$ & 1,0 & $342 \pm 6$ & 4,3 & $40,8 \pm 1,4$ & $-0,5$ \\
\hline
\end{tabular}


Apresentação gráfica dos resultados do ensaio de tração em função do aumento gradativo do grau de redução está conforme FIG. 5.18 a 5.20.

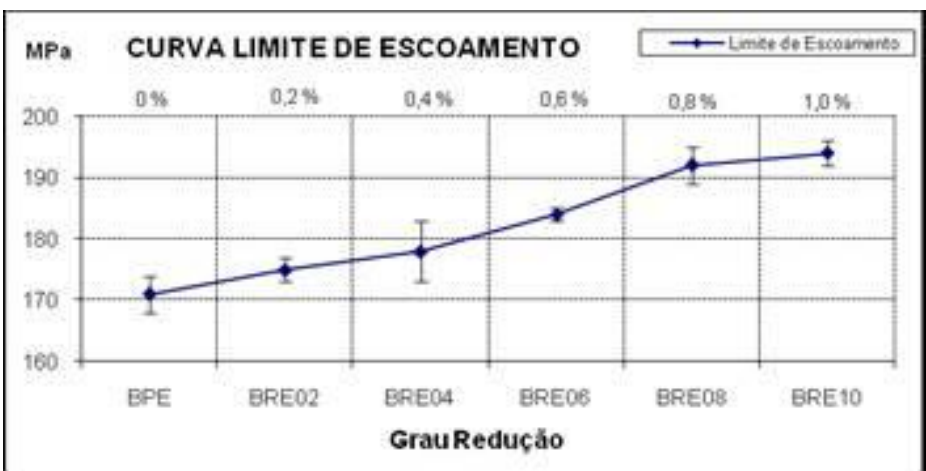

FIGURA 5.18 - Variação do Limite de Escoamento da amostra 073351

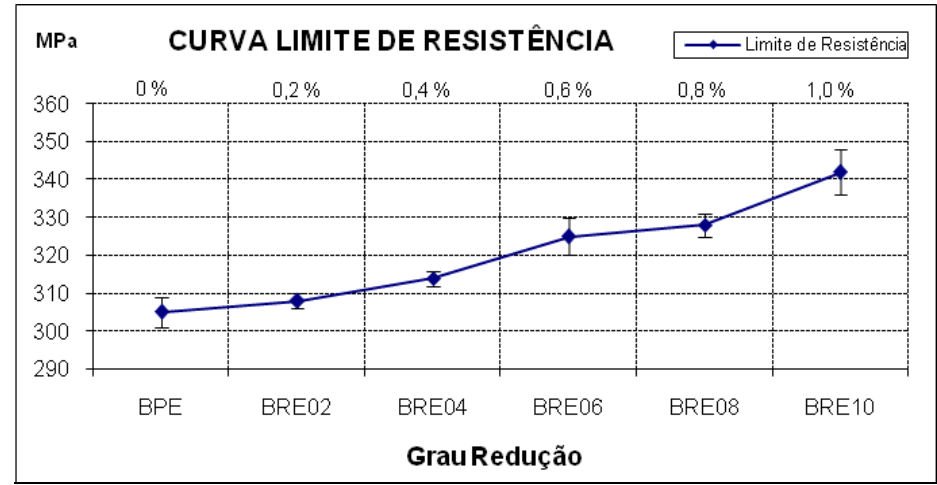

FIGURA 5.19 - Variação do Limite de Resistência da amostra 073351

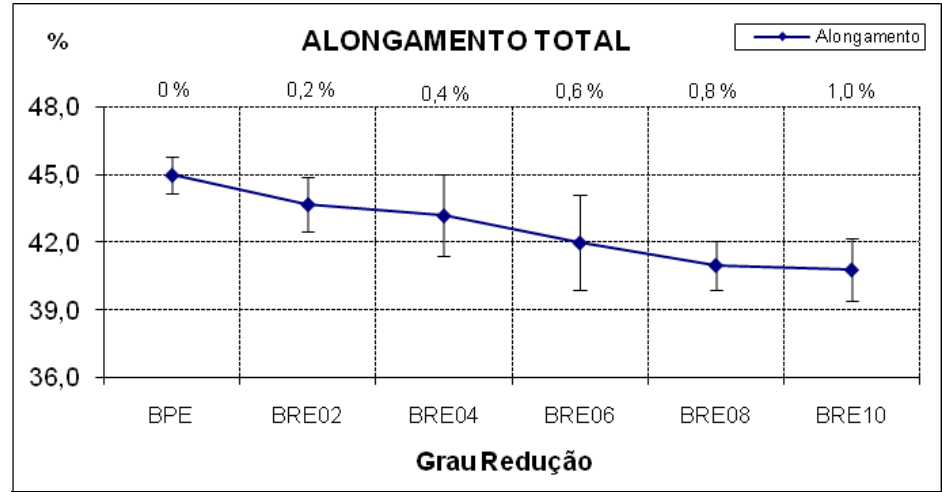

FIGURA 5.20 - Variação do Alongamento Total da amostra 073351 
TABELA 5.5 - Resultados dos ensaios de tração

\begin{tabular}{|c|c|c|c|c|c|c|c|}
\hline \multirow{2}{*}{\multicolumn{2}{|c|}{$\begin{array}{c}\text { Amostra } \\
\text { Bobina } 073352\end{array}$}} & \multicolumn{2}{|c|}{ Limite de Escoamento } & \multicolumn{2}{|c|}{ Limite de Resistência } & \multicolumn{2}{|c|}{ Alongamento Total } \\
\hline & & LE (MPa) & $\mathrm{VP}(\%)$ & LR (MPa) & $\mathrm{VP}(\%)$ & $\mathrm{AL}(\%)$ & $\mathrm{VP}(\%)$ \\
\hline & 3PE & $172 \pm 3$ & - & $306 \pm 6$ & - & $45,0 \pm 1,3$ & - \\
\hline \multirow{5}{*}{ 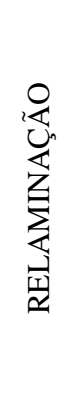 } & BRE 02 & $173 \pm 2$ & 0,6 & $305 \pm 7$ & $-0,3$ & $44,0 \pm 0,9$ & $-2,2$ \\
\hline & BRE 04 & $178 \pm 4$ & 2,9 & $312 \pm 4$ & 2,3 & $43,2 \pm 1,4$ & $-1,8$ \\
\hline & BRE 06 & $181 \pm 1$ & 1,7 & $318 \pm 5$ & 1,9 & $41,0 \pm 1,5$ & $-5,1$ \\
\hline & BRE 08 & $189 \pm 5$ & 4,4 & $335 \pm 2$ & 5,3 & $40,5 \pm 1,6$ & $-1,2$ \\
\hline & BRE10 & $190 \pm 2$ & 0,5 & $339 \pm 3$ & 1,2 & $39,0 \pm 0,7$ & $-3,7$ \\
\hline
\end{tabular}

Apresentação gráfica dos resultados do ensaio de tração em função do aumento gradativo do grau de redução está conforme FIG. 5.21 a 5.23.

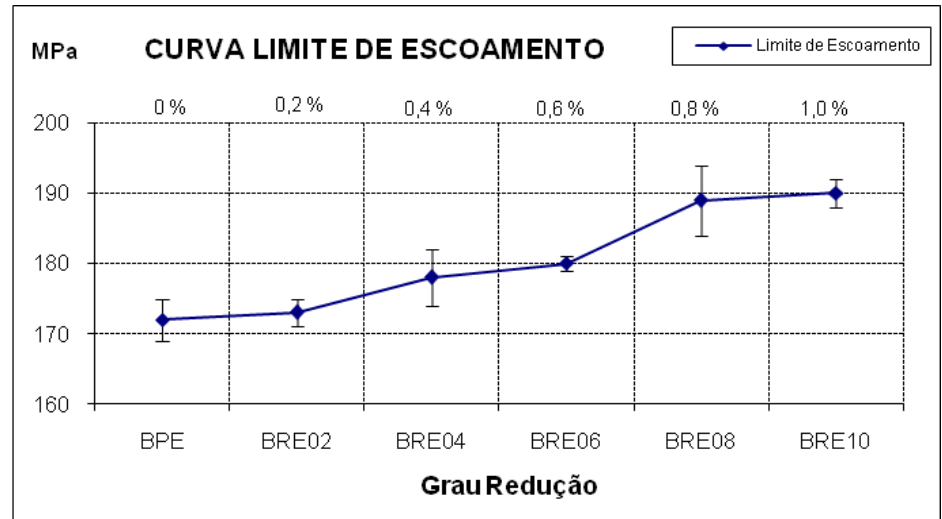

FIGURA 5.21 - Variação do Limite de Escoamento da amostra 073352

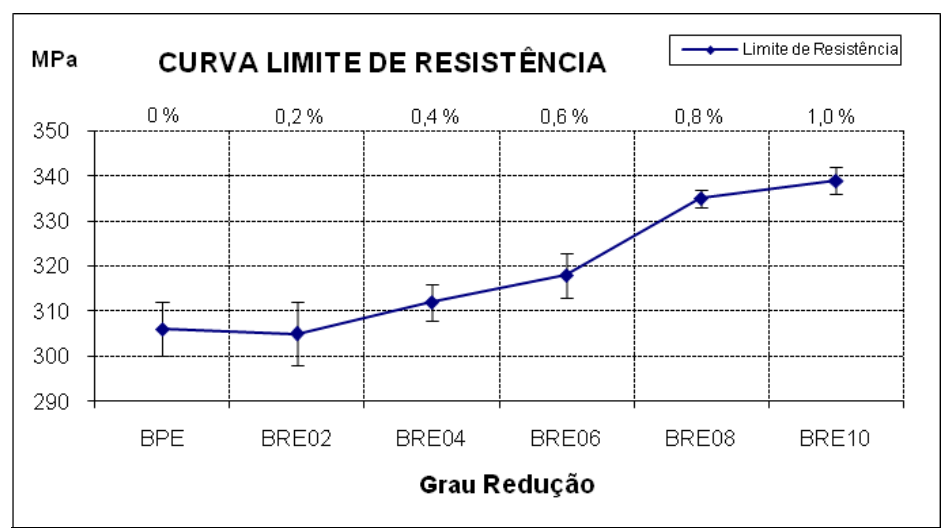

FIGURA 5.22 - Variação do Limite de Resistência da amostra 073352 


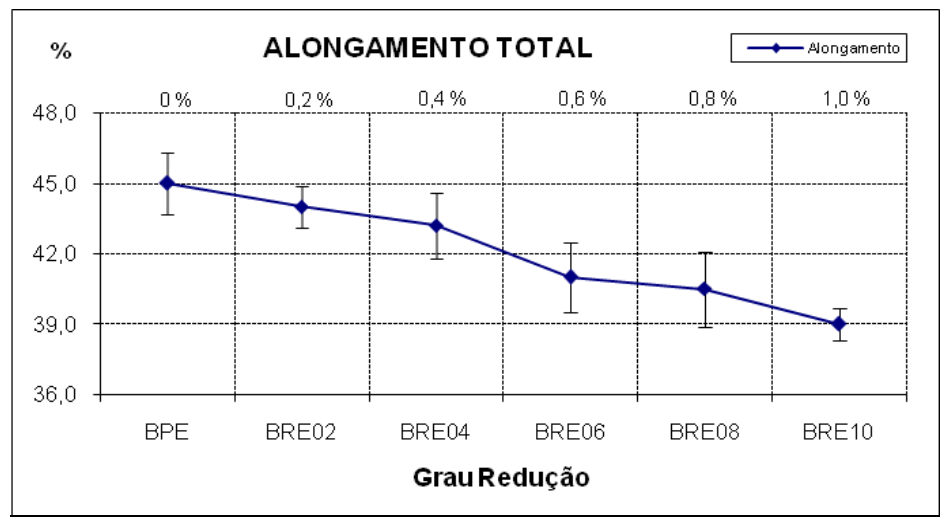

FIGURA 5.23 - Variação do Alongamento Total da amostra 073352

As propriedades mecânicas obtidas a partir do ensaio de embutimento no aço IF-Ti nas condições de BPE e BRE das amostras 073351 e 073352 são apresentadas respectivamente na TAB. 5.6.

TABELA 5.6 - Resultados dos ensaios de Embutimento de Erichsen

\begin{tabular}{|c|c|c|c|c|}
\hline \multirow{2}{*}{ Etapas } & \multicolumn{2}{|c|}{ Bobina 073351 } & \multicolumn{2}{c|}{ Bobina 073352 } \\
\cline { 2 - 5 } & Índice Erichsen & VP (\%) & Índice Erichsen & VP (\%) \\
\hline BPE & $10,9 \pm 0,03$ & - & $10,9 \pm 0,04$ & - \\
\hline BRE02 & $10,8 \pm 0,08$ & $-0,9$ & $10,9 \pm 0,05$ & 0,0 \\
\hline BRE04 & $10,8 \pm 0,10$ & 0,0 & $10,8 \pm 0,10$ & $-0,9$ \\
\hline BRE06 & $10,8 \pm 0,09$ & 0,0 & $10,8 \pm 0,04$ & 0,0 \\
\hline BRE08 & $10,7 \pm 0,05$ & $-0,9$ & $10,7 \pm 0,085$ & $-0,9$ \\
\hline BRE10 & $10,6 \pm 0,09$ & $-0,9$ & $10,7 \pm 0,11$ & 0,0 \\
\hline
\end{tabular}

Apresentação gráfica dos resultados do ensaio de embutimento em função do aumento gradativo do grau de redução está conforme FIG. 5.24 e 5.25. 


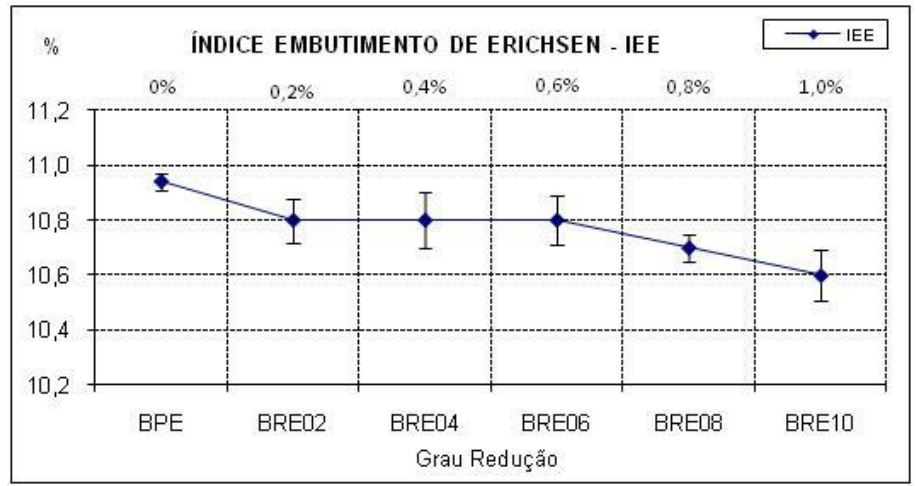

FIGURA 5.24 - Variação do Índice Erichsen da amostra 073351

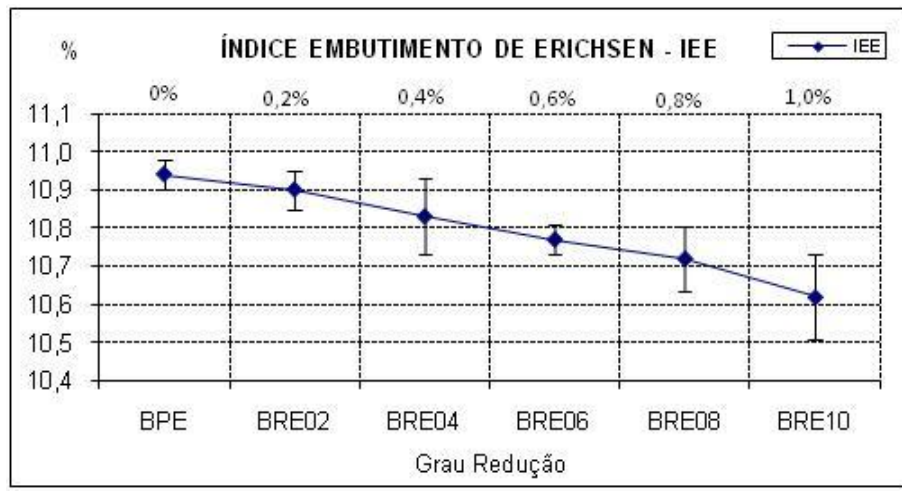

FIGURA 5.25 - Variação do Índice Erichsen da amostra 073352

As propriedades de Anisotropia do material, obtidas a partir do ensaio de tração no aço IF-Ti nas condições de BPE e BRE estão apresentadas na TAB. 5.7.

TABELA 5.7 - Resultados do Valor do R de Lankford

\begin{tabular}{|c|c|c|c|c|c|c|c|c|c|c|c|}
\hline & \multirow{2}{*}{ Amostra } & \multicolumn{6}{|c|}{ Valor R de Lankford } & \multirow{2}{*}{$\mathrm{R}_{\mathrm{m}}$} & \multirow{2}{*}{$\mathrm{VP}(\%)$} & \multirow{2}{*}{$\Delta \mathrm{R}$} & \multirow{2}{*}{$\mathrm{VP}(\%)$} \\
\hline & & $\mathrm{R}_{90}$ & $\mathrm{VP}(\%)$ & $\mathrm{R}_{0}$ & $\mathrm{VP}(\%)$ & $\mathrm{R}_{45}$ & $\mathrm{VP}(\%)$ & & & & \\
\hline \multirow{6}{*}{ 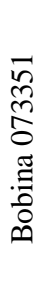 } & BPE & $3,70 \pm 0,10$ & - & $1,76 \pm 0,03$ & - & $0,90 \pm 0,02$ & - & $2,02 \pm 0,03$ & - & $0,54 \pm 0,02$ & - \\
\hline & BRE02 & $3,68 \pm 0,11$ & $-0,54$ & $1,74 \pm 0,07$ & $-1,13$ & $0,84 \pm 0,06$ & $-6,67$ & $2,00 \pm 0,07$ & $-0,80$ & $0,52 \pm 0,06$ & $-3,70$ \\
\hline & BRE04 & $3,49 \pm 0,05$ & $-5,16$ & $1,76 \pm 0,01$ & 1,13 & $0,86 \pm 0,04$ & 2,38 & $1,98 \pm 0,01$ & $-1,30$ & $0,42 \pm 0,04$ & $-20,19$ \\
\hline & BRE06 & $3,50 \pm 0,18$ & 0,29 & $1,74 \pm 0,07$ & $-1,13$ & $0,84 \pm 0,10$ & $-2,38$ & $1,96 \pm 0,07$ & $-1,11$ & $0,43 \pm 0,10$ & 3,61 \\
\hline & BRE08 & $3,45 \pm 0,13$ & $-1,43$ & $1,69 \pm 0,01$ & $-2,87$ & $0,80 \pm 0,09$ & $-4,76$ & $1,91 \pm 0,01$ & $-2,20$ & $0,44 \pm 0,09$ & 1,16 \\
\hline & BRE10 & $3,43 \pm 0,07$ & $-0,58$ & $1,72 \pm 0,05$ & 1,77 & $0,86 \pm 0,06$ & 7,50 & $1,93 \pm 0,05$ & 1,05 & $0,43 \pm 0,06$ & $-2,30$ \\
\hline \multirow{6}{*}{ 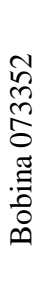 } & BPE & $3,43 \pm 0,14$ & - & $1,59 \pm 0,07$ & - & $0,73 \pm 0,05$ & - & $1,84 \pm 0,07$ & - & $0,49 \pm 0,05$ & - \\
\hline & BRE02 & $3,38 \pm 0,19$ & $-1,46$ & $1,58 \pm 0,03$ & $-0,62$ & $0,72 \pm 0,08$ & $-1,37$ & $1,82 \pm 0,03$ & 1,09 & $0,47 \pm 0,08$ & $-3,09$ \\
\hline & BRE04 & $3,28 \pm 0,23$ & 0,00 & $1,60 \pm 0,04$ & 1,26 & $0,66 \pm 0,04$ & $-8,33$ & $1,79 \pm 0,04$ & 1,65 & $0,37 \pm 0,04$ & $-21,28$ \\
\hline & BRE06 & $3,31 \pm 0,09$ & 0,91 & $1,58 \pm 0,02$ & $-1,26$ & $0,57 \pm 0,03$ & $-13,64$ & $1,76 \pm 0,02$ & 1,68 & $0,36 \pm 0,03$ & $-4,05$ \\
\hline & BRE08 & $3,18 \pm 0,04$ & $-3,93$ & $1,49 \pm 0,06$ & $-5,70$ & $0,50 \pm 0,07$ & $-12,28$ & $1,67 \pm 0,06$ & $-5,11$ & $0,35 \pm 0,07$ & $-2,81$ \\
\hline & BRE10 & $3,14 \pm 0,13$ & $-1,26$ & $1,50 \pm 0,05$ & 0,67 & $0,48 \pm 0,08$ & $-4,00$ & $1,66 \pm 0,05$ & $-0,60$ & $0,31 \pm 0,08$ & $-10,14$ \\
\hline
\end{tabular}


Apresentação gráfica dos resultados de Anisotropia do material no ensaio de tração em função do aumento gradativo do grau de redução está conforme FIG. 5.26 a 5.29.

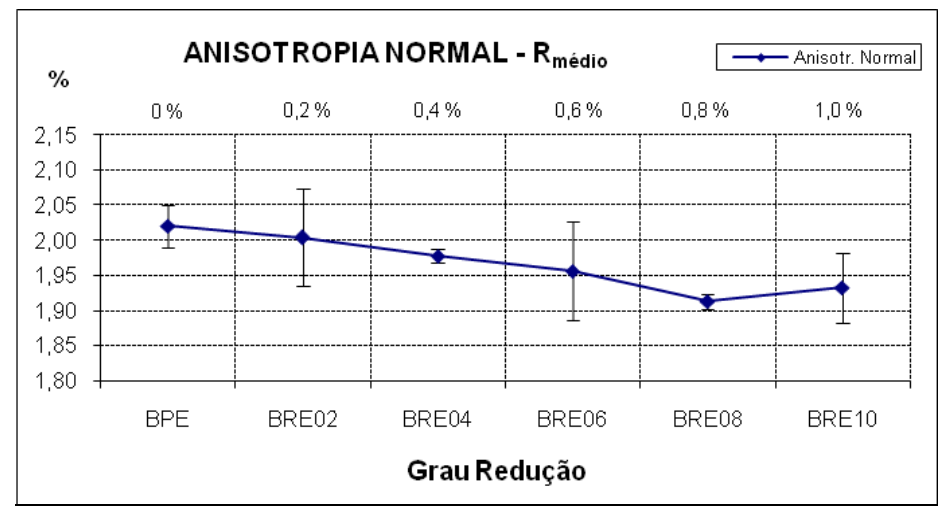

FIGURA 5.26 - Variação da Anisotropia Normal da amostra 073351

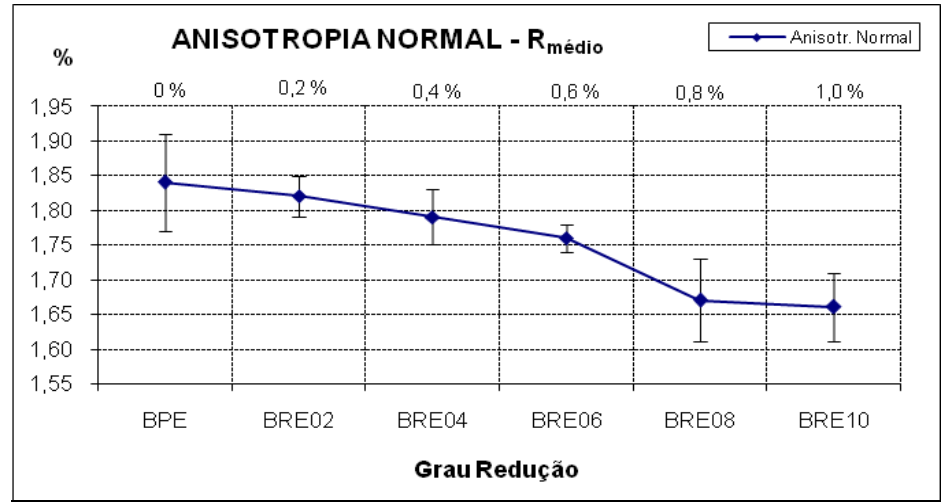

FIGURA 5.27 - Variação da Anisotropia Normal da amostra 073352

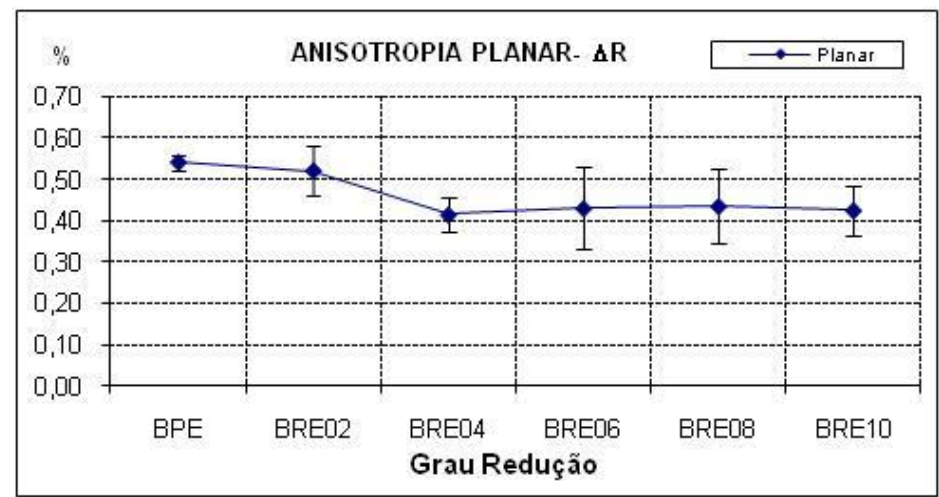

FIGURA 5.28 - Variação da Anisotropia Planar da amostra 073351 


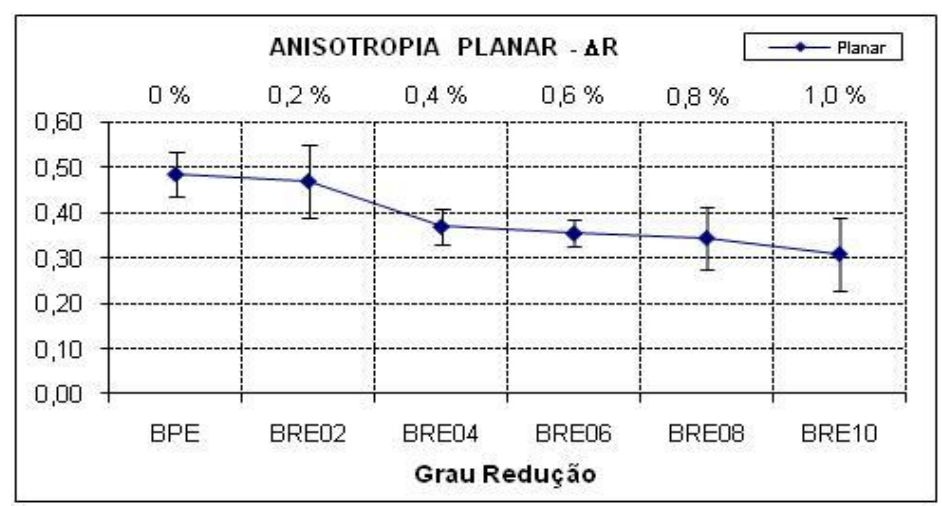

FIGURA 5.29 - Variação da Anisotropia Planar da amostra 073352

As propriedades de Coeficiente de Encruamento do material, obtidas a partir do ensaio de tração no aço IF-Ti nas condições de BPE e BRE estão apresentadas na TAB. 5.8.

TABELA 5.8 - Resultados do Valor do n médio

\begin{tabular}{|c|c|c|c|c|c|c|c|c|c|}
\hline & Amostra & $\mathrm{n}_{90}$ & VP (\%) & $\mathrm{n}_{0}$ & VP (\%) & $\mathrm{n}_{45}$ & VP (\%) & $\mathrm{n}_{\text {médio }}$ & $\operatorname{VP}(\%)$ \\
\hline \multirow{6}{*}{ 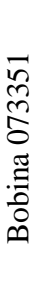 } & BPE & $0,240 \pm 0,005$ & - & $0,239 \pm 0,003$ & - & $0,248 \pm 0,002$ & - & $0,242 \pm 0,002$ & - \\
\hline & BRE02 & $0,230 \pm 0,003$ & $-4,16$ & $0,239 \pm 0,001$ & 0,00 & $0,247 \pm 0,002$ & $-0,40$ & $0,239 \pm 0,002$ & $-1,24$ \\
\hline & BRE04 & $0,240 \pm 0,004$ & 4,16 & $0,240 \pm 0,004$ & 0,41 & $0,237 \pm 0,023$ & $-4,04$ & $0,239 \pm 0,003$ & 0,00 \\
\hline & BRE06 & $0,244 \pm 0,005$ & $-1,64$ & $0,239 \pm 0,003$ & $-0,41$ & $0,230 \pm 0,002$ & $-2,95$ & $0,238 \pm 0,003$ & $-0,42$ \\
\hline & BRE08 & $0,249 \pm 0,002$ & 0,25 & $0,238 \pm 0,002$ & $-0,42$ & $0,223 \pm 0,001$ & $-3,04$ & $0,237 \pm 0,001$ & $-0,43$ \\
\hline & BRE10 & $0,232 \pm 0,003$ & $-6,83$ & $0,228 \pm 0,002$ & $-4,20$ & $0,231 \pm 0,001$ & 3,59 & $0,230 \pm 0,002$ & $-2,91$ \\
\hline \multirow{6}{*}{ 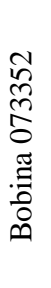 } & BPE & $0,235 \pm 0,006$ & - & $0,233 \pm 0,003$ & - & $0,254 \pm 0,003$ & - & $0,239 \pm 0,003$ & - \\
\hline & BRE02 & $0,230 \pm 0,002$ & $-2,13$ & $0,240 \pm 0,002$ & 3,00 & $0,242 \pm 0,002$ & $-4,72$ & $0,238 \pm 0,002$ & 0,42 \\
\hline & BRE04 & $0,242 \pm 0,003$ & 5,22 & $0,233 \pm 0,004$ & $-3,00$ & $0,235 \pm 0,004$ & $-2,89$ & $0,236 \pm 0,004$ & $-0,84$ \\
\hline & BRE06 & $0,244 \pm 0,005$ & 0,83 & $0,234 \pm 0,003$ & 0,40 & $0,225 \pm 0,003$ & $-4,25$ & $0,234 \pm 0,003$ & $-0,85$ \\
\hline & BRE08 & $0,241 \pm 0,005$ & $-1,23$ & $0,247 \pm 0,002$ & 5,56 & $0,198 \pm 0,001$ & $-1,20$ & $0,233 \pm 0,002$ & $-0,43$ \\
\hline & BRE10 & $0,221 \pm 0,003$ & $-8,29$ & $0,234 \pm 0,001$ & $-5,56$ & $0,209 \pm 0,002$ & 5,56 & $0,225 \pm 0,002$ & $-3,43$ \\
\hline
\end{tabular}

Apresentação gráfica dos resultados de Coeficiente de Encruamento do material em função do aumento gradativo do grau de redução está conforme FIG. 5.30 e 5.31. 


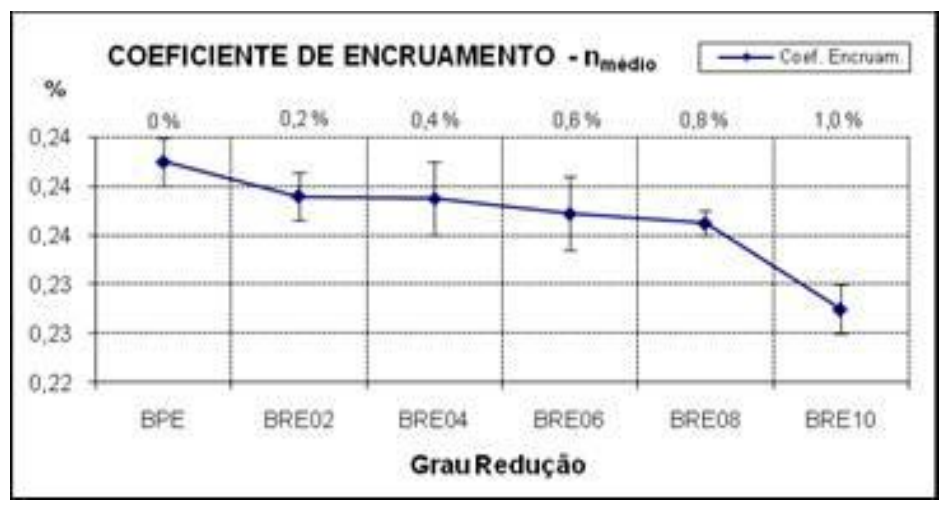

FIGURA 5.30 - Variação do Coeficiente de Encruamento da amostra 073351

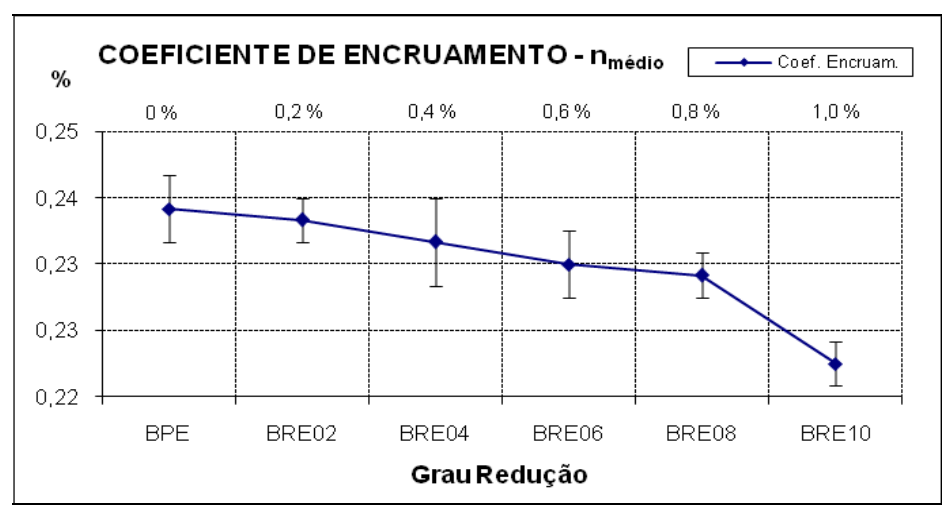

FIGURA 5.31 - Variação do Coeficiente de Encruamento da amostra 073352

Com base nos valores obtidos nas tabelas e figuras apresentadas, verifica-se que, de acordo com a norma NBR 5915:2002 existiria uma condição limite de redução adicional no encruamento do material IF-Ti. Sendo que na condição de BRE, até a redução adicional de 0,4\% atenderia a especificação da norma, além deste valor o Limite de Escoamento (LE) ficaria acima do limite superior estabelecido, consequentemente fora de especificação e liberação para o cliente original, conforme TAB. 5.4 e 5.5 .

Os parâmetros das propriedades que se enquadram na norma NBR 5915:2002 (grau EEP-IF) e na norma EN 10130:1991+A1: 1998 (grau DC06) estão apresentados na TAB. 5.9. 
TABELA 5.9 - Propriedades mecânicas do material BPE em relação às normas ABNT 5915:2002 (Grau EEP-IF) e EN 10130:1991+A1: 1998 (Grau DC06)

\begin{tabular}{|c|c|c|c|c|c|c|c|}
\hline \multirow[b]{2}{*}{ Grau } & \multirow[b]{2}{*}{$\begin{array}{c}\mathrm{LE} \\
(\mathrm{MPa})\end{array}$} & \multirow[b]{2}{*}{$\begin{array}{c}\mathrm{LR} \\
(\mathrm{MPa})\end{array}$} & \multirow{2}{*}{$\begin{array}{l}\text { ALO } \\
(\%)^{*} \\
\text { Mín. }\end{array}$} & \multirow[b]{2}{*}{$\begin{array}{l}\mathrm{R}_{\mathrm{m}} \\
\text { Mín. }\end{array}$} & \multirow[b]{2}{*}{$\begin{array}{c}n \\
\text { Min. }\end{array}$} & Embutimento & \\
\hline & & & & & & $\begin{array}{c}\text { Espessura do } \\
\text { material }(\mathrm{mm})\end{array}$ & $\begin{array}{l}\mathrm{IEE}^{* *} \\
(\mathrm{~mm})\end{array}$ \\
\hline \multirow{2}{*}{ Grau EEP-IF } & \multirow{2}{*}{$140-180$} & \multirow{2}{*}{$270-350$} & \multirow{2}{*}{38} & \multirow{2}{*}{1,8} & \multirow{2}{*}{0,22} & 0,70 & $>10,4$ \\
\hline & & & & & & 0,75 & $>10,5$ \\
\hline Grau DC06 & $<180$ & $270-350$ & 40 & 1,8 & 0,22 & - & - \\
\hline $\begin{array}{l}* \text { Base de medid } \\
* * \text { IEE = Índice }\end{array}$ & $\begin{array}{l}80 \mathrm{~mm} \\
\text { mbutim }\end{array}$ & & ficado & & & & \\
\hline
\end{tabular}

Portanto, verificou-se que os materiais processados e relaminados no Laminador de Encruamento apresentaram as características apresentadas e descritas a seguir:

- O Limite de Escoamento aumentou com a variação do grau de deformação na relaminação de encruamento.

- O Limite de Resistência quase não variou o que pode ser constatado pelos valores percentuais. Também os intervalos de incerteza das medidas de BRE indicam que a pequena variação dos valores do material BRE em relação à BPE pode não ser significativa, já que esse intervalo de incerteza contém o valor de BPE.

Como o aço IF-Ti é produzido de forma a possuir pouco ou nenhum elemento em solução sólida, pode-se concluir que o aumento do LE com a elevação do grau de deformação na relaminação deve ser reflexo exclusivo da elevação da densidade de discordância, que interagem entre si e provocam o endurecimento do material. 
Não houve decréscimo significativo do Alongamento Total provocado pelo aumento no grau de deformação na relaminação conforme o que está descrito nas TAB. 5.4 e 5.5, embora o intervalo do erro de medida do material BRE contenha o valor BPE. Acredita-se que isso pode estar associado aos seguintes fatores:

a) O alongamento total varia pouco em relação às pequenas deformações;

b) Todo o experimento foi processado em escala industrial, por isso possui pequenas variações de propriedades mecânicas.

A pequena variação do valor de Coeficiente de Anisotropia Normal $\left(R_{m}\right)$ com os graus de deformação na relaminação está de acordo com o trabalho de Muschenborn et al. [21]. Os valores deste último são mostrados na TAB. 5.10 para graus de deformação maiores que o descrito nesta dissertação. Entretanto, a variação de $\mathrm{R}_{\mathrm{m}}$ mostrada na TAB. 5.7 e FIG. 5.26 e 5.27 são semelhantes à obtida no trabalho Muschenborn et al. [21] apesar da diferença nos graus de deformação. Isso é devido, provavelmente, ao efeito da variação da textura ao longo da bobina, que influi no $\mathrm{R}_{\mathrm{m}}$, como descrito a seguir. É preciso, entretanto, salientar que o trabalho de Muschenborn foi feito na década de 70 com aço IF de $1^{\mathrm{a}}$ geração, que torna mais difícil de fazer uma comparação.

TABELA 5.10 - Efeito do aumento da redução na laminação de encruamento nas propriedades mecânicas do aço IF-Ti

\begin{tabular}{|c|c|c|c|c|c|}
\hline $\begin{array}{c}\text { Grau de Redução } \\
(\%)\end{array}$ & $\begin{array}{c}\text { LE* } \\
\mathrm{MPa}\end{array}$ & $\begin{array}{c}\mathrm{LR} \\
\mathrm{MPa}\end{array}$ & $\begin{array}{c}\text { ALO** } \\
(\%)\end{array}$ & $\mathrm{R}_{\mathrm{m}}$ & $n$ \\
\hline 0 & 117 & 316 & 41,2 & 2,47 & 0,253 \\
\hline 2 & 197 & 320 & 39,8 & 2,46 & 0,224 \\
\hline 4 & 265 & 324 & 38,2 & 2,44 & 0,184 \\
\hline 6 & 287 & 323 & 37,5 & 2,45 & 0,167 \\
\hline 8 & 343 & 357 & 34,7 & 2,42 & 0,140 \\
\hline 10 & 343 & 348 & 27,4 & - & - \\
\hline \multirow{2}{*}{$\begin{array}{l}\text { FONTE obtido a 0,2\% de deformação } \\
\text { FONCHENBORN et al., 1978 Base de Medida }=50 \mathrm{~mm}\end{array}$} \\
\hline
\end{tabular}


A alteração da textura após a deformação (textura de deformação) em materiais isentos de textura somente irá acontecer se a redução na laminação for superior a 30\%. Para materiais com textura semelhante a este trabalho, irá ocorrer com menores intensidades de deformação [9]. Como pode ser visto nas curvas de nível nas FIG. 5.7 a 5.9 (comparativo dos materiais BPE e BRE), onde as deformações geradas após a laminação de encruamento não afetaram significativamente a textura das principais componentes. As diferenças de textura observadas nessas figuras podem ser explicadas pelo fato dos materiais BPE e BRE, terem sido obtidos de um material processado em escala industrial e, por isso, apresentarem pequenas diferenças na textura ao longo do seu comprimento, como observou Braga Jr.[50]. Assim, pode-se afirmar que não houve mudança de textura na superfície do material após a relaminação de encruamento principalmente na fibra Alfa conforme FIG. 5.27.

No entanto, é verificado que a formação da textura tem início após a laminação a frio, tem sua intensidade de orientação aumentada após o tratamento térmico nos fornos de recozimento e estabilizando-se na laminação de encruamento. É possível que variações de textura tenham influenciado este resultado ao longo da bobina, o que justifica as diferenças observadas nos valores do coeficiente de anisotropia conforme TAB. 5.8. Esse resultado é diferente do obtido por Muschenborn et al. [21], apresentado na TAB. 5.10.

A diminuição dos valores de $n$ com o grau de deformação estão de acordo com os autores [11] [19] [20] [21]. Como o índice Erichsen possui uma correlação positiva com o valor $n$ conforme apresenta TAB. 5.6 e FIG. 5.24 e 5.25 para os resultados de Erichsen e TAB. 5.8 e FIG. 5.31 e 5.32 para os resultados do Coeficiente de Encruamento. Esperava-se que $n$ diminuísse com o aumento do grau de deformação na laminação de encruamento, o que se comprovou. Isso porque a laminação de encruamento aumenta a quantidade de 
discordâncias, que, por sua vez, diminui a ductilidade do material e, conseqüentemente, o seu valor $n$ e o índice Erichsen.

Os valores de $n$ médio e do índice Erichsen, em geral, apresentaram um decréscimo. $\mathrm{O}$ maior aumento percentual para esses valores deverá ser o obtido no material submetido ao maior grau de deformação na relaminação de encruamento, ou seja, na condição BRE10.

\subsection{Curva Limite de Conformação - CLC}

As FIG. 5.32 a 5.34 mostram as curvas limite de conformação levantada para os aços BRE02 e BRE10 ensaidados até a estricção e, a combinação das CLC com os pontos experimentais e seus respectivos intervalos de incerteza.

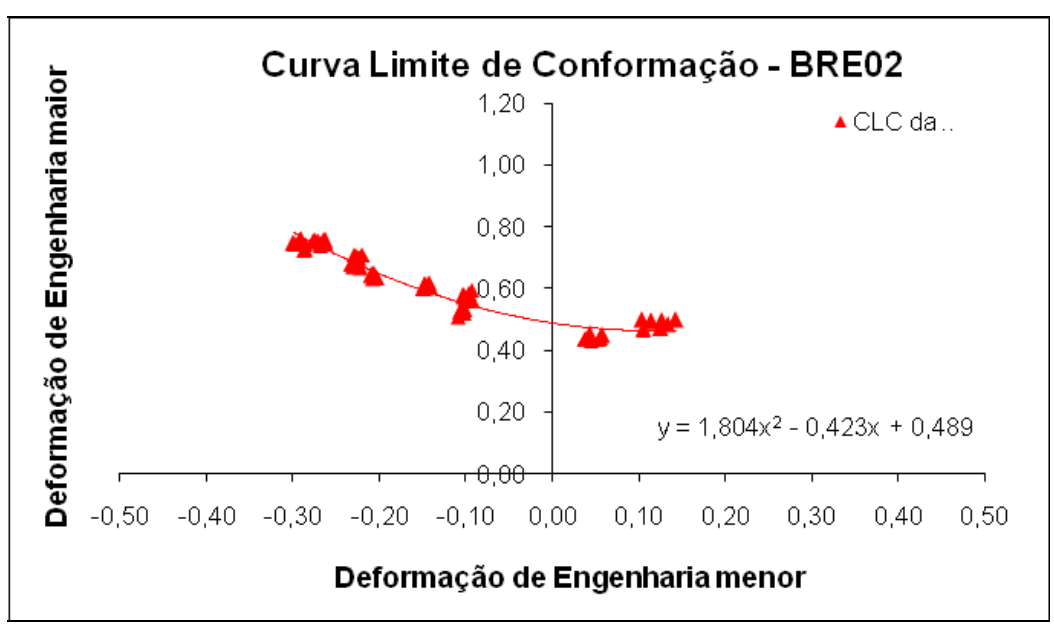

FIGURA 5.32 - CLC do aço IF-Ti nas condições de BRE02 


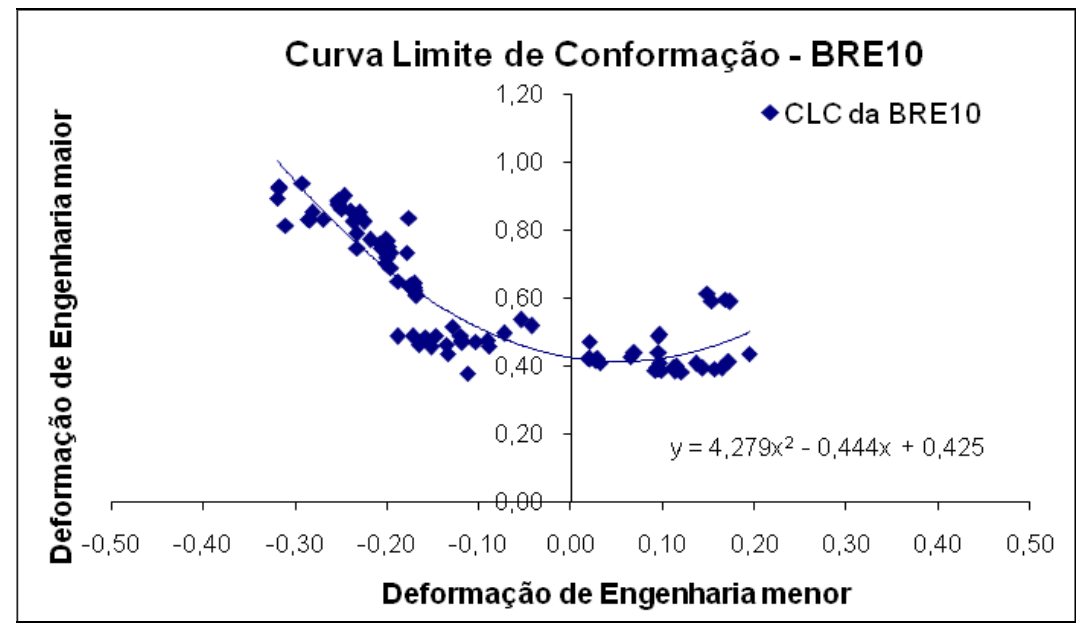

FIGURA 5.33 - CLC do aço IF-Ti nas condições de BRE10

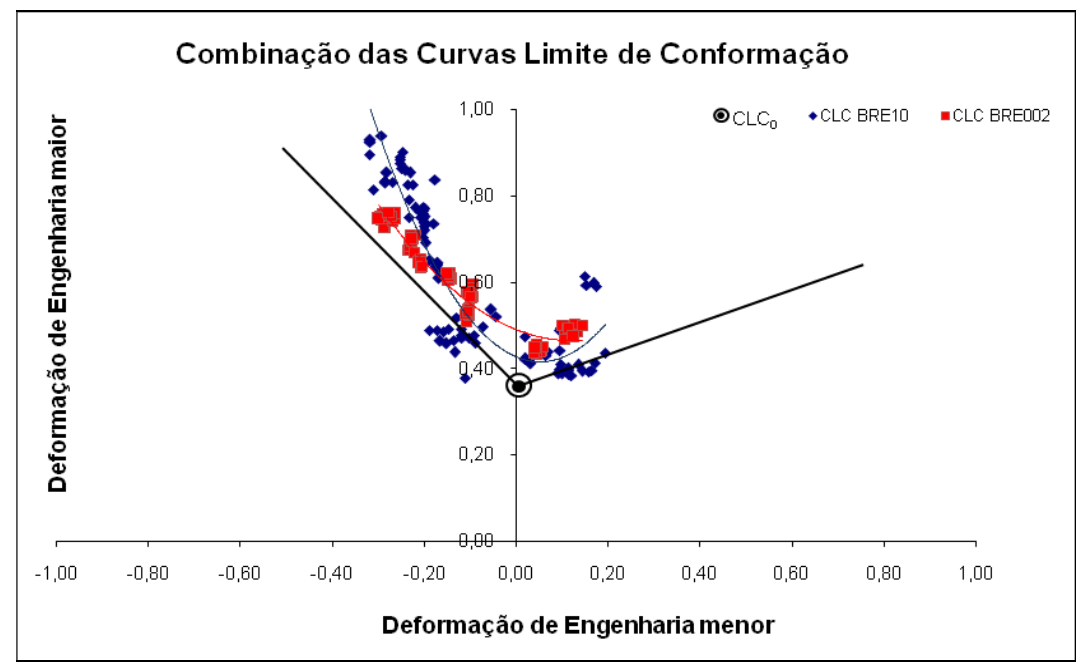

FIGURA 5.34 - Combinação das CLC nas condições de BRE02 e BRE10

Na FIG. 5.34 os pontos experimentais dos materiais BRE02 e BRE10 indicam características semelhantes após os ensaios de Nakazima, onde avaliam a estampabilidade do material. Essa semelhança era esperada, já que esses materiais não apresentam diferenças significativas nas propriedades mecânicas obtidas nos ensaios avaliados, no item 5.4, principalmente os relacionados à estampagem, como o índice Erichsen e os valores $\mathrm{R}$ e $n$. 
Visando simplificar a determinação experimental e teórica da CLC e, auxiliando na utilização em nível da fábrica, o NADDRG (North American Deed Drawing Research Group) desenvolveu uma equação empírica conhecida como equação de Keeler-Brasier, conforme EQUAÇÃO 4.6, que é utilizada para estimar o valor da deformação planar ou $\mathrm{CLC}_{0}$ em termos da deformação convencional, dada por:

$e_{0}=(23,3+14,2 * t)\left(\frac{n}{0,21}\right)$

onde, $\mathrm{t}$ é a espessura da chapa em $\mathrm{mm}$, com $\mathrm{t}<3,1 \mathrm{~mm}$.

Aplicando a EQUAÇÃO 4.6 de Keeler-Brasier aos dados do material em estudo, temos:

- $\quad$ Espessura da chapa (aço IF)

- Coeficiente de encruamento médio $\mathrm{t}=0,75 \mathrm{~mm}$

$n=0,235$

Substituindo na EQUAÇÃO 4.6 temos:

$e_{0}=(23,3+14,2 * t)\left(\frac{0,235}{0,21}\right)$

Assim, obtemos o valor de $\mathrm{e}_{0}=0,38$. Este valor está coerente com os dados experimentais observados na FIG. 5.35.

Na FIG. 5.35 são apresentados os resultados em trabalho de Muschenborn et al [21], com dados obtidos das curvas limite conformação. 


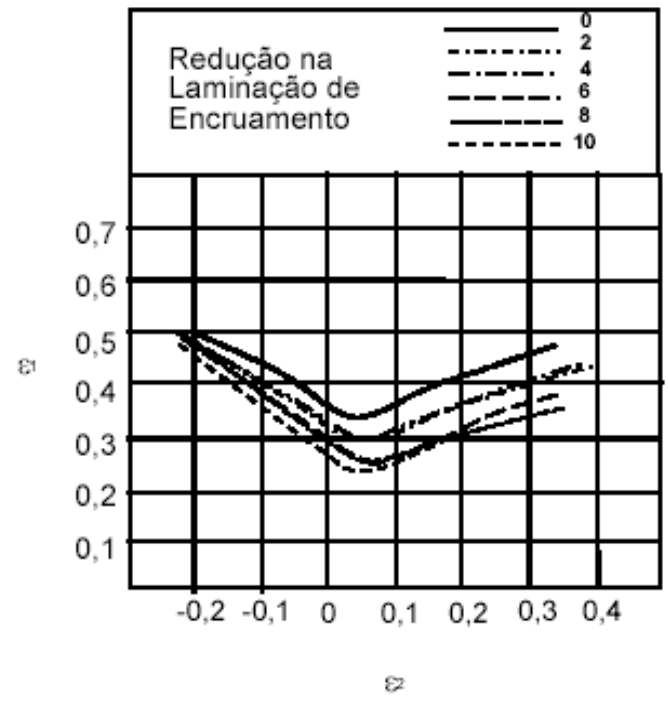

FIGURA 5.35 - Efeito do encruamento na CLC de um aço IF-Ti [21]

A FIG. 5.36 compara os resultados experimentais deste estudo com os resultados obtidos da literatura [21] na condição de $2 \%$ de redução na laminação de encruamento na CLC de um aço IF-Ti.

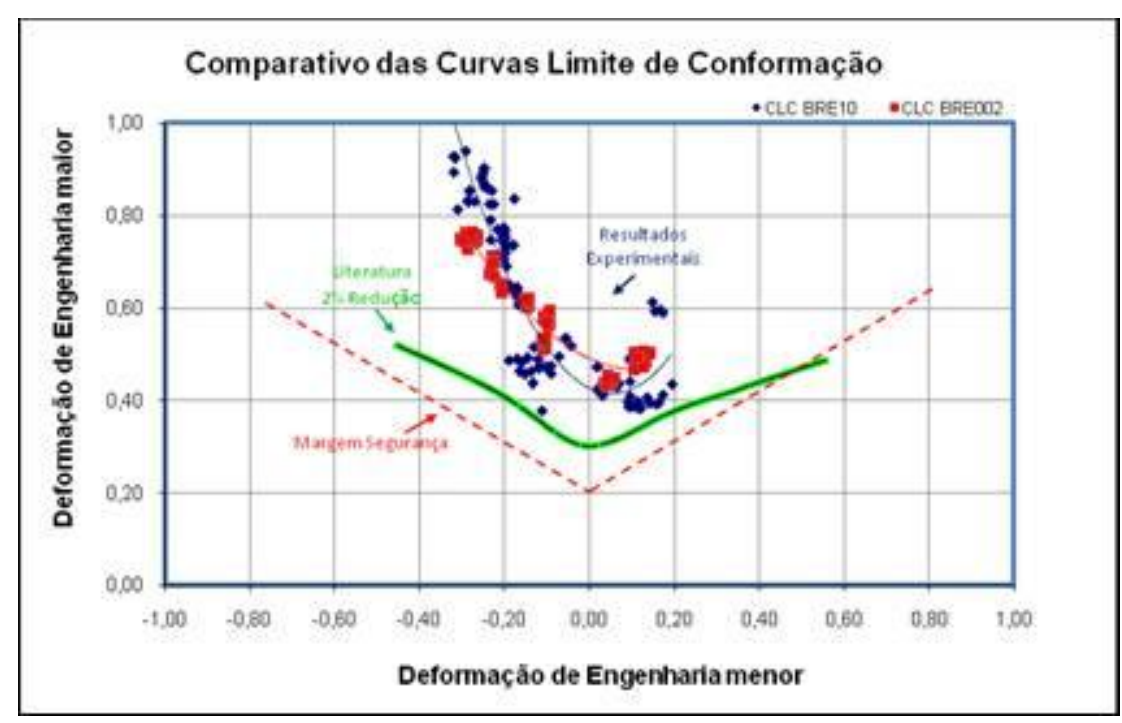

FIGURA 5.36 - Comparativo das CLC experimentais e literatura 
Os valores encontrados no estudo estão compatíveis com a literatura, considerando que no estudo realizado por Muschenborn et al [21], o valor total das reduções corresponde a $2 \%$ de redução adicionado de $0,20 \%$ antes da relaminação, obtém-se um total de $2,20 \%$. No estudo realizado, o total de reduções obtido para a condição de BRE02 e BRE10, que correspondem respectivamente às reduções de $0,70 \%$ e $1,50 \%$. Considerando $0,50 \%$ de redução no encruamento antes da relaminação.

\section{CONSIDERAÇÕES FINAIS}

\subsection{Conclusões}

Os objetivos propostos foram alcançados, de forma que este estudo permitiu avaliar a estampabilidade de materiais IF-Ti após a relaminação de encruamento com aumento gradativo da redução e comparar ao de materiais IF-Ti sem esse retrabalho, como se descreve a seguir.

Foi caracterizada a chapa IF relaminada em termos de propriedades mecânicas, conforme proposição do estudo através dos ensaios realizados e resultados apresentados.

O tamanho de grão permaneceu estável durante os vários de graus de relaminação, em torno de 8 ASTM $(22,5 \mu \mathrm{m})$, conforme Norma ASTM E112-96. Com isto, o material na condição BRE10 possui TG semelhante à condição BPE do material. 
Observou-se que para o grau de $0,60 \%$ de redução adicional, ultrapassou o limite superior do Limite de Escoamento, segundo tolerância da Norma NBR 5915:2002. Portanto, até $0,40 \%$ de grau de redução o parâmetro Limite de Escoamento estaria dentro do estabelecido pela Norma, como critério de avaliação e aprovação do material.

Referente aos coeficientes de Anisotropia Normal $\left(\mathrm{R}_{\mathrm{m}}\right)$ verificou-se uma diminuição dos valores com o aumento gradativo do grau de redução na relaminação, podendo influenciar nas características de estampabilidade do material.

Referente ao Coeficiente de Anisotropia Planar $(\Delta \mathrm{R})$ verificou uma diminuição não significativa dos valores, com o aumento gradativo do grau de redução na relaminação.

A diminuição dos valores de $n$ com o grau de deformação estão de acordo com a literatura. Como o Índice de Embutimento de Erichsen (IEE) possui uma correlação positiva com o valor $n$, era de se esperar que ele diminuísse com o aumento do grau de deformação na laminação de encruamento, o que se comprovou. Isso porque a laminação de encruamento aumenta a quantidade de discordâncias, que, por sua vez, diminui a ductilidade do material e, conseqüentemente, o seu valor de $n$ e IEE.

Com referência à fibra Gama na superfície e no centro, não foi evidenciado uma correlação direta da intensidade de orientação em relação ao aumento do grau de redução aplicado na relaminação. 
Com referência ao comportamento da textura em relação à fibra Alfa na superfície e central não foram verificados um aumento na intensidade de orientação com o aumento do grau de redução aplicado. Na região central, é observada textura típica de aços IF recristalizados destinados a estampagem, ou seja, com forte predominância da componente $(111)<110>$. Com relação à textura na região na superfície, se assemelha a de materiais na condição como laminado a frio, onde, além da componente $(111)<110\rangle$, são observadas as componentes $(100)<110\rangle$ e $(112)<110>$.

Com base na CLC do material IF-Ti em estudo, na condição de relaminação de encruamento, verificou-se que o mesmo possui um campo de conformabilidade e uma estampabilidade semelhante à desse material sem a relaminação. Através da equação Keeler-Brasier pode-se estimar o valor da deformação planar $\mathrm{CLC}_{0}=0,38$, coerente com o valor experimental.

Se for considerar somente o Limite de Escoamento como critério de avaliação de aplicação do produto, conforme a norma o material deveria ser rejeitado. No entanto, pelos outros procedimentos utilizados durante o estudo, tais como: CLC, textura, metalografia, coeficientes de anisotropia e de encruamento, não necessariamente o material deveria ser desclassificado para aplicação ao pedido original. 


\subsection{Relevância do Resultado do Trabalho}

O experimento permitiu demonstrar que, o aumento gradativo de redução na relaminação de encruamento para o material IF-Ti não afetou significativamente suas propriedades mecânicas e metalúrgicas, tal que este material fosse desclassificado. Sendo assim, à luz destes resultados sugere-se, uma revisão nos parâmetros e critérios utilizados pela norma ABNT 5915:2002 (Grau EEP-IF), tal que seja considerado como referência de liberação e aplicação deste segmento de produto outros ensaios mecânicos, que não somente ensaio de tração e seus respectivos parâmetros.

\subsection{Sugestões para Futuros Trabalhos}

Avaliar a evolução da subestrutura (p.ex. discordâncias) via microscopia eletrônica de transmissão, durante a seqüência de processo utilizado neste experimento para o melhor entendimento do processo.

Estudo comparativo da estampabilidade do Aço IF-ti na espessura de 0,75 mm, em peças reais e comparando com modelos de FEM (AUTOFORM) visando à viabilidade do uso e chapas relaminadas, obtido da presente dissertação.

Estudo para avaliar o taxa de deformação de encruamento ao longo da espessura do material durante o processo de redução no Laminador de Encruamento, através de modelamento matemático. 


\section{APÊNDICE I}

Correlação entre deformação uniforme e coeficiente de encruamento $(n)$.

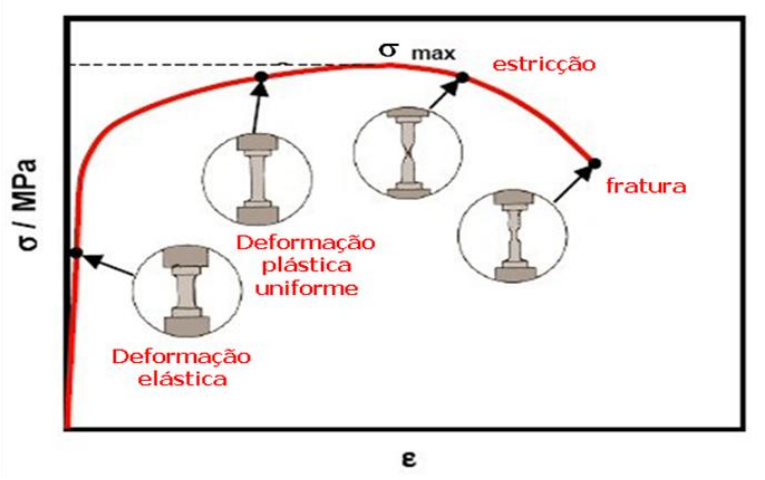

FIGURA 6.1 - Curva Tensão versus deformação no teste de tração [52]

Em $\sigma_{\text {máx }}$ ocorre o início da estricção

$$
\sigma_{\text {máx }} \Rightarrow \mathrm{d} \sigma=0 ;
$$

Por outra parte, $\sigma=\mathrm{P} / \mathrm{A}_{\mathrm{o}}$,

onde $\mathrm{P}=$ carga instantânea e $\mathrm{A}_{\mathrm{o}}$ é a área da seção transversal inicial.

Portanto, $\quad \mathrm{d} \sigma=0 \Rightarrow \mathrm{dP}=0$;

$$
\begin{aligned}
& \mathrm{dP}=\mathrm{d}(\sigma \mathrm{A})=\sigma \mathrm{d} \mathrm{A}+\mathrm{Ad} \sigma=0 \\
& \sigma=-(\mathrm{A} / \mathrm{dA}) \mathrm{d} \sigma=\mathrm{d} \sigma /(-\mathrm{dA} / \mathrm{A})(1)
\end{aligned}
$$

Sendo o volume ( $\mathrm{V}=\mathrm{A} \mathrm{L})$ constante:

$$
\begin{aligned}
& \mathrm{dV}=\mathrm{AdL}+\mathrm{LdA}=0 \\
& \mathrm{dL} / \mathrm{L}=-\mathrm{dA} / \mathrm{A}(2)
\end{aligned}
$$

De (1) e (2) temos:

$$
\sigma=\mathrm{d} \sigma /(\mathrm{dL} / \mathrm{L})
$$

Se $\sigma$ é expressa pela equação de Hollomon $\left(\sigma=K \varepsilon^{\mathrm{n}}\right)$, então resulta:

$$
\mathrm{d} \sigma / \mathrm{d} \varepsilon=\mathrm{K} \varepsilon^{\mathrm{n}-1}
$$

No instante da estricção:

$$
\begin{aligned}
& \sigma \mathrm{U}=(\mathrm{d} \sigma / \mathrm{d} \varepsilon) \mathrm{IU} \\
& \mathrm{K} \varepsilon^{\mathrm{n}}=\mathrm{Kn} \varepsilon_{\mathrm{u}}^{\mathrm{n}-1} \\
& \varepsilon_{\mathrm{u}}{ }^{\mathrm{n}}=\mathrm{n} \varepsilon_{\mathrm{u}}{ }^{\mathrm{n}-1} \\
& \varepsilon_{\mathrm{u}}=\mathrm{n} .
\end{aligned}
$$




\section{APÊNDICE II}

Com objetivo de reconfirmar alguns resultados obtidos, foi realizado ensaio com mais uma bobina experiência. Sendo que o processo de fabricação, dimensão e composição química são semelhantes aquelas duas bobinas processadas anteriormente. Lembrando que variações no processo e composição química podem levar a resultados diferentes àqueles encontrados.

Segue os dados de processo e resultados encontrados da $3^{\text {a }}$ bobina experiência, apresentados nas respectivas TAB 6.1 e 6.2 .

TABELA 6.1 - Composição química do aço IF-Ti

\begin{tabular}{|c|c|c|c|c|c|c|c|c|c|}
\hline \multicolumn{10}{|c|}{ Composição Química (\% em peso) } \\
\hline $\begin{array}{c}\text { Amostra do } \\
\text { distribuidor }\end{array}$ & $\boldsymbol{C}$ & $\boldsymbol{M n}$ & $\boldsymbol{P}$ & $\boldsymbol{S}$ & $\boldsymbol{A l}$ & $\boldsymbol{T} \boldsymbol{N}$ & $\boldsymbol{N} \boldsymbol{N}$ & $\boldsymbol{N}$ & $\boldsymbol{T}^{*}$ \\
\hline $\mathbf{0 1 9 3 1 8}$ & 0,0030 & 0,1220 & 0,0100 & 0,0055 & 0,0340 & 0,0600 & 0,0004 & 0,0020 & 0,017 \\
\hline
\end{tabular}

TABELA 6.2 - Tamanho de grão das amostras BPE e BRE

\begin{tabular}{|c|c|c|c|}
\hline \multicolumn{2}{|c|}{ Amostra } & \multicolumn{2}{|c|}{ Tamanho de grão } \\
\hline \multirow{2}{*}{ Bobina 019318 } & ASTM & VP(\%) \\
\hline \multirow{7}{*}{ BPE } & $8,0 \pm 0,5$ & - \\
\hline \multirow{4}{*}{ BRE } & BRE02 & $8,2 \pm 0,5$ & $2,4 \%$ \\
\cline { 2 - 4 } & BRE04 & $8,4 \pm 0,4$ & $2,4 \%$ \\
\cline { 2 - 4 } & BRE06 & $8,1 \pm 0,6$ & $-3,7 \%$ \\
\hline & BRE08 & $8,1 \pm 1,2$ & $0,0 \%$ \\
\cline { 2 - 4 } & BRE10 & $8,2 \pm 0,8$ & $1,2 \%$ \\
\hline
\end{tabular}


As FIG. 6.4 a 6.9 mostram as micrografias da bobina 019318 na condição de Bobina Produto Encruada (BPE) e da Bobina Relaminada Encruada (BRE) nas diversas reduções.

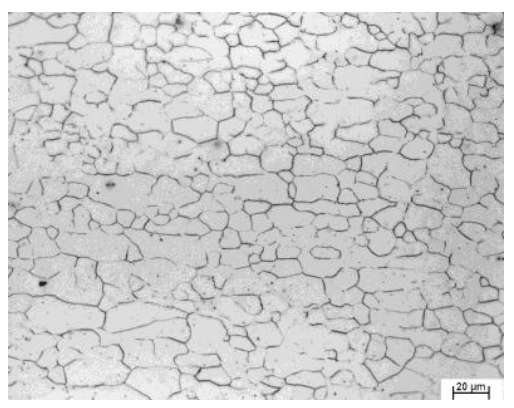

FIGURA 6.4- Microestrutura relaminação BRE10

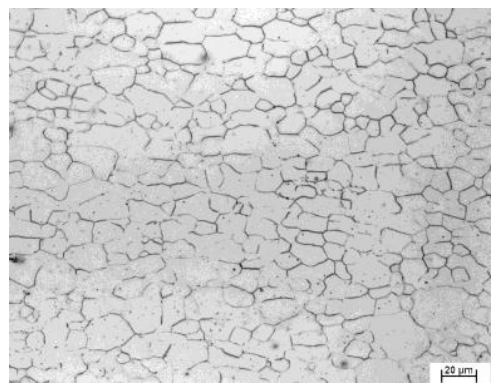

FIGURA 6.5 - Microestrutura relaminação BRE08

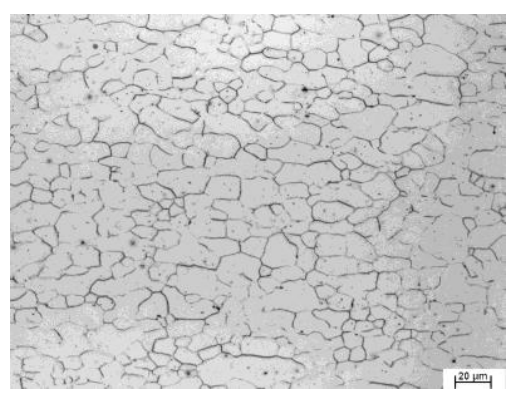

FIGURA 6.6 - Microestrutura relaminação BRE06

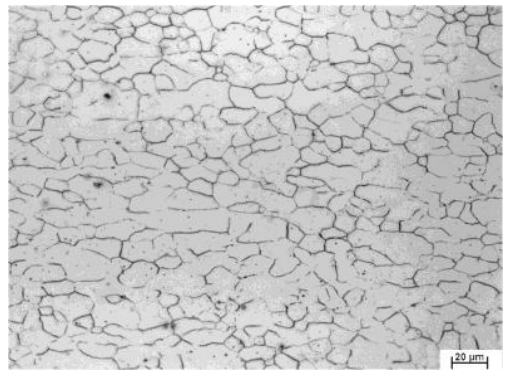

FIGURA 6.7 - Microestrutura relaminação BRE04 


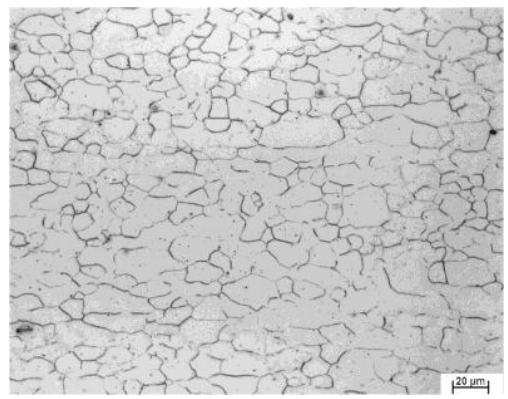

FIGURA 6.8 - Microestrutura relaminação BRE02

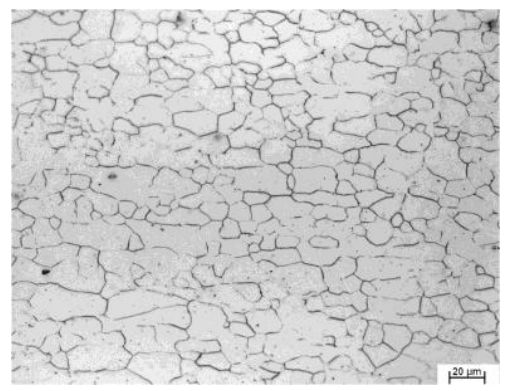

FIGURA 6.9 - Microestrutura sem relaminação BPE

Semelhante as bobinas experiência, as micrografias da bobina se trata de uma estrutura típica de aços IF totalmente recristalizada, isto é, com grãos ferríticos alongados (panqueca). Sendo que as micrografias apresentam grãos com tamanhos semelhantes ao longo das etapas de redução da bobina

Os resultados da textura do aço IF em estudo, medidos na condição BPE e BRE na superfície e centro da amostra, estão conforme FIG. 6.10 a 6.18 .

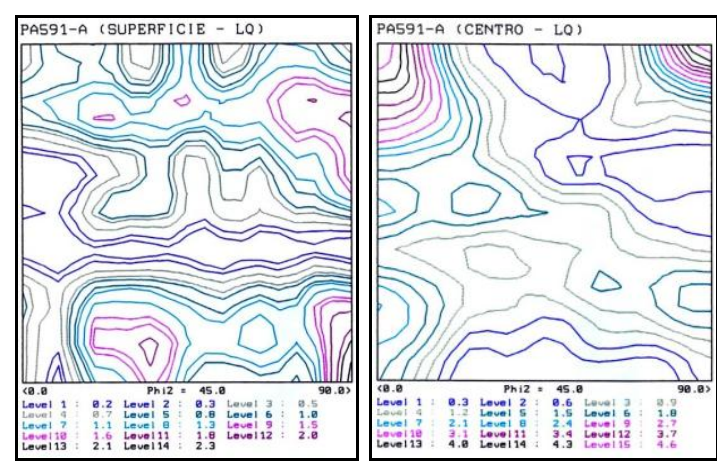

FIGURA 6.10 - Nível de intensidade nas ODF na Laminação a quente 


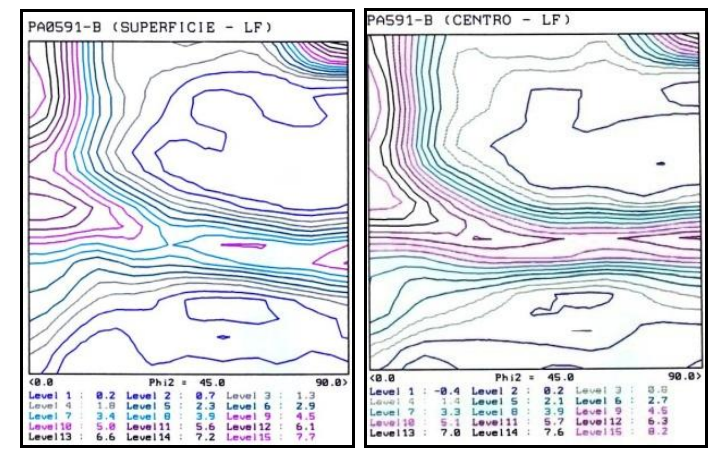

FIGURA 6.11 - Nível de intensidade nas ODF na Laminação a frio

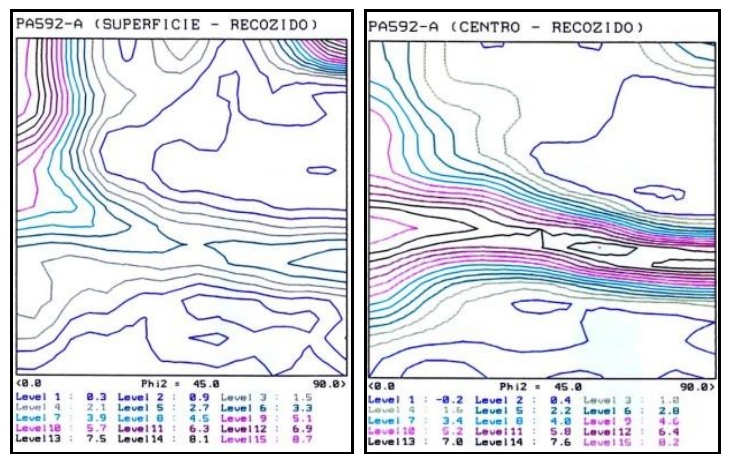

FIGURA 6.12 - Nível de intensidade nas ODF no recozimento

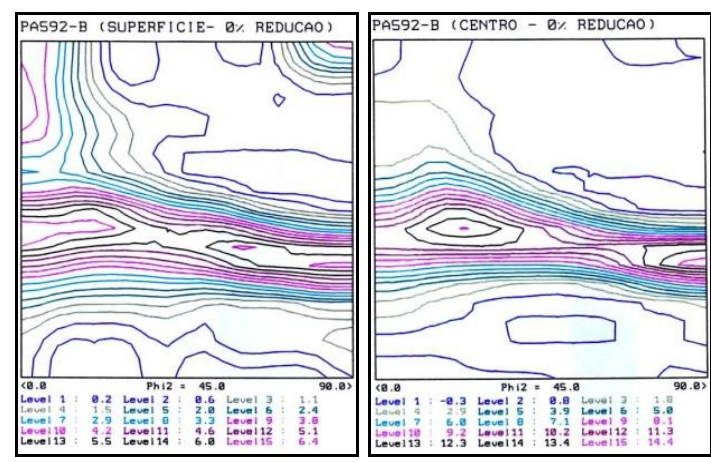

FIGURA 6.13 - Nível de intensidade nas ODF no Encruamento

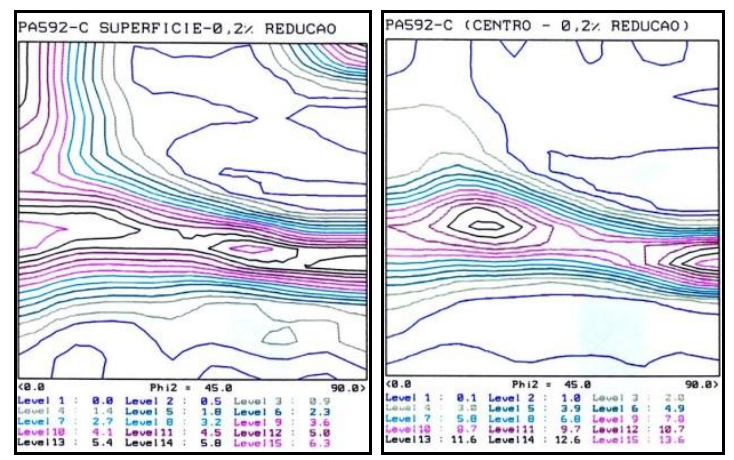

FIGURA 6.14 - Nível de intensidade nas ODF no encruamento com 0,2\% relaminação 


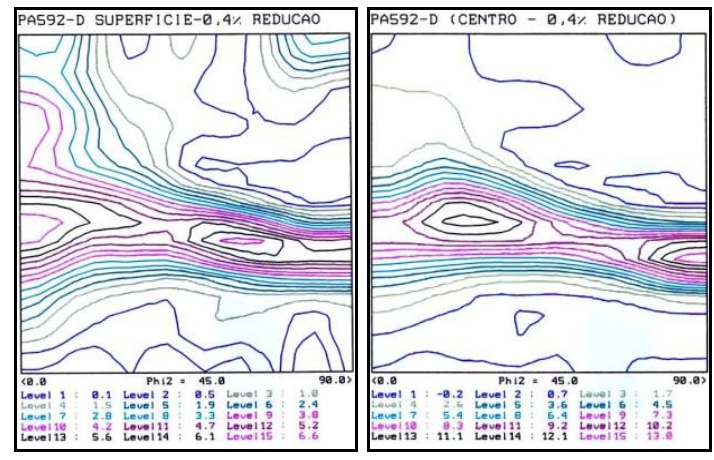

FIGURA 6.15 - Nível de intensidade nas ODF no encruamento com 0,4\% relaminação

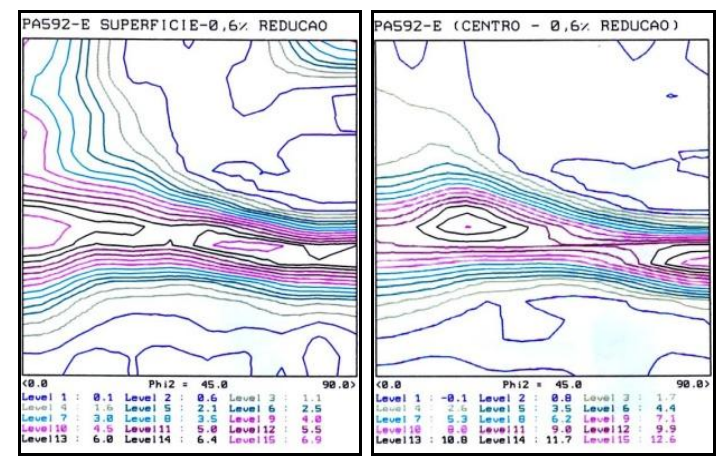

FIGURA 6.16 - Nível de intensidade nas ODF no encruamento com 0,6\% relaminação

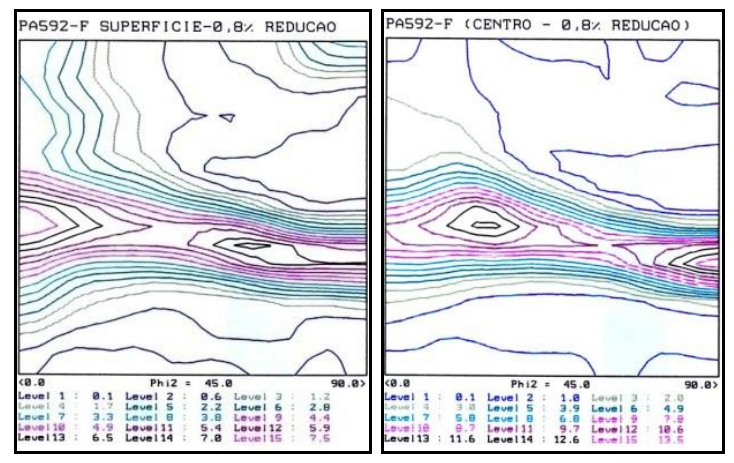

FIGURA 6.17 - Nível de intensidade nas ODF no encruamento com 0,8\% relaminação

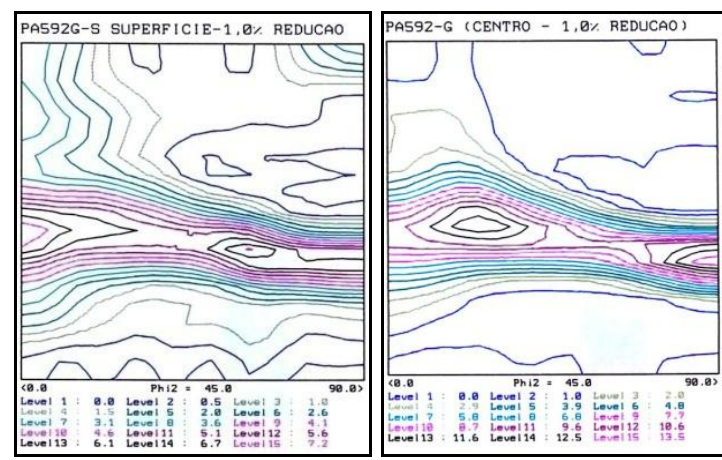

FIGURA 6.18 - Nível de intensidade nas ODF no encruamento com 1,0\% relaminação 
As FIG. 6.19 e 6.20 apresentam a intensidade de textura da fibra Gama na Superfície e centro das amostras.

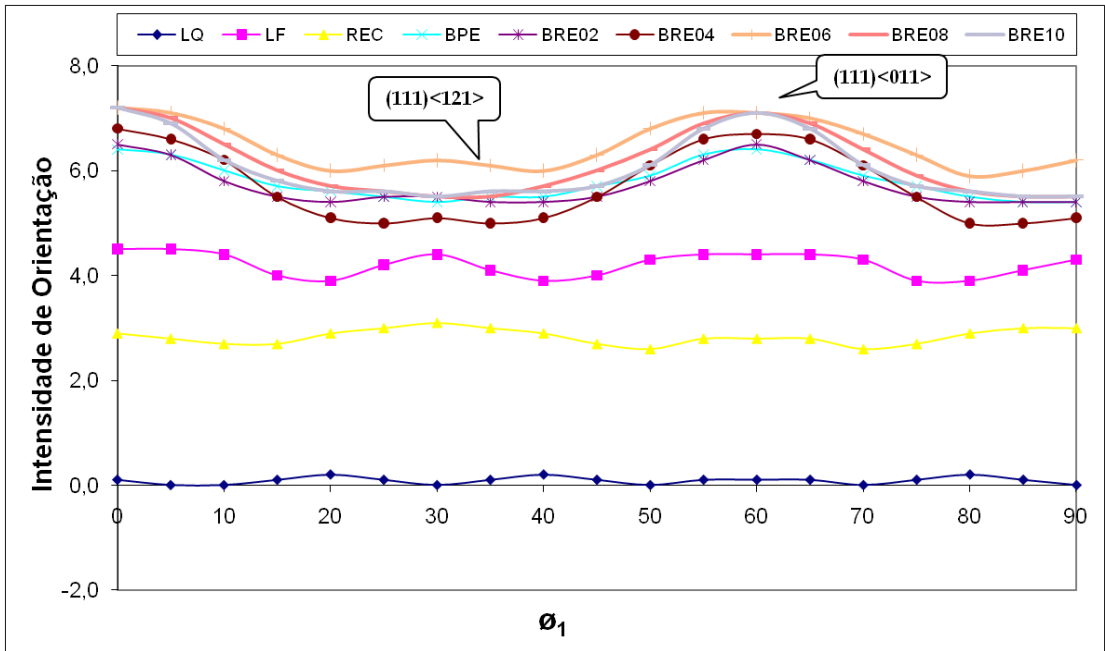

FIGURA 6.19 - ODF ao longo da fibra Gama na superfície da amostra 019318

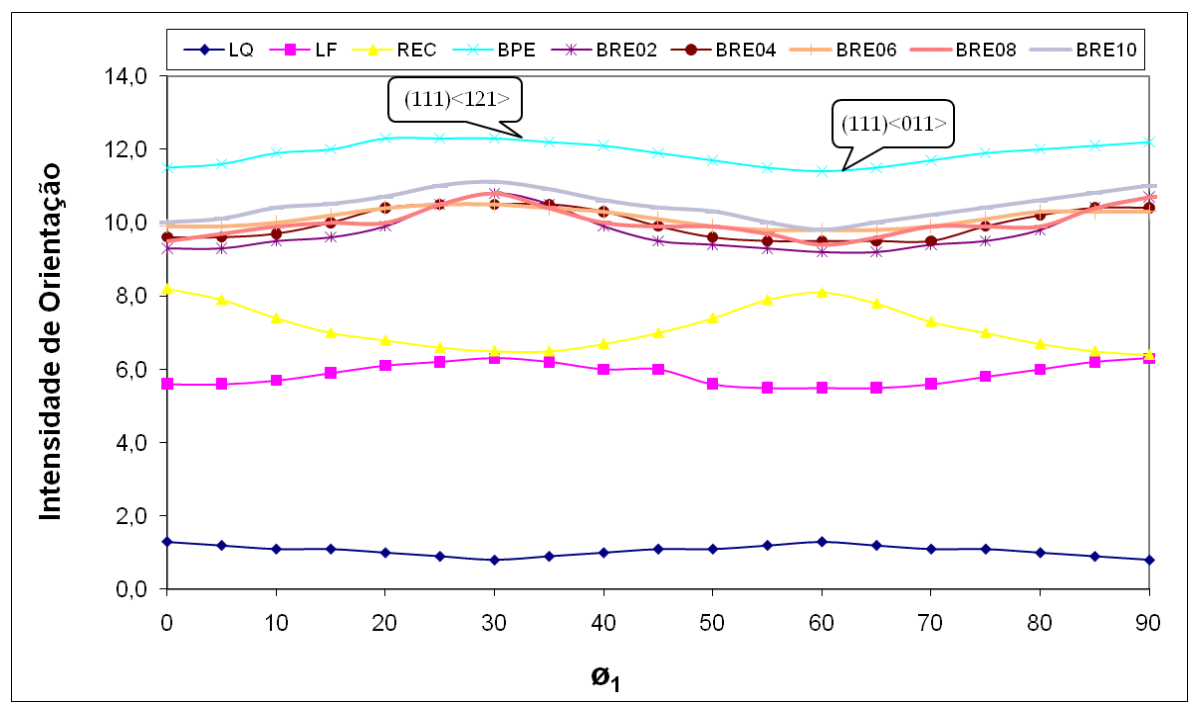

FIGURA 6.20 - ODF ao longo da fibra Gama no centro da amostra 019318 
As FIG. 6.21 a 6.22 apresentam a intensidade de textura da fibra Alfa na superfície e centro da amostra.

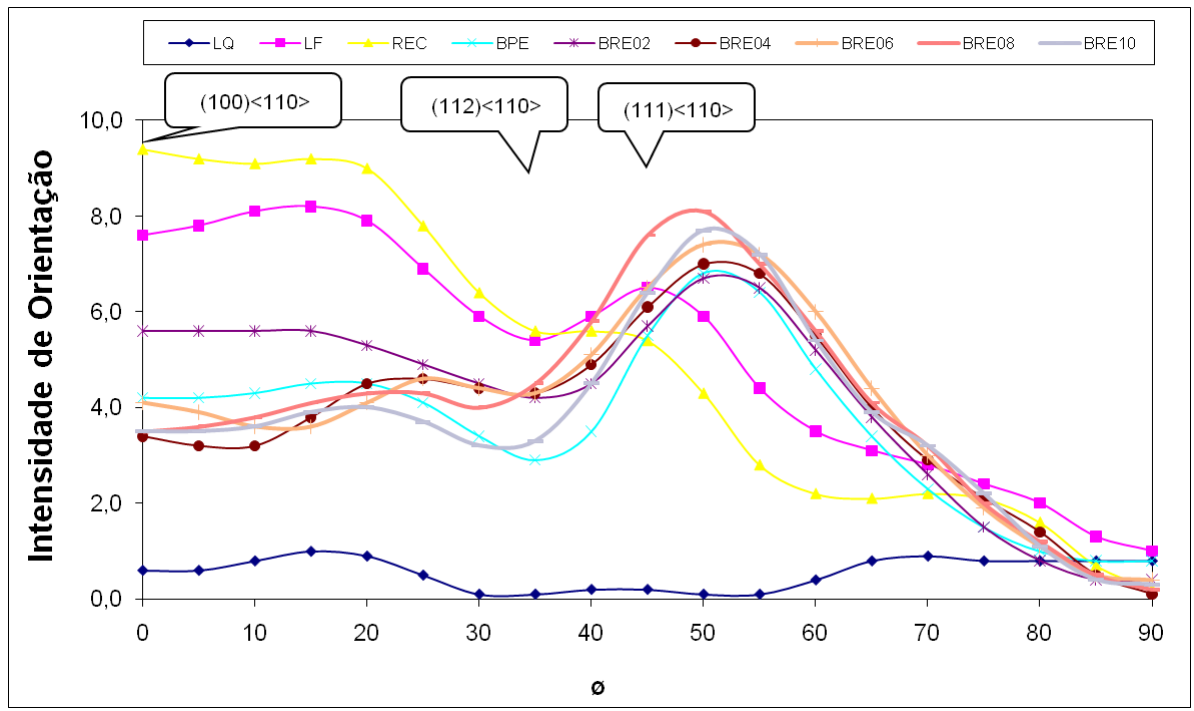

FIGURA 6.21 - ODF ao longo da fibra Alfa na superfície da amostra 019381

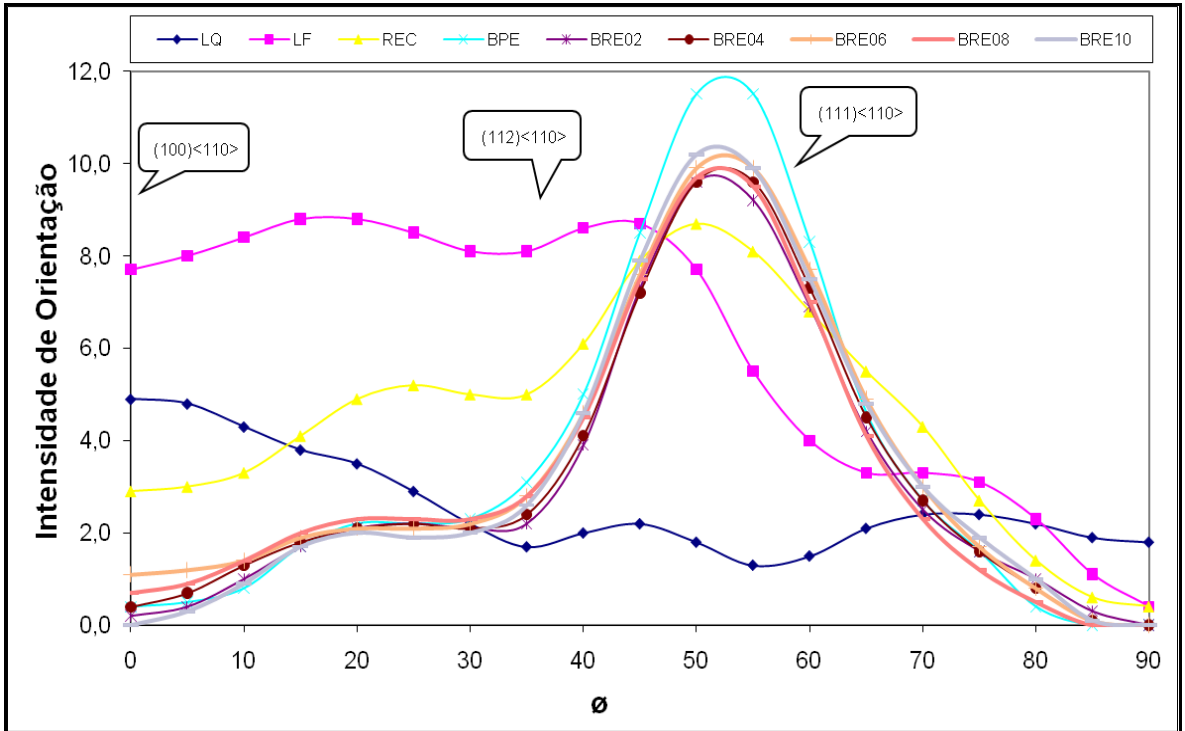

FIGURA 6.22 - ODF ao longo da fibra Alfa no centro da amostra 019381 
As propriedades mecânicas obtidas a partir do ensaio de tração no aço IF-Ti nas condições de BPE e BRE da amostra 019318 estão apresentadas respectivamente nas TAB. 6.3 e nas FIG. 6.23 a 6.25 .

TABELA 6.3 - Resultados dos ensaios de tração

\begin{tabular}{|c|c|c|c|c|c|c|c|}
\hline \multirow{2}{*}{\multicolumn{2}{|c|}{$\begin{array}{c}\text { Amostra } \\
\text { Bobina } 019318\end{array}$}} & \multicolumn{2}{|c|}{ Limite de Escoamento } & \multicolumn{2}{|c|}{ Limite de Resistência } & \multicolumn{2}{|c|}{ Alongamento Total } \\
\hline & & $\mathrm{LE}(\mathrm{MPa})$ & $\mathrm{VP}(\%)$ & LR (MPa) & $\mathrm{VP}(\%)$ & $\mathrm{AL}(\%)$ & $\mathrm{VP}(\%)$ \\
\hline \multicolumn{2}{|c|}{ BPE } & $171 \pm 5$ & - & $313 \pm 8$ & - & $43,4 \pm 0,6$ & - \\
\hline \multirow{5}{*}{ 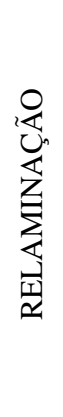 } & BRE 02 & $176 \pm 4$ & 2,9 & $314 \pm 11$ & 0,3 & $46,0 \pm 1,2$ & 6,0 \\
\hline & BRE 04 & $191 \pm 6$ & 8,5 & $317 \pm 8$ & 0,1 & $43,6 \pm 1,5$ & $-5,2$ \\
\hline & BRE 06 & $188 \pm 4$ & $-1,6$ & $316 \pm 9$ & $-0,3$ & $43,2 \pm 0,7$ & $-1,0$ \\
\hline & BRE 08 & $194 \pm 5$ & 3,2 & $326 \pm 25$ & 3,2 & $42,6 \pm 0,9$ & $-1,4$ \\
\hline & BRE10 & $195 \pm 4$ & 0,5 & $325 \pm 7$ & $-0,3$ & $42,2 \pm 1,3$ & $-1,0$ \\
\hline
\end{tabular}

Apresentação gráfica dos resultados do ensaio de tração em função do aumento gradativo do grau de redução está conforme FIG. 6.23 a 6.25.

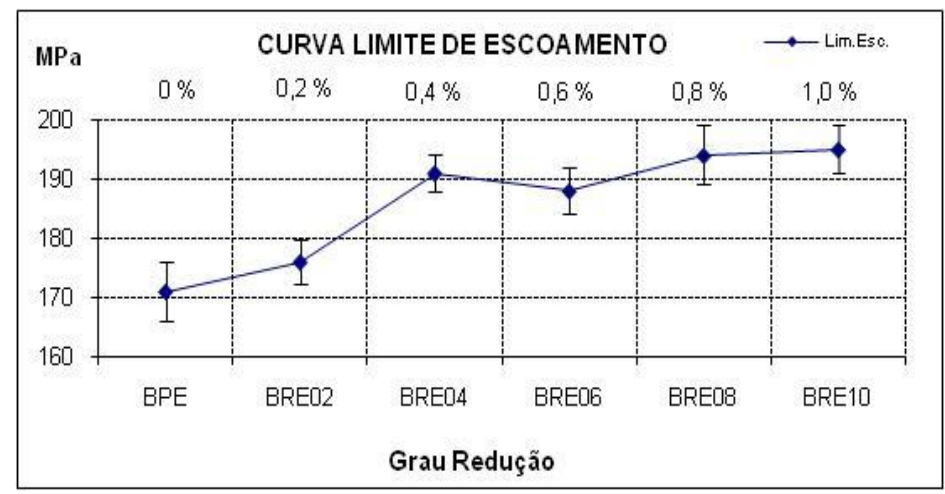

FIGURA 6.23 - Variação do Limite de Escoamento da amostra 019318 


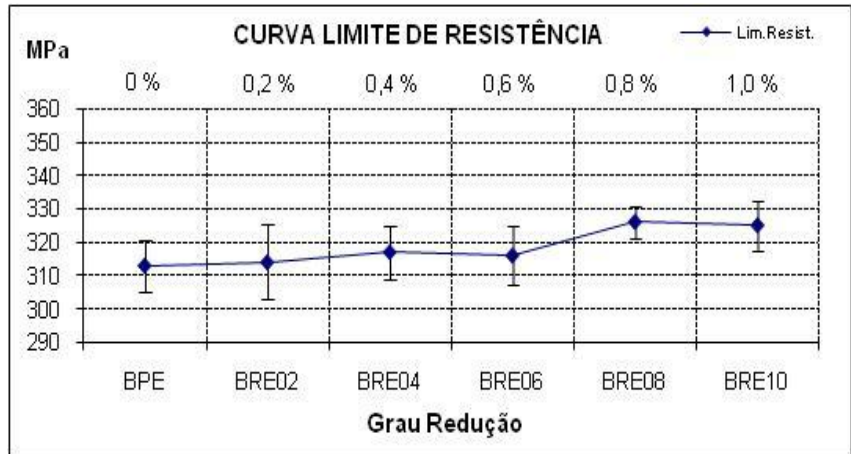

FIGURA 6.24 - Variação do Limite de Resistência da amostra 019318

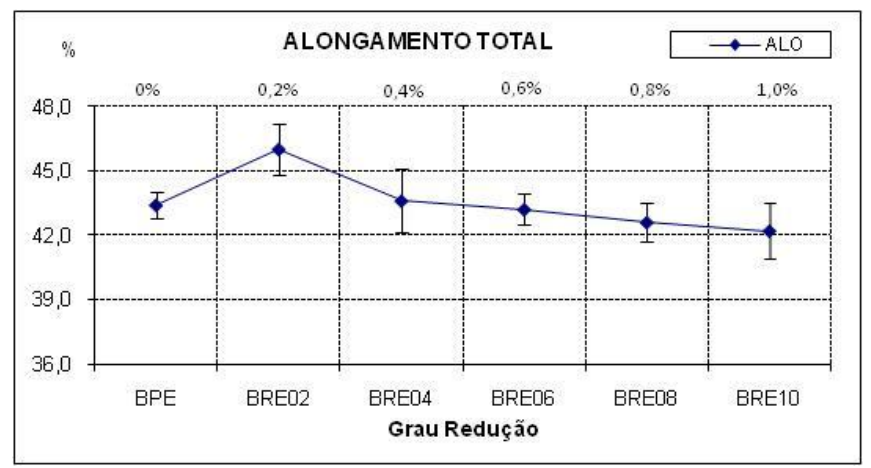

FIGURA 6.25 - Variação do Alongamento Total da amostra 019318

As propriedades mecânicas obtidas a partir do ensaio de embutimento no aço IF-Ti nas condições de BPE e BRE da amostra 019318 são apresentadas respectivamente na TAB. 6.4.

TABELA 6.4 - Resultados dos ensaios de Embutimento de Erichsen

\begin{tabular}{|c|c|c|}
\hline \multirow{2}{*}{ Etapas } & \multicolumn{2}{|c|}{ Bobina 019318 } \\
\cline { 2 - 3 } & Índice Erichsen & VP (\%) \\
\hline BPE & $11,7 \pm 0,18$ & - \\
\hline BRE02 & $11,4 \pm 0,10$ & 2,6 \\
\hline BRE04 & $11,4 \pm 0,23$ & 0,0 \\
\hline BRE06 & $11,3 \pm 0,09$ & $-0,9$ \\
\hline BRE08 & $11,4 \pm 0,05$ & 0,9 \\
\hline BRE10 & $11,2 \pm 0,09$ & $-1,8$ \\
\hline
\end{tabular}


Apresentação gráfica dos resultados do ensaio de embutimento em função do aumento gradativo do grau de redução está conforme FIG. 6.26.

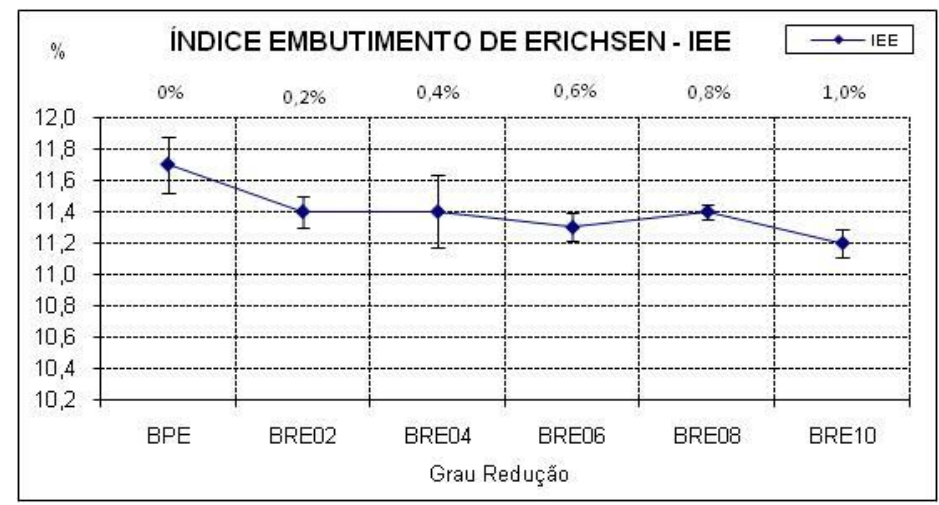

FIGURA 6.26 - Variação do Índice Erichsen da amostra 019318

As propriedades de Anisotropia do material, obtidas a partir do ensaio de tração no aço IF-Ti nas condições de BPE e BRE estão apresentadas na TAB. 6.5.

TABELA 6.5 - Resultados do Valor do R de Lankford

\begin{tabular}{|c|c|c|c|c|c|c|c|c|c|c|c|}
\hline & \multirow{2}{*}{ Amostra } & \multicolumn{6}{|c|}{ Valor R de Lankford } & \multirow{2}{*}{$\mathrm{R}_{\mathrm{m}}$} & \multirow{2}{*}{$\mathrm{VP}(\%)$} & \multirow{2}{*}{$\Delta \mathrm{R}$} & \multirow{2}{*}{$\mathrm{VP}(\%)$} \\
\hline & & $\mathrm{R}_{90}$ & $\mathrm{VP}(\%)$ & $\mathrm{R}_{0}$ & $\mathrm{VP}(\%)$ & $\mathrm{R}_{45}$ & $\mathrm{VP}(\%)$ & & & & \\
\hline \multirow{6}{*}{$\begin{array}{l}\frac{\infty}{0} \\
\hat{\sigma} \\
0 \\
\stackrel{0}{0} \\
0 \\
0 \\
\infty\end{array}$} & BPE & $3,64 \pm 0,04$ & - & $1,88 \pm 0,03$ & - & $1,16 \pm 0,09$ & - & $2,14 \pm 0,03$ & - & $0,52 \pm 0,09$ & - \\
\hline & BRE02 & $3,71 \pm 0,10$ & 1,92 & $1,87 \pm 0,06$ & $-0,53$ & $0,99 \pm 0,04$ & $-14,66$ & $2,11 \pm 0,02$ & $-1,40$ & $0,48 \pm 0,07$ & $-7,69$ \\
\hline & BRE04 & $3,64 \pm 0,09$ & $-1,92$ & $1,91 \pm 0,09$ & 2,14 & $1,14 \pm 0,07$ & 15,15 & $2,15 \pm 0,05$ & $-2,79$ & $0,48 \pm 0,10$ & 0,00 \\
\hline & BRE06 & $3,60 \pm 0,14$ & $-1,10$ & $1,89 \pm 0,02$ & $-1,05$ & $0,90 \pm 0,10$ & $-21,05$ & $2,07 \pm 0,02$ & $-4,55$ & $0,36 \pm 0,03$ & $-25,00$ \\
\hline & BRE08 & $3,70 \pm 0,08$ & 2,78 & $1,82 \pm 0,11$ & $-3,70$ & $0,90 \pm 0,06$ & 0,00 & $2,08 \pm 0,03$ & $-10,18$ & $0,48 \pm 0,04$ & 25,00 \\
\hline & BRE10 & $3,64 \pm 0,12$ & $-1,62$ & $1,79 \pm 0,08$ & $-1,64$ & $0,74 \pm 0,08$ & $-17,78$ & $1,98 \pm 0,04$ & $-10,84$ & $0,40 \pm 0,06$ & $-16,67$ \\
\hline
\end{tabular}

Apresentação gráfica dos resultados de Anisotropia do material no ensaio de tração em função do aumento gradativo do grau de redução está conforme FIG. 6.27 e 6.28. 


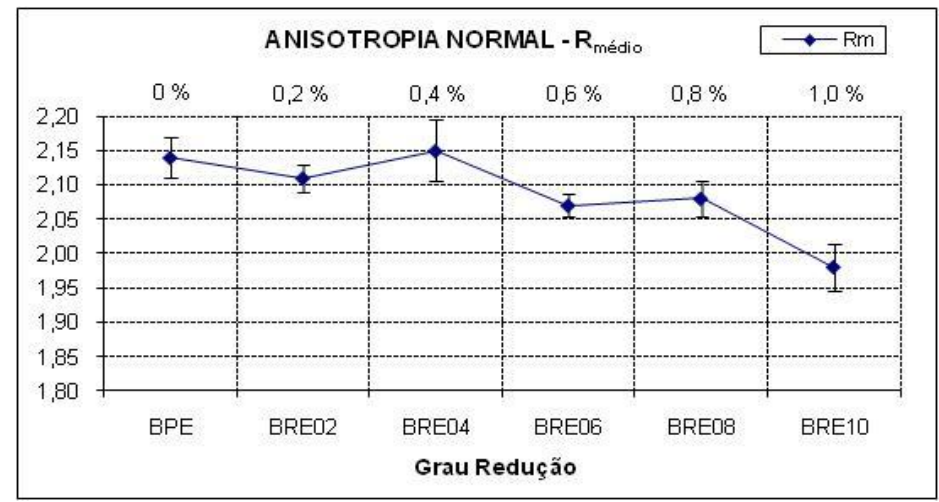

FIGURA 6.27 - Variação da Anisotropia Normal da amostra 019318

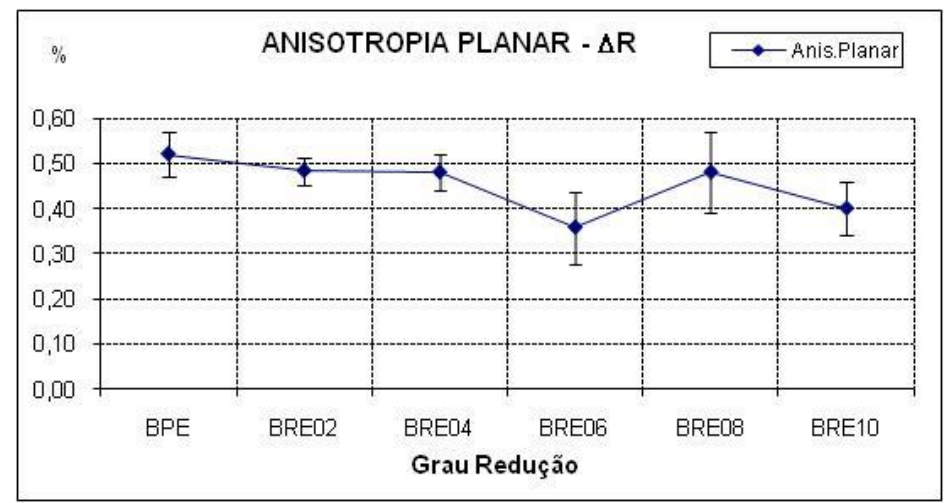

FIGURA 6.28 - Variação da Anisotropia Planar da amostra 019318

As propriedades de Coeficiente de Encruamento do material, obtidas a partir do ensaio de tração no aço IF-Ti nas condições de BPE e BRE estão apresentadas na TAB. 6.6.

TABELA 6.6 - Resultados do Valor do n médio

\begin{tabular}{|c|c|c|c|c|c|c|c|c|c|}
\hline & Amostra & $n_{90}$ & $\mathrm{VP}(\%)$ & $\mathrm{n}_{0}$ & $\mathrm{VP}(\%)$ & $\mathrm{n}_{45}$ & VP (\%) & $\mathrm{n}_{\text {médio }}$ & $\mathrm{VP}(\%)$ \\
\hline \multirow{6}{*}{ 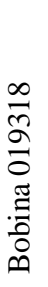 } & BPE & $0,254 \pm 0,009$ & - & $0,240 \pm 0,009$ & - & $0,265 \pm 0,005$ & - & $0,250 \pm 0,003$ & - \\
\hline & BRE02 & $0,251 \pm 0,002$ & $-1,18$ & $0,235 \pm 0,004$ & $-2,08$ & $0,256 \pm 0,007$ & $-3,39$ & $0,244 \pm 0,002$ & $-2,40$ \\
\hline & BRE04 & $0,256 \pm 0,004$ & 1,99 & $0,232 \pm 0,007$ & $-1,28$ & $0,251 \pm 0,005$ & $-1,89$ & $0,243 \pm 0,002$ & $-0,41$ \\
\hline & BRE06 & $0,251 \pm 0,008$ & $-1,99$ & $0,228 \pm 0,010$ & $-1,72$ & $0,239 \pm 0,008$ & $-4,78$ & $0,237 \pm 0,004$ & $-2,47$ \\
\hline & BRE08 & $0,261 \pm 0,004$ & 3,98 & $0,231 \pm 0,007$ & 1,32 & $0,231 \pm 0,006$ & $-3,35$ & $0,239 \pm 0,002$ & 0,84 \\
\hline & BRE10 & $0,250 \pm 0,006$ & $-4,21$ & $0,227 \pm 0,005$ & $-1,73$ & $0,238 \pm 0,009$ & 3,03 & $0,236 \pm 0,002$ & $-1,26$ \\
\hline
\end{tabular}


Apresentação gráfica dos resultados de Coeficiente de Encruamento do material em função do aumento gradativo do grau de redução está conforme FIG 6.29.

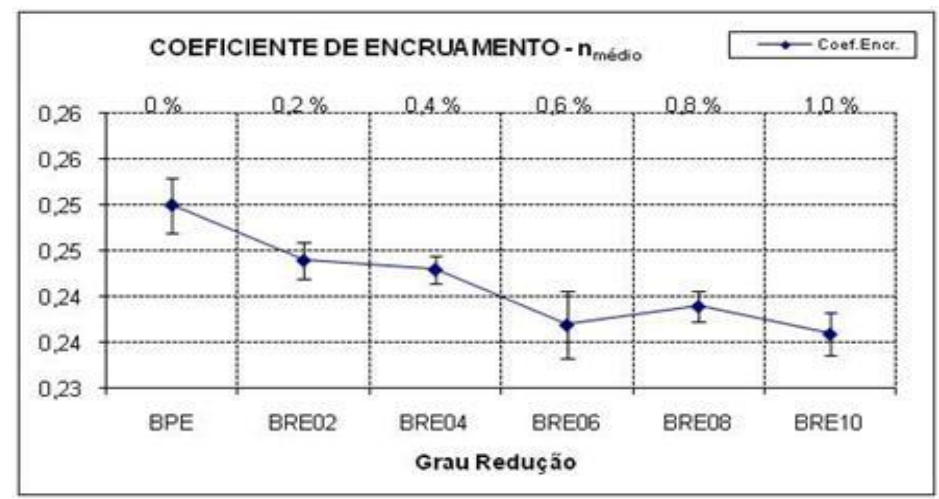

FIGURA 6.29 - Variação do Coeficiente de Encruamento da amostra 019318 


\section{REFERÊNCIAS}

1- BACKOFEN, W. A. Deformation Processing. S.1. Addison-Wesley, 1972.

2- HOILE, S. Processing and properties of mild interstitial free steels. Materials Science and Technology, October 2000, p. 1079-1093.

3- PINTO, M. C; KLEIN, L.N.T; CASTRO, L.C.; ALVES, ALVES, A.C. Desenvolvimento de aços Interstitial Free pela Usiminas. Metalurgia e Materiais - ABM, V.48. No 406. Jun 1992.

4- FILHO, A. F., LIMA, L. M. G., PADILHA, A. F.; LIMA, N. B. Controle da microestrutura e da textura de chapas de aço baixo carbono para estampagem. Departamento de Engenharia Metalúrgica e de Materiais da Escola Politécnica da USP. p. 189-203.

5- BRESCIANi, E. F.; ZAVAGliA, C. A. C.; BUTtON, S. T.; NERY, F. A. C. Conformação plástica dos metais. Edição Unicamp. 1991. p. 121-142, 251-261.

6- LORENTE, G. et al. Fundamentos de ensaios mecânicos. 1980. p. 28 Departamento de Engenharia Metalúrgica da Universidade Federal de Minas Gerais, Belo Horizonte.

7- NAKAZIMA, K.; KIZUMA, T.; HASUKA, K. Study on the formability of steel sheets. In: Yamata Technical Report, 1970. p. 264.

8- FERRAN, E. M. Curvas limite de conformação: aplicação aos processos de estiramento e estampagem. Metalurgia e Materiais. São Paulo, ABM, 29 (192), nov.1973.

9- HOSFORD, W. I. e BACKOFEN, W. A. - Proceedings of the $9^{\text {th }}$ Sagamore Conference. 1962.

10- BLANKFORD, W. B; SNYDER, S. e BAUCHER, J. A. Trans. ASTM volume 42. 1950. Página 1 a 197. 
11- Manual de operação e procedimentos operacionais do Laminador de Encruamento da Usiminas - unidade Cubatão (Cosipa). 2000.

12- ASSOCIAÇÃO BRASILEIRA DE NORMAS TÉCNICAS - ABNT. Determinação do índice de embutimento em chapas de aço pelo método Erichsen modificado. NBR 5902. Rio de Janeiro, 1980.

13- ASSOCIAÇÃO BRASILEIRA DE NORMAS TÉCNICAS - ABNT. Chapas finas a frio de aço-carbono para estampagem. NBR 5915. 2002.

14- KEELER, S. P. Understanding Sheet Metal Formability: Part 5 - Die Design and Lubrication. New York. 1968.

15- KLEIN, L. N. T. Conformação na prensa. Belo Horizonte: Usiminas, Out. 1980. p.1-83.

16- NELSON P.G.; WINLOCK L. Method of determining the percentage elongation at maximum load in the tension test. In: Bulletin ASTM, January, 1949. p. 53 - 55.

17- GONÇALVES, L. O.; KLEIN, L. N. Controle de estampagem de chapas finas a frio. In: SIMPÓSIO INTERNO DA USIMINAS, 3, Ipatinga, set. 1971.

18- MELO JR., A. A. Estampabilidade de chapas finas do aço inoxidável ABNT 304. 1990. Dissertação (Mestrado em Engenharia Metalúrgica) - Escola de Engenharia da Universidade Federal de Minas Gerais, Belo Horizonte.

19- LESLIE, W. C. The physical metallurgy of steels. McGraw-Hill International Student Edition, 1982, p.156.

20- KLEIN, L. N.; MOREIRA, L. O. G.; CARVALHO, J. J. N.; MARIA, V. J. Controle de estampagem de chapas finas a frio. In: SIMPÓSIO INTERNO DA USIMINAS, 3, Ipatinga, set. 1971 .

21- MUSCHENBORN, W; SONNE, H. M. Material properties controlling the strain. Conference: Sheet metal forming and formability, proceedings 10th BIENNAIAL 
CONGRESS. The International Deep Drawing Research Group, University of Warwick, England, 17-21 Apr. 1978. Publ.; Portcullis Presse Ltd, Redhill, Surrey 1978 p. 193-201.

22- ALMEIDA, L. O. Influência da redução a frio sobre a estampabilidade de chapas de aço inoxidável ABNT 430 laminadas a frio. 1987. Dissertação (Mestrado em Engenharia Metalúrgica) - Escola de Engenharia, Universidade Federal de Minas Gerais, Belo Horizonte.

23- JONAS, J. J.; RAY, K. R.; HOOK, R. E. Cold rolling and annealing textures in low carbon and extra low carbon steels. International Materials Reviews, v. 39, p. 129-172, 1994.

24- PRADHAN, R. Cold-rolled interstitial-free steels: a discussion of some metallurgical topics. In: PROCEEDINGS OF INTERNATIONAL FORUM FOR PHISYCAL METALLURGY OF STEELS, Tóquio, ISIJ INTERNATINAL, 1996, p.165-177.

25- EVANGELISTA, S. H. Diagramas de Limite de Conformação Aplicados à Análise por Elementos Finitos de um Processo de Estampagem em Chapas Metálicas. Dissertação de mestrado, Escola de Engenharia de São Carlos - USP. São Carlos. 2000.

26- KIM, G.; KWON, O.; YIM C. H. Production and application of ultra-low carbon steels in Korea - IF steels 2000 proceedings. International Conference On The Processing Microstructure And Properties of IF Steels. 2000, p.111-123.

27- FONSTEIN, N. M.; GIRINA, O.A. Evolution of structure, texture, ferrite - solid solution and mechanical properties during recrystalization of cold-rolled IF steels. International forum for physical metallurgy of IF steels. 1994. p. 33-36.

28- ALVES, A C; CASTRO, L. C; KLEIN, L. N; PINTO, M. C. Desenvolvimento de aços "Interstitial free" pela Usiminas. In: Metalurgia e Materiais - ABM, v. 48, n. 406, 1992. p. $327-333$

29- BLECK, W; BODE, R; HAHN F. Production and properties of IF steel. Thyssen Technische Berichte. 1990. p. 69-76. 
30- BHATTACHARYA, D.; GUPTA, I. Metallurgy of formable vacuum degassed interstitial free steels. In: Metallurgy of Vacuum Degassed Steels, 1990, p. 43-72.

31- SANAGI, S.; KOHNO, R.; TAKAHASHI, N.; AKISE, O.; YAMADA, T.; ODA, M. CAMP-ISIJ, 391990), p. 1768.

32- YAMADA, T.; ODA, M.; AKISUE, OSAMU. Effects of copper, nickel, chromium and tin on mechanical properties of titanium-bearing extra low-carbon steel sheets. ISIJ International, v. 35, n. 11, 1995, p. 1422-1429.

33- GORNI, A. A.; SIVEIRA, J. H. D.; ALMEIDA F., C. Estudo do processo de laminação a quente sobre as propriedades mecânicas de chapas finas de aço IF laminadas a frio. SEMINÁRIO DE LAMINAÇÃO, 39, 2002, Ouro Preto. Processos e produtos laminados e revestidos, ABM. p. 155-156.

34- HELD, J. F; GOODENOW, R. H. Recrystalization of low-carbon titanium stabilized steel. Metallurgical Transactions, v. 1. 1970.p. 2507-2515.

35- ANTENOR, F. F; LIMA, L. M. G; PADILHA, A. F; LIMA, N. B. Controle da microestrutura e da textura de chapas de aço baixo carbono para estampagem. São Paulo: EPUSP, 2001. p. 189-204.

36- GUY, A. G. Ciência dos materiais. Rio de Janeiro: Ed. Universidade de São Paulo, 1980. p. 305 a 313.

37- PADILHA, A. F.; SICILIANO JR. F. Encruamento, recristalização, crescimento de grão e textura. São Paulo: ABM, 1996.

38- WALKER, E. F.; HUDD, R. C. Annealing treatment of extra low and ultra low carbon steels. in: international symposium modern LC and ULC sheet steels for cold forming: processing and properties, 1998, Aachen, 1998. p.211-214.

39- BARBOSA, A. H. A.; PEREIRA, J. F.B.; RIBEIRDO, C. F. Influência das condições de encharque no recozimento contínuo nas propriedades mecânicas de aços interstitial free - IF 
microligado com Ti. In: CONGRESSO ANUAL DA ASSOCIAÇÃO BRASILEIRA DE METALURGIA, 56. Belo Horizonte, 16 a 20 jul. 2001.

40- STRUGALA, D. C.; FEKETE, J. R.; YAO, Z. Advanced sheet steels for automotive applications, JOM, 1992, p. 17-21.

41- COSTA, S. F.; PEREIRA, J. F. B.; MARRA, K. M.; NUNES, W. P. Estudo da evolução da textura de aços IF: proposta de pesquisa. Ipatinga, MG: Usiminas, Dez 2001. P. 1-24.

42- SUBRAMANIAN, S. V.; GAO, J. Effect of precipitate size and dispersion on Lankford values of titanium stabilized interstitial-free steels. ISIJ International, v.34, 1996, p. 53-65.

43- HUNDY, B. B. Inhomogeneous Deformations during the Temper-Holling of Annealed Mild Steel. In: Journal of the Iron and Steel Institute. Dec. 1955,p. 313-315.

44- BUTLER, R. D.; WILSON, D. V. The Mechanical behavior of temper rolled steel. In: Journal of the Iron and Steel Institute. Jan. 1963, p. 16-33.

45- YENDELL, B. M.; HUDD, R. C. Effect of tensile straining on the strain-aging behavior of temper-rolled rimming steel. Journal of the Iron and SteelInstitute, nov. 1970, p. 10081011.

46- BUSCH, M. L; BIAUSSER, H.; BIARD, G.; BON, A. L; GRUMBACH, M. Metallurgical and mechanical aspects of the temper rolling process. Conference: $4^{\text {th }}$ International Steel Rolling Conference - The Science and Technology of Flat Rolling. v. 2, Publ.; Association Technique de la Siderurgie Fraçaise, France, 1987.

47- JUTEAU, C. et al. Etude du Skin-pass. Applications industrielles, reveu de metallurgia, CIT, Dec. 1982, p. 991-1005.

48- PARGAMONOV, E A; NESTERENKO, A M; MAZUR, V. L. Influence of temper rolling conditions on mechanical properties and structure of low carbon steel. (Translation). STEEL USSR 17, (6), p268-270, Jun. 1987, ISSN: 0038-9218. 
49- ABE. H.; TSUNOYAMA, K.; UESUGI, N.; SHIBASAKI O.; SATOH, S.; OBARA, T. Development of extra-deep drawing cold-rolled sheet steels for integrated automotives parts. Kawasaki Steel Technical Report, n. 24, April 1991. p. 84-90.

50- BRAGA JR., F. S. Avaliação da estampabilidade do aço livre de intersticial obtido através de recozimento contínuo e em caixa. 2002. Dissertação (Mestrado em Engenharia Mecânica) - Faculdade de Engenharia, Pontifícia Universidade Católica de Minas Gerais, Belo Horizonte.

51- KAWASE, H.; HAMANAKA, S.; ISHIMOTO, Y.; MUNESHITA, M. Effect of temper rolling on R-value (plastic strain ratio) of cold rolled steel sheet. (Synopsis). TRANS. IRON STEEL INST. JPN. 25, (2), B78, Feb. 1985.

52- REED-HILL, R. E. Physical Metallurgy Principles. D. Van Nostrand. 2a Edição. 1973.

53- VIANA, C.S. da C.; PAULA, A. dos S. Textura e relações de orientação. 2a Edição. EPUSP. 2003. p. 35-54.

54- LOPES, A. M. Textura da transformação de fase CFC-CCC. Instituto Militar de Engenharia. 1998. Mestrado

55- BUNGE, H. J. Texture Analysis in Materials Science.Butteworths. 1982.

56- GHOSCH, A. K; HECKER, S.S. Met Trans. V.6A. 1975. p. 1849-1856.

57- SCHACHER, H.D. handbuch der Fertigungstechnik. Vol. 2/3. Cap. 4.34. Ed. G. Spur, Th. Stoeferle, Carl Hanser. Munique. 1985. pp. 1129-1193.

58- USIMINAS - CUBATÃO - Equipamentos utilizados no laboratório de materiais da unidade Cubatão.

59- WALKER, E. F.; HUDD, R. C. Annealing treatment of extra low and ultra low carbon steels. IN: INTERNATIONAL SYMPOSIUM MODERN LC AND ULC SHEET STEELS FOR COLD FORMING: PROCESSING AND PROPERTIES, 1998, Aachen, p. 211-214. 
60 - LEE, C.S.; DUGGAN B.J. A Simple Theory for the Development of Inhomogeneous Rolling Textures. Metallurgical transactions volume 22a, November 1991-2637. 